Universidad de Lima

Facultad de Ingeniería y Arquitectura

Carrera de Ingeniería Industrial

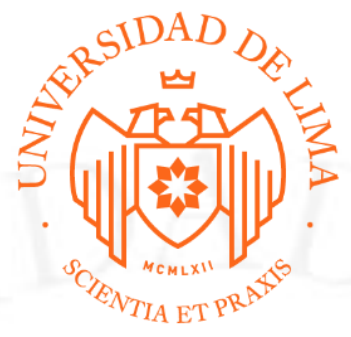

\title{
ESTUDIO DE PREFACTIBILIDAD PARA LA INSTALACIÓN DE UNA PLANTA DE PROCESAMIENTO DE CHOCOLATE BITTER ORGÁNICO EN BARRA
}

Tesis para optar el Título Profesional de Ingeniero Industrial

\author{
Andrea Pilar Paucar Quispe
}

Código 20071737

Asesor

Martín Fidel Collao Diaz

Lima - Perú

Enero de 2020 


\section{PREFACTIBILITY STUDY FOR THE INSTALLATION OF AN ORGANIC CHOCOLATE BITTER PROCESSING PLANT IN BAR}




\section{TABLA DE CONTENIDO}

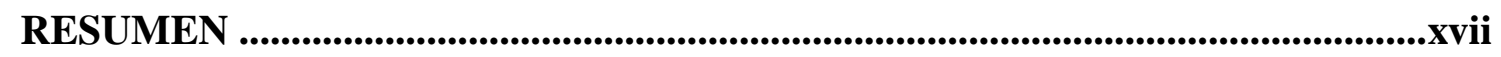

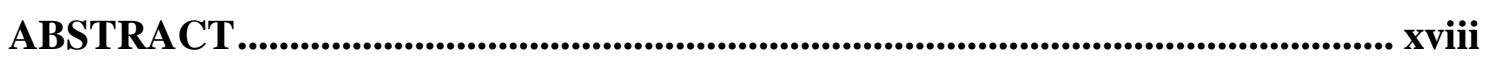

CAPÍTULO I: ASPECTOS GENERALES...................................................................1

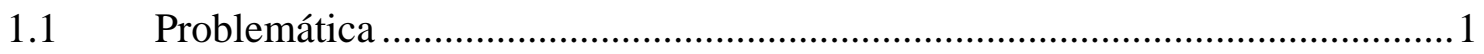

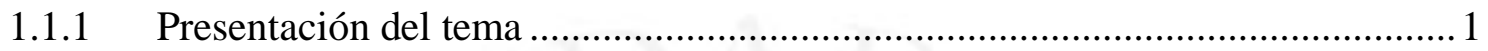

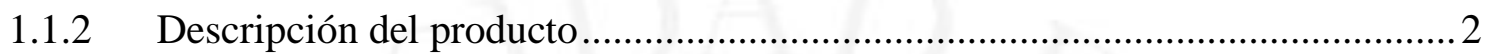

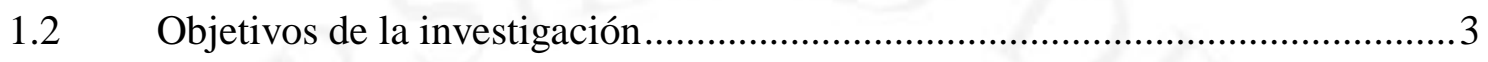

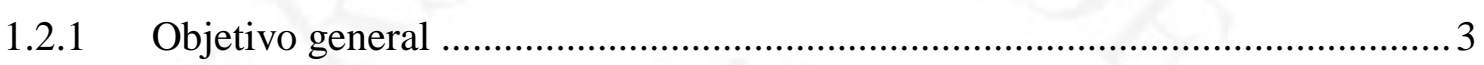

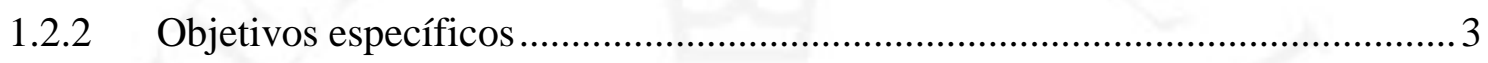

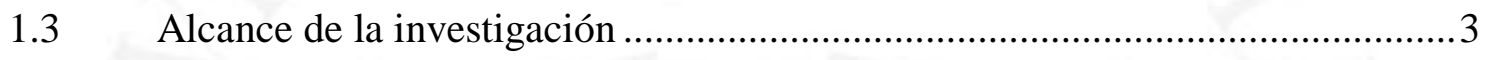

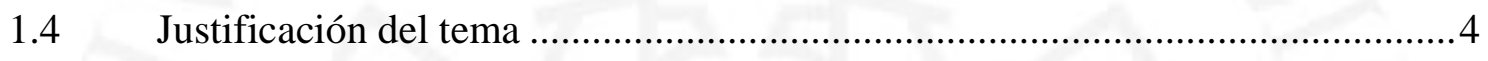

1.5 Hipótesis de trabajo ..................................................................................

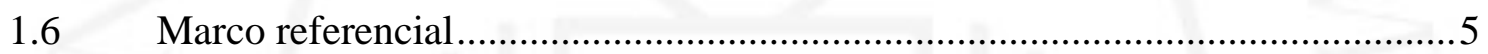

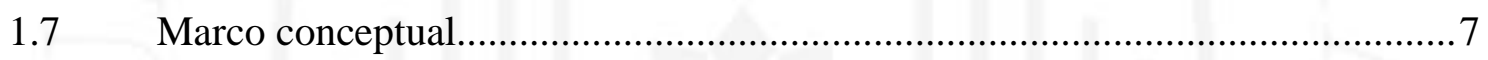

CAPÍTULO II: ESTUDIO DE MERCADO .................................................................9

2.1 Aspectos generales del estudio de mercado.................................................

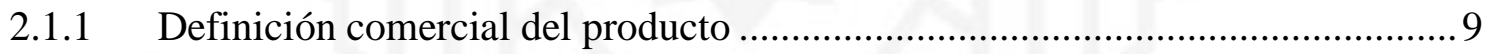

2.1.2 Usos del producto bienes sustitutos y complementarios. ................................ 13

2.1.3 Determinación del área geográfica que abarcará el estudio ............................ 13

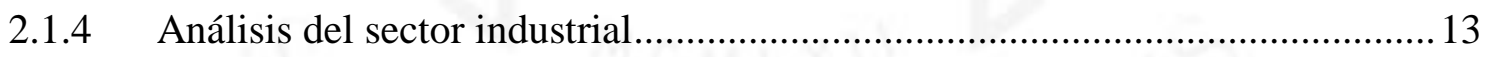

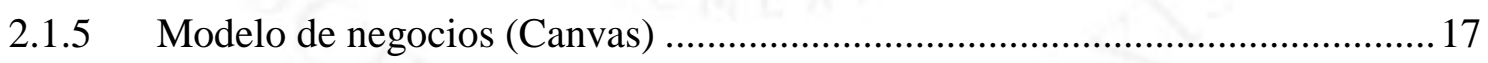

2.2 Metodología a emplear en la investigación de mercado...................................20

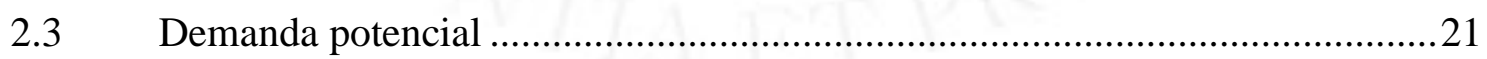

2.3.1 Patrones de consumo: incremento poblacional, estacionalidad, aspectos culturales.

2.3.2 Determinación de la demanda potencial en base a patrones de consumo similares.

2.4 Determinación de la demanda de mercado en base a fuentes secundarias primarias . .22

2.4.1 Demanda del proyecto en base a data histórica ...........................................22 
2.4.1.1 Demanda interna aparente histórica tomando como fuente bases de datos de producción, importaciones y exportaciones; o las ventas tomando como fuente bases de

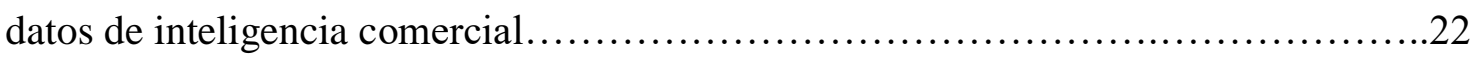

2.4.1.2 Proyección de la demanda.....................................25

2.4.1.3 Definición del mercado objetivo teniendo en cuenta criterios de

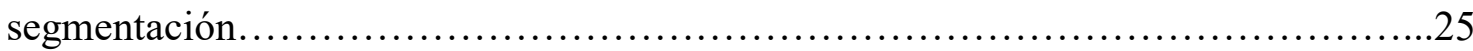

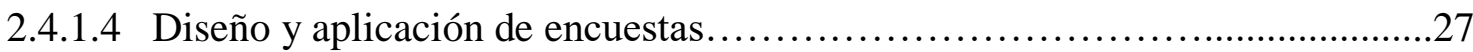

2.4.1.5 Resultados de la encuesta: intención e intensidad de compra, frecuencia, cantidad

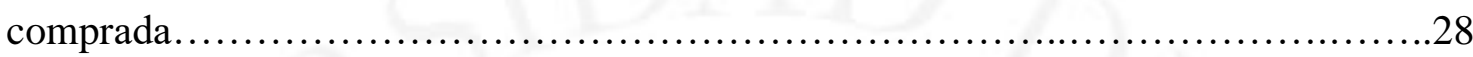

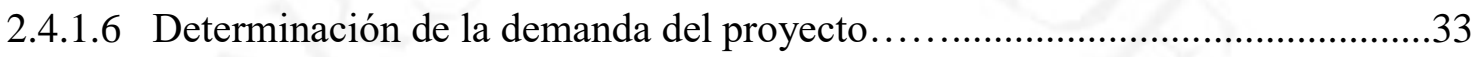

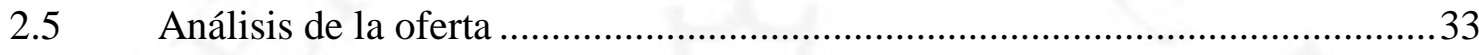

2.5.1 Empresas productoras, importadoras y comercializadoras.............................. 33

2.5.2 Participación de mercado de los competidores actuales................................... 34

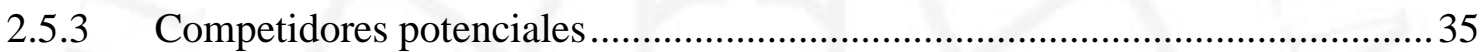

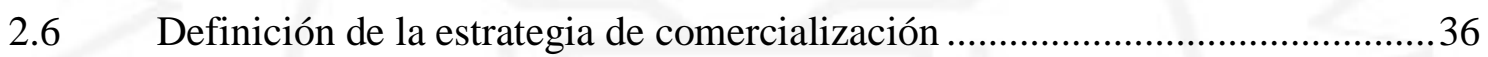

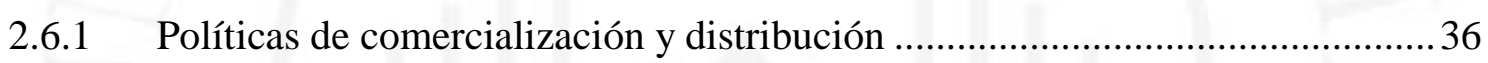

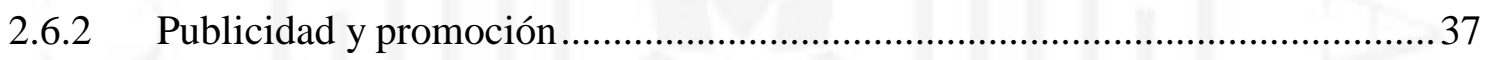

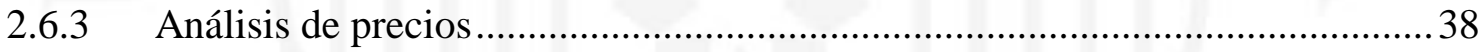

CAPÍTULO III: LOCALIZACIÓN DE PLANTA..................................................................40

3.1 Identificación y análisis detallado de los factores de localización ...................40

3.2 Identificación y descripción de las alternativas de localización........................54

3.3 Determinación del modelo de evaluación a emplear........................................54

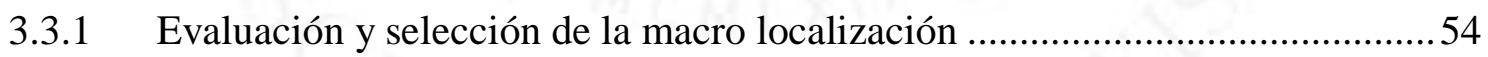

3.3.2 Evaluación y selección de Micro localización .................................................56

CAPÍTULO IV: TAMAÑO DE PLANTA ................................................................58

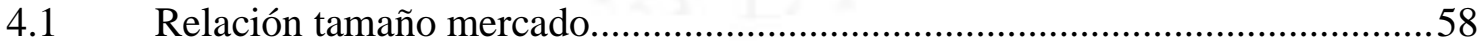

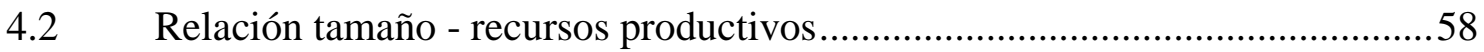

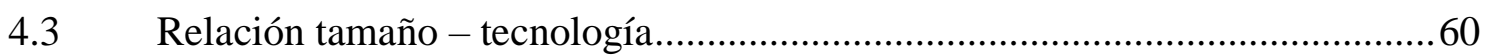

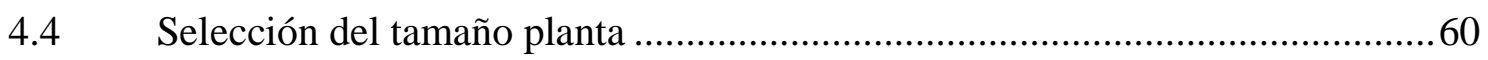

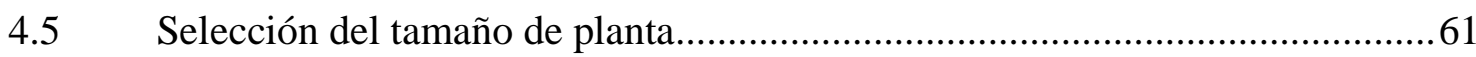

CAPÍTULO V: INGENIERÍA DEL PROYECTO...................................................6 63

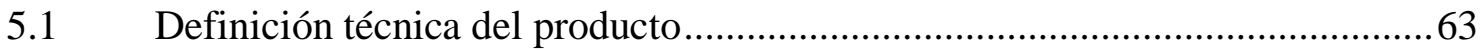

5.1.1 Especificaciones técnicas, composición y diseño del producto..........................64 


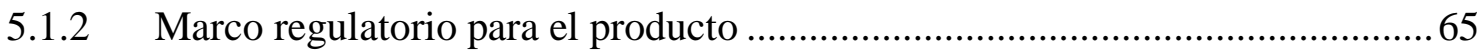

5.2 Tecnologías existentes y procesos de producción ............................................66

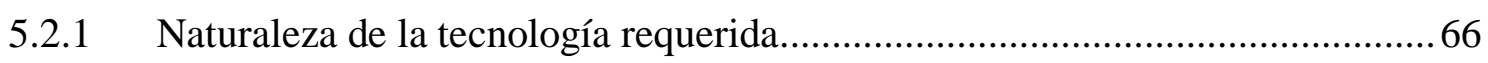

5.2.1.1 Descripción de las tecnologías existentes..........................66

5.2.1.2 Selección de la tecnología........................................66

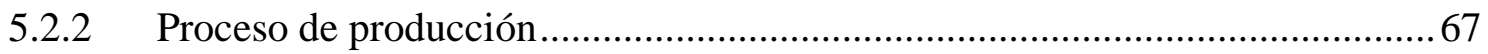

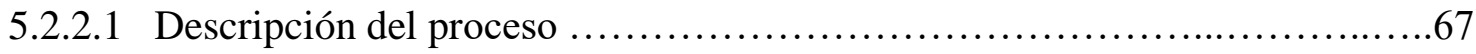

5.2.2.2 Diagrama de proceso: DOP.........................................69

5.2.2.3 Balace de materia......................................................... 70

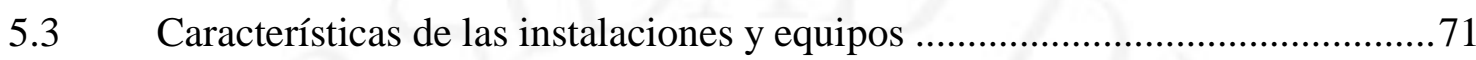

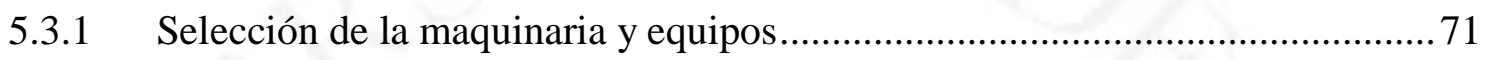

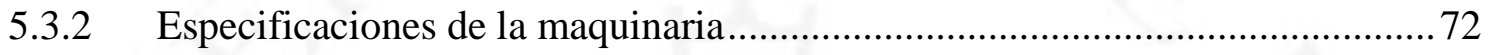

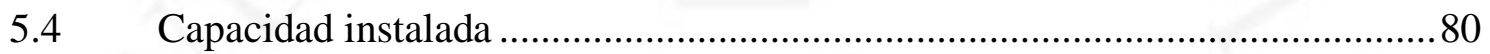

5.4.1 Cálculo detallado del número de máquinas y operarios requeridos ................. 80

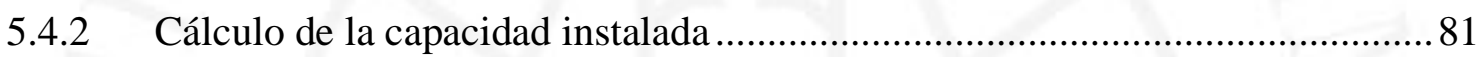

5.5 Resguardo de la calidad y/o inocuidad del producto .................................... 83

5.5.1 Calidad de la materia prima, de los insumos, del proceso y del producto........ 83

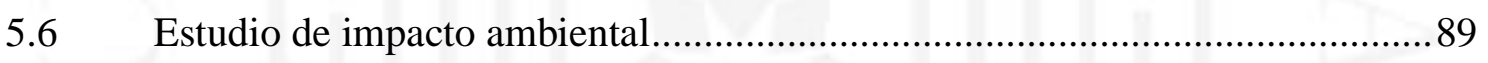

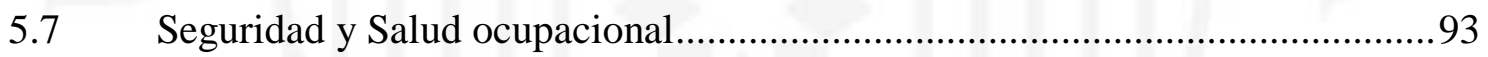

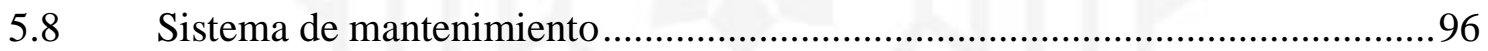

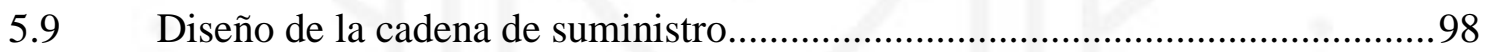

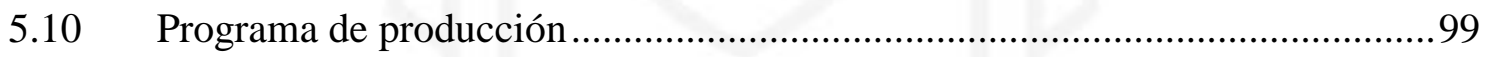

5.11 Requerimiento de insumos, servicios y personal indirecto ............................99

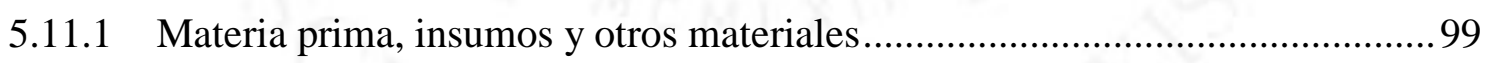

5.11.2 Servicios: energía eléctrica, agua, vapor, combustible, etc........................... 102

5.11.3 Determinación del número de trabajadores indirectos ................................... 104

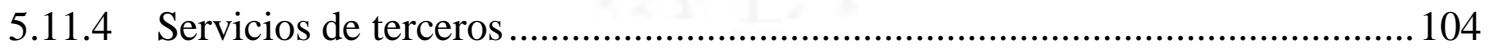

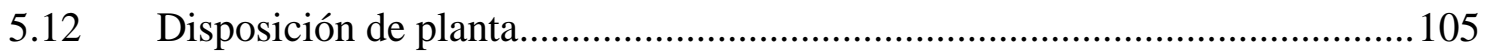

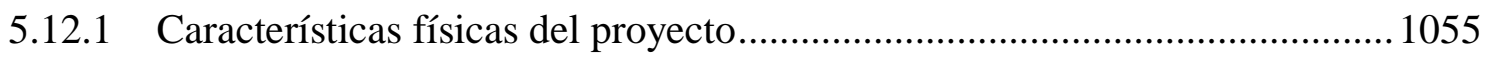

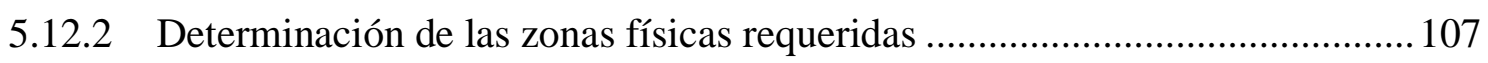

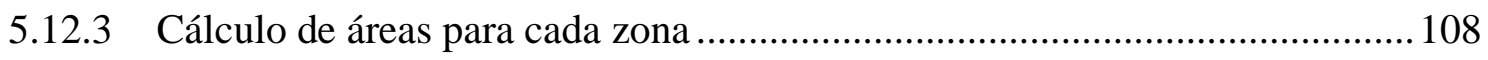

5.12.4 Dispositivos de seguridad industrial y señalización ...................................... 109

5.12.5 Disposición de detalle de la zona productiva ..............................................110

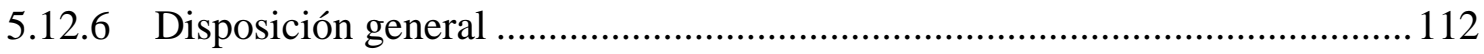


5.13 Cronograma de implementación del proyecto

CAPÍTULO VI: ORGANIZACIÓN ADMINISTRATIVA

6.1 Requerimientos de personal directivo, administrativo y de servicios; funciones generales de los principales puestos. 116

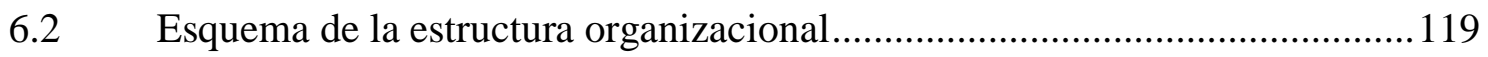

\section{CAPÍTULO VII: PRESUPUESTOS Y EVALUACIÓN DEL PROYECTO.........120}

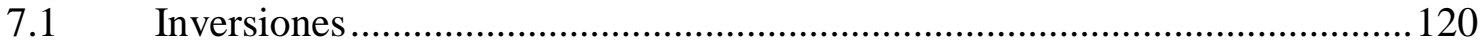

7.1.1 Estimación de las inversiones de largo plazo (tangibles e intangibles)..........120

7.1.2 Estimación de las inversiones de corto plazo (Capital de trabajo) ..................124

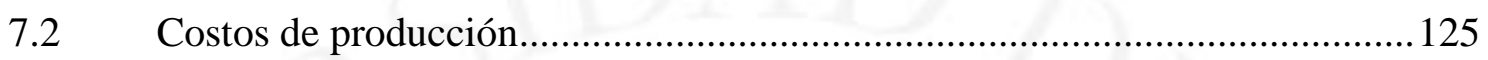

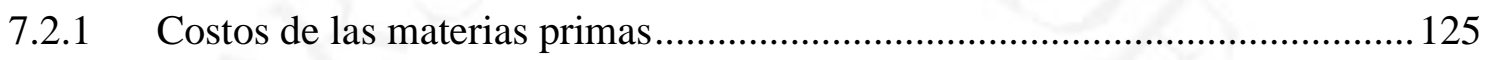

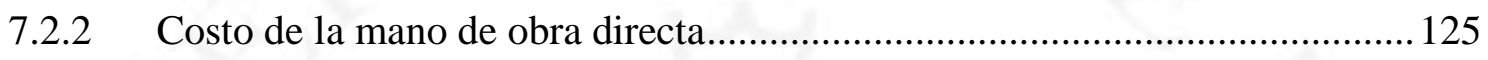

7.2.3 Costo indirecto de fabricación (materiales indirectos, mano de obra indirecta y

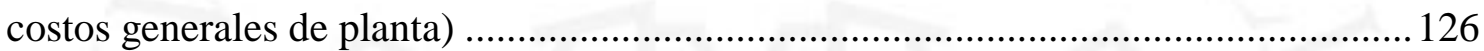

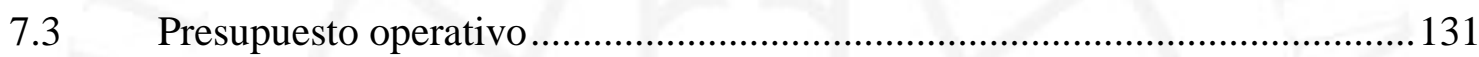

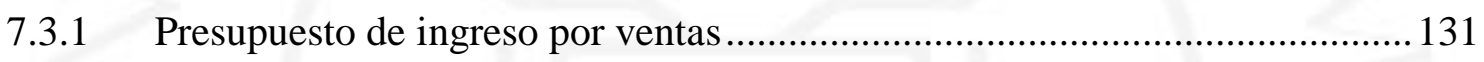

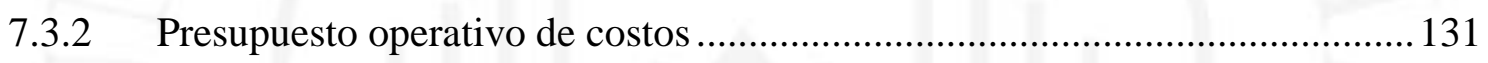

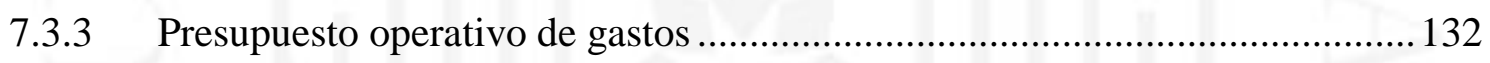

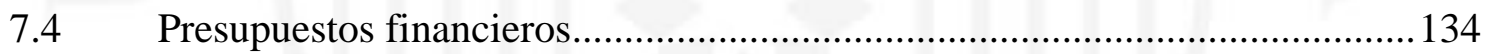

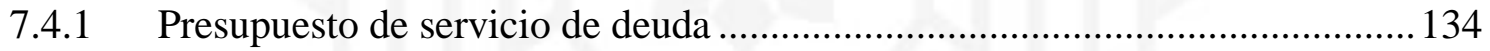

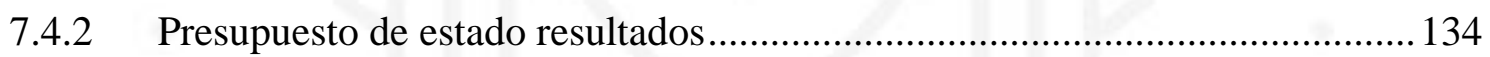

7.4.3 Presupuesto de estado de situación financiera (apertura) ...............................135

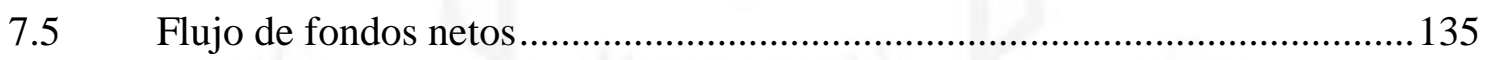

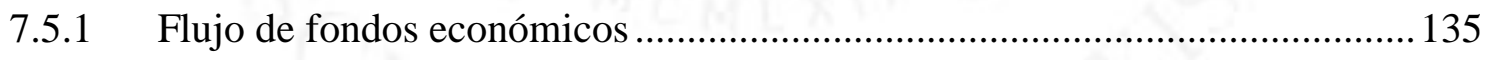

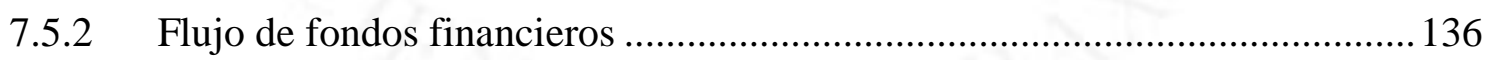

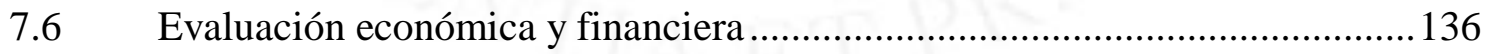

7.6.1 Evaluación económica: VAN, TIR, B/C, PR ............................................... 137

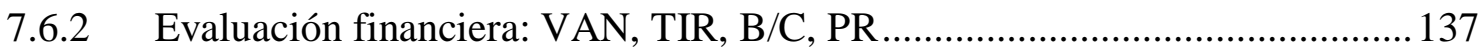

7.6.3 Análisis de ratios (liquidez, solvencia, rentabilidad) e indicadores económicos

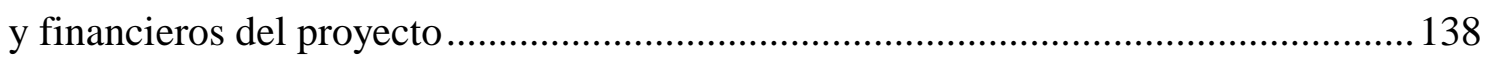

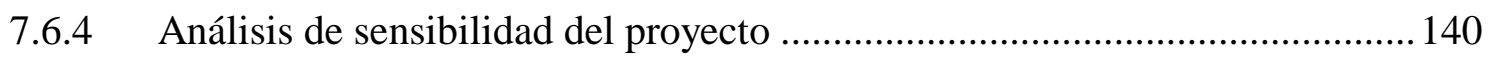

CAPÍTULO VIII: EVALUACIÓN SOCIAL DEL PROYECTO .............................144

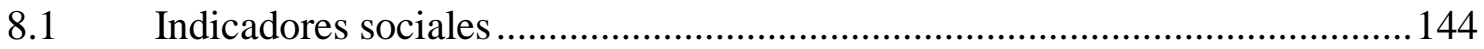

8.2 Interpretación de indicadores sociales ........................................................ 144 
CONCLUSIONES

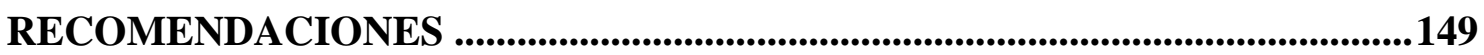

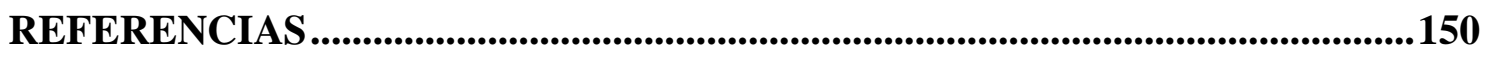

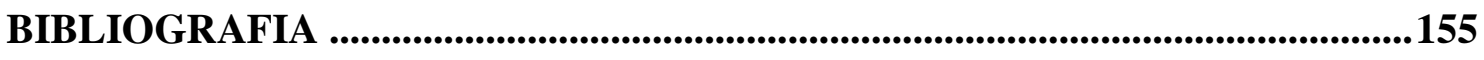

ANEXOS..................................................................156 


\section{ÍNDICE DE TABLAS}

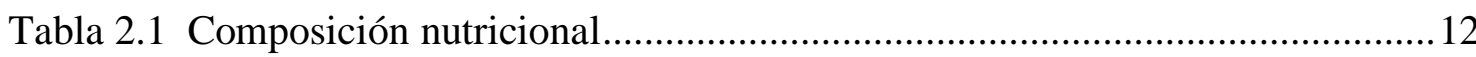

Tabla 2.2 Productores certificados y superficie orgánica (2017) ................................ 15

Tabla 2.3 Indicadores de competencia de chocolates orgánicos (Matriz MPC)............ 15

Tabla 2.4 Tiendas de conveniencia vistas alguna vez en la calle ................................ 18

Tabla 2.5 Producción de chocolate en el perú ..............................................................23

Tabla 2.6 Exportaciones e importaciones de chocolate en tm .....................................24

Tabla 2.7 Demanda histórica de chocolate en Tm........................................................2 24

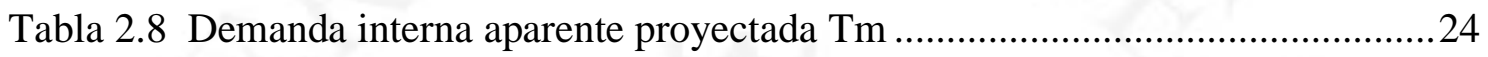

Tabla 2.9 Línea de proyección de demanda interna aparente ......................................25

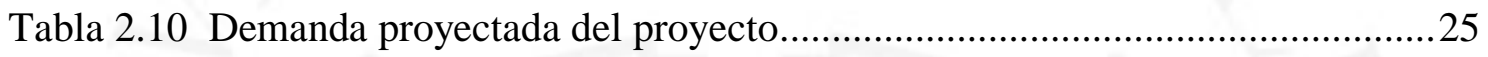

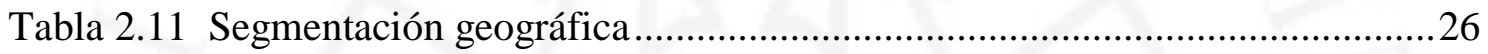

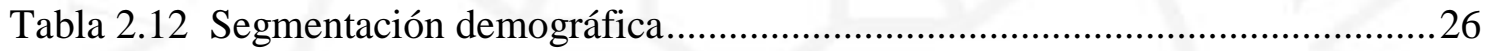

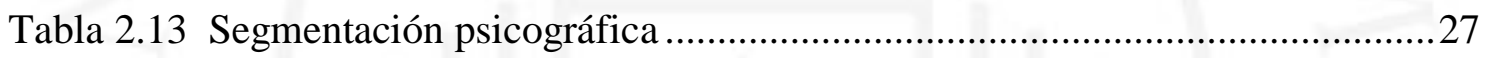

Tabla 2.14 Población por segmentos de hogar en Lima Metropolitana ........................27

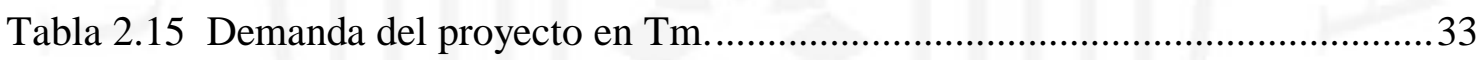

Tabla 2.16 Lista de precios de chocolates orgánicos ................................................... 38

Tabla 2.17 Lista de precios de chocolates no orgánicos .............................................. 38

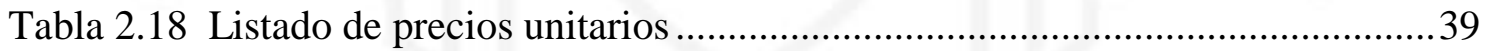

Tabla 3.1 Distancias del lugar de la materia prima.................................................... 41

Tabla 3.2 PEA ocupada y tasa de desempleo por departamento ...................................43

Tabla 3.3 Nivel de educación alcanzado de la población de 14 a más años .................. 43

Tabla 3.4 Trabajadores en el sector de manufactura ................................................... 44

Tabla 3.5 Trabajadores según categoría ocupacional a nivel provincial Satipo............44

Tabla 3.6 Trabajadores según categoría ocupacional a nivel provincial La Convención

Tabla 3.7 Trabajadores según categoría ocupacional a nivel provincial Mariscal Cáceres .45

Tabla 3.8 Trabajadores según categoría ocupacional en Lima ....................................45

Tabla 3.9 Costos por cargo de tarifa eléctrica Cusco .................................................. 45

Tabla 3.10 Costos por cargo de tarifa eléctrica Lima Sur ...........................................46 
Tabla 3.11 Costos por cargo de tarifa eléctrica Lima Norte .........................................46

Tabla 3.12 Costos por cargo de tarifa eléctrica San Martin..........................................46

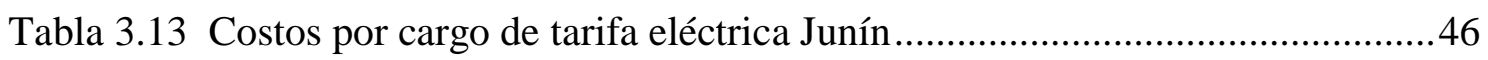

Tabla 3.14 Distribución $\mathrm{m}^{2}$ de terrenos con zonificación industrial..............................52

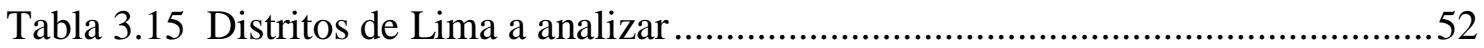

Tabla 3.16 Valores de inmuebles industriales USD (\$/M2) ......................................52

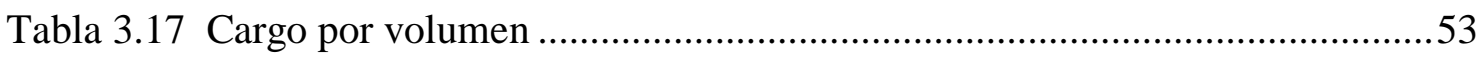

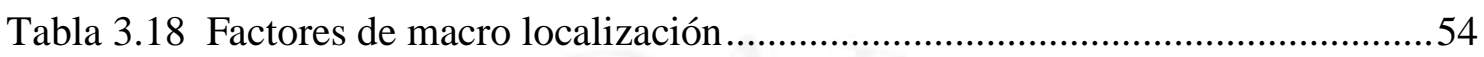

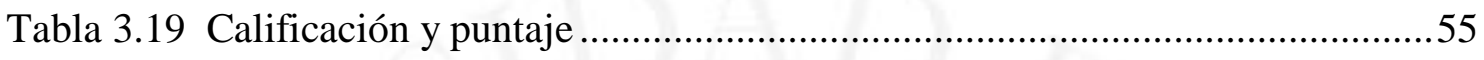

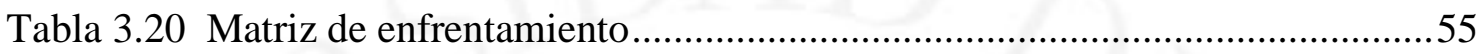

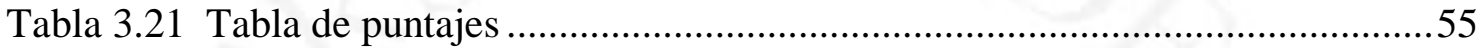

Tabla 3.22 Ranking de factores de micro localización................................................56

Tabla 3.23 Factores de micro localización ...................................................................56

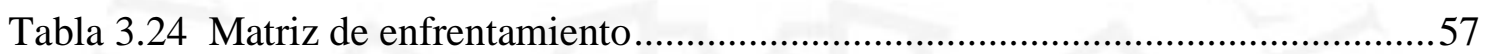

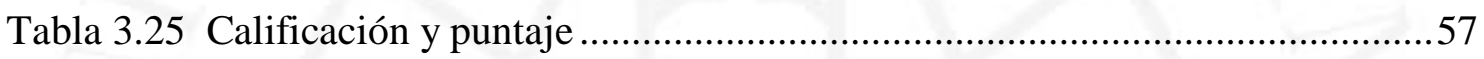

Tabla 3.26 Ranking de factores de micro localización ................................................57

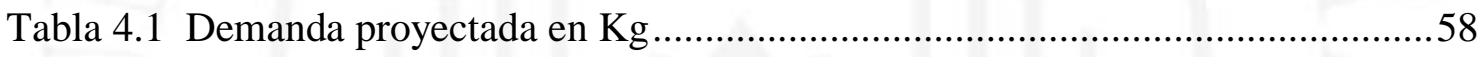

Tabla 4.2 Producción proyectada de cacao convencional .............................................59

Tabla 4.3 Capacidad de máquina según tipo operación.................................................60

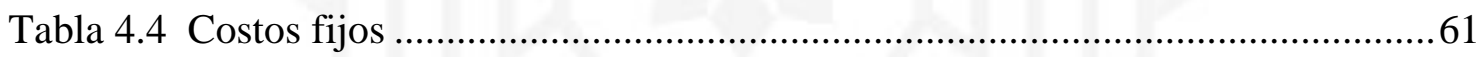

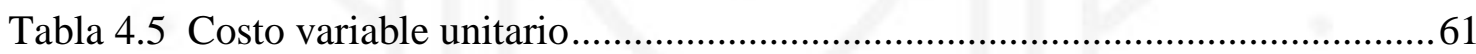

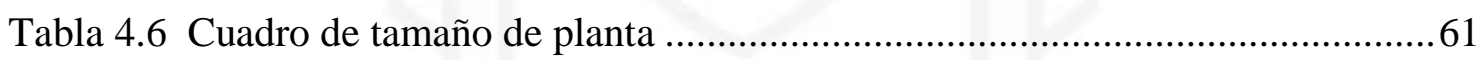

Tabla 5.1 Informe nutricional de chocolate orgánico premium con arandano rojo.......64

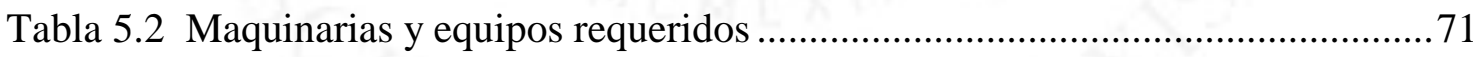

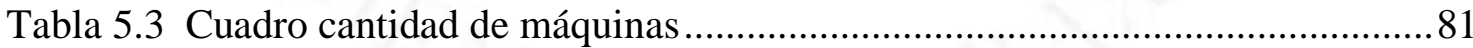

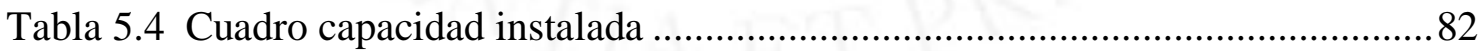

Tabla 5.5 Composición nutricional de los granos de cacao orgánico.............................83

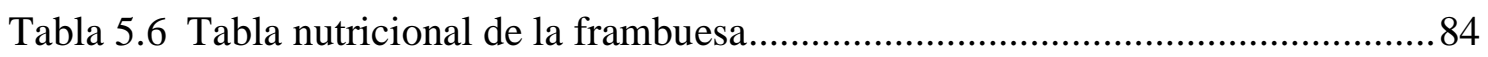

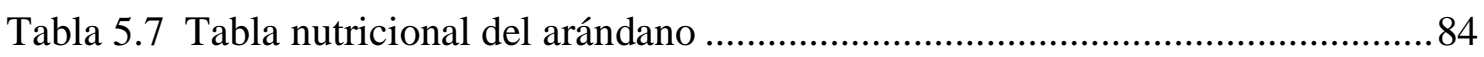

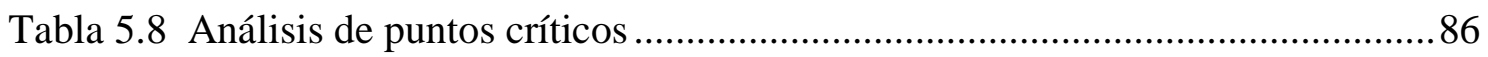

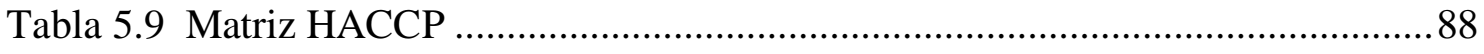

Tabla 5.10 Parámetros de valoración de magnitud y valor.............................................89

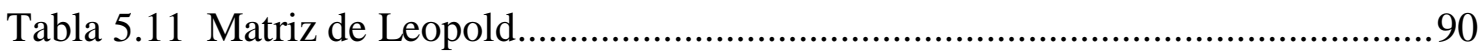


Tabla 5.12 Matriz de caracterización por etapas .....................................................91

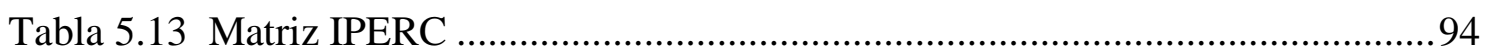

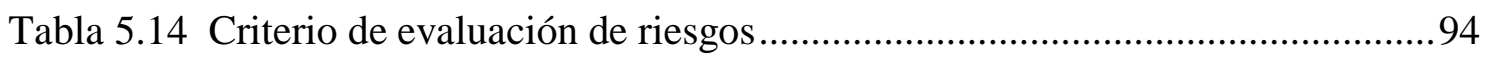

Tabla 5.15 Identificación de impactos por proceso ...................................................95

Tabla 5.16 Tabla de mantenimientos programados ................................................97

Tabla 5.17 Tabla de mantenimientos programados para complementos de las máquinas.

Tabla 5.18 Plan de producción anual de chocolates .99

Tabla 5.19 Plan de materiales de cacao $(\mathrm{Kg})$ ¡¡Error! Marcador no definido.

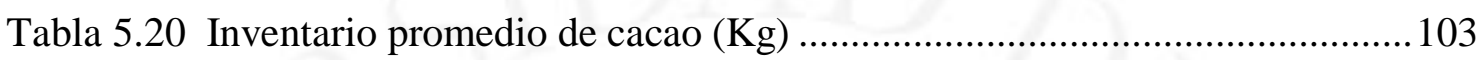

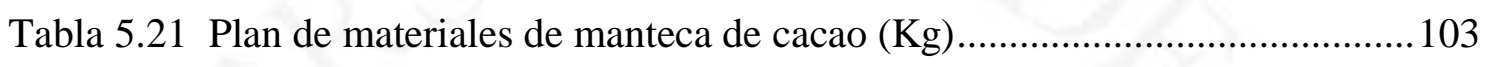

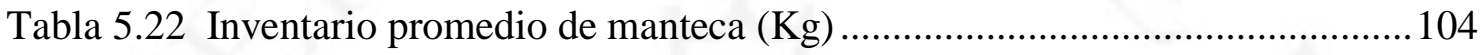

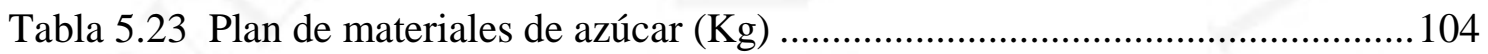

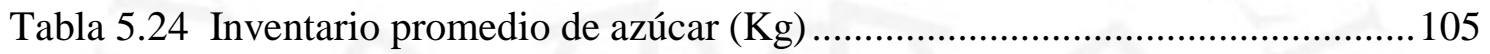

Tabla 5.25 Plan de materiales de fruta deshidratada $(\mathrm{Kg})$.......................................... 108

Tabla 5.26 Inventario de fruta deshidratada $(\mathrm{Kg})$.................................................. 108

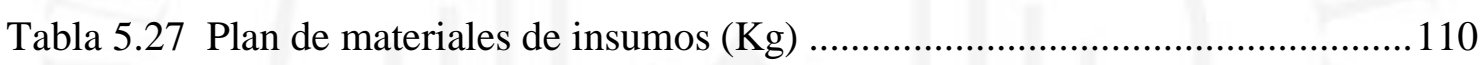

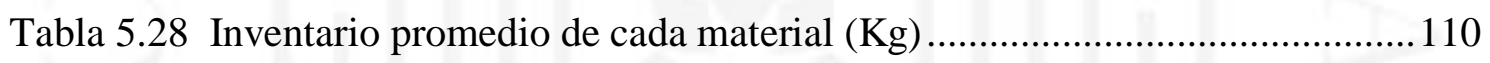

Tabla 5.29 Consumo anual de energía eléctrica para máquinas de producción (S/.) ..103

Tabla 5.30 Consumo de energía eléctrica para uso administrativo y producción ........103

Tabla 5.31 Consumo de agua potable para uso administrativo y producción ..............104

Tabla 5.32 Cargos de trabajadores indirectos .............................................................. 104

Tabla 5.33 Consumo de agua potable para uso administrativo y producción ..............105

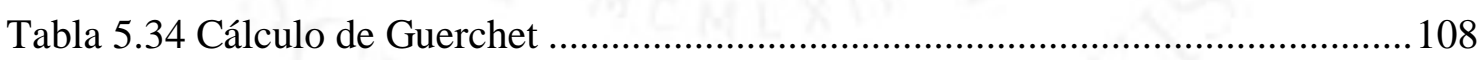

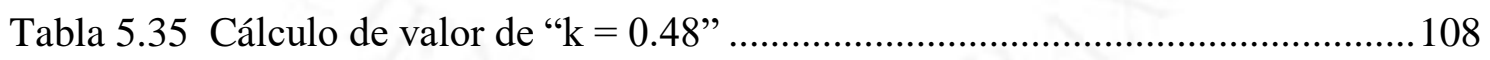

Tabla 5.36 Códigos de proximidades para el diagrama relacional .............................110

Tabla 6.1 Detalle de personal administrativo y producción ........................................116

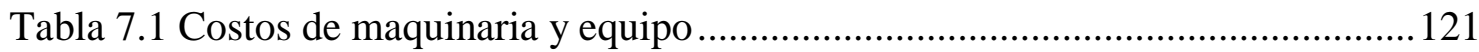

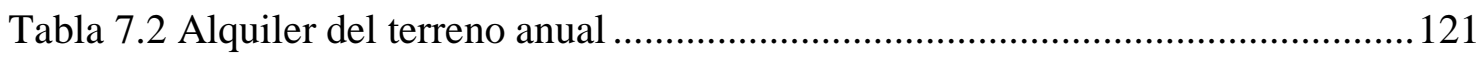

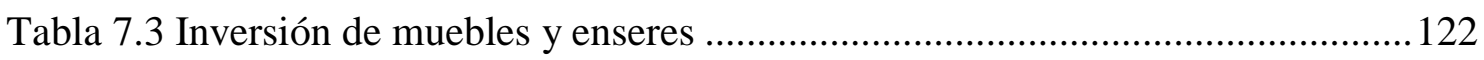

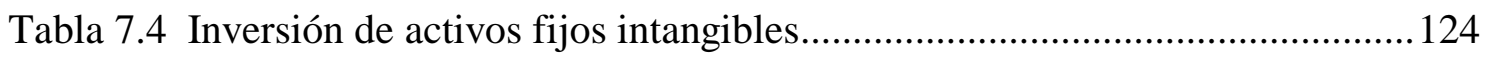

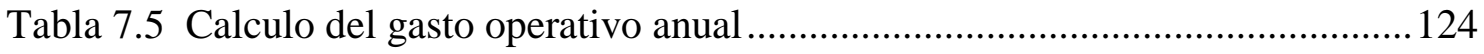

Tabla 7.6 Presupuesto de materia prima (S/. año) ..................................................... 125

Tabla 7.7 Presupuesto de mano de obra (S/. año) ........................................................126 
Tabla 7.8 Costos indirectos de fabricación.....

Tabla 7.9 Costo de energía eléctrica de máquinas de producción (S/.año) ..................127

Tabla 7.10 Costo de energía eléctrica de otros equipos para producción (S/. año) .....127

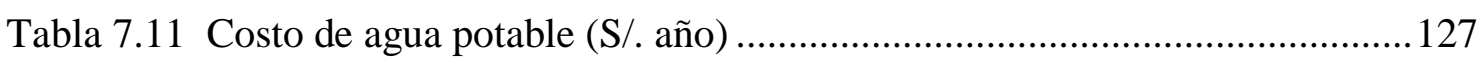

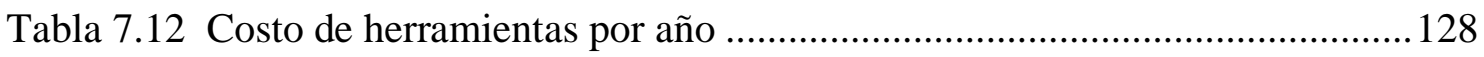

Tabla 7.13 Costo de implementos de seguridad por año ...........................................128

Tabla 7.14 Depreciación de maquinarias de producción ................................................129

Tabla 7.15 Depreciación de equipos y muebles de producción...................................129

Tabla 7.16 Cálculo de mano de obra indirecta (S/.año)............................................. 130

Tabla 7.17 Costos de servicios de terceros (S/.año) .................................................. 130

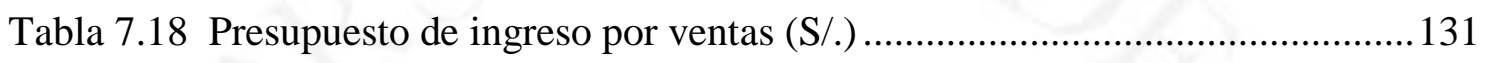

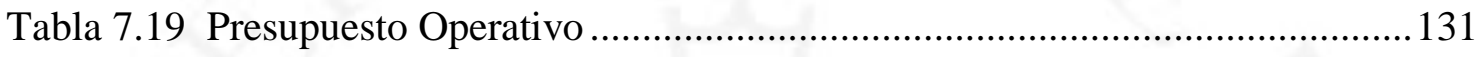

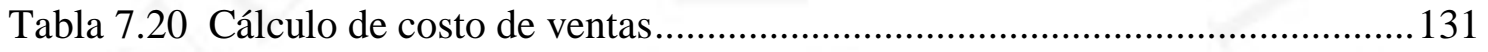

Tabla 7.21 Presupuesto de gastos administrativos, ventas y marketing ......................132

Tabla 7.22 Presupuesto de sueldos administrativos (S/. año) ..................................... 132

Tabla 7.23 Costo de agua potable para administración (soles/año).............................133

Tabla 7.24 Costo de energía eléctrica para administración (soles/año).......................133

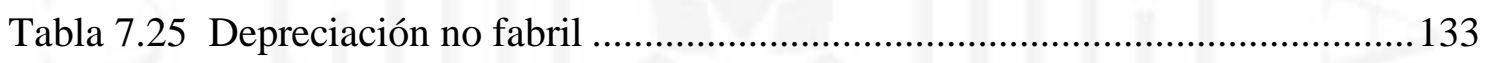

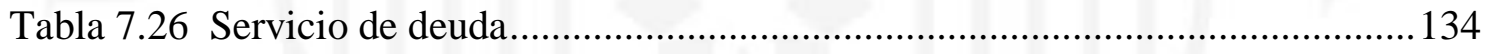

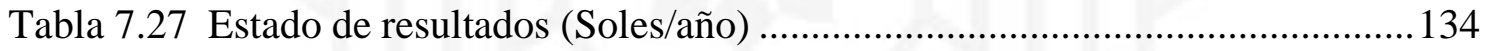

Tabla 7.28 Estado de situación financiera de apertura (2020)....................................135

Tabla 7.29 Flujo de fondos económicos (Soles/año) ............................................... 135

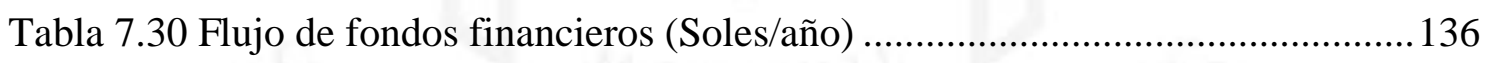

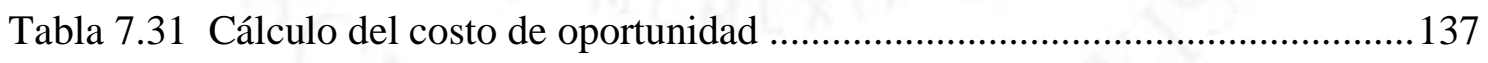

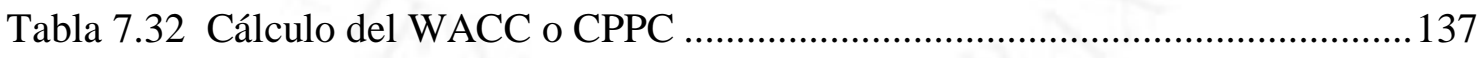

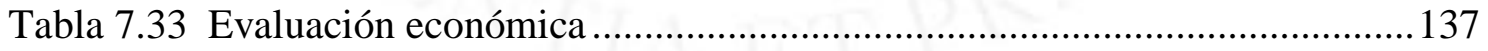

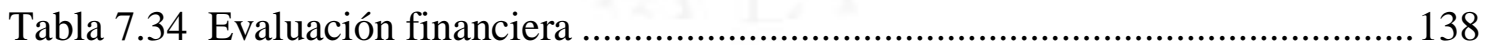

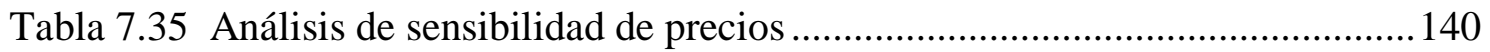

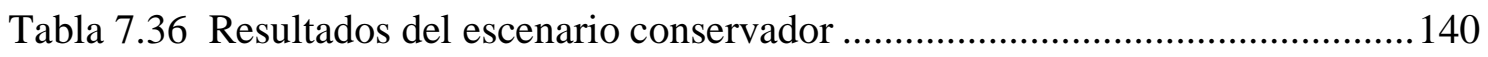

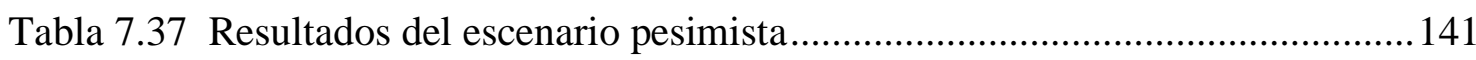

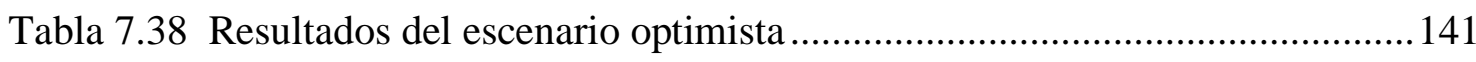

Tabla 7.39 Estado de resultados para el escenario pesimista.......................................141

Tabla 7.40 Flujo de fondo financiero - Pesimista (S/.) .............................................142

Tabla 7.41 Estado de resultados para escenario optimista $(\mathrm{S} /.) \ldots \ldots \ldots \ldots \ldots \ldots \ldots . \ldots 142$ 
Tabla 7.42 Flujo de fondo financiero - Optimista ..................................................... 143

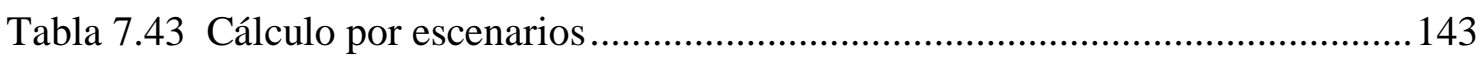

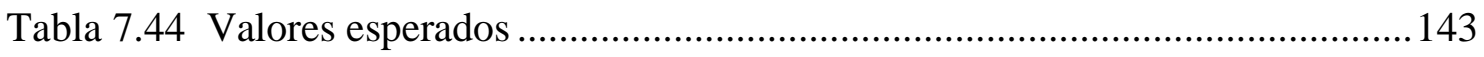

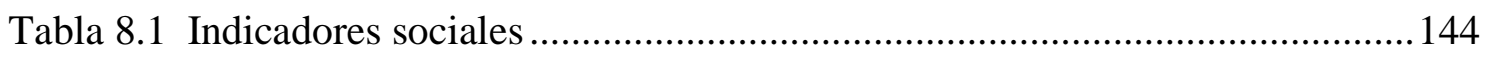

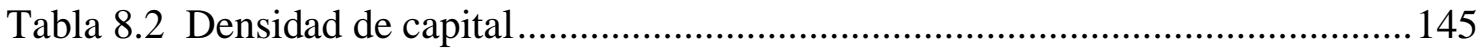

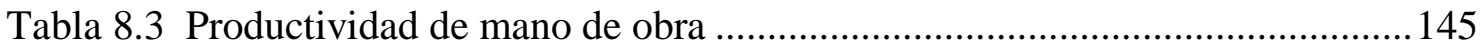

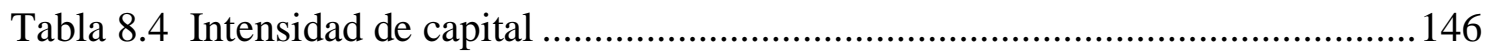




\section{ÍNDICE DE FIGURAS}

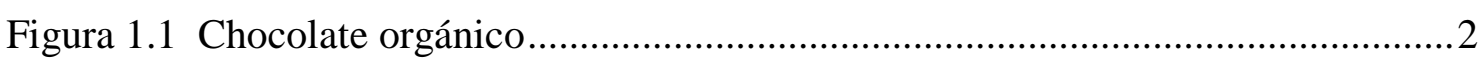

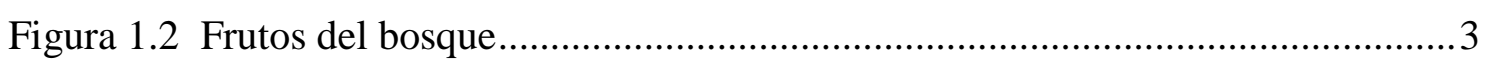

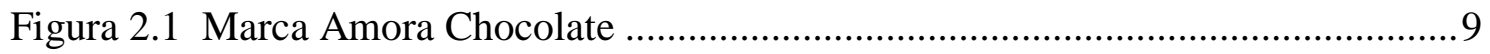

Figura 2.2 Etiqueta de Amora Chocolate premium ...................................................... 10

Figura 2.3 Alimentos sólidos y parámetros de octógonos ........................................... 11

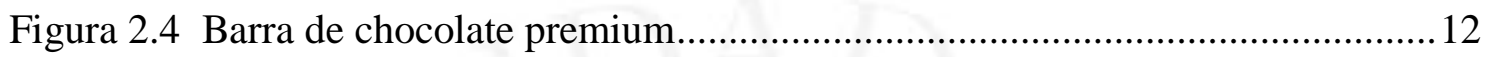

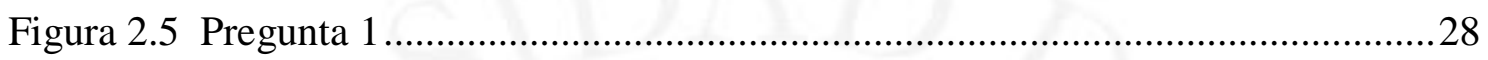

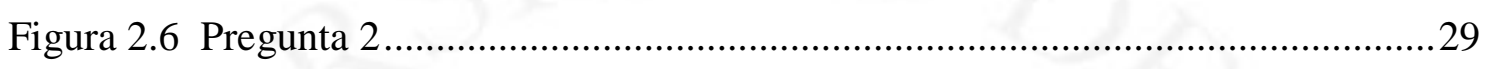

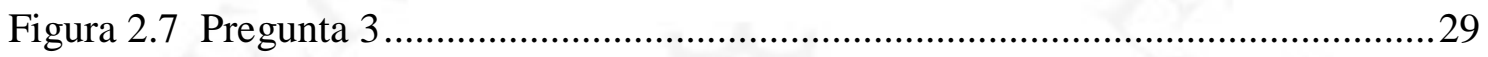

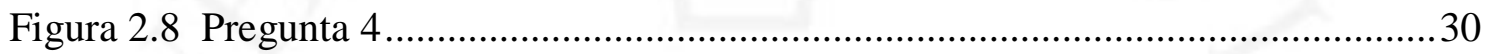

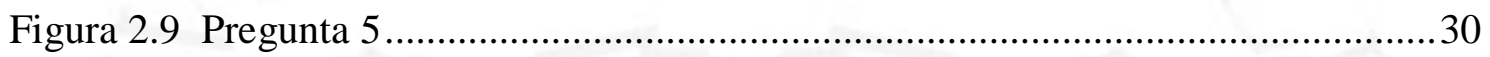

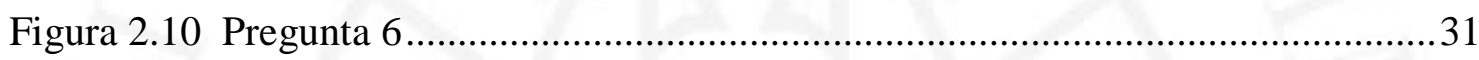

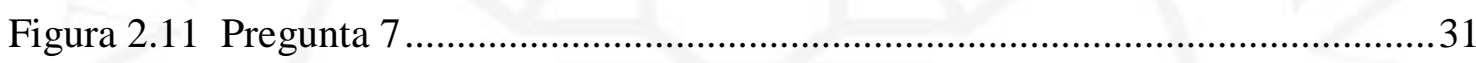

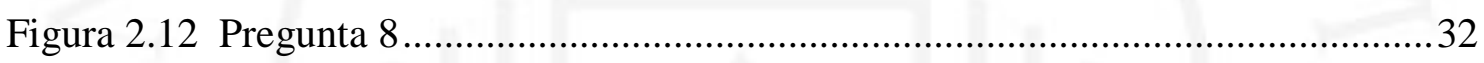

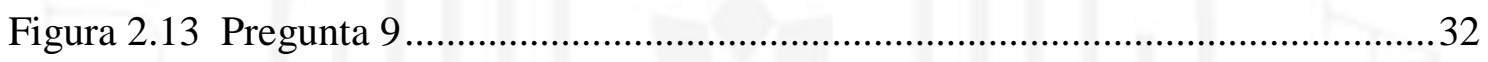

Figura 2.14 Participación de mercado de competidores actuales de chocolate ..............35

Figura 2.15 Análisis de competencia del mercado de chocolates 2018........................35

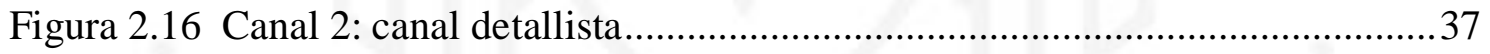

Figura 3.1 Productores certificados y superficie orgánica (2017)...............................41

Figura 3.2 Mapa de ruta del departamento de Junín - Lima ........................................ 42

Figura 3.3 Mapa de ruta del departamento de San Martin - Lima................................ 42

Figura 3.4 Mapa de ruta del departamento de Cusco - Lima........................................ 42

Figura 3.5 Acceso de fuentes de agua en Cusco .................................................... 47

Figura 3.6 Acceso a fuentes de agua en Lima ....................................................... 48

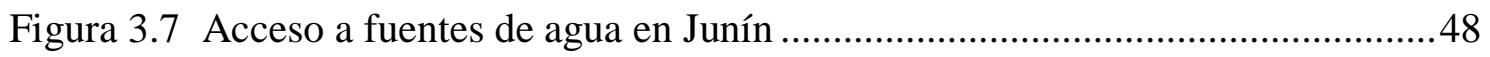

Figura 3.8 Acceso a fuentes de agua en San Martin .......................................................48

Figura 3.9 Acceso a servicio sanitario por red pública en Cusco .................................50

Figura 3.10 Acceso a servicio sanitario por red pública en Lima .................................50

Figura 3.11 Acceso a servicio sanitario por red pública en Junín ................................50

Figura 3.12 Acceso a servicio sanitario por red pública en San Martín .........................51

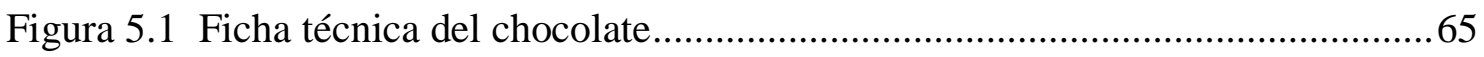


Figura 5.2 Diagrama de procesos DOP

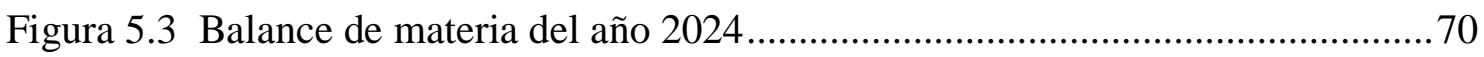

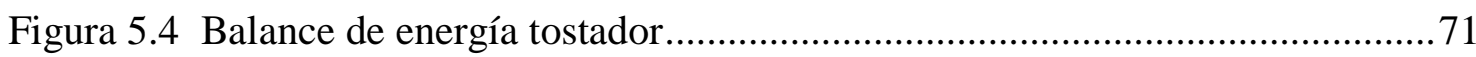

Figura 5.5 Balance de energía temperador ........................................................ 71

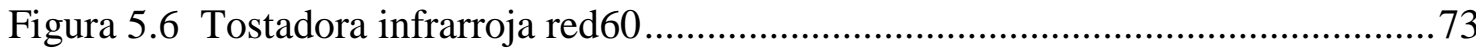

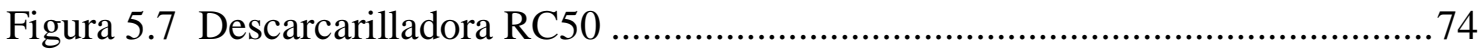

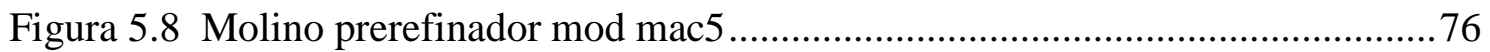

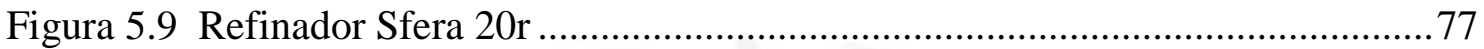

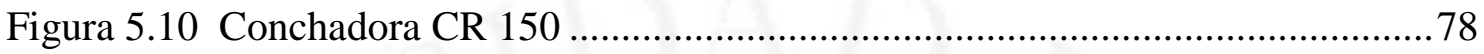

Figura 5.11 Temperadora con rueda y mesa vibratoria .............................................. 79

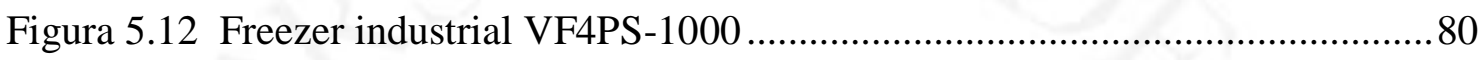

Figura 5.13 Diseño de cadena de suministro .......................................................... 98

Figura 5.14 Diagrama de Gozinto de una barra de chocolate premium con fruto

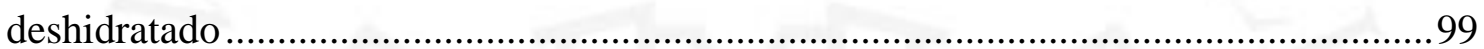

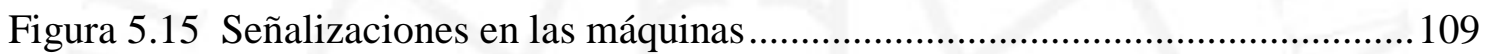

Figura 5.16 Señalizaciones de salvamento o de auxilio .........................................109

Figura 5.17 Señales de prohibiciones, peligros ....................................................... 110

Figura 5.18 Señalización de uso obligatorio de EPP ............................................... 110

Figura 5.19 Diagrama relacional de actividades................................................... 111

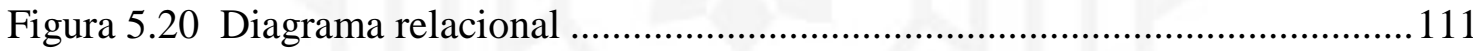

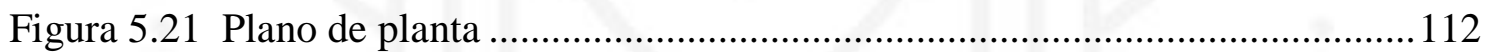

Figura 5.22 Cronograma de implementación del proyecto........................................ 113

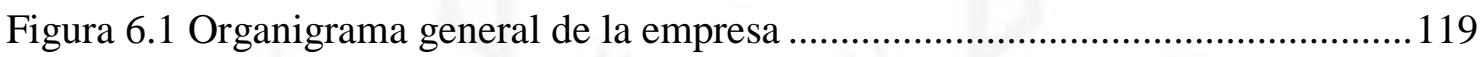




\section{ÍNDICE DE ANEXOS}

Anexo 1: Encuesta de chocolate orgánico 


\section{RESUMEN}

El presente estudio evalúa la factibilidad económica, tecnológica, financiera, social y de mercado para la instalación de una planta procesadora de chocolate orgánico premium en barra al 65\% de cacao, fino de aroma, con frutos del bosque deshidratados para el mercado de Lima Metropolitana.

Este producto llevará el nombre de "Amora Chocolate" y se venderá a un precio de 15 soles al consumidor final en la presentación de una tableta de 50 gramos con el contenido de una barra de chocolate bitter con trocitos de arándanos y frambuesas deshidratadas, las cuales se distribuirán en tiendas especializadas, supermercados y auto servicios de Lima Metropolitana. El mercado objetivo del producto lo conformará los habitantes de Lima Moderna, que pertenecen a los niveles socioeconómicos A/B y se encuentran entre las edades de 18 a 55 años, obteniendo una demanda del proyecto de 425,820 barras de chocolate orgánico Premium para el primer año del proyecto.

Por otro lado, mediante un análisis de localización de planta se determinó que la mejor ubicación es en el departamento de Lima, en el distrito de Pachacamac, con un requerimiento de terreno de $350 \mathrm{~m}^{2}$. El tamaño de planta para el presente proyecto será de 670,580 unidades de producto terminado al año 2024 y estará limitado por el Punto de equilibrio como límite inferior y como límite superior por el recurso productivo; asimismo, se determinó que el cuello de botella del proceso sería la máquina refinadora.

Finalmente, la implementación de una planta procesadora de chocolate orgánico premium con frutos deshidratados requiere de una inversión total de aproximadamente S/. $1,668,678$.

Palabras clave: chocolate, bitter, orgánico, planta, frutos deshidratados. 


\begin{abstract}
The present study evaluates the economic, technological, financial, social and market feasibility for the installation of a $65 \%$ premium organic chocolate bar processing plant, fine aroma, with dehydrated forest fruits for the Metropolitan Lima's market.

This product will be called "Amora Chocolate" and will be sold at a price of 15 soles to the final consumer in the presentation of a 50 gram tablet containing the content of a bitter chocolate bar with pieces of blueberries and dehydrated raspberries, which they will be distributed in specialized stores, supermarkets and auto services of Metropolitan Lima. The target market of the product which will be distributed of the inhabitants of Modern Lima, who belong to the A / B socioeconomic levels and are between the ages of 18 and 55, obtaining a project demand of 425,820 bars of Premium organic chocolate bars for the first year of the project.

On the other hand, through a plant location analysis it was determined that the best location is in the department of Lima, in the district of Pachacamac, with a land requirement of $350 \mathrm{~m}^{2}$. The plant size for this project will be 670,580 units of finished product by 2024 and will be limited by the Point of equilibrium as a lower limit and as an upper limit for the productive resource; Likewise, it was determined that the process bottleneck would be the refining machine.

Finally, the implementation of a premium organic chocolate processing plant with dehydrated fruits requires a total investment of approximately S/. 1,668,678.
\end{abstract}

Keywords: chocolate, bitter, organic, processing plant, dehydrated fruits. 


\section{CAPÍTULO I: ASPECTOS GENERALES}

\subsection{Problemática}

En los últimos años y con mayor frecuencia, son más las personas que prefieren un estilo de vida saludable por lo que tienden a elegir productos que favorezcan esta dieta. Hecho que se ve reflejado en el aumento notable del consumo de productos orgánicos, alimentos sin aditivos químicos tratados con abonos naturales. Perú no es ajeno a este fenómeno, pues también existen compañías que apuestan por lo saludable como lo evidencia la proliferación de tiendas orgánicas, bio ferias y la creación de productos orgánicos que tienen un lugar posicionado en supermercados y tiendas específicas. Entre las tiendas que comercializan productos cuya elaboración no dañan y están en pro al medio ambiente tenemos a Flora \& Fauna, Mara Biomarket, La Calandria, Salvia, La Bodega Orgánica y Eco Tienda Natural.

Se debe subrayar que el Perú destaca mundialmente como segundo exportador de cacao orgánico por sus granos de alta calidad y fino aroma; y como poseedor del $60 \%$ de todas las variedades de cacao que existen. Así mismo, es productor de berries (arándano, fresa, aguaymanto y frambuesa). De los cuales el arándano, ha crecido una tasa promedio de $206 \%$ anual entre el 2012 y el 2018.

De esta manera se tiene propuesto presentar un producto que fusione los granos de cacao orgánico y berries (arándanos y frambuesas) deshidratados, de modo que no solo el Perú sea reconocido por su alta calidad de materia prima, sino también por la fina calidad de sus productos elaborados que beneficien a más peruanos y permita defender responsablemente su biodiversidad.

\subsubsection{Presentación del tema}

Hoy en día el chocolate es un alimento universal, saludable, energético y placentero. El Perú se caracteriza por exportar granos de cacao de alta calidad para la producción de chocolates de marcas conocidas que luego son importados, comercializados y consumidos por todos los peruanos. En la actualidad contamos con diferentes oportunidades para realizar industria; ya sea por apoyo financiero como por el acceso de tecnología moderna que existe en el país; es debido a ello que se realiza una investigación más a fondo de este proyecto. El presente estudio busca instalar una 
planta procesadora de chocolate al $65 \%$ de cacao orgánico en barra con arándanos y frambuesas deshidratadas.

\subsubsection{Descripción del producto}

La barra de chocolate a realizar esta hecha a base de granos finos de aroma; es decir de cacao criollo orgánico al $65 \%$ con inclusiones de arándanos y frambuesas deshidratas que en su conjunto combinan el ligero amargor del cacao, la sutil acidez de los frutos deshidratados y el preciso dulzor para que la mezcla de sabores sean uno y muchos a la vez. La barra será de 50 gramos envuelta en un empaque ecológico con abre fácil y con diseños delicados y artísticos.

La Organización Internacional del Cacao (ICCO) clasifica a los granos de cacao en dos grupos: a) finos o "de sabor" y b) "a granel” u ordinarios. De los cuales destacan, obviamente, los primeros por sus aromas y sabores frutales, florales, de nueces y malta. Estos grados que se presentan mayormente en dos variedades: criollo o trinitario deben su calidad al clima y a la composición del suelo donde son cultivados y al trabajo posterior a su cosecha.

En Perú, el año 2010, se constituyó la Asociación de Productores Kemito Ene, promovida por la Central Ashaninka del Río Ene-CARE y constituida por la comunidad nativa de Centro Tsomabeni. En la actualidad, cuenta con 234 socios productores de cacao abarcando 28 comunidades nativas de la cuenta del río Ene, de los distritos de Rio Tambo. Mazamiri y Pangoa del Departamento de Junín. Quienes producen cacao criollo fino de aroma, orgánico y ecológico y cuentan con sellos USDA/NOP y UE.

Figura 1.1

Chocolate orgánico

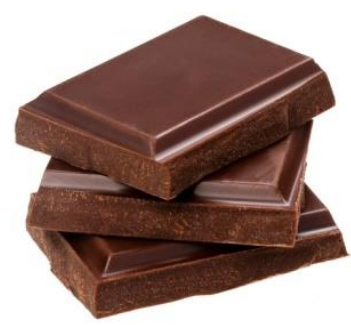

Fuente: https://www.freepik.es/fotos-premium/barras-chocolate-oscuro-aisladas-sobre-fondo-blanco-pilatrozos-chocolate-primer-plano 5733973.htm (2019) 
Figura 1.2

Frutos del bosque

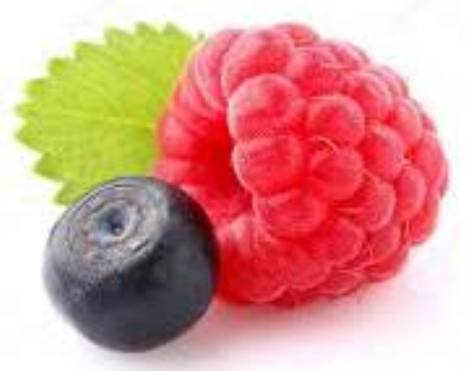

Nota: Arándano y frambuesa

Fuente: https://mx.depositphotos.com/49224385/stock-photo-raspberry-with-bilberry.html(2014)

\subsection{Objetivos de la investigación}

\subsubsection{Objetivo general}

Establecer la viabilidad técnica, financiera, económica, ambiental, social y de mercado para la instalación de una planta de procesamiento de chocolate bitter orgánico con frambuesas y arándanos deshidratados.

\subsubsection{Objetivos específicos}

- Identificar y analizar las empresas que actualmente comercializan chocolate orgánico en el Perú.

- Realizar el estudio de mercado del consumo de chocolates orgánicos en el Perú.

- Evaluar y determinar la ubicación de la planta

- Establecer el tamaño de planta.

- Precisar y desarrollar los conceptos claves de la ingeniería del proyecto

- Determinar y definir la organización empresarial del proyecto.

- Evaluar la viabilidad económica y financiera del proyecto.

- Evaluar la viabilidad social del proyecto.

\subsection{Alcance de la investigación}

La presente investigación será de carácter cuantitativo con base en un estudio de prefactibilidad de una planta, estadísticas y data medible. Para así establecer de forma pertinente la viabilidad técnica, económica, financiera y social de esta investigación. 


\subsection{Justificación del tema}

\section{Técnica}

La instalación de la planta procesadora de chocolates permitirá una producción y comercialización eficiente de una manera sostenible e innovadora; con tecnología moderna como: el uso de maquina descascarilladora de cacao, molino pre refinador de granos, tostadora y la conchadora, las cuales se fabrican en el país y en el extranjero.

\section{Económica}

Considerando la investigación sobre exportación de aguaymanto orgánico deshidratado cubierto con chocolate bitter y otros trabajos similares, se encontró que el margen de ganancia fue del 25\%, un VAN 16,924.28 y una TIR de $36.47 \%$ con un COK de $15.47 \%$. Tales indicadores hacen que el proyecto sea atractivo y viable al contar con un VAN mayor que 0 y una TIR mayor al costo de oportunidad (COK). A esto se suma el costo económico de elaboración del producto, pues la mano de obra es barata y no se precisa de operarios muy tecnificados. Además, el consumo de energía eléctrica es relativamente bajo con una tensión media de tarifa MT4 según Luz del Sur (2019).

\section{Social}

Una de las finalidades más importantes de este proyecto es de mejorar las condiciones económicas de los agricultores trabajando estrechamente con ellos y defendiendo responsablemente la biodiversidad. Cabe resaltar que se comprará el cacao directamente a las cooperativas cacaoteras amazónicas a un precio justo, pues el precio lo decide la cooperativa ya que ellos conocen los procesos de cosecha y post cosecha adecuados a los requisitos de los estándares de calidad que nosotros esperamos de sus granos. El precio que se les paga incluye las primas de las certificaciones de comercio justo y agricultura orgánica; estas primas permiten financiar proyectos que ayuden a toda la comunidad.

\section{Ambiental}

Al trabajar con materia prima que proviene directamente de comunidades indígenas quienes logran una agricultura sostenible; ya que sus productos son $100 \%$ orgánicos y ecológicos. Somos y nos consideramos responsables que cada paso que damos deja 
huella en nuestro ecosistema; por lo tanto, procuramos fomentar una agricultura sostenible y una industria responsable.

\subsection{Hipótesis de trabajo}

El montaje de una planta de procesamiento de chocolate premium en barra es factible ya que el producto tiene buena aceptación en el mercado y, además es técnica, económica, financiera, ambiental y socialmente viable.

\subsection{Marco referencial}

Los siguientes artículos, revistas e informes fueron examinados y están relacionados con la industria del chocolate. Fueron extraídos de Gale OneFile y Proquest:

- En principio, se revisó un artículo de la Universidad Autónoma Metropolitana Unidad Xochimilco, México publicado por la revista Chilena de Nutrición (2015) y desarrollado por Coronado M., Vega y León S., Gutiérrez R., Vázquez M, Radilla C., con el título: “Antioxidantes: perspectiva actual para la salud humana" (2014). Quienes, apoyándose en un estudio local exploratorio sobre el consumo de antioxidantes, remarcan la importancia de éstos producidos por el chocolate y los frutos rojos.

- Nutrióloga resalta propiedades estimulantes del chocolate. (2019, Feb 23). Recuperado de http://fresno.ulima.edu.pe/ss_bd00102.nsf/Recurso Referido?OpenForm\&id=PROQUEST-41716\&url=/docview/21850478 17 ? accountid $=45277$

- Vázquez-Ovando, A., Ovando-Medina, I., Adriano-Anaya, L., BetancurAncona, D., y Salvador-Figueroa, M. (2016). Alcaloides y polifenoles del cacao, mecanismos que regulan su biosíntesis y sus implicaciones en el sabor y aroma. Archivos Latinoamericanos De Nutrición, 66 (3). Recuperado de http://fresno.ulima.edu.pe/ss_bd00102.nsf/RecursoReferi do?OpenForm\&id=PROQUEST-41716\&url=/docview/2076965894?acc ountid $=45277$

- Nuevos sabores para chocolate. (2009, Julio). Industria Alimenticia, 20(7), 10. Recuperado de https:// link-gale-com.ezproxy.ulima.edu.pe/ apps/doc/A206689283/IFME?u=ulima\&sid=IFME\&xid=2962c836 
- Procesamiento real de chocolate: el sistema de molino de bola que vino a mejorar los procesos. (2012, Enero). Industria Alimenticia, 23(1), 52+. Recuperado de https://link-gale-com.ezproxy.ulima.edu.pe/apps/doc/A2 92513880/IFME?u=ulima\&sid=IFME\&xid=9bd 15051

- La importancia que ha llegado a tener el empaque, así como su significado como marca dentro de la industria y asociado al estilo de vida del consumidor es abordado en la revista Industria Alimenticia, 25(2) de Febrero (2014).

Simultáneamente, se identificaron tres tesis afines al presente estudio tomando como fuente la base de datos de biblioteca de la Universidad de Lima, las cuales se detallan a continuación:

- Palomino-Salazar, R., Rojas-Bustamante, D., Chávez-Ugaz, R., y Universidad de Lima. Facultad de Ingeniería y Arquitectura. Carrera de Ingeniería Industrial. (2017). Estudio de pre-factibilidad para la instalación de una planta dedicada a la producción de chocolate con cacao orgánico peruano.

La principal similitud es el mercado al cual se encuentran dirigidos, siendo ambos chocolates orgánicos con diferentes porcentajes de cacao; es decir otra formulación y origen de cacao diferente. En el presente proyecto nos enfocamos en la innovación constante de sabores, cuidando siempre la calidad y el sabor original del cacao, teniendo en cuenta que nos encontramos en una industria altamente competitiva nos proponemos a destinar cierto porcentaje de ventas en investigación, desarrollo e innovación; ya que nos encontramos en una época disruptiva. En cuanto a la presentación del producto es diferente; ya que el empaque de presentación es práctico y ecológico, pudiendo volver a guardar el chocolate restante para su siguiente consume y sellando el empaque sin ningún esfuerzo.

- Martínez Barrios, M. F., Arroyo-Rizo-Patrón, M., y Universidad de Lima. Escuela Universitaria de Negocios. Facultad de Economía. Carrera de Negocios Internacionales. (2015). Exportación de 
aguaymanto orgánico deshidratado cubierto con chocolate bitter a Estados Unidos.

Se encuentran diferencias como el mercado externo al que va dirigido y el tipo de producto final, uno se considera snack y el otro chocolate. Y como similitud principal: ambos productos tienen como materia prima frutos orgánicos.

- Asencios Hidalgo, L. R., Delgado Cruz, C. A., y Universidad de Lima. Escuela Universitaria de Ingeniería. Facultad de Ingeniería Industrial. (2014). Estudio de prefactibilidad para la implementación de una planta para la elaboración de bombones rellenos de ganache de frutas peruanas para Lima Metropolitana.

Entre las similitudes que se encuentra entre los presentes proyectos es la segmentación de mercado realizada; es decir ambos se encuentran orientados al sector socioeconómico A y B, ambos tienen alta amenaza de bienes sustitutos y los insumos son netamente peruanos. En cuanto a diferencias se tiene: la materia prima que usan no es cacao orgánico, las inclusiones, la presentación y el porcentaje de cacao del producto final son notablemente diferentes.

\subsection{Marco conceptual}

Glosario de términos

- Agricultura orgánica: es el sistema holístico de producción que se adapta a las condiciones locales para promover y mejorar la salud del agroecosistema y en extensión la biodiversidad y la actividad biológica del suelo prefiriendo los propios insumos de una finca antes que los externos. Para esto hay que utilizar medios biológicos, culturales y mecánicos, pero en oposición a los materiales sintéticos para satisfacer cualquier función del sistema (Codex, 1999).

- Conchado: es un proceso para refinar la pasta básica de chocolate, para mejorar y armonizar su sabor logrando su fluidez (Educalingo, 2019).

- Descascarillar: Quitar la cascarilla (RAE, 2019).

- Disruptivo: Que produce disrupción. (RAE, 2019). 
- Fruta deshidratada: fruta natural que ha sido sometida a un proceso de absorción del agua para dar como resultado una fruta deshidratada. (Esalud,2017)

- Innovación: Creación o transformación de un producto para introducirlo al mercado (RAE, 2019).

- Manteca de cacao: Grasa natural comestible que procede del haba del cacao (Infoagro, 2019). 


\section{CAPÍTULO II: ESTUDIO DE MERCADO}

\subsection{Aspectos generales del estudio de mercado}

En este apartado se establecerá la definición del producto y se analizará el sector dónde se encuentra. Además, se definirá el mercado objetivo y se presentarán los resultados del estudio mercantil que se efectuarán para determinar la demanda potencial, demanda interna aparente y demanda proyectada a las que se circunscribirá esta investigación.

\subsubsection{Definición comercial del producto}

La marca de chocolate gourmet que se busca elaborar, se identifica con el nombre de “Amora" Chocolate, pues la marca invita al amor, el acto más sublime. En consecuencia, a la tendencia Bean to bar, Amora Chocolate propone ser bean to hearth. De esta manera la marca capta la atención del consumidor a través de las emociones que guarda registro en su memoria, siendo más susceptible a la próxima compra por impulso.

Amora Chocolate está hecho de cacao fino de aroma y orgánico, originario de Junín producido por la Central Ashaninka del Río Ene. Siendo un cacao criollo orgánico; esto quiere decir que no se usa ningún tipo de químico durante la etapa de crecimiento y de cuidado de la planta. En Perú, los fertilizantes orgánicos usados son el guano de la isla, el potasio y el humus. Productos libres de agrotóxicos que juntos a otros factores tienden a favorecer la alimentación natural y saludable.

\section{- Marca}

Figura 2.1

Marca Amora Chocolate

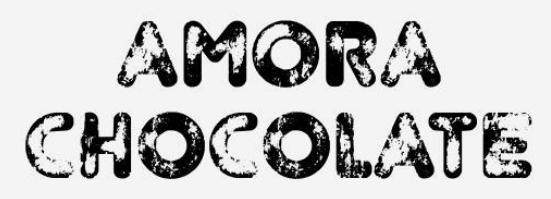

Elaboración propia 


\section{- Etiqueta}

Figura 2.2

Etiqueta de Amora Chocolate premium

cancounte

AMORA

BEAN TO

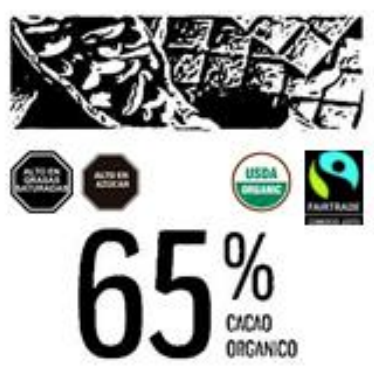

ous chocenare

- mintos da Bosque-

Nota: Incluyen octógonos y sellos USDA y Fair Trade.

Elaboración propia

El producto tendrá la presentación de una barra de chocolate con trocitos de frambuesas y arándanos deshidratados de 50 gramos. Estará óptimamente diseñado con divisiones muy atractivas a la vista y serán prácticas para un correcto quiebre a la hora de consumirlo. En la etiqueta se muestra el contenido, la marca, el tipo de chocolate con inclusiones de frutos del bosque, el sello orgánico y de comercio justo. También se incluyen los octógonos en el marco de la Ley de Promoción de Alimentación Saludable que corresponden a los alimentos procesados, El Comercio (2019). 
Figura 2.3

Alimentos sólidos y parámetros de octógonos

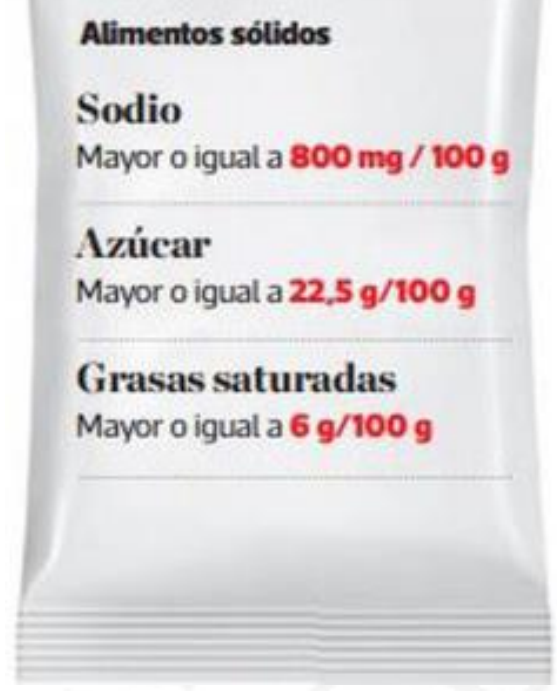

Fuente: El Comercio (2019)

El contenido de cacao que tiene el chocolate orgánico es al 65\% siendo libre de gluten y sin emulsionantes. Además, los empaques serán hechos con materiales ecológicos, como una medida de cuidado al medio ambiente y con abre fácil que permitirá un práctico acceso al contenido y al guardado del mismo para su próximo deleite. De esta manera es posible consumir chocolate sin ningún peso en la conciencia, haciéndose un bien a sí mismo y a la naturaleza.

\section{Producto básico}

Barra de chocolate de 50 gramos que busca satisfacer con gran placer el hambre del consumidor.

\section{Producto real}

Barra de chocolate envuelto en un empaque ecológico de alto relieve, con abre fácil, cuidadosamente reciclado con diseños artísticos y muy atractivos a la vista.

\section{Producto aumentado}

El producto mostrará en la etiqueta, la información nutricional, el sello que garantiza ser un producto orgánico y la certificación de comercio justo (Vease Figura 2.2) También llevará un código QR en la parte reversa del empaque donde se tendrá la 
oportunidad de obtener más información del producto, se realizarán concursos y los clientes potenciales obtendrán descuentos para su próxima compra, pues linkeará a la página de Instagram, donde se enfocará en postear los beneficios nutricionales de Amora Chocolate, se compartirá mensajes de empoderamiento, trascendencia y armonía. Adicional a ello, se compartirá el whatsapp para comunicación directa con los consumidores finales para cualquier duda, reclamo o sugerencia.

\section{Figura 2.4}

Barra de chocolate premium

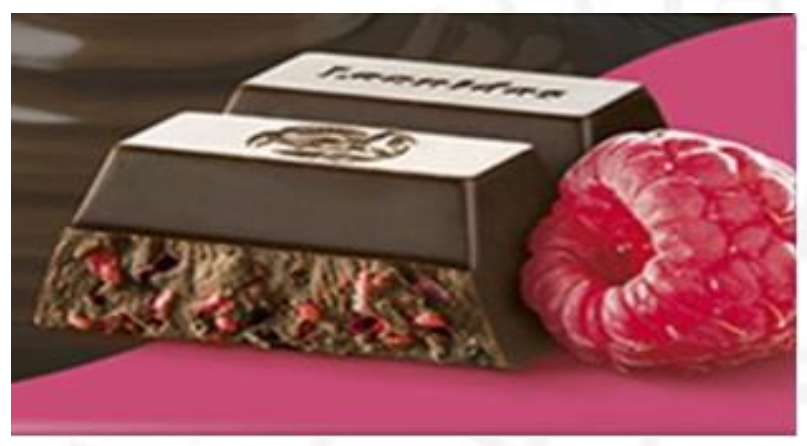

Nota: Chocolate con frutos rojos deshidratados

Fuente:https://www.leonidasfleur.be/index.php/en/component/hikashop/product/Dark\%20Chocolate\%20 Raspberry

Tabla 2.1

\section{Composición nutricional}

\begin{tabular}{|c|c|c|c|}
\hline \multicolumn{4}{|c|}{ INFORME NUTRICIONAL } \\
\hline \multicolumn{2}{|l|}{ Tamaño por porción } & $10 \mathrm{~g}$ & \\
\hline \multicolumn{2}{|l|}{ Porciones por envase } & 5 & \\
\hline \multirow{2}{*}{\multicolumn{2}{|c|}{$\begin{array}{l}\text { Energía (calorías) por porción } \\
\text { Energía de grasas (calorías de grasa) }\end{array}$}} & \multirow{2}{*}{\multicolumn{2}{|c|}{$\begin{array}{l}251 \mathrm{~kJ}(60 \mathrm{kcal}) \\
147 \mathrm{~kJ}(35 \mathrm{kcal})\end{array}$}} \\
\hline & & & \\
\hline \multicolumn{4}{|c|}{$\%$ de valor diario* } \\
\hline Grasa total & $4 \mathrm{~g}$ & & $6 \%$ \\
\hline Grasa saturada & $2 g$ & & $10 \%$ \\
\hline Grasa mono insaturada & 19 & & - \\
\hline Grasa poli insaturada & og & & - \\
\hline Grasa trans & og & & $0 \%$ \\
\hline Colesterol & Omg & & $0 \%$ \\
\hline Sodio & Omg & & $0 \%$ \\
\hline Carbohidratos totales & $5 g$ & & $2 \%$ \\
\hline Fibra dietética & og & & $0 \%$ \\
\hline Azúcares & $5 g$ & & - \\
\hline Proteína & $1 \mathrm{~g}$ & & $2 \%$ \\
\hline
\end{tabular}

Fuente: https://www.camari.org/index.php/catalogo/alimentos/confiteria/barra-de-chocolate-premiumorganico-con-arandano-rojo-pacari-detail\#tabla-nutricional (2019) 


\subsubsection{Usos del producto bienes sustitutos y complementarios.}

El producto que se elaborará es un chocolate premium orgánico con frutos deshidratados, es considerado un producto gourmet, es saludable y delicioso destinado a un consumo directo.

\section{Bienes sustitutos y complementarios}

El chocolate convencional es el principal competidor y el sustituto con mayor consumo. Tiene un menor precio en comparación al chocolate orgánico. Contiene insumos refinados, con preservantes y la materia prima es tratada con pesticidas y productos químicos por lo que puede ser considerado: no beneficioso a la salud. Contiene productos lácteos, siendo perjudicial para personas intolerantes a la lactosa. Poseen gran cantidad de azúcar, muy dañino para personas que poseen diabetes. Todo esto puede considerarse como desventajas frente al chocolate orgánico; el cual, además de tener granos de cacao cultivados en campos libres de pesticidas sin antibióticos y sin hormonas de crecimiento, conserva las propiedades originales del cacao.

Dulces surtidos, helados, tortas, alfajores, etc. Son ejemplos de productos sustitutos y complementarios al chocolate.

\subsubsection{Determinación del área geográfica que abarcará el estudio}

Considerando criterios estratégicos, económicos y sociales que maximicen utilidades y reduzcan costos, se ha establecido a Lima Metropolitana como lugar idóneo para desarrollar una estrategia comercial; ya que es el área donde se localizan ingresos más notorios y la mayor concentración de la población.

\subsubsection{Análisis del sector industrial}

Tal como lo indica Porter (1979) es importante conocer las fuerzas competitivas del sector para determinar su rentabilidad y a partir de allí, elaborar las estrategias significativas.

\section{Amenaza de nuevos ingresantes}

El ingreso de nuevos competidores representa una amenaza media alta, debido al fuerte posicionamiento que tiene en la actualidad marcas como Nestlé que, de estar dispuestos a crear una nueva categoría de chocolates orgánicos, sería un fuerte competidor; ya que 
tienen la cadena de suministro casi en su totalidad cubierta y tienen un notable posicionamiento en el mercado con una participación del 51,5\% según Euromonitor (2019).

Nuevos competidores también pueden ser empresas de chocolate orgánico que nacieron en otros países y buscan expandir sus mercados.

Otros posibles competidores serían nuevos emprendedores que se encuentren dispuestos a invertir en tecnología o que cuenten con el capital suficiente para poder competir con marcas consolidadas como: Shattel, Orquidea, Cacaosuyo, Maraná, etc. Esto indica contar con una resaltante presentación del producto, alta calidad y un buen respaldo financiero que avale los costos de producción, comercialización, publicidad y tiempos de espera para la remuneración por ventas según canal establecido. Es lo mínimo que se necesita para comenzar con el negocio.

\section{Poder de negociación de los clientes}

Debido a que la oferta del producto es alta, el poder de negociación del cliente también es alto. Además, los chocolates por estar de moda y ser de fácil elaboración, cuentan con muchas solicitudes de personas deseosas de colocar su producto en el canal moderno. Sin embargo, se toma un tiempo de aproximadamente 4 meses entre verificaciones de certificaciones/fichas técnicas de producto, evaluación del mix de productos actual de la tienda para poder procesar su petición de ingreso a la tienda" (Jiménez, Mezarina, Perezy Quinto, 2018, p.27). Esto indica que los canales modernos como supermercados, tiendas especializadas y tiendas de conveniencia (Tambo, Listo, etc.) tienen sus propias condiciones de pagos, tiempos de entrega, reposición, etc.

\section{Poder de negociación de proveedores}

Un fenómeno similar ocurre con el poder de negociación del proveedor: es medio alto. Y se debe a la cantidad de productores de cacao que cuentan con las certificaciones necesarias y el volumen de producción según requerimiento.

Es de saber que la materia prima del chocolate es el cacao y para este año 2019 se estima que la producción de cacao alcance las 149,000 toneladas a nivel nacional, superando las 134,676 toneladas producidas durante el 2018, proyectó el Ministerio de Agricultura y Riego (Minagri).

A diferencia del chocolate convencional, el chocolate orgánico tiene como materia prima el cacao orgánico. El SENASA que es el ente responsable de certificar la 
producción orgánica indicó que en el año 2017 se certificaron 9,7 mil productores con una superficie orgánica de 32,1 mil ha de cacao. A nivel regional, la mayor superficie orgánica se encuentra en San Martín, con 13315 ha certificadas. Asimismo, el mayor número de productores de cacao orgánico está en San Martín, donde 3383 agricultores producen cacao orgánico. La capacidad de integración hacia adelante es baja debido a que necesitarían de inversión relativamente alta.

Tabla 2.2

Productores certificados y superficie orgánica (2017)

\begin{tabular}{|l|r|r|}
\hline \multicolumn{1}{|c|}{ Región } & $\begin{array}{c}\text { Productores } \\
(\mathbf{n})\end{array}$ & $\begin{array}{c}\text { Sup. Orgánica } \\
\text { (ha) }\end{array}$ \\
\hline Total & 9653 & 32107 \\
\hline San Martín & 3383 & 13315 \\
Ayacucho & 1118 & 4647 \\
Huánuco & 743 & 3956 \\
Ucayali & 1055 & 2961 \\
Junín & 774 & 2927 \\
Cusco & 489 & 1778 \\
Piura & 1038 & 1448 \\
Amazonas & 396 & 954 \\
Cajamarca & 657 & 121 \\
Puno & 0 & 0 \\
Tumbes & 0 & 0 \\
\hline
\end{tabular}

Fuente: SENASA (2018)

\section{Amenazas de productos sustitutos}

Se considera como una amenaza alta; ya que existe una amplia variedad de golosinas sabor a chocolate cuyos precios hacen que sean de fácil acceso. Tales como: princesa, sublime, triangulo, vicio, etc.

Se encontró en el mercado a los chocolates premium no orgánicos, los cuales son productos sustitutos directos; es decir chocolates que proceden del cacao convencional o no llevan la certificación orgánica.

\section{Intensidad de la rivalidad de las competencias actuales}

La intensidad de rivalidad en competidores actuales es alta. Esto se debe a la valoración de nuestro cacao por parte de las empresas quienes apostaron por darle un valor agregado a las exportaciones de cacao en bruto.

Cada año se realiza la competencia International Chocolate Awards en diferentes países donde empresas productoras de chocolate se encuentran mejorando e 
innovando sus productos y procesos para presentarse cada año a dicha competencia. Esta competencia de chocolatería fina que es única en su tipo y completamente independiente apoya tanto a las empresas productoras y chocolateros artesanos quienes trabajan con cacao fino de aroma, cuanto a los agricultores que lo cultivan para que puedan crecer y seguir desarrollándose.

Tabla 2.3

Indicadores de competencia de chocolates orgánicos (Matriz MPC).

\begin{tabular}{|c|c|c|c|c|c|c|c|c|c|c|c|}
\hline \multirow[t]{2}{*}{ Indicatores de competencia } & \multirow[t]{2}{*}{ Peso } & \multicolumn{2}{|c|}{ SHATELIONOCOLTT } & \multicolumn{2}{|c|}{ ML2ANÁ } & \multicolumn{2}{|c|}{ SLEVDER } & \multicolumn{2}{|c|}{ CACAOSUYO } & \multicolumn{2}{|c|}{ DFEANS OF ENA } \\
\hline & & Calificaoion & Totd & Galificadion & Total & Galificodion & Total & Calificaóón & Total & Calificatón & Total \\
\hline Fuerza de vertas adeouada & 128 & 4 & 0.48 & 3 & 0.36 & 3 & 0.30 & & 0.48 & & 036 \\
\hline Penetración en los canales de distribución & 9g: & 3 & 0.2 & 2 & 0.18 & 3 & 0.27 & 5 & 0.45 & 2 & 0.18 \\
\hline Costos de produción & $\Leftrightarrow$ & 2 & 0.15 & 3 & 0.24 & 2 & 0.15 & 3 & 024 & & 024 \\
\hline Imagen de marcas de servidos comeríal lizatos & 国 & 2 & 0.12 & 2 & 0.12 & 1 & 0.18 & & 024 & 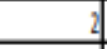 & 0.12 \\
\hline Solvendafinancera & 8 & 4 & 0.32 & 3 & 0.24 & 2 & 0.16 & & 024 & & 024 \\
\hline Inversion en mercado y publicidad & 8 & 3 & 0.24 & 3 & 0.24 & 2 & 0.15 & & 032 & 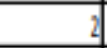 & 0.18 \\
\hline Áreade investigaón y desamollo & 30 & 3 & 0.00 & 2 & 0.06 & & 0.006 & & 000 & 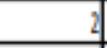 & 0.006 \\
\hline Participación de metcodo & 118: & 4 & 0.4 & 3 & 0.33 & 3 & 0.33 & & 0.44 & 2 & 0.22 \\
\hline Tecolologia de procesos y sistemas & 100 & 3 & 0.3 & 3 & 0.3 & 2 & 0.2 & 3 & 0.3 & 2 & 0.2 \\
\hline Posidonamiento de la marta & 118 & 4 & 0.4 & 3 & 0.33 & 3 & 0.33 & 4 & 0.44 & 4 & 0.4 \\
\hline Predo & 10 & 3 & 0.42 & 3 & 0.42 & 2 & 0.2 & 3 & 0.42 & 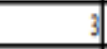 & 0.42 \\
\hline & & & & & & & & & & & \\
\hline & $100 \%$ & & 328 & & 2.82 & & 249 & & 3.66 & & 2.64 \\
\hline
\end{tabular}

Fuente: Jimenez, Mezarina, Perez y Quinto (2018)

Según se puede observar en el cuadro desarrollado acerca de la competencia existente en la categoría chocolates elaborados de cacao orgánico, se puede analizar que la empresa Cacaosuyo es la empresa que mayor competencia muestra en el estudio. Esto al ser considerada en la actualidad como la marca que cuenta con el chocolate de mayor calidad, ganadora de diversos premios y reconocimientos, $\mathrm{y}$, además, de tener una fuerte presencia en retail moderno tanto en Hipermercados (TOTTUS), tiendas por conveniencia (PRIMAX), entre otras.

SHATELL CHOCOLATE, es otra de las empresas de chocolate que también tiene un fuerte posicionamiento en la categoría. La calidad de sus productos y los reconocimientos hacen de ella, una empresa de fuerte competencia en el rubro.

Las otras tres empresas como son el caso de MARANÁ, SLENDER y DREAMS OF EVA, si bien es cierto cuentan con algunos años en el mercado y de cierto prestigio por sus productos, hay ciertas características de la empresa y la marca que deben mejorar con el fin de hacerse de una competencia fuerte en la categoría. 
Como se detalla, su nivel de penetración en los canales de distribución y su participación en el mercado son ítems considerados muy por debajo de las otras empresas con las cuales compiten.

Es así, que podemos concluir que el mercado de chocolates elaborados de cacao orgánico en el Perú está en reciente crecimiento, con mucho potencial y camino a desarrollar por las empresas existentes y que, de no realizar cambio alguno, dejan abierto la posibilidad de la aparición de nuevas marcas que puedan cubrir las necesidades y oportunidades que, debido a su falta de desarrollo, dejan a merced de potenciales competencias. (Jimenez, Mezarina, Perez y Quinto, 2018, p.27).

\subsubsection{Modelo de negocios (Canvas)}

- Segmentación de mercados

AMORA Chocolate ofrece barras de chocolate orgánico premium con el fin de complacer a los paladares limeños de manera saludable con las contribuciones nutricionales que posee el cacao $100 \%$ orgánico, fino de aroma. De modo que este producto va dirigido a personas de nivel socioeconómico A y B del sector 7 (Miraflores, Surco, San Isidro y La Molina) entre 18 y 55 años. Nuestro segmento se encuentra dirigido a personas caracterizadas por un estilo de vida saludable, la actividad física; con gusto por productos de alta calidad y comprometidas con el medio ambiente. Estos clientes prefieren comprar a través de canales modernos de venta por lo cual, también, se está planteando la distribución por estos medios.

\section{- Propuesta de valor}

Se tiene como objetivo ofrecer a los clientes chocolates de sabores innovadores manteniendo siempre los altos estándares que ameritan los chocolates de categoría internacional. Se trabajará de la mano con artistas quienes diseñarán y brindarán mensajes de empoderamiento personal y de felicidad en el empaque. Es importante resaltar que el eslogan: "Amora, chocolate que enamora" hace alusión al amor; ya que la feniletilamina (o PEA) presente en el chocolate es la misma que produce el cerebro emocional de quienes están enamorados y que les da esa sensación placentera de bienestar, exaltación y euforia (Mundo Chocolates, 2017). 
Se desempeñará un rol más social y medioambiental que busque interactuar y beneficiar a todos los grupos de interés, en la que todos se vean favorecidos con los resultados de la empresa. En otras palabras, se busca crecer sosteniblemente, produciendo sin contaminación y siendo responsables con el medio ambiente, incentivar proyectos en los que participen agricultores de Kemito Ene; ya que al tenerlos de socios estratégicos aseguraremos la sostenibilidad y se lograra mejores relaciones comerciales.

“Amora Chocolate" encausará sus esfuerzos hacia una constante innovación que permita el desarrollo de nuevos sabores para introducir, a futuro, chocolates funcionales, cuidando siempre la calidad y el sabor original del cacao. Pues se tiene en cuenta que es una industria altamente competitiva, se propone destinar cierto porcentaje de ventas en investigación, desarrollo e innovación; ya que se vive en una época disruptiva. En cuanto a la presentación del producto es diferente; ya que el empaque de presentación es práctico y ecológico, pudiendo volver a guardar el chocolate restante para su siguiente consume y sellando el empaque sin ningún esfuerzo.

\section{- Canales}

Para la venta de los chocolates se tendrá una fuerza de ventas de tres ejecutivos de venta quienes se encargarán de colocarlos en tiendas especializadas como: Flora \& Fauna, La Zanahoria, Mara Biomarket, la Calandria, Eco Natural Market, la Colorada; los cuales mantienen el concepto de la marca "saludable" para poder transmitirla a los clientes potenciales; además de posicionar en supermercados Wong y en cadenas de Minimarkets como Tambo, Listo y Repshop. También se encargarán de vender y relacionarse con mayoristas, quienes por comprar en volumen tendrán un margen mejor considerado.

Tabla 2.4

Tiendas de conveniencia vistas alguna vez en la calle 


\begin{tabular}{l|c|c|c|c|c|c|}
\hline & Total & \multicolumn{3}{c}{} & \multicolumn{3}{c}{ NSE } & \\
\hline & & A & B & C & D & E \\
\hline Base sin ponderar & 602 & 120 & 120 & 120 & 120 & 122 \\
\hline Base ponderada (Abs) & 602 & 30 & 132 & 241 & 151 & 48 \\
\hline Tambo & $73 \%$ & $93 \%$ & $86 \%$ & $77 \%$ & $56 \%$ & $51 \%$ \\
\hline Repshop & $52 \%$ & $72 \%$ & $70 \%$ & $51 \%$ & $39 \%$ & $27 \%$ \\
\hline Listo & $36 \%$ & $73 \%$ & $51 \%$ & $36 \%$ & $21 \%$ & $15 \%$ \\
\hline Mimarket & $30 \%$ & $39 \%$ & $40 \%$ & $27 \%$ & $26 \%$ & $23 \%$ \\
\hline Viva & $21 \%$ & $52 \%$ & $38 \%$ & $17 \%$ & $11 \%$ & $9 \%$ \\
\hline Ninguno & $13 \%$ & $4 \%$ & $4 \%$ & $12 \%$ & $20 \%$ & $32 \%$ \\
\hline No precisa & $1 \%$ & - & - & $1 \%$ & $1 \%$ & $1 \%$ \\
\hline
\end{tabular}

Fuente: Ipsos Perú (2018)

\section{- Relación con los clientes}

La comunicación que se mantendrá con el cliente será una comunicación personalizada, esto gracias a nuestros ejecutivos de venta, quienes harán seguimiento de las ventas y afianzarán la relación con las tiendas quienes se encargarán de vender nuestros productos.

Para que los clientes potenciales puedan conocer la nueva marca "Amora Chocolate", se utilizará las redes sociales (Instragram, Facebook) las que linkearán a nuestra página web para fomentar el conocimiento de marca y producto. Por medio de las redes sociales se podrá interactuar con los clientes finales; es decir se contará con un Social Media Manager quien se encargará de postear concursos, promociones, próximas degustaciones, mensajes relativos a la esencia de nuestro ser: "el amor"; ya que nuestra marca "Amora chocolate" lo denota. Así como también aclarar las dudas posibles que tengan sobre el producto. Se realizarán campañas promocionales de acuerdo con fechas especiales tales como: el día de los enamorados o el día de la madre o del padre, etc.

- Flujo de ingresos

Los ingresos se darán principalmente por la venta de chocolates orgánicos a tiendas especializadas; así como también por ingresos por maquila usando la capacidad instalada y venta de cascarillas de cacao. Para la venta de chocolates al por mayor se establecerá facilidades de pago (pago a 30 y 45 días).

- Recursos claves 
Como recursos claves se tendrá la tecnología en maquinarias tales como: maquina tostadora, descascarilladora, pre-refinadora, refinadora de bolas, conchadora y templadora, siendo máquinas con tecnología evolutiva privilegiada de calidad, eficiencia y eficacia.

Los activos más valiosos son los trabajadores quienes deberán estar calificados, especialmente el personal operativo, comercial y el de Investigación Desarrollo e innovación. Esto se debe a que todos trabajan de manera integral y creativa.

- Actividades claves

La actividad principal es elaboración de chocolates premium, seguido del almacenamiento y control de inventarios y por último la venta, logística y distribución del producto.

- $\quad$ Red de partners

Se tendrá como socio estratégico a los productores de cacao orgánico: Kemito Ene. Con quienes se mantendrá una relación a largo plazo, fijando para ello alianzas estratégicas que permitan asegurar la compra de insumos que son claves para la fabricación del producto. Asimismo, nuestra fuerza de venta y el gerente comercial se encargarán de incentivar las ventas en coordinación con las tiendas especializadas, tiendas por conveniencia, ferias, instituciones, supermercados y otros, se programarán visitas y se enviará a vendedores para promocionar y realizar degustaciones de los productos.

- Estructura de costos

Los costos para considerar en todo el proceso productivo, venta y distribución de chocolates premium son:

A. Costo operativo (insumos, mano de obra, materiales)

B. Costo de distribución (logística y transporte)

C. Costo de almacén

D. Sueldos de trabajadores

E. Marketing e impuestos.

F. $\mathrm{I}+\mathrm{D}+\mathrm{I}$

\subsection{Metodología a emplear en la investigación de mercado}

Fuentes de datos primarios: 
Se realizará encuestas al posible mercado consumidor de chocolates orgánicos y también nos entrevistaremos con productores de cacao orgánico, proveedores de maquinaria y con productores actuales de chocolate para obtener datos verídicos que sustenten el presente estudio.

\section{Fuentes de datos secundarios:}

Se utilizan datos publicados electrónicos e impresos. Tales como: publicaciones en diarios (Gestión, El Comercio.), tesis, estudios preliminares, estudios de prefactibilidad, bases de datos como: DataTrade, VeriTrade, Euromonitor, Maximixe, Ipsos Apoyo, Perú Números, etc.

Información de internet de páginas como: INEI, Ministerio de Producción, Gobierno Peruano, Ministerio de Agricultura y Riego, APEIM, Nielsen, etc.

Publicación en revistas obtenidas de bases de datos por Gale OneFile y Proquest.

\subsection{Demanda potencial}

\subsubsection{Patrones de consumo: incremento poblacional, estacionalidad, aspectos culturales.}

De acuerdo con Euromonitor (2019), la confitería de chocolate con alto contenido de cacao se está volviendo cada vez más popular. Algunos consumidores están demostrando un mayor conocimiento y ahora asocian calidad con contenido de cacao. Esto se refleja en la creciente presencia de marcas, principalmente nacionales, que pueden ofrecer productos de confitería de chocolate con un 55\% de contenido de cacao a precios inferiores a los de los dos años anteriores. Se espera que este nicho continúe expandiéndose durante el período de pronóstico ya que estos productos se consideran más saludables, con menor contenido de grasa y azúcar.

Las ventas de dulces de chocolate son estacionales, en gran parte debido al clima. El volumen de ventas minoristas estuvo cerca del estancamiento en 2019, y la estacionalidad nuevamente caracterizó las ventas. El consumo generalmente aumenta entre mayo y octubre, cuando el clima es más frío. La distribución y el almacenamiento son difíciles durante el verano, ya que la mayoría de los centros de transporte y distribución no están refrigerados, mientras que pocos supermercados pequeños independientes tienen aire acondicionado. El período más importante para la confitería de chocolate es la Pascua, cuando las marcas tradicionales ofrecen sus huevos de 
chocolate en diferentes tamaños y colores. La Navidad es otra temporada navideña importante para los fabricantes de chocolate y Pascua y Navidad representan la gran mayoría de todas las ventas de chocolate de temporada.

La mayoría de las ventas son impulsivas, a través de los minoristas tradicionales. Las compras suelen ser impulsivas en lugar de planificadas. Esto ha permitido que los minoristas de comestibles tradicionales dominen las ventas durante muchos años. Estos puntos de venta están cerca de los consumidores e incluyen kioscos y vendedores ambulantes, que a menudo están cerca de las escuelas y centros de empleo, y pequeños supermercados independientes, que están en todas partes en Perú. Las tiendas de conveniencia también se están expandiendo en el país y están tomando parte de las ventas de dulces de chocolate $y$, aunque siguen siendo un pequeño canal para estos productos en 2019, las perspectivas son buenas para el período de pronóstico.

\subsubsection{Determinación de la demanda potencial en base a patrones de consumo} similares.

- Según el INEI calcula 32`495,500 habitantes en el Perú.

- Consumo per-cápita Chile: $2.1 \mathrm{Kg} / \mathrm{Hab}$ (Euromonitor, 2019)

- Consumo per-cápita Perú: 0.5 Kg/Hab (Minagri, 2019)

- Demanda potencial: 32`495,500 hab x $2.1 \mathrm{Kg} / \mathrm{Hab}=68240550 \mathrm{Kg}=68,240$ $\mathrm{Tm}$

\subsection{Determinación de la demanda de mercado en base a fuentes secundarias} primarias

\subsubsection{Demanda del proyecto en base a data histórica}

\subsubsection{Demanda interna aparente histórica tomando como fuente bases de datos} de producción, importaciones y exportaciones; o las ventas tomando como fuente bases de datos de inteligencia comercial

\section{Producción}

El incremento de la producción de chocolate en el Perú ha ido gradual conforme han pasado los años gracias a:

- La inversión en proyectos agrícolas a mayor escala como DEVIDA.

- Las campañas de promoción del sector cacaotero realizadas por empresas privadas, entidades gubernamentales y ONGs quienes buscan la rehabilitación 
de plantaciones antiguas para que los pequeños agricultores pueden incrementar sus ingresos.

- La producción de las plantaciones que han sido sembradas en los últimos 10 años y que han alcanzado la madurez.

Tabla 2.5

Producción de chocolate en el Perú

\begin{tabular}{c|c}
\hline Año & $\begin{array}{c}\text { Producción de chocolate } \\
\text { (Tm) }\end{array}$ \\
\hline 2011 & 15,203 \\
2012 & 28,222 \\
2013 & 35,713 \\
2014 & 37,118 \\
2015 & 35,639 \\
2016 & 40,088 \\
2017 & 40,432 \\
\hline
\end{tabular}

Fuente: Tomado de INEI - Compendio estadístico y Tomado de Economic Analysis No.3 Industria de Alimentos y Bebidas - Perú (2018)

Elaboración propia

\section{Importaciones $\mathbf{y}$ exportaciones}

Para calcular las importaciones y exportaciones, se consideró la partida arancelaria número 1806.90.00.00 con la descripción: Chocolate y sus preparaciones alimenticias, en bloques, tabletas o barras, y demás.

Las importaciones totales de agregados de cacao y sus derivados alcanzó en el 2018 un valor de US\$ 59,0 millones, 74,1\% mayor al valor importado en el 2017. De este total destacan las importaciones de Chocolates que representan el $64 \%$ del total importado (38,0 millones). Otros rubros de importación, aunque de menores valores son: La pasta de cacao, la manteca de cacao y el cacao en polvo suman en conjunto US $\$ 20,9$ millones. Por otro lado, las principales importaciones de chocolates provienen de los siguientes países: Estados Unidos (23\%), Chile (12\%), Brasil y Colombia (9\% respectivamente) principalmente. (Minagri, 2019)

Los principales destinos del cacao y sus derivados durante el 2018 fueron los Países Bajos con el 19\% de participación, seguido por los Estados Unidos (18\%), Bélgica (10\%) y Alemania (7\%); los cuales tuvieron unas tasas de variación de $+10 \%$, $5 \%,-19 \%$ y $+50 \%$, respectivamente. Los principales productos exportados en esta línea fueron el cacao en grano con una participación del 52\%, manteca de cacao (25\%), 
chocolates $(8 \%)$, cacao en grano tostado $(7.5 \%)$, polvo de cacao $(5 \%)$ y pasta de cacao (2.2\%). (Prom Perú, 2018)

Tabla 2.6

Exportaciones e importaciones de chocolate en Tm

\begin{tabular}{c|cc}
\hline & $\begin{array}{c}\text { Exportaciones } \\
\text { (Tm) }\end{array}$ & $\begin{array}{c}\text { Importaciones } \\
\text { (Tm) }\end{array}$ \\
\hline 2011 & 1,579 & 3,057 \\
2012 & 1,306 & 4,069 \\
2013 & 1,785 & 4,066 \\
2014 & 1,951 & 4,173 \\
2015 & 2,319 & 5,005 \\
2016 & 2,524 & 4,473 \\
2017 & 3,251 & 4,986 \\
\hline
\end{tabular}

Fuente: Tomado de Promperu (2019) y Sunat(2019)

Elaboración propia.

La demanda interna aparente (DIA) se calcula con los datos de producción, importación y exportación.

$$
\text { DIA }=\mathbf{P}+\mathbf{I}-\mathbf{X}
$$

Tabla 2.7

Demanda histórica de chocolate en Tm

\begin{tabular}{l|l}
\hline Año & DIA $^{\mathbf{T M}}$ \\
\hline 2011 & 23,834 \\
2012 & 30,985 \\
2013 & 34,490 \\
2014 & 39,340 \\
2015 & 40,181 \\
2016 & 42,037 \\
2017 & 42,167 \\
\hline \multicolumn{2}{|c}{ Elaboración propia. }
\end{tabular}

Tabla 2.8

Demanda interna aparente proyectada Tm

\begin{tabular}{c|c}
\hline Año & DIA(Tm) \\
\hline 2020 & 53,890 \\
2021 & 56,847 \\
2022 & 59,804 \\
2023 & 62,761 \\
2024 & 65,718 \\
\hline
\end{tabular}

Elaboración propia 
Tabla 2.9

Línea de proyección de demanda interna aparente

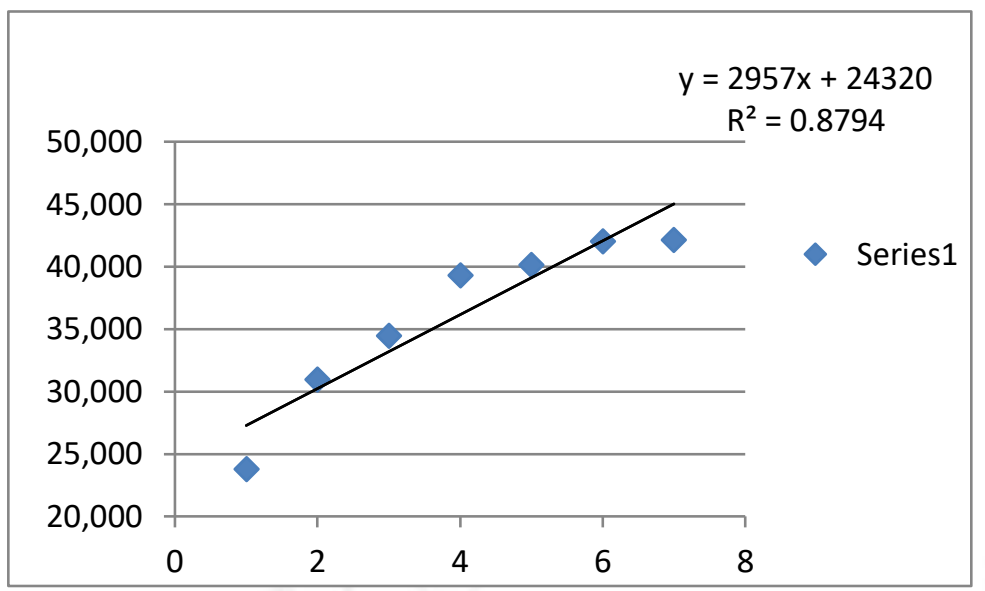

Elaboración propia

\subsubsection{Proyección de la demanda}

La demanda proyectada se establece gracias a los datos obtenidos en los puntos anteriores donde se estimó la demanda histórica (véase tabla 2.4).

Utilizando una regresión lineal, se calculó la ecuación para proyectar a los próximos años. Se consideraron los datos a partir del año 2011. $\quad \mathrm{y}=2957 \mathrm{x}+24320$ con un coeficiente de determinación: $\mathrm{R}^{2}=0.8794$

En donde:

Y: representa la demanda proyectada en toneladas.

t: representa el año a proyectar.

Tabla 2.10

Demanda proyectada del proyecto

\begin{tabular}{c|c}
\hline Año & $\begin{array}{r}\text { Demanda } \\
\text { Proyectada }(\mathbf{K g})\end{array}$ \\
\hline 2020 & 21,291 \\
2021 & 23,060 \\
2022 & 25,944 \\
2023 & 28,995 \\
2024 & 32,212 \\
\hline
\end{tabular}

Elaboración propia

\subsubsection{Determinación de la demanda potencial en base a patrones de consumo} similares.

La segmentación de mercado de consumo es fundamental para identificar a los consumidores potenciales, lo que a su vez permitirá desarrollar un plan comercial con una estrategia muy eficaz. 
Para la segmentación geográfica, se considera a Perú con 32‘495,500 habitantes, tomando a Lima Metropolitana (el 35.8\% de población peruana) como mercado objetivo. Sin embargo, por tratarse de un producto que será elaborado con materia prima orgánica tendrá un valor agregado al chocolate convencional lo que explica que su precio sea mayor que el precio normal. Motivo por el cual la segmentación psicográfica se enfocará en los niveles socioeconómicos A y B de Lima Metropolitana (79.1\%) quienes habitan los distritos de Miraflores, San Isidro, Surco, La Molina (Zona 7). Cabe subrayar que la zona 7 constituye el $7.7 \%$ de Lima Metropolitana.

Para la segmentación demográfica el rango de edades comprenderá desde los 18 años hasta los 55 años que pertenecen, a su vez, al 58\% de la población de Lima Metropolitana y son quienes toman decisiones de consumo más firmes, pues tienen un mayor poder adquisitivo y de decisión.

Según Arellano Marketing, el 8\% de la población Limeña lleva un estilo de vida sofisticado; es decir que los hombres y mujeres jóvenes de mediana edad que pertenecen a los niveles socioeconómicos A, B y C al contar con mayor nivel de instrucción y confianza en sí mismos buscan marca, calidad y servicio; donde el indicador de calidad lo constituye el precio y el símbolo de diferenciación, la marca. En un ranking de frecuencia de compra se encuentra que el $30 \%$ de peruanos compran habitualmente alimentos con características orgánicas. El cual consideramos para realizar la segmentación y obtener la demanda proyectada de "Amora Chocolate".

Tabla 2.11

Segmentación geográfica

\begin{tabular}{c|c}
\hline \multicolumn{2}{c}{ Variable geográfica } \\
\hline $\begin{array}{c}\text { Ubicación } \\
\text { Población }\end{array}$ & Perú \\
\% población \\
lima \\
$\begin{array}{c}\text { metropolitana } \\
\text { \% población } \\
\text { zona 7 }\end{array}$ & $35.60 \%$ \\
\hline
\end{tabular}

Fuente: Instituto Nacional de Estadística e Información, INEI (2017)

Elaboración propia.

Tabla 2.12

Segmentación demográfica

\begin{tabular}{l|c}
\hline \multicolumn{2}{c}{ Variable demográfica } \\
\hline $\begin{array}{c}\text { Índice demográfico } \\
\text { por edad 18-55 años }\end{array}$ & $58 \%$ \\
\hline
\end{tabular}

Fuente: I.N.E.I. Estimaciones y proyecciones de población en base al Censo (2017)

Elaboración propia 
Tabla 2.13

Segmentación psicográfica

\begin{tabular}{c|c}
\hline \multicolumn{2}{c}{ Variable psicográfica } \\
\hline & Zona 7 de lima \\
Ubicación & metropolitana \\
Nse a y b & $79.10 \%$ \\
\hline
\end{tabular}

Fuente: Asociación Peruana de Empresas de Inteligencia de Mercados, APEIM (2018)

Elaboración propia

\subsubsection{Diseño y aplicación de encuestas (muestreo de mercado)}

La población de estudio la constituyen los habitantes de Lima Metropolitana entre 18 y 55 años y para su distribución se ha tomado los datos de CPI (Compañía Peruana de Estudios de Mercado y Opinión Pública S.A.C.) de abril del 2019:

Tabla 2.14

Población por segmentos de hogar en Lima metropolitana

\begin{tabular}{l|c}
\hline Grupo de edad & $\begin{array}{c}\text { Población por segmentos } \\
\text { de edad en Lima } \\
\text { Metropolitana 2019 (en } \\
\text { miles) }\end{array}$ \\
\hline 18-24 años & $1,357.40$ \\
25-39 años & $2,683.40$ \\
40-55 años & $2,086.50$ \\
56- +años & $1,581.30$ \\
TOTAL & $7,708.60$ \\
\hline
\end{tabular}

Nota: Estimaciones y proyecciones de población en base al Censo 2017 Fuente: Instituto Nacional de Estadística e Información, INEI (2017)

La tabla $\mathrm{N}^{\circ} 2.14$ brinda la población $(\mathrm{N}=7,708.6)$ que aplicando la fórmula correspondiente permitirá obtener la muestra que requiere el presente estudio:

$$
n=\frac{N \times \sigma^{2} \times Z^{2}}{\left((N-1) \times E^{2}\right)+\left(\sigma^{2} \times Z^{2}\right)}
$$

Dónde:

$\mathrm{n}=$ Muestra

$\mathrm{N}=$ Población

$\sigma=$ Desviación estándar asumida 0.5

$\mathrm{Z}=$ Nivel de confianza $95 \%$

$\mathrm{E}=$ Margen de error aceptado 5\%

Reemplazando los datos en la fórmula: 


$$
\begin{gathered}
n=\frac{6127.3 \times 0.5^{2} \times 1.96^{2}}{\left((6127.3-1) \times 0.05^{2}\right)+\left(0.5^{2} \times 1.96^{2}\right)} \\
n=361
\end{gathered}
$$

Tras efectuar la ecuación correspondiente se obtiene como muestra 361 personas, pero para un resultado más preciso y considerando algún margen de error, se realizaron 390 encuestas en total.

\subsubsection{Resultados de la encuesta: intención e intensidad de compra, frecuencia,} cantidad comprada.

Las encuestas que se ejecutaron fueron 390 encuestas virtuales (ver anexo) con 12 ítems a llenar y marcar. Para validar la existencia real de los encuestados se le solicito el correo electrónico a cada uno. Los resultados de las encuestan se presentaron de la siguiente manera:

Figura 2.5

Pregunta 1

\section{Seleccione el rango de edad al que pertenece:}

390 respuestas

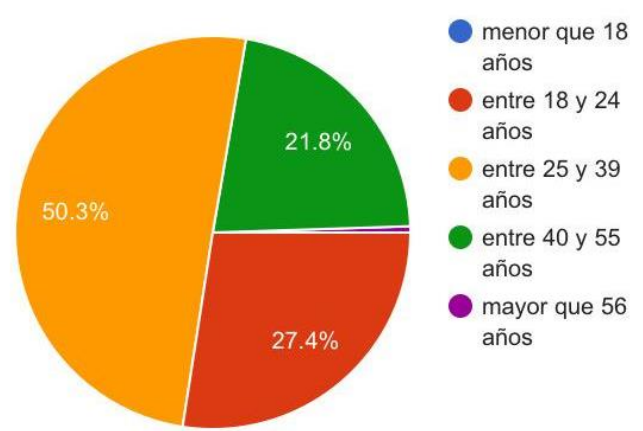

Nota:50,3\% tiene entre 25 y 39 años de edad

Elaboración propia 
Figura 2.6

Pregunta 2

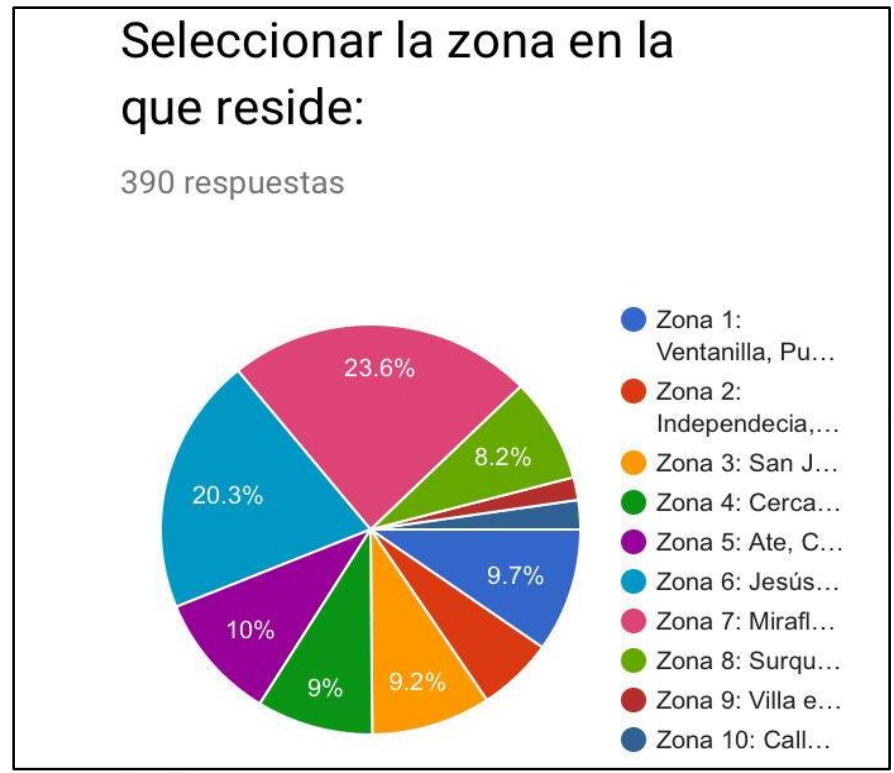

Nota:23,6\% residen en el sector 7

Elaboración propia

Figura 2.7

Pregunta 3

¿Cual es el grado de estudio alcanzado?

390 respuestas

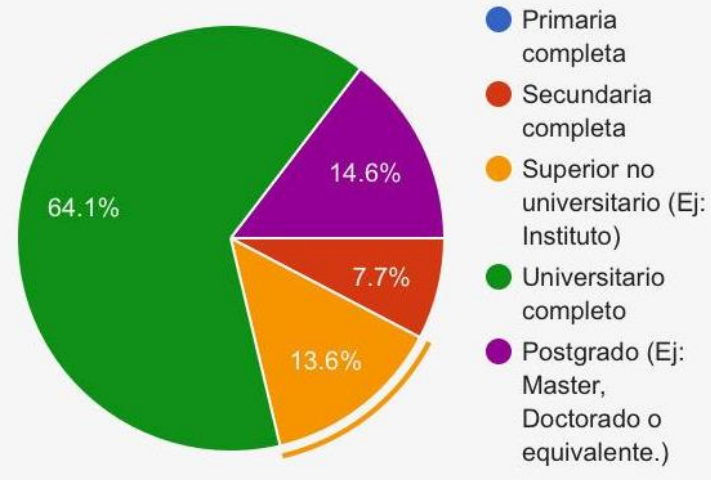

Nota:el 64,1\% tienen el nivel de educación de estudios universitarios completo. Elaboración propia 
Figura 2.8

Pregunta 4

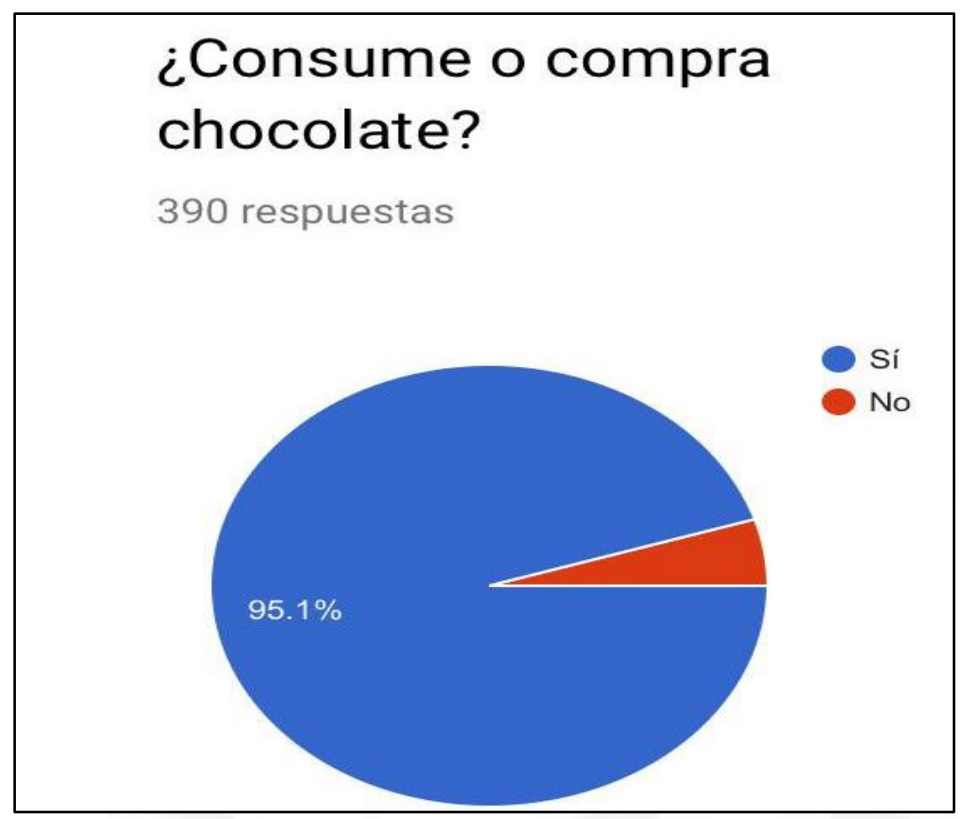

Nota: El 95,1\% consume o compra chocolate

Elaboración propia

Figura 2.9

Pregunta 5

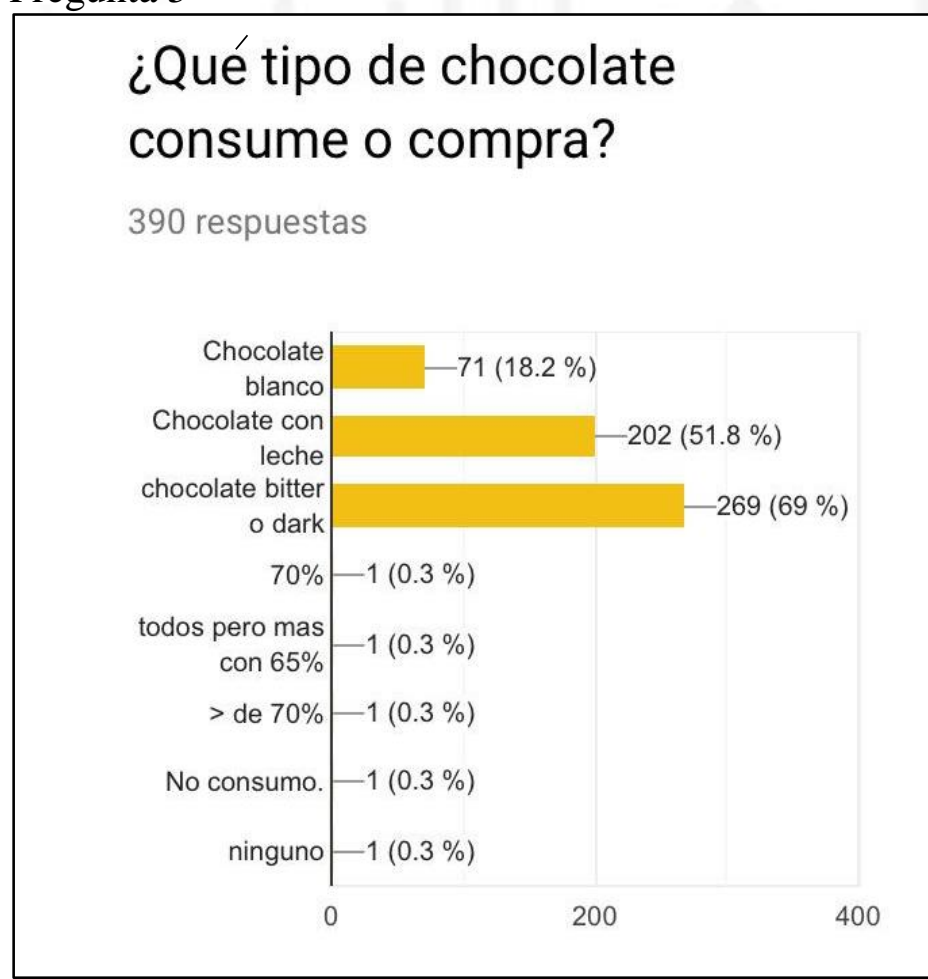

Nota:el 69\% consume o compra chocolates bitter Elaboración propia 
Figura 2.10

Pregunta 6

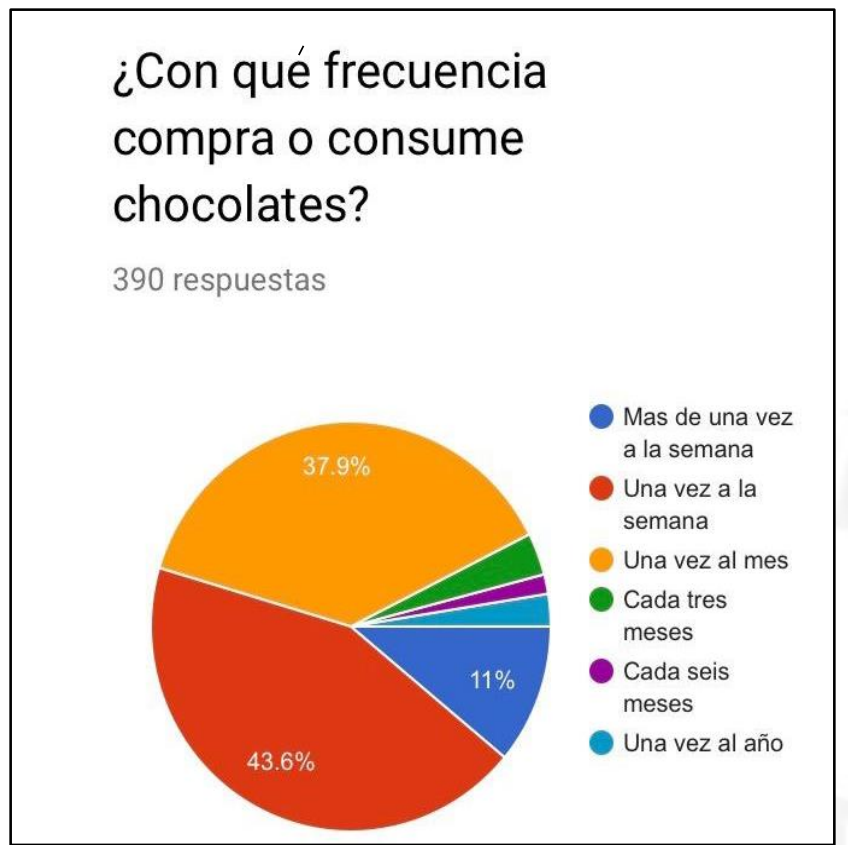

Nota: el 43,6\% consume chocolates una vez a la semana Elaboración propia

Figura 2.11

Pregunta 7

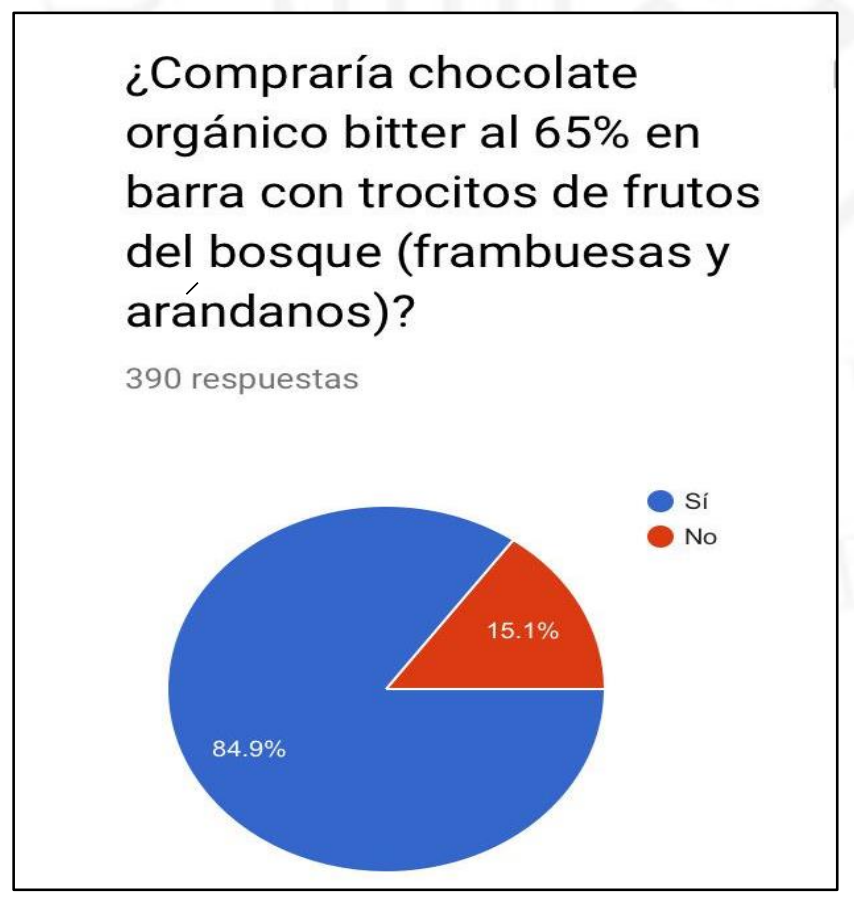

Nota:84,9\% compraría chocolate orgnico bitter al $65 \%$ Elaboración propia 
Figura 2.12

Pregunta 8

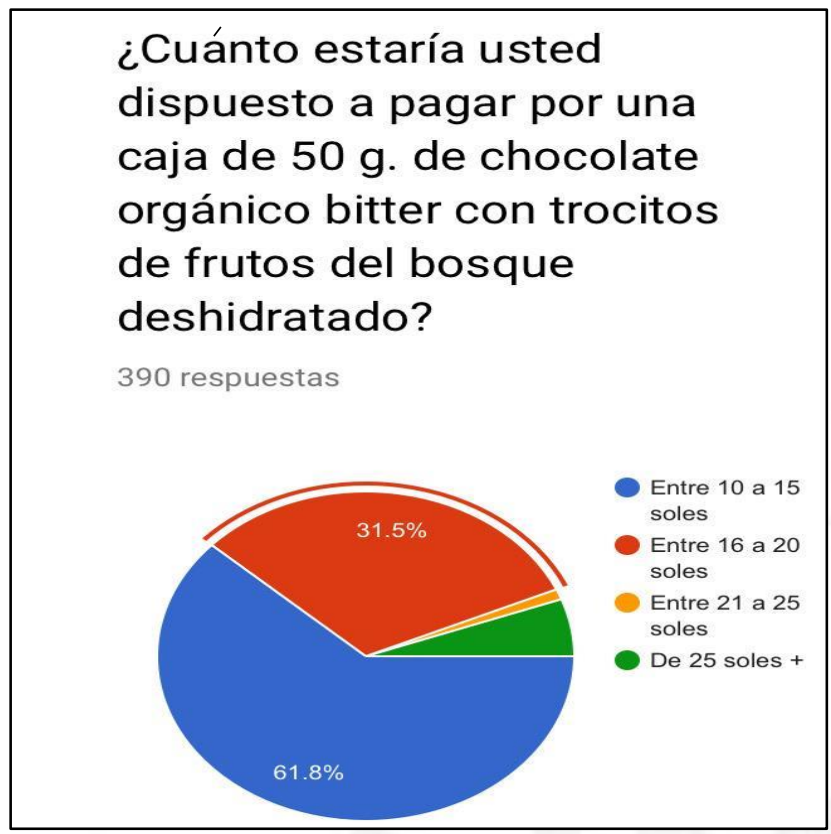

Nota:61,8\% estaría dispuesto a pagar entre 10 y 15 soles Elaboración propia

Figura 2.13

Pregunta 9

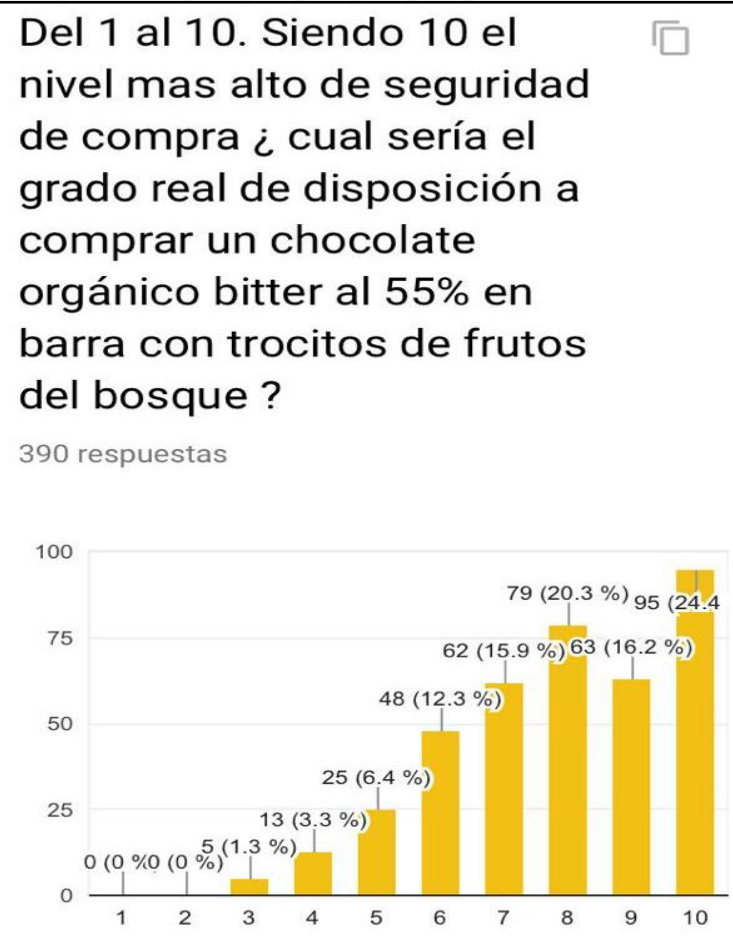

Elaboración propia 
En base a las encuestas respondidas se encuentra un nivel de intención de compra de $85 \%$ y un nivel de intensidad de $66 \%$. Entonces la demanda susceptible de ser captada por el proyecto será: $85 \% * 66 \%$. $=56,10 \%$.

\subsubsection{Determinación de la demanda del proyecto}

Tabla 2.15

Demanda del proyecto en Tm.

\begin{tabular}{|c|c|c|c|c|}
\hline Año & DIA(Tm) & $\begin{array}{c}\text { Segmentación } \\
(35.6 \% * 7.7 \% * 58 \% * 79.1 \% * 8 \%)\end{array}$ & $\begin{array}{l}\text { Corrección de } \\
\text { intención }\end{array}$ & $\begin{array}{c}\text { Demanda } \\
\text { proyectada Tm }\end{array}$ \\
\hline 2020 & 53,890 & 0.0010 & 0.56 & 21.29 \\
\hline 2021 & 56,847 & 0.0010 & 0.56 & 23.06 \\
\hline 2022 & 59,804 & 0.0010 & 0.56 & 25.94 \\
\hline 2023 & 62,761 & 0.0010 & 0.56 & 28.99 \\
\hline 2024 & 65,718 & 0.0010 & 0.56 & 32.21 \\
\hline
\end{tabular}

Elaboración Propia.

\subsection{Análisis de la oferta}

\subsubsection{Empresas productoras, importadoras y comercializadoras}

\section{Empresas Productoras}

Shattell es una empresa que produce chocolate artesanal ubicado en Lima con la visión de fabricar chocolates de calidad, utilizando cacao orgánico, producido en diferentes zonas de la amazonia peruana. Produce chocolates bitter 100\% orgánicos con un $70 \%$ $100 \%$ de contenido de cacao, también chocolates de leche y chocolate blanco. Incluso sus chocolates dark son libres de gluten, soya y no contienen leche. Cuentan con certificación HACCP, garantizando la inocuidad de pesticidas en su elaboración. Cuenta con premios en International Chocolate Awards y en el 2017 ganó cinco medallas de oro.

Industrias Mayo, que inicialmente fue un proyecto para cultivar cacao como producto alternativo a la hoja de coca logró producir "chocolates Orquídea", que constituyeron los primeros chocolates peruanos oriundos de una zona productora de cacao.

La planta de procesamiento de chocolates está situada en Tarapoto produciendo barras de chocolates de $65 \%$ a $72 \%$ de cacao. Tienen la línea orgánica y la convencional. Producen chocolates con leche, bitter y con inclusiones. 
"Cacaosuyo" ha sido catalogada como uno de los mejores chocolates en 2014 y 2015 por la International Chocolate Awards, exporta principalmente a países europeos y cuenta con presencia en retail moderno a través de Tottus, PRIMAX, entre otros.

"Marana". Produce tabletas de chocolate "Bean to Bar", son elaborados con granos de cacao de Cusco, Piura y San Martín. Usan productos 100\% orgánicos, y cuenta con certificación de USDA Organic.

La Ibérica es una empresa familiar arequipeña de mucho prestigio y calidad para el Perú, dedicada desde sus orígenes a la producción y comercialización de chocolate y otros productos de confitería como toffees, turrones, entre otros. Empero, a pesar de ser un líder en este rubro, hasta la actualidad no ha producido chocolates orgánicos.

Nestlé Perú mantiene un sólido liderazgo en el sector chocolatero en 2019, con una extensa red de distribución, que incluye distribuidores externos, con sus productos disponibles en todos los minoristas de comestibles, tradicionales y modernos. EUROMONITOR (2019). Al igual que Ibérica se considera como fuertes sustitutos a los chocolates orgánicos.

\subsubsection{Participación de mercado de los competidores actuales}

En cuanto a la participación con productos sustitutos dentro del mercado peruano se encuentran las empresas Nestlé Perú SA con el 51,50\%, quienes comercializan las chocolatinas Sublime, Triangulo, Princesa, etc. Seguido por la empresa Molitalia SA con un 10,20\% de participación con los productos Cañonazo, Mecano, etc. En tercer lugar, con un 9,7\% se encuentra Cía Nacional de Chocolates de Perú SA produciendo los conocidos Chin Chin, Chocolate Winter's, XL, etc. Así sucesivamente como se muestra en el siguiente gráfico se encontró dentro de otros con un $12,5 \%$ de participación a la empresa importadora Tierra del Monte Sociedad Comercial de Responsabilidad Limitada. EUROMONITOR (2019) 
Figura 2.14

Participación de mercado de competidores actuales de chocolate

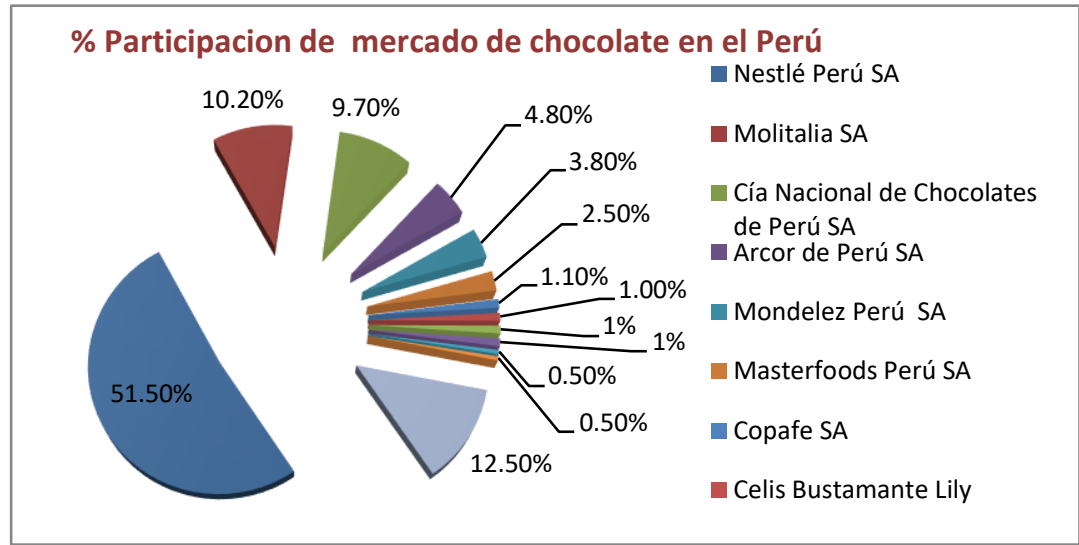

Fuente: Euromonitor (2019)

Elaboración propia

A continuación, se muestra un análisis de competencia de mercado de chocolates.

Figura 2.15

Análisis de competencia del mercado de chocolates 2018

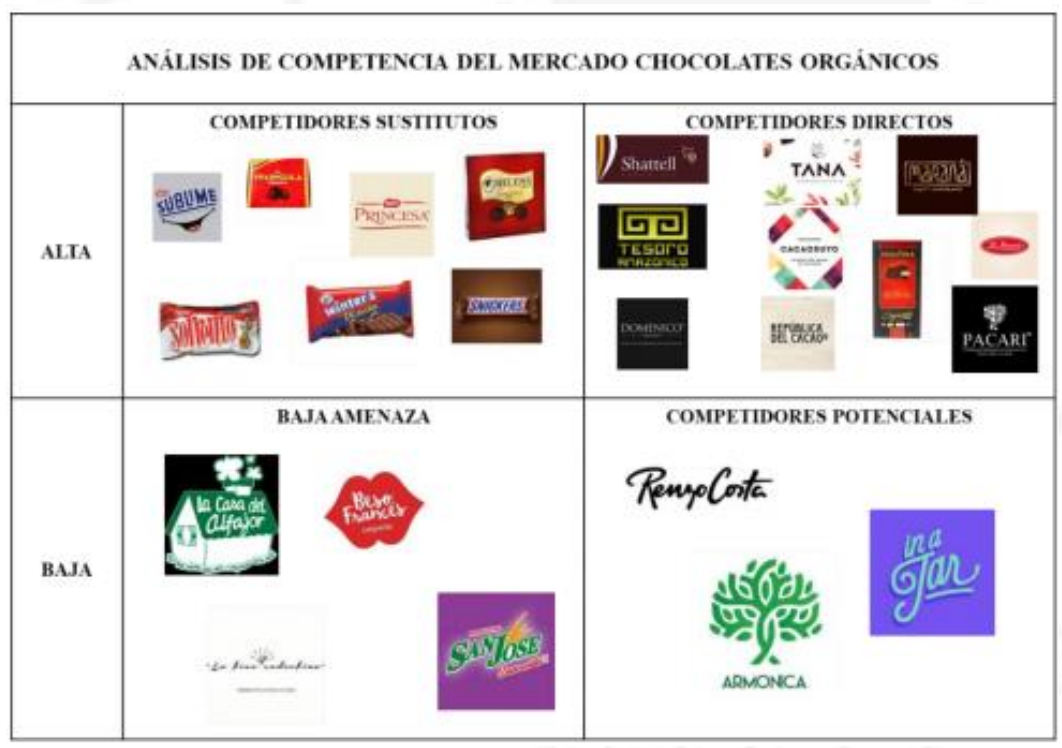

Fuente: Jimenez, Mezarina, Perezy Quinto (2018)

\subsubsection{Competidores potenciales}

Se considera como competidores potenciales a Nestlé y a La Ibérica que, si bien no venden chocolates orgánicos, pueden tomar esta decisión a futuro y gracias a su fuerte posicionamiento en el mercado serían un rival muy fuerte para competir. 


\subsection{Definición de la estrategia de comercialización}

\subsubsection{Políticas de comercialización y distribución}

Para la distribución de los productos se contará con una fuerza de ventas de tres ejecutivos quienes se encargarán de las ventas. El ejecutivo 1 se encargará de las ventas a mayoristas y el ejecutivo 2 y 3 se encargarán de posicionar y entablar una estrecha relación laboral con tiendas especializadas, con supermercados y minimarkets. Como estrategia de distribución se considera una distribución selectiva; ya que la relación con el distribuidor no será exclusiva, de manera que también venderá otras marcas de chocolates.

Chris Malta (2018) indica que los márgenes de ganancia a los que puede aspirar un vendedor mayorista son de 30 o $40 \%$ como límite superior.

Como política de comercialización se considera que se dará un crédito 30 días; ya que los productos se dejarán en tiendas orgánicas, supermercados, minimarkets. A continuación, se calcularán los márgenes de comercialización:

$$
\begin{gathered}
M B C=\frac{\text { Precio del consumidor }- \text { Precio del productor }}{\text { P.consumidor }} \times 100 \\
P D P=\frac{\text { Precio pagado } x \text { consumidor }- \text { Margen Bruto mercado }}{\text { P.pagado } x \text { consumidor }} \times 100
\end{gathered}
$$

MBC: margen bruto de comercialización

PDP: producción directa del productor (fábrica)

$P D P=\frac{15-5}{15} \times 100=66,7 \%$

$M B C$ mayorista $=\frac{12-10}{12} \times 100=13,3 \%$

$M B C$ minorista $=\frac{15-12}{15} \times 100=20 \%$

Dentro de los agentes de la cadena de comercialización, la fábrica recibe el $66.7 \%$ de participación directa del consumidor de las barras de 50 gr; es decir, el $33.3 \%$, restante se encuentra distribuido entre los diferentes agentes intermediarios. 
Figura 2.16

Canal 2: Canal detallista

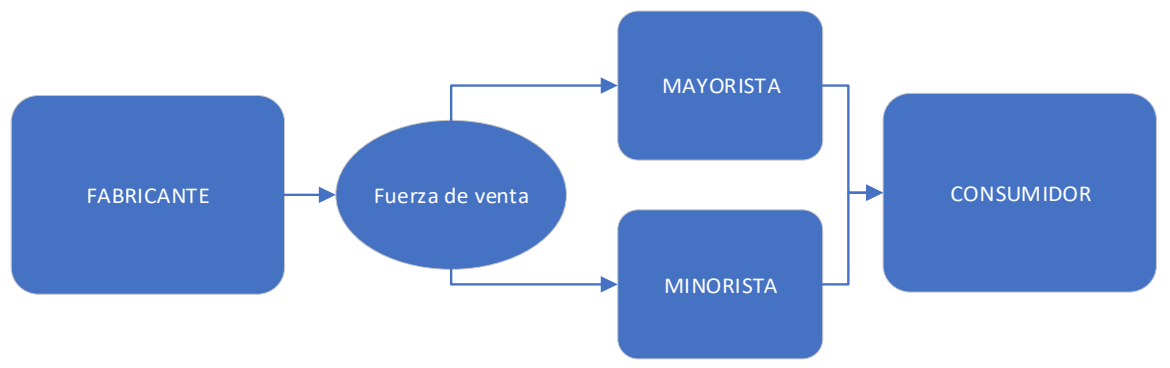

Elaboración propia

\subsubsection{Publicidad y promoción}

\section{Publicidad}

La publicidad es vital para llegar al consumidor final; ya que, mediante una estrategia de marketing pull se pretende dar a conocer el producto y atraer a dichos consumidores a comprar el producto a ofrecer. Esto se logrará mediante una correcta publicidad acorde con las tendencias en marketing digital. A través de videomarketing, página web, redes sociales como Instagram y Facebook se captará la atención de los consumidores y se los motivará para consumir los productos saludables y de calidad enfatizando en los detalles artísticos de la marca. Para aquellos clientes potenciales que no usen redes sociales se harán publicaciones en revistas como "COSAS" y periódicos como "El Comercio". La publicación de carteles y paneles en las calles será un foco visual para los consumidores que gustan de chocolates y no olvidar que en la actualidad mediante las publicaciones en redes sociales e internet son maneras de llegar más rápido a los posibles clientes orgánicos.

\section{Promoción}

La promoción de "Amora Chocolate" será BTL, ya que se contará con impulsadoras en el supermercado de Wong y en Flora\&Fauna. Estas promociones se darán también en ferias como el Salón del Chocolate, concursos virtuales, sorteos virtuales, muestras y degustaciones en supermercados para divulgar el producto y motivar al consumidor final a la compra de un producto saludable y de calidad.

Adicionalmente se destinará cierta cantidad para publicidad de medios digitales utilizando las redes sociales Facebook e Instagram para desarrollar campañas con el objetivo de generar brand awarness; es decir para llegar al top of mind o ranking mental de los consumidores. 


\subsubsection{Análisis de precios}

\section{Tendencia histórica de los precios}

El portal de Euromonitor (2019) indicó que el precio unitario promedio del chocolate aumentó un 3\% durante el presente año porque el contenido de cacao se vuelve cada vez más popular en la confitería de chocolate.

\section{Precios actuales}

Reparando en el plan de marketing estratégico para chocolates orgánicos de Jiménez, Mezarina, Perez y Quinto, 2018, se obtuvieron los siguientes listados de precios:

Tabla 2.16

Lista de precios de chocolates orgánicos

\begin{tabular}{|l|c|c|c|}
\hline \multicolumn{1}{|c|}{ Chocolates orgánicos } & Gramos & Precio & $\begin{array}{c}\text { Precio } \mathbf{x} \\
\text { gramo }\end{array}$ \\
\hline Cacaosuyo 70\% cacao Piura & 70 & 21.50 & 0.31 \\
\hline Orquídea 80\% & 90 & 18.50 & 0.21 \\
\hline Domenico Organic dark 70\% & 80 & 15.90 & 0.20 \\
\hline Pacari Esmeraldas 60\% & 50 & 15.19 & 0.30 \\
\hline Shattell 70\% cacao & 70 & 22.99 & 0.33 \\
\hline Marana Craft chocolate - Cusco 70\% & 70 & 19.90 & 0.28 \\
\hline Precio promedio - Chocolates orgánicos & $\mathbf{7 1 . 6 7}$ & $\mathbf{1 9 . 0 0}$ & $\mathbf{0 . 2 7}$ \\
\hline
\end{tabular}

Fuente: Jimenez, Mezarina, Perez y Quinto (2018)

Tabla 2.17

Lista de precios de chocolates no orgánicos

\begin{tabular}{|l|c|c|c|}
\hline \multicolumn{1}{|c|}{ Chocolates No orgánicos } & Gramos & Precio & $\begin{array}{c}\text { Precio x } \\
\text { gramo }\end{array}$ \\
\hline La Ibérica 73\% cacao - dark chocolate & 100 & 22.00 & 0.22 \\
\hline Montblanc chocolate 73\% cacao & 90 & 11.20 & 0.12 \\
\hline Tesoro Amazónico dark 76\% & 70 & 16.90 & 0.24 \\
\hline TANA chocolate negro 64\% & 70 & 17.90 & 0.26 \\
\hline Guirardelli Intense dark 72\% & 100 & 16.90 & 0.17 \\
\hline Lindt Excellence 85\% & 100 & 16.55 & 0.17 \\
\hline Lindt Excellence 70\% & 100 & 14.6 & 0.15 \\
\hline Valor 70\% & 100 & 13.7 & 0.14 \\
\hline Innato linea premium 70\% & 100 & 11.5 & 0.12 \\
\hline
\end{tabular}

Fuente: Jimenez, Mezarina, Perez y Quinto (2018) 


\section{Estrategia de precio}

Para fijar el precio se empleará la estrategia de precios promedio que sugiere establecer precios iguales o cercanos a los que se manejan en el mercado. Si bien este paso no presenta grado de complejidad si lo será la competencia, aunque existirá una diferenciación de producto a través de la presentación en el empaque, la calidad de sabor y lo novedoso de los ingredientes que se encargarán de encantar a los paladares peruanos. En la siguiente tabla se pueden apreciar las políticas de comercialización descritas en el punto 2.6.1.

Tabla 2.18

Listado de precios unitarios

\begin{tabular}{c|ccc}
\hline $\begin{array}{c}\text { Listado de } \\
\text { Precios }\end{array}$ & $\begin{array}{c}\text { Precio } \\
\text { Mayorista }\end{array}$ & $\begin{array}{c}\text { Precio } \\
\text { Minorista }\end{array}$ & $\begin{array}{c}\text { P.U Público } \\
\text { sugerido }\end{array}$ \\
\hline $\begin{array}{c}\text { Amora Chocolate } \\
\text { 50g }\end{array}$ & 10 & 12 & 15 \\
\hline Elaboración propia & &
\end{tabular}




\section{CAPÍTULO III: LOCALIZACIÓN DE PLANTA}

En este capítulo se analizarán y se determinarán las alternativas posibles para la ubicación de la planta procesadora de chocolates Premium. Mediante la matriz de enfrentamiento se evaluarán los factores de micro y macro localización y a través del método de ranking de factores se establecerá la ubicación de la planta.

\subsection{Identificación y análisis detallado de los factores de localización}

\section{Factores de Macro localización}

- Proximidad de la materia prima

En el territorio peruano, el cacao es cultivado entre los 300 y $900 \mathrm{msnm}$, principalmente en la selva peruana y en la parte baja occidental de los andes. Los departamentos que destacan por su cultivo son Amazonas, San Martín, Piura, Ayacucho, Cusco y Junín que en total representan el $80 \%$ del total de la producción nacional.

El Perú además de poseer el 60\% de las variedades de cacao del mundo, ha sido calificado por la ICCO como productor y exportador del $36 \%$ de cacao fino a nivel mundial lo que le otorga un valor agregado a las fábricas de chocolate y lo convierte, junto al café, en un producto peruano de calidad mundial.

Además de haber recibido premios internacionales en los últimos años, el cacao peruano ha sido catalogado entre los mejores del mundo, por lo que importantes fábricas de chocolate en Francia, Bélgica y Suiza, emplearon nuestro cacao para elaborar sus productos (PeruInfo, 2019).

Asimismo, hay varias cooperativas que traen cacao orgánico al departamento de Lima, como son las siguientes:

$>$ Asociación de productores Kemito Ene

$>$ Cacao VRAE SAC

$>$ Cooperativa Agraria Industrial Naranjillo

$>$ Cooperativa Acopagro

$>$ Cooperativa Agraria cafetalera Sapito 
El grano de cacao se cultiva en diversos departamentos del Perú, pero el cacao orgánico solo se cultiva en algunos departamentos. A continuación, se muestra las regiones donde se producen cultivan orgánicamente.

Figura 3.1

Productores certificados y superficie orgánica 2017

\begin{tabular}{|l|r|r|}
\hline \multicolumn{3}{|c|}{$\begin{array}{c}\text { PRODUCTORES CERTIFICADOS Y SUPERFICIE ORGANICA } \\
\text { SEGÚN REGIÓN, 2017 }\end{array}$} \\
\hline \multicolumn{1}{|c|}{ Región } & $\begin{array}{r}\text { Productores } \\
\text { (n) }\end{array}$ & $\begin{array}{c}\text { Sup. Orgánica } \\
\text { (ha) }\end{array}$ \\
\hline Total & 9653 & $\mathbf{3 2 1 0 7}$ \\
San Martín & 3383 & 13315 \\
Ayacucho & 1118 & 4647 \\
Huánuco & 743 & 3956 \\
Ucayali & 1055 & 2961 \\
Junín & 774 & 2927 \\
Cusco & 489 & 1778 \\
Piura & 1038 & 1448 \\
Amazonas & 396 & 954 \\
Cajamarca & 657 & 121 \\
Puno & 0 & 0 \\
Tumbes & 0 & 0 \\
\hline
\end{tabular}

Fuente: SENASA (2018)

Según la cercanía relativa a Lima, en donde se realizará la comercialización, las posibles ubicaciones en donde se busca implementar la planta son los departamentos de Junín, Cusco, San Martín y Lima.

- Cercanía de mercado

El público objetivo del proyecto se circunscribe a personas entre 18 y 55 años de edad de un nivel socioeconómico A y B de las cuales Lima concentra el 25,7 \%. En otras palabras, Lima reúne el más alto porcentaje de ingresos y población de personas con un nivel socioeconómico A y B. Por ello, se puede concluir que Lima cuenta con mayores puntos de atracción para desarrollar este mercado.

Tabla 3.1

Distancias del lugar de la materia prima

\begin{tabular}{|l|l|l|l|l|}
\hline \multicolumn{1}{|c|}{ Distancia $(\mathrm{km})$} & $\begin{array}{l}\text { Junín } \\
\text { (Satipo } \\
\text { Satipo) }\end{array}$ & $\begin{array}{l}\text { San Martín } \\
\text { (Mariscal Cáceres- } \\
\text { Pachiza) } \\
\text { De destino (Lima) }\end{array}$ & $\begin{array}{l}\text { Lima } \\
\text { (Lima - Pachacamac) }\end{array}$ & $\begin{array}{l}\text { Cusco } \\
\text { (La convención - } \\
\text { Echarati) }\end{array}$ \\
\hline Lima & $349 \mathrm{Km}$ & $833 \mathrm{Km}$ & $0 \mathrm{Km}(*)$ & $1.097 \mathrm{Km}$ \\
\hline
\end{tabular}

Nota: (*) las empresas que venden la matería prima, la dejan en el almacén de la empresa Elaboración propia 


\section{$\underline{\text { Junín - Lima }}$}

Figura 3.2

Mapa de ruta del departamento de Junín - Lima

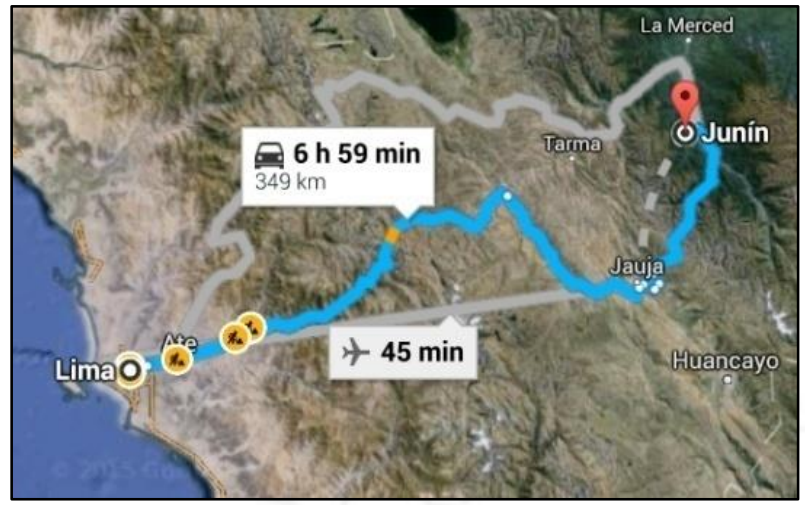

Fuente: Google Maps (2019)

\section{$\underline{\text { San Martin - Lima }}$}

Figura 3.3

Mapa de ruta del departamento de San Martin - Lima

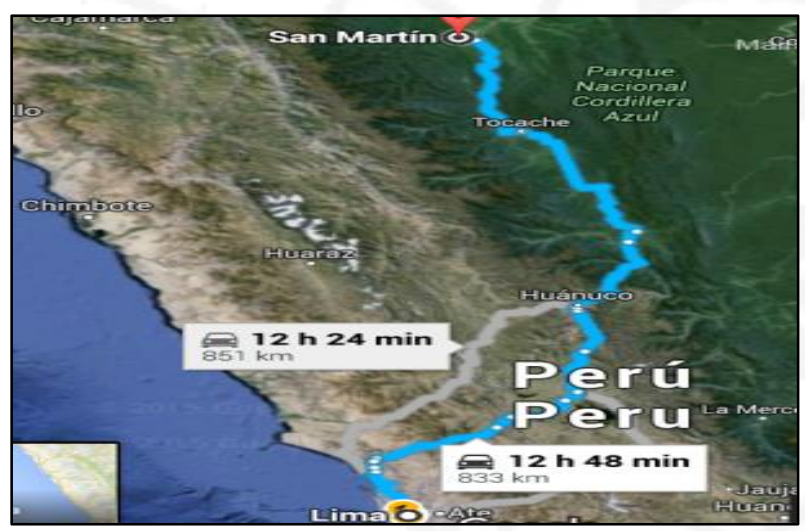

Fuente: Google Maps (2019)

\section{Cusco - Lima}

Figura 3.4

Mapa de ruta del departamento de Cusco - Lima

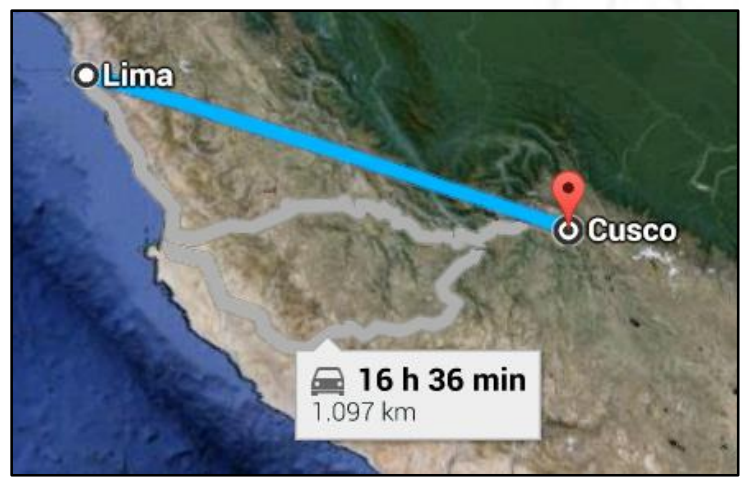

Fuente: Google Maps (2019) 
- Disponibilidad de mano de obra

La mano de obra es un aspecto importante que se deberá considerar para la puesta en marcha de la empresa, puesto que realizará los procesos productivos de manera adecuada.

Al tratarse de un producto de calidad se requiere personal calificado que cumpla con requerimientos mínimos de conocimiento, experiencia, capaz de controlar e inspeccionar cada etapa del proceso. Para determinar la disponibilidad de mano de obra, está se basará en la tasa de desempleo por departamento junto al nivel educativo de la población.

Tabla 3.2

PEA ocupada y tasa de desempleo por departamento

\begin{tabular}{|c|c|c|c|c|c|c|c|}
\hline \multicolumn{8}{|c|}{ Perú: principales indicadores del mercado de trabajo, según departamento, 2017} \\
\hline \multicolumn{8}{|c|}{ (Miles de personas) } \\
\hline \multirow[b]{2}{*}{$\begin{array}{l}\text { Departa } \\
\text { mento }\end{array}$} & \multirow{2}{*}{$\begin{array}{l}\text { Població } \\
\text { n en } \\
\text { Edad de } \\
\text { Trabajar } \\
\text { (PET) 1/ }\end{array}$} & \multicolumn{3}{|c|}{$\begin{array}{l}\text { Población económicamente activa } \\
\text { (PEA) } 2 /\end{array}$} & \multicolumn{3}{|c|}{ Indicadores (\%) } \\
\hline & & Total & Ocupada 3/ & $\underset{4 /}{\text { Desocupada }}$ & $\begin{array}{c}\text { Tasa de } \\
\text { activida } \\
\text { d }\end{array}$ & $\begin{array}{c}\text { Ratio } \\
\text { empleo / } \\
\text { población }\end{array}$ & $\begin{array}{c}\text { Tasa de } \\
\text { desempleo } \\
5 /\end{array}$ \\
\hline Perú & $23,771.7$ & $17,215.7$ & $16,511.0$ & 704.8 & 72.4 & 69.5 & 4.1 \\
\hline Cusco & $1,144.8$ & 777.2 & 755.1 & 22.1 & 79.1 & 66.0 & 2.8 \\
\hline Junín & $1,130.7$ & 714.9 & 699.7 & 15.2 & 73.1 & 61.9 & 2.1 \\
\hline Lima & $8,486.2$ & $5,543.3$ & $5,190.3$ & 353.0 & 71.1 & 61.2 & 6.4 \\
\hline $\begin{array}{c}\text { San } \\
\text { Martín }\end{array}$ & 726.8 & 483.3 & 472.2 & 11.2 & 76.8 & 65.0 & 2.3 \\
\hline
\end{tabular}

Nota: Encuesta Nacional de Hogares sobre Condiciones de Vida y Pobreza, continúa 2017 Fuente: Instituto Nacional de Estadística e Información, INEI (2017)

Tabla 3.3

Nivel de educación alcanzado de la población de 14 a más años

\begin{tabular}{|l|r|r|r|r|r|r|c|}
\hline \multicolumn{7}{|c|}{ Perú: distribución de la pea ocupada por nivel educativo, según departamento, 2017} \\
\hline Departamento & $\begin{array}{c}\text { Sin } \\
\text { nivel } \\
\text { 1/ }\end{array}$ & Primaria & Secundaria & $\begin{array}{c}\text { Superior no } \\
\text { universitaria } \\
\mathbf{2 /}\end{array}$ & $\begin{array}{c}\text { Superior } \\
\text { Universitaria } \\
\mathbf{2 /}\end{array}$ & $\begin{array}{c}\text { Total } \\
\text { relativo }\end{array}$ & $\begin{array}{c}\text { PEA ocupada } \\
\text { (Miles de } \\
\text { personas) }\end{array}$ \\
\hline Perú & $\mathbf{1 . 5}$ & $\mathbf{2 5 . 5}$ & $\mathbf{4 1 . 6}$ & $\mathbf{1 4 . 7}$ & $\mathbf{1 6 . 7}$ & $\mathbf{1 0 0 . 0}$ & $16,511.0$ \\
\hline Cusco & - & 37.4 & 37.9 & & 24.7 & 100.0 & 755.1 \\
\hline Junín & - & 29.1 & 41.9 & - & 29.0 & 100.0 & 699.7 \\
\hline Lima & - & 16.1 & 48.9 & - & 35.1 & 100.0 & $5,190.3$ \\
\hline San Martín & - & 44.0 & 34.5 & - & 21.6 & 100.0 & 472.2 \\
\hline
\end{tabular}

Nota: Encuesta Nacional de Hogares sobre Condiciones de Vida y Pobreza, continúa 2017

Fuente: Instituto Nacional de Estadística e Información, INEI (2017) 
El Recurso humano es importante, ya que de este depende que las estaciones de trabajo de desempeñen de una manera eficiente, eficaz y efectiva.

A continuación, se muestran las tablas, en las cuales se observa la mano de obra en el sector de manufacturera.

Tabla 3.4

Trabajadores en el sector de manufactura

\begin{tabular}{|c|c|c|c|c|c|c|c|c|c|c|}
\hline \multirow{2}{*}{} & \multicolumn{8}{|c|}{ Trabajadores en el sector privado por meses, según actividad } \\
económica, a nivel provincial \\
\cline { 4 - 12 } \\
\cline { 4 - 12 }
\end{tabular}

Fuente: Ministerio de Trabajo y Promoción del empleo (2014)

Tabla 3.5

Trabajadores según categoría ocupacional a nivel provincial Satipo

\begin{tabular}{|c|c|c|c|c|c|c|c|c|c|c|}
\hline \multicolumn{2}{|c|}{} & \multicolumn{8}{|c|}{$\begin{array}{c}\text { Trabajadores en el sector privado por mes, según categoría } \\
\text { ocupacional a nivel provincial }\end{array}$} \\
\cline { 2 - 14 } & \multicolumn{8}{|c|}{$\mathbf{2 0 1 4}$} \\
\hline \multirow{3}{*}{ Provincia } & $\begin{array}{c}\text { Categoría } \\
\text { ocupacional }\end{array}$ & ENE & FEB & MAR & ABR & MAY & JUN & JUL & AGO & SEP \\
\hline \multirow{3}{*}{ Satipo } & Ejecutivo & 56 & 58 & 58 & 60 & 61 & 61 & 61 & 62 & 62 \\
\cline { 2 - 13 } & Empleado & 1,124 & 1,152 & 1,242 & 1,341 & 1,568 & 1,756 & 1,802 & 1,702 & 1,808 \\
\cline { 2 - 12 } & Obrero & 562 & 381 & 396 & 707 & 1,309 & 2,128 & 2,696 & 2,922 & 2,807 \\
\cline { 2 - 11 } & ND & 4 & 4 & 4 & 4 & 4 & 4 & 4 & 4 & 4 \\
\hline
\end{tabular}

Fuente: Ministerio de Trabajo y Promoción del empleo (2014)

Tabla 3.6

Trabajadores según categoría ocupacional a nivel provincial La Convención

\begin{tabular}{|c|c|c|c|c|c|c|c|c|c|c|}
\hline \multirow{2}{*}{} & \multicolumn{7}{|c|}{ Trabajadores en el sector privado por mes, según categoría } \\
ocupacional a nivel provincial
\end{tabular}

Fuente: Ministerio de Trabajo y Promoción del empleo (2014) 
Tabla 3.7

Trabajadores según categoría ocupacional a nivel provincial Mariscal Cáceres

\begin{tabular}{|c|c|c|c|c|c|c|c|c|c|c|}
\hline \multirow[b]{3}{*}{ Provincia } & \multirow[b]{3}{*}{$\begin{array}{c}\text { Categoría } \\
\text { ocupacional }\end{array}$} & \multicolumn{9}{|c|}{$\begin{array}{c}\text { Trabajadores en el sector privado por mes, según categoría } \\
\text { ocupacional a nivel provincial }\end{array}$} \\
\hline & & \multicolumn{9}{|c|}{2014} \\
\hline & & Ene & Feb & Mar & Abr & May & Jun & Jul & Ago & Sep \\
\hline \multirow{4}{*}{$\begin{array}{l}\text { Mariscal } \\
\text { Cáceres }\end{array}$} & Ejecutivo & 29 & 30 & 29 & 30 & 30 & 30 & 29 & 31 & 31 \\
\hline & Empleado & 588 & 598 & 587 & 582 & 603 & 599 & 599 & 620 & 623 \\
\hline & Obrero & 40 & 65 & 66 & 48 & 55 & 63 & 66 & 61 & 54 \\
\hline & $\mathrm{Nd}$ & - & - & - & - & - & - & - & - & - \\
\hline
\end{tabular}

Fuente: Ministerio de Trabajo y Promoción del empleo (2014)

Tabla 3.8

Trabajadores según categoría ocupacional en Lima

\begin{tabular}{|c|c|c|c|c|c|c|c|c|c|}
\hline \multicolumn{2}{|c|}{} & \multicolumn{7}{|c|}{ Trabajadores en el sector privado por mes, según categoría } \\
ocupacional a nivel provincial \\
\cline { 3 - 12 }
\end{tabular}

Fuente: Ministerio de Trabajo y Promoción del empleo (2014)

- Servicio de energía eléctrica

Reconociendo el rol imprescindible de la energía eléctrica para el correcto funcionamiento de una planta industrial contará con el servicio de una empresa que de las garantías del caso brindando energía constante para así evitar problemas eléctricos durante las jornadas laborales, lo cual podría paralizar la producción.

Las siguientes tablas mostrarán las tarifas por uso de energía eléctrica en cada departamento propuesto como alternativa de realización de la planta.

Tabla 3.9

Costos por cargo de tarifa eléctrica Cusco

\begin{tabular}{l|ccc}
\hline $\begin{array}{c}\text { Departamento de } \\
\text { Cusco }\end{array}$ & Unidad & $\begin{array}{c}\text { Media tensión } \\
\text { tarifa sin IGV }\end{array}$ & $\begin{array}{c}\text { Baja tensión } \\
\text { tarifa sin IGV }\end{array}$ \\
\hline $\begin{array}{l}\text { Cargo por Energía } \\
\text { Activa en Punta }\end{array}$ & $\begin{array}{c}\mathrm{ctm} . \\
\mathrm{S} / . / \mathrm{kW} . \mathrm{h} \\
\mathrm{ctm} .\end{array}$ & 24.22 & 26.26 \\
$\begin{array}{l}\text { Cargo por Energía } \\
\text { Activa Fuera de Punta }\end{array}$ & \begin{tabular}{c}
$\mathrm{S} / . / \mathrm{kW} . \mathrm{h}$ \\
\hline
\end{tabular} & 19.64 & 21.29 \\
\hline
\end{tabular}

Fuente: Electro Sur Este (2019) 
Tabla 3.10

Costos por cargo de tarifa eléctrica Lima Sur

\begin{tabular}{l|ccc}
\hline $\begin{array}{l}\text { Departamento de } \\
\text { Lima (Lima Sur) }\end{array}$ & Unidad & $\begin{array}{c}\text { Media tensión } \\
\text { tarifa sin IGV }\end{array}$ & $\begin{array}{c}\text { Baja tensión } \\
\text { tarifa sin IGV }\end{array}$ \\
\hline $\begin{array}{l}\text { Cargo por Energía } \\
\text { Activa en Punta }\end{array}$ & ctm. S/. /kW.h & 24.64 & 26.88 \\
$\begin{array}{l}\text { Cargo por Energía } \\
\text { Activa Fuera de } \\
\text { Punta }\end{array}$ & ctm. S/. /kW.h & 20.61 & \\
\hline
\end{tabular}

Fuente: Luz del Sur (2019)

Tabla 3.11

Costos por cargo de tarifa eléctrica Lima Norte

\begin{tabular}{l|ccc}
\hline \multicolumn{1}{c|}{$\begin{array}{c}\text { Departamento de } \\
\text { Lima (Lima Norte) }\end{array}$} & Unidad & $\begin{array}{c}\text { Media } \\
\text { tensión } \\
\text { tarifa sin } \\
\text { IGV }\end{array}$ & $\begin{array}{c}\text { Baja tensión } \\
\text { Tarifa sin } \\
\text { IGV }\end{array}$ \\
\hline $\begin{array}{l}\text { Cargo por Energía } \\
\begin{array}{l}\text { Activa en Punta } \\
\text { Cargo por Energía } \\
\text { Activa Fuera de Punta }\end{array}\end{array}$ & ctm. S/./kW.h & 24.02 & 26.01 \\
\hline
\end{tabular}

Fuente: Enel Distribución (2019)

Tabla 3.12

Costos por cargo de tarifa eléctrica San Martín

\begin{tabular}{l|ccc}
\hline $\begin{array}{c}\text { Departamento San } \\
\text { Martín }\end{array}$ & Unidad & $\begin{array}{c}\text { Media } \\
\text { tensión } \\
\text { tarifa sin } \\
\text { IGV }\end{array}$ & $\begin{array}{c}\text { Baja tensión } \\
\text { tarifa sin } \\
\text { IGV }\end{array}$ \\
\hline $\begin{array}{l}\text { Cargo por Energía Activa } \\
\text { en Punta }\end{array}$ & ctm. S/./kW.h & 29.45 & 31.92 \\
$\begin{array}{l}\text { Cargo por Energía Activa } \\
\text { Fuera de Punta }\end{array}$ & $\mathrm{ctm} . \mathrm{S} / . / \mathrm{kW} . \mathrm{h}$ & 23.84 & 25.85 \\
\hline
\end{tabular}

Fuente: Empresa: Electro Oriente (2019)

Tabla 3.13

Costos por cargo de tarifa eléctrica Junín

\begin{tabular}{l|lcc}
\hline \multicolumn{1}{c|}{ Departamento Junín } & Unidad & $\begin{array}{c}\text { Media } \\
\text { tensión } \\
\text { tarifa sin } \\
\text { IGV }\end{array}$ & $\begin{array}{c}\text { Baja tensión } \\
\text { tarifa sin } \\
\text { IGV }\end{array}$ \\
\hline $\begin{array}{l}\text { Cargo por Energía } \\
\begin{array}{l}\text { Activa en Punta } \\
\text { Cargo por Energía } \\
\text { Activa Fuera de Punta }\end{array}\end{array}$ & ctm. S/./kW.h & 24.71 & 26.79 \\
\hline
\end{tabular}

Fuente: Empresa Electrocentro (2019) 
- Disponibilidad de agua

El 93,7\% de las viviendas utilizan agua de la red pública para su consumo. De las cuales en la zona rural se observa que el $82,5 \%$ de las viviendas tienen acceso a este servicio, mientras que en la zona rural solo el 70,8\%.

\section{Lima y Callao}

El 82,2\% de las viviendas en la provincia de Lima el usa el agua de red pública dentro o fuera de la vivienda. Mientras que las viviendas de la Lima urbana lo hacen en un $84,6 \%$.

\section{Junín}

El 88,9\% de las viviendas cuentan con este servicio procedente de la red pública para beber. En el área urbana se registra que el 91,4\% de las viviendas cuentan con acceso a agua proveniente de la red pública, mientras que en el ámbito rural se observa un $83,8 \%$.

\section{San Martín}

El 56,4\% de las viviendas utilizan el recurso hídrico de la red pública para su consumo, ya sea dentro o fuera de la vivienda.

\section{Cusco}

El porcentaje de acceso a agua proveniente de red pública dentro de la vivienda fue de $95,1 \%$ y en las viviendas ubicadas en el ámbito rural un 92,1\%.

Figura 3.5

Acceso de fuentes de agua en Cusco

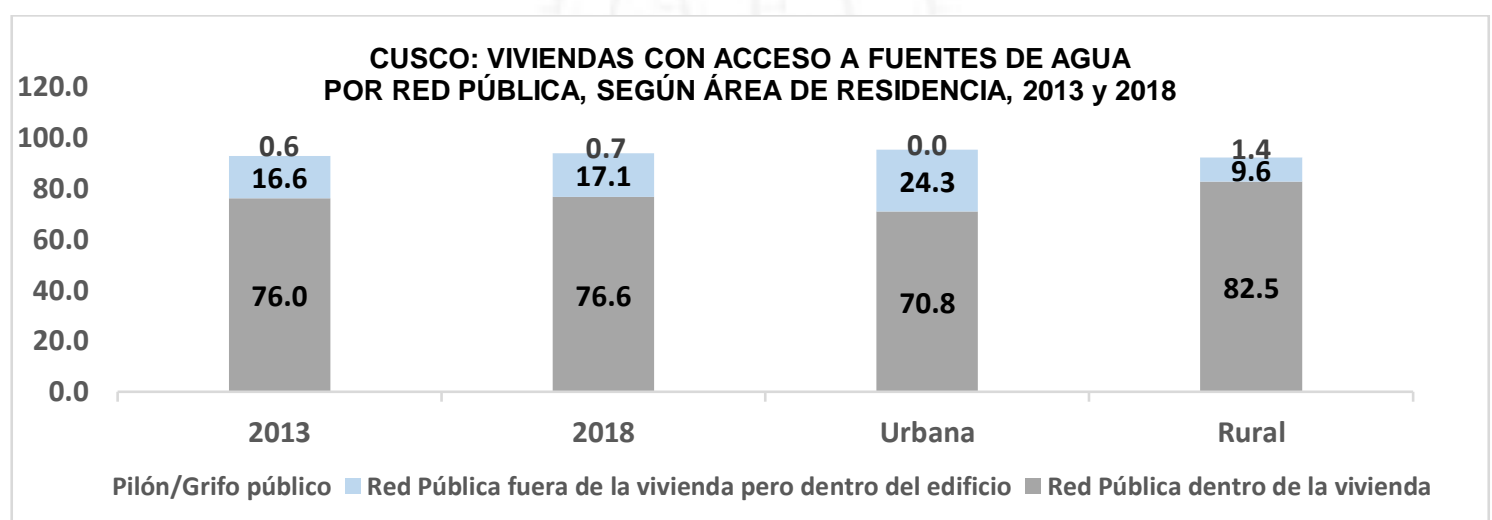

Fuente: Instituto Nacional de Estadística e Informática (2019) 
Figura 3.6

Acceso a fuentes de agua en Lima

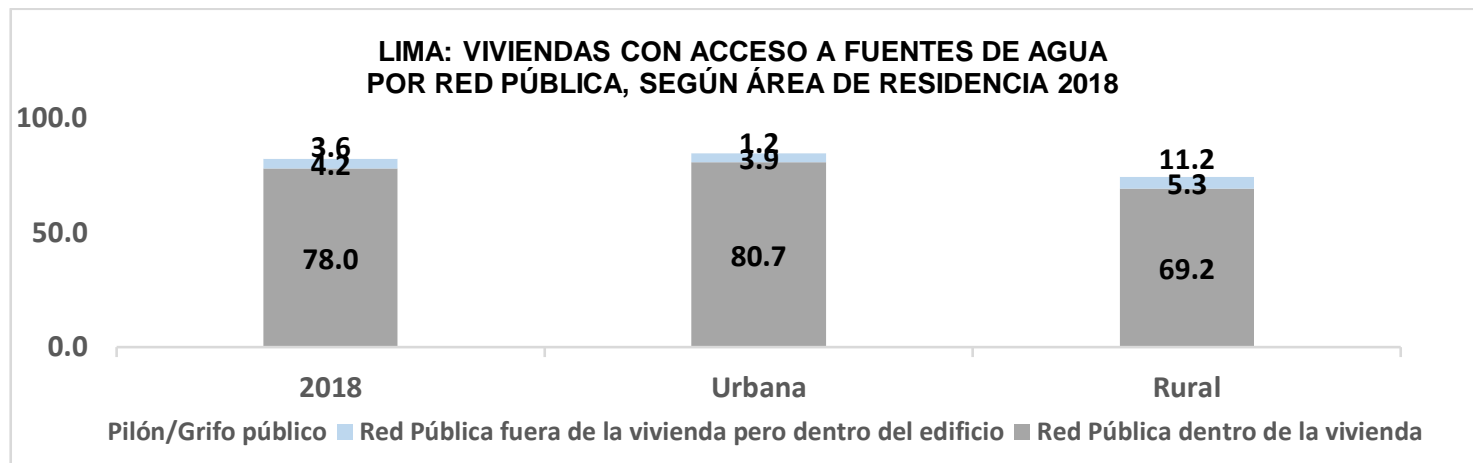

Fuente: Instituto Nacional de Estadística e Informática (2019)

Figura 3.7

Acceso a fuentes de agua en Junín

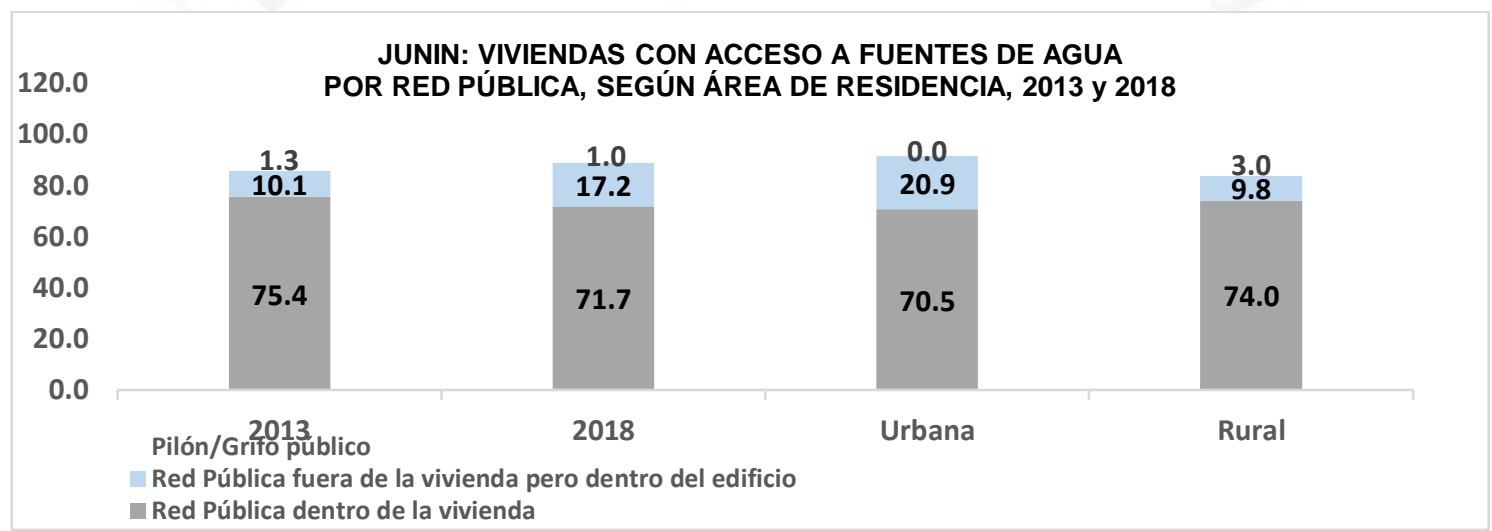

Fuente: Instituto Nacional de Estadística e Informática (2019)

Figura 3.8

Acceso a fuentes de agua en San Martín

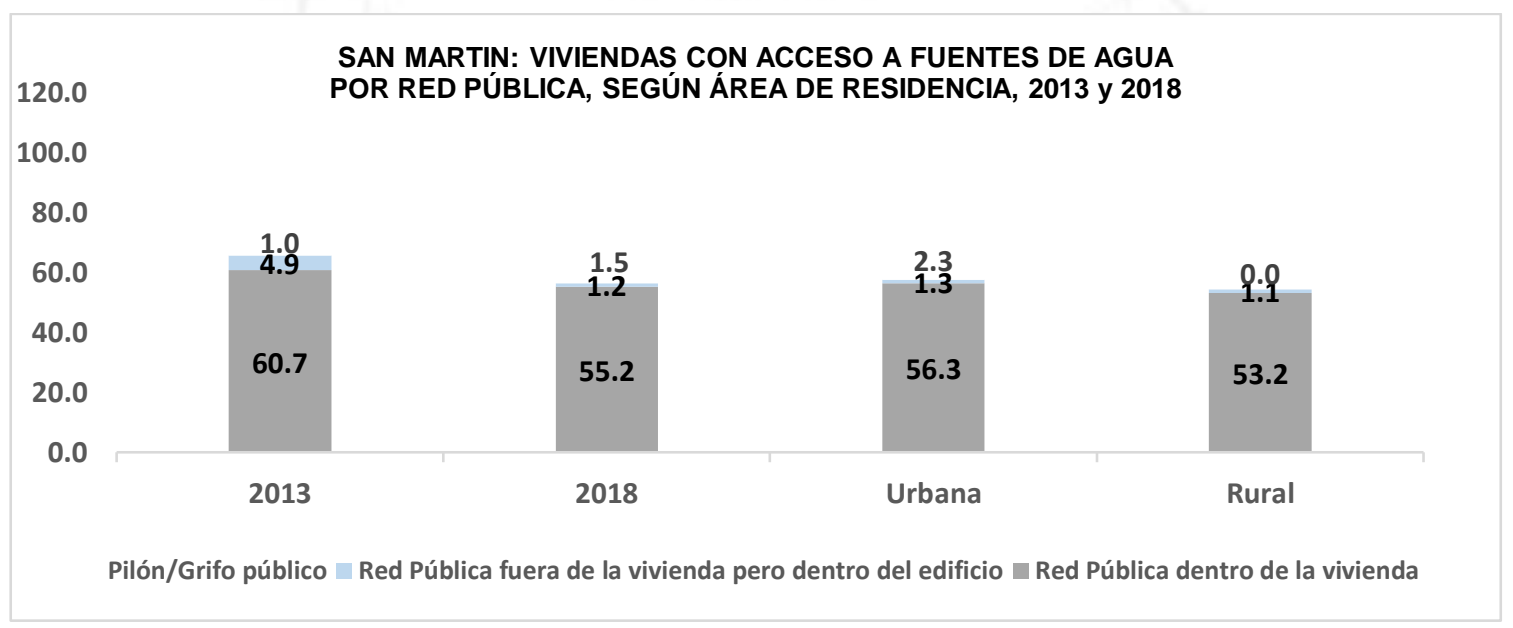

Fuente: Instituto Nacional de Estadística e Informática (2019) 
- Servicio higiénico o sanitario

\section{Cusco}

El 47,9\% de las viviendas de este departamento disponen de servicio higiénico conectado a la red pública en la misma vivienda, mientras que otro $14 \%$ está fuera de la vivienda. También se debe subrayar que el $26,8 \%$ de las viviendas cusqueñas utilizan letrinas para sus deposiciones.

Si se comparan los servicios higiénicos que están conectados a una red pública, las del área urbana constituyen 68,9\% mientras que del área rural solo el 26,2\%

\section{Lima}

Los servicios higiénicos de las viviendas que forman parte de la red pública en Lima constituyen el $81.6 \%$

Sin embargo, en Lima provincias se encontró las mayores carencias en cuanto al acceso de un adecuado sistema de servicio de higiénico. Lima Provincias 52\%, 14\% sin servicios higiénicos y en un 22,8\% de viviendas se registró el uso de letrinas.

\section{Junín}

El $54.1 \%$ de las viviendas cuentan con servicio higiénico conectado a la red pública dentro de la vivienda y un $13.7 \%$ integrado a la red pública fuera de ella.

Los servicios higiénicos que están conectados a una red pública en el área urbana comprenden al $70.3 \%$, en cambio el área rural solo el $22.4 \%$.

\section{San Martín}

Los servicios higiénicos de las viviendas que forman parte de la red pública en San Martín constituyen el 43,8\%.

Pero si se comparan los servicios higiénicos que están conectados a una red pública, los del área urbana constituyen 59,5\% mientras que del área rural solo el $15,7 \%$. 
Figura 3.9

Acceso a servicio sanitario por red pública en Cusco

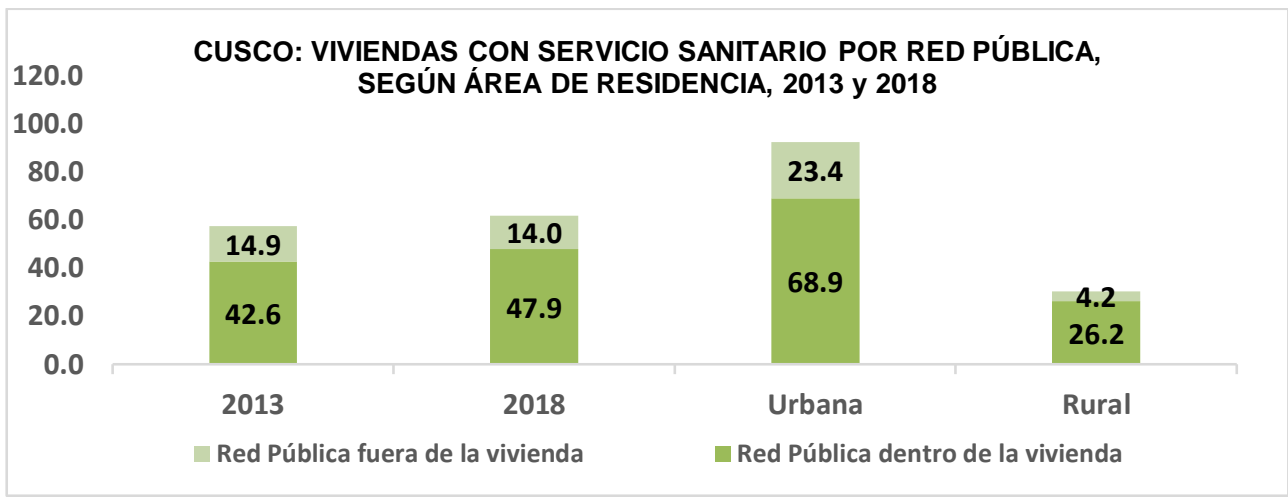

Fuente: Instituto Nacional de Estadística e Informática (2019)

Figura 3.10

Acceso a servicio sanitario por red pública en Lima

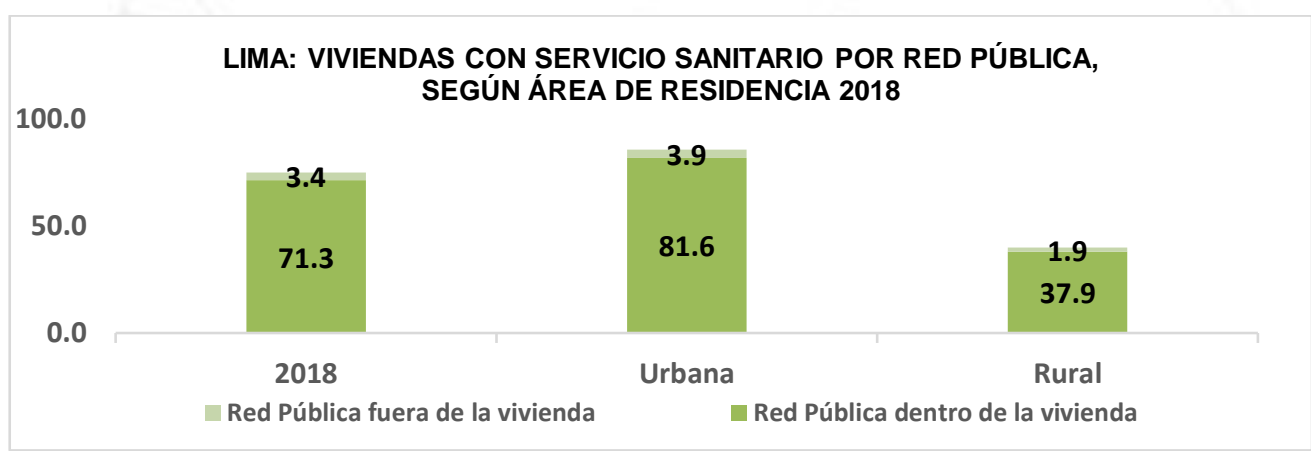

Fuente: Instituto Nacional de Estadística e Informática (2019)

Figura 3.11

Acceso a servicio sanitario por red pública en Junín

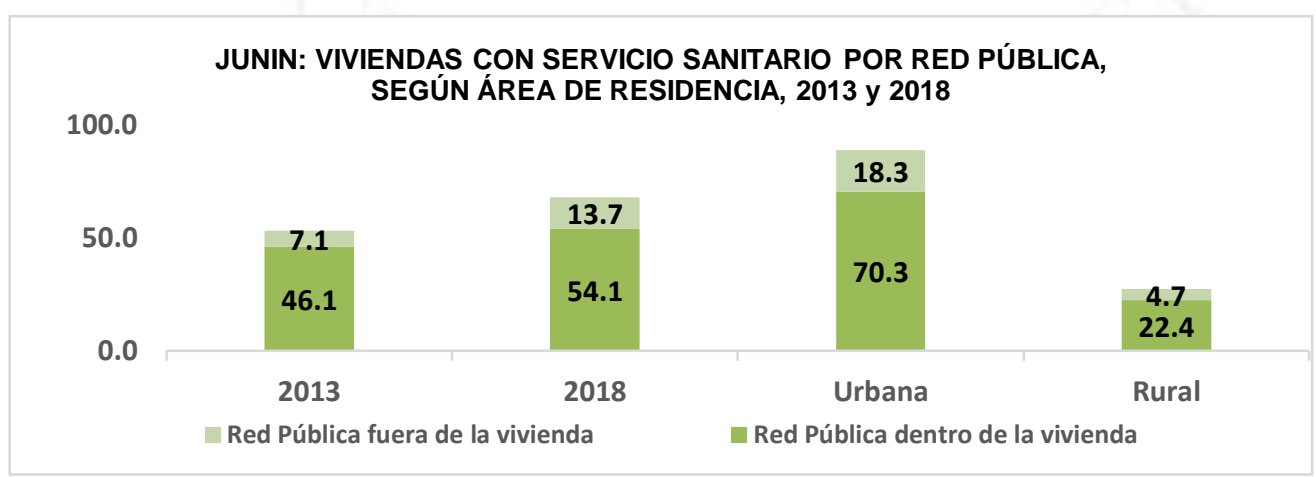

Fuente: Instituto Nacional de Estadística e Informática (2019) 
Figura 3.12

Acceso a servicio sanitario por red pública en San Martín

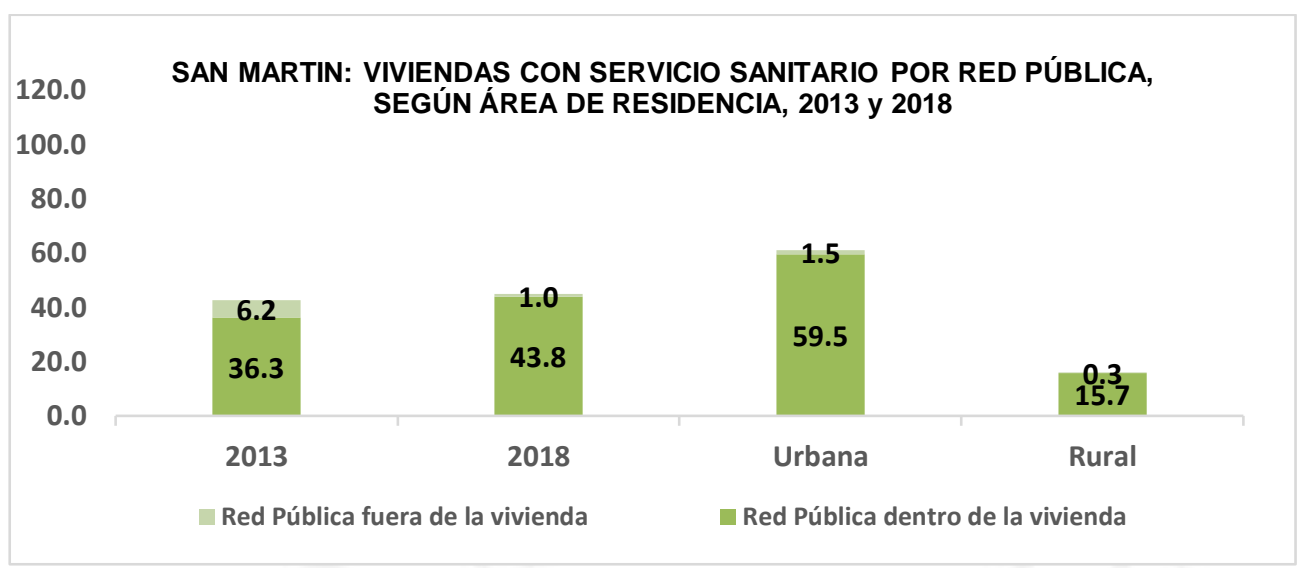

Fuente: Instituto Nacional de Estadística e Informática (2019)

\section{Factores de Micro localización}

- Disponibilidad de terrenos

En el Perú, no existe un desarrollo adecuado de la zona industrial porque su crecimiento es desordenado y no cuenta con una planificación urbana. Sin embargo, en Lima se pueden identificar 5 zonas industriales.

Lima Centro, es la Zona de menor área industrial en oferta y que se encuentra mayormente ocupada y se ubica por la Av. Colonial, Dueñas y Argentina.

$>$ Lima Este, tiene la mayor concentración de terreno industrial y posee un nivel importante de demanda por su buena ubicación y los mejores accesos; esta zona comprende los distritos de Ate Vitarte, Santa Anita y Huachipa.

Lima Norte, comprende las zonas de Puente Piedra, Comas, Carabayllo e Independencia este último posee la mayor concentración de industrias en funcionamiento.

Lima Sur, es una zona que ha estado en crecimiento por la buena ubicación, a pesar de que algunas zonas carecen de servicios de agua, desagüe y energía se concentra principalmente en Lurín.

$>$ Callao, el atractivo de esta zona es la proximidad al aeropuerto y al puerto. 
Tabla 3.14

Distribución $\mathrm{m}^{2}$ de terrenos con zonificación industrial

\begin{tabular}{ll}
\hline \multicolumn{2}{c}{ AL I TRIMESTRE DEL 2019 } \\
\hline Lima Centro & $3,004.64$ \\
Lima Sur & $16,612.57$ \\
Lima Este & $36,595.95$ \\
Lima Norte & $5,706.82$ \\
Callao & $8,544.97$ \\
\hline TOTAL & $70,464.95$ \\
\hline
\end{tabular}

Fuente: CBRE (2019)

Para los factores de Micro localización vamos a tomar en cuentan los siguientes distritos que pertenecen al Departamento de Lima:

Tabla 3.15

Distritos de Lima a analizar

\begin{tabular}{ccc}
\hline \multicolumn{3}{c}{ Departamento de Lima } \\
\hline Pachacámac & Ate Vitarte & Carabayllo \\
\hline Elaboración propia & &
\end{tabular}

- Costo de terreno por $\mathrm{m}^{2}$

En Lima, debido al proyecto del corredor industrial que conectará Lurín hasta Pisco ha ocasionado una desaceleración industrial en Lima Norte ante la especulación de precios.

El distrito de Ate registra los precios más altos para la venta y arrendamiento de locales industriales.

Tabla 3.16

Valores de inmuebles industriales USD $\left(\$ / \mathrm{m}^{2}\right)$

\begin{tabular}{lll}
\hline Distrito & $\begin{array}{l}\text { Precio promedio }\left(\mathrm{US} \$ \mathrm{~m}^{2}\right) \\
\text { Venta Terreno }\end{array}$ & Renta local mensual \\
\hline Pachacámac & USD 230 - USD 280 & USD 1.0 - USD 2 \\
Ate Vitarte & USD 600 - USD 800 & USD 6 - USD 8 \\
Carabayllo & USD 480 - USD 600 & USD 5 - USD 5.5 \\
\hline
\end{tabular}

Fuente: Diario Gestión (2019)

Se puede observar en el cuadro que la zona con el menor precio es Pachacamac, pero se debe tener en cuenta que el precio de esta zona se va a incrementar en los próximos años. 
- Disponibilidad de agua

Según el factor abastecimiento de agua, Lima es la ciudad con mayores provisiones y establecimientos de conexiones de agua potable, siendo más costoso, SEDAPAL brinda mayor seguridad y confort para dicho servicio.

Tabla 3.17

Cargo por volumen

\begin{tabular}{|l|c|c|c|}
\hline \multirow{2}{*}{$\begin{array}{c}\text { CLASE } \\
\text { CATEGORIA }\end{array}$} & $\begin{array}{c}\text { RANGOS DE } \\
\text { CONSUMOS }\end{array}$ & \multicolumn{2}{c|}{ Tarifa $\left(\mathrm{S} / / \mathrm{m}^{3}\right.$ ) } \\
\cline { 2 - 4 } & $\mathrm{m}^{3} / \mathrm{mes}$ & Agua Potable & Acantarillado $^{(1)}$ \\
\hline RESIDENCIAL & & & \\
Social & 0 a más & 1.255 & 0.575 \\
Doméstico Subsidiado & $0-10$ & 1.255 & 0.575 \\
& $10-20$ & 1.400 & 0.668 \\
& $20-50$ & 1.478 & 0.901 \\
& 50 a más & 5.360 & 2.499 \\
Doméstico No Subsidiado & $0-20$ & 1.478 & 0.901 \\
& $20-50$ & 2.098 & 1.262 \\
No RESIDENCIAL & 50 a más & 5.360 & 2.499 \\
Comercial & & & 2.499 \\
& 0 a 1000 & 5.360 & 2.680 \\
Industrial & 1000 a más & 5.751 & 2.680 \\
Estatal & 0 a más & 5.751 & 1.591 \\
\hline
\end{tabular}

Fuente: Servicio de Agua Potable y Alcantarillado de Lima, Sedapal (2018)

- Ubicación y accesos viales

El distrito de Ate es una de las zonas industriales con mejor ubicación ya que tienen accesos a dos vías principales de Lima, que son la panamericana y la carretera central, mientras que los distritos de Lurín en el cual tenemos a Pachacamac, cuenta con solo acceso inmediato a la Panamericana Sur y con respecto al distrito de Carabayllo, este solo tiene acceso inmediato a la Panamericana Norte. 


\subsection{Identificación y descripción de las alternativas de localización}

Las alternativas de ubicación a considerar para la localización de planta se determinan según los presentes criterios.

- Por la proximidad a la materia prima y disponibilidad, los departamentos de Cuzco, San Martin, Junín y Lima serían los posibles departamentos a considerar.

- Considerando el clima promedio ideal para el mantenimiento de grado de humedad del producto, se considera como opciones el departamento de Lima, Junín y Cuzco.

- Debido a la cercanía al mercado objetivo de Lima Metropolitana, se consideran como posibles ubicaciones los distritos de Pachacamac, Ate y Carabayllo por la disponibilidad de zonas industriales.

\subsection{Determinación del modelo de evaluación a emplear}

El método de evaluación que se empleará para la localización de planta, será mediante el método de ranking de factores. Se tomará en cuenta los factores de micro y macro localización.

\subsubsection{Evaluación y selección de la macro localización}

Se asignarán letras para referirse a cada factor como se muestran a continuación:

Tabla 3.18

Factores de macro localización

\begin{tabular}{|c|lr|}
\hline A & $\begin{array}{l}\text { Proximidad de } \\
\text { Materia Prima }\end{array}$ \\
B & \multicolumn{2}{|l}{ Cercanía al mercado } \\
C & $\begin{array}{l}\text { Disponibilidad de } \\
\text { mano de obra } \\
\text { Servicio de energía } \\
\text { D }\end{array}$ & $\begin{array}{l}\text { eléctrica de } \\
\text { Disponibilidad de } \\
\text { agua } \\
\text { Eervicios Higiénicos }\end{array}$ \\
\hline
\end{tabular}

Elaboración Propia

Se considerará la siguiente escala de evaluación para asignar el puntaje correspondiente a cada factor: 
Tabla 3.19

Calificación y puntaje

\begin{tabular}{c|c}
\hline Calificación & Puntaje \\
Más importante & 1 \\
Menos importante & 0 \\
Igual importante & 1 (ambos) \\
\hline Elaboración Propia
\end{tabular}

Tabla 3.20

Matriz de enfrentamiento

\begin{tabular}{|l|l|l|l|l|l|l|l|l|}
\hline & A & B & C & D & E & F & Conteo & Ponderado \\
\hline A & & 1 & 1 & 1 & 1 & 1 & 5 & 0.29 \\
\hline B & 1 & & 1 & 1 & 1 & 1 & 5 & 0.29 \\
\hline C & 0 & 0 & & 0 & 1 & 1 & 2 & 0.12 \\
\hline D & 0 & 0 & 1 & & 1 & 1 & 3 & 0.18 \\
\hline E & 0 & 0 & 0 & 0 & & 1 & 1 & 0.06 \\
\hline F & 0 & 0 & 0 & 0 & 1 & & 1 & 0.06 \\
\hline \multicolumn{2}{|l|}{ TOTAL }
\end{tabular}

Elaboración Propia

Seguidamente se desarrollará la tabla de ranking de factores, considerando la siguiente escala de evaluación para asignar el puntaje correspondiente a cada factor:

Tabla 3.21

Tabla de puntajes

\begin{tabular}{c|c}
\hline Calificación & Puntaje \\
Excelente & 10 \\
Muy Bueno & 8 \\
Bueno & 6 \\
Regular & 4 \\
Malo & 2 \\
\hline
\end{tabular}

Elaboración Propia 
Tabla 3.22

Ranking de factores de micro localización

\begin{tabular}{|c|c|c|c|c|c|c|c|c|c|}
\hline \multirow{2}{*}{$\begin{array}{l}\text { Factores de } \\
\text { Localización }\end{array}$} & \multirow{2}{*}{$\begin{array}{l}\text { Pond. } \\
\%\end{array}$} & \multicolumn{2}{|l|}{ Lima } & \multicolumn{2}{|l|}{ Cusco } & \multicolumn{2}{|l|}{ Junín } & \multicolumn{2}{|c|}{ San Martin } \\
\hline & & Calif. & Punt. & Calif. & Punt. & Calif. & Punt. & Calif. & Punt. \\
\hline $\begin{array}{l}\text { Proximidad de } \\
\text { Materia Prima }\end{array}$ & 0.29 & 8 & 2.35 & 6 & 1.76 & 6 & 1.76 & 10 & 2.94 \\
\hline Cercanía al mercado & 0.29 & 10 & 2.94 & 4 & 1.18 & 6 & 1.76 & 2 & 0.59 \\
\hline $\begin{array}{l}\text { Disponibilidad de } \\
\text { mano de obra }\end{array}$ & 0.12 & 10 & 1.18 & 4 & 0.47 & 4 & 0.47 & 4 & 0.47 \\
\hline $\begin{array}{l}\text { Servicio de energía } \\
\text { eléctrica }\end{array}$ & 0.18 & 8 & 1.41 & 6 & 1.06 & 4 & 0.71 & 2 & 0.35 \\
\hline $\begin{array}{l}\text { Disponibilidad de } \\
\text { agua }\end{array}$ & 0.06 & 8 & 0.47 & 6 & 0.35 & 8 & 0.47 & 4 & 0.24 \\
\hline Servicios Higiénicos & 0.06 & 8 & 0.47 & 4 & 0.24 & 6 & 0.35 & 4 & 0.24 \\
\hline & & & 8.82 & & 5.06 & & 5.53 & & 4.82 \\
\hline
\end{tabular}

Elaboración Propia

De acuerdo con el resultado se elegiría la Ciudad de Lima como la más adecuada para la localización de la planta.

\subsubsection{Evaluación y selección de Micro localización}

En base a los factores de micro localización desarrollados, se procederá a evaluar cada factor en una matriz de enfrentamiento, para de esta forma poder obtener una ponderación de acuerdo con su nivel de importancia para el proyecto y así obtener la importancia relativa de cada uno. Los números por utilizar en referencia a cada factor se muestran a continuación:

Tabla 3.23

Factores de micro localización

\begin{tabular}{c|l}
\hline A & $\begin{array}{l}\text { Disponibilidad de } \\
\text { terrenos } \\
\text { Costo de terreno por } \\
\text { m2 } \\
\text { Disponibilidad de } \\
\text { agua } \\
\text { Ubicación y accesos } \\
\text { viales }\end{array}$ \\
D & \\
\hline
\end{tabular}

Fuente: Elaboración Propia

Se considerará la siguiente escala de evaluación para asignar el puntaje correspondiente a cada factor: 
Tabla 3.24

Matriz de enfrentamiento

\begin{tabular}{|l|c|c|c|c|c|c|}
\hline & A & B & C & D & Conteo & Ponderado \\
\hline A & & 1 & 1 & 1 & 3 & 0.33 \\
\hline B & 1 & & 1 & 1 & 3 & 0.33 \\
\hline C & 0 & 1 & & 1 & 2 & 0.22 \\
\hline D & 0 & 1 & 0 & & 1 & 0.11 \\
\hline TOTAL
\end{tabular}

Fuente: Elaboración Propia

Seguidamente se desarrollará la tabla de ranking de factores, considerando la siguiente escala de evaluación para asignar el puntaje correspondiente a cada factor:

Tabla 3.25

Calificación y puntaje

\begin{tabular}{l|c}
\hline Calificación & Puntaje \\
\hline Excelente & 10 \\
Muy Bueno & 8 \\
Bueno & 6 \\
& 4 \\
Malo & 2 \\
\hline
\end{tabular}

Fuente: Elaboración Propia

Tabla 3.26

Ranking de factores de micro localización

\begin{tabular}{|l|c|c|c|c|c|c|c|}
\hline Factores de & Pond. & \multicolumn{3}{l|}{ Pachacamac } & \multicolumn{2}{l|}{ Ate Vitarte } & \multicolumn{2}{l|}{ Carabayllo } \\
\cline { 2 - 8 } Localización & $\%$ & Calif. & Punt. & Calif. & Punt. & Calif. & Punt. \\
\hline $\begin{array}{l}\text { Disponibilidad de } \\
\text { terrenos }\end{array}$ & 0.33 & 8 & 2.64 & 4 & 1.32 & 6 & 1.98 \\
\hline $\begin{array}{l}\text { Costo de terreno por } \\
\text { m2 }\end{array}$ & 0.33 & 8 & 2.64 & 4 & 1.32 & 6 & 1.98 \\
\hline $\begin{array}{l}\text { Disponibilidad de } \\
\text { agua }\end{array}$ & 0.22 & 6 & 1.32 & 6 & 1.32 & 6 & 1.32 \\
\hline $\begin{array}{l}\text { Ubicación y accesos } \\
\text { viales }\end{array}$ & 0.11 & 6 & 0.66 & 6 & 0.66 & 4 & 0.44 \\
\hline & & & 7.26 & & 4.62 & & 5.72 \\
\hline
\end{tabular}

Fuente: Elaboración Propia

Conforme al resultado obtenido se preferiría el distrito de Pachacamac, ya que cuenta con un mayor puntaje; es decir, se considera que tiene las mejores condiciones para la localización de la planta. 


\section{CAPÍTULO IV: TAMAÑo DE PLANTA}

En este apartado se determinará el tamaño de planta del proyecto; lo cual implica evaluar la relación que existe entre los factores tecnológicos, económicos y sociales para establecer el tamaño viable de la planta.

\subsection{Relación tamaño mercado}

El tamaño máximo de la planta se analiza de acuerdo al mercado que va relacionado al volumen de producción.

Este proyecto espera cubrir la demanda del consumo de chocolate en Lima como lo indica la siguiente tabla.

Tabla 4.1

Demanda proyectada en $\mathrm{Kg}$

\begin{tabular}{cc}
\hline Año & Demanda Proyectada $(\mathbf{K g})$ \\
\hline 2020 & 21,291 \\
2021 & 23,060 \\
2022 & 25,944 \\
2023 & 28,995 \\
2024 & 32,212 \\
\hline
\end{tabular}

Elaboración propia

Como se observa en la tabla anterior el año 2024 se pronostica una demanda estimada de 32,212 kg de chocolate y 664,240 barras de Amora Chocolate.

Considerando que la planta funcionará 52 semanas al año y 5 días a la semana, se obtiene la capacidad máxima de planta:

$$
\text { Capacidad Máxima }=\frac{32,212 \mathrm{~kg} / \text { año }}{52 \frac{\operatorname{sem}}{a \tilde{n} o} * 5 \frac{\text { días }}{\operatorname{sem}}}=123,89 \mathrm{~kg} / \text { día }
$$

Esto nos indica que el tamaño de planta debería atender como máximo 123,89 kg de chocolate por día, según la demanda proyectada del mercado al 2024.

\subsection{Relación tamaño - recursos productivos}

Es importante evaluar la disponibilidad de los recursos productivos como la mano de obra, los materiales y la energía para la ejecución del proyecto; de esta manera se reconocerá cuál de ellos restringirá la producción. 
En este caso el único factor a considerar sería la producción de granos de cacao, la materia prima. Según los bancos históricos del INEI, la producción de chocolate en el Perú y la producción de granos de cacao se estima en:

Tabla 4.2

Producción proyectada de cacao convencional

\begin{tabular}{cc}
\hline Año & $\begin{array}{c}\text { Proyección de producción de } \\
\text { granos de cacao (Tm) }\end{array}$ \\
\hline 2019 & 149000.0 \\
2020 & 161364.8 \\
2021 & 174652.3 \\
2022 & 187939.8 \\
2023 & 201227.3 \\
\hline Nota: Proyección de producción de granos de cacao
\end{tabular}

Nota: Proyección de producción de granos de cacao Fuente: Minagri (2018)

Según el Minagri, en 2018 la producción de cacao alcanzó un máximo histórico de 134,676 toneladas. Hecho que ha sido posible gracias al crecimiento anual de $14.8 \%$ desde 2008 hasta 2018 a nivel nacional.

Estos datos se ven corroborados por lo señalado por Luis Mendoza, gerente de la Asociación Peruana de Productores de Cacao (APPCacao), quien comparó las toneladas exportadas en 2010 con las del 2016. En 2010 se exportaron 6 mil toneladas mientras que, en 2016, 16.500 toneladas de cacao certificado. Incluso si las compara con las cifras de 2017 el incremento es también notable pues llega a 20.500 toneladas (Andina, 2019).

Asimismo, las exportaciones de Kemito-Ene subrayan el prestigio del cacao peruano. Kemito-Ene, principal de Amora Chocolate, el año 2017 logró exportar a mercados europeos (incluyendo Rusia) y australianos 70 mil TM de cacao criollo y 10 TM de café arábica 100\% orgánicos producidos bajo sistemas agroforestales concorde con el estilo de vida ashaninka y respetando el medio ambiente (Careashaninka, 2019)

De esta manera considerando la producción de cacao criollo orgánico y con certificación de comercio justo se obtienen los 70,000 Tm de cacao criollo orgánico de nuestro proveedor Kemito Ene, que al convertir la producción de cacao con el factor de conversión obtenemos un tamaño de producción de 53,200 Tm de chocolate orgánico anual. 
Por último, se puede considerar que la oferta de cacao orgánico no es una limitante. Cabe resaltar, que se posee una relación estrecha con la Asociación Kemito Ene como alianza estratégica.

\subsection{Relación tamaño - tecnología}

La tecnología es preponderante para la capacidad de producción. Es por ello que el tamaño de planta está vinculado a la disposición de equipos y maquinarias que existen en el mercado. A continuación, se muestran la capacidad de las máquinas requeridas para el proceso de producción de chocolate orgánico.

Tabla 4.3

Capacidad de máquina según tipo operación

\begin{tabular}{l|c}
\hline Operaciones & $\begin{array}{c}\text { Capacidad de } \\
\text { procesamiento }(\mathrm{kg} / \mathrm{h})\end{array}$ \\
\hline Tostado & 50 \\
Descascarillado & 50 \\
Molido & 50 \\
mezclado y & 20 \\
refinado & 37.5 \\
Conchado & 40 \\
Temperado & Fuente: Empresa Cultura Americana (2019) \\
Elaboración propia
\end{tabular}

A partir de las capacidades mostradas en el cuadro de arriba, se observa que la tecnología no constituye ninguna limitante para el proyecto porque las capacidades de las maquinarias cubren las necesidades de la demanda, considerando que el cuello de botella sería la máquina refinadora produciendo $38,363 \mathrm{~kg} / \mathrm{anual}$ de chocolate; es decir 767,260 barras de chocolate.

\subsection{Selección del tamaño planta}

La definición de punto de equilibrio es un factor importante para determinar el volumen de producción de modo que establezca el valor mínimo de ventas para generar beneficios y determinar la rentabilidad del proyecto. Y se determina de la siguiente manera:

$$
\text { Punto de equilibrio }=\frac{\text { Costosfijos }}{\text { Preciodeventa-costovariableunitario }}
$$


Se considera como costos fijos a aquellos costos que no dependen de la cantidad producida, a diferencia de los costos variables quienes si están en función de la producción. A continuación, se mostrarán los cuadros de costos fijos y variables:

Tabla 4.4

Costos fijos

\begin{tabular}{cc}
\hline \multicolumn{1}{c}{ Costos fijos } & Monto (S/.) \\
\hline Costos y gastos fijos totales & 1 1'551,054 \\
\hline
\end{tabular}

Elaboración propia

Tabla 4.5

Costo variable unitario

\begin{tabular}{lr}
\hline Costo variable unitario & Monto (S/.) \\
\hline Costo Variable Unitario & 2.35 \\
\hline
\end{tabular}

Elaboración propia

Como se utilizó la estrategia de precio promedio del mercado, entonces el precio de venta por caja de chocolate de 50 gramos es de S/.10,5 y un valor de venta de S/.8,9. A partir de la formula ya propuesta y con los valores de costos obtenidos se obtiene el punto de equilibro.

$$
Q=\frac{1^{\prime} 551,054}{8,9-2,35}
$$

Siendo 236,840 barras de chocolate Premium al año, la cantidad de unidades como mínimo a producir para que no existan pérdidas; es decir 11,842 kg de chocolate orgánico Premium.

\subsection{Selección del tamaño de planta}

La capacidad de producción de planta se determina a partir de las siguientes comparaciones presentadas en el siguiente cuadro, que fueron obtenidas de puntos anteriores.

Tabla 4.6

Cuadro de tamaño de planta

\begin{tabular}{lccc}
\hline Tamaño de planta & Kg/ año & Unid/ año & Cajas/ año \\
\hline Mercado & 32212 & 644240 & 32212 \\
Recursos productivos & 53200000 & 1064000000 & 53200000 \\
Tecnología & 38,363 & 767260 & 38,363 \\
Punto de equilibrio & 11842 & 236,840 & 11842 \\
\hline
\end{tabular}

Elaboración propia 
La relación tamaño mercado permite saber la capacidad máxima de tamaño de planta a no superar, puesto que de ser así existiría sobreproducción que incurriría a sobrecostos y disminución de precios afectando el margen de utilidad.

Como se puede observar el punto de equilibrio no supera la capacidad de tamaño de planta de esta manera el proyecto genera rentabilidad y cubre los costos asociados.

Se considera como limitante superior recursos productivos y al inferior el punto de equilibrio que logra satisfacer a la demanda. 


\section{CAPÍTULO V: INGENIERÍA DEL PROYECTO}

En este capítulo se analizará la importancia de la disposición de las instalaciones para disminuir costos, así como para mejorar el nivel de productividad y calidad para ello utilizaremos diferentes métodos que suele emplear las empresas manufactureras.

\subsection{Definición técnica del producto}

\section{Propiedades nutricionales del cacao}

El chocolate y sus derivados se caracterizan especialmente por su alto índice de carbohidratos y grasas. Tras exprimir las almendras de cacao estas generan un aceite que constituye la manteca de cacao de la cual proviene la grasa.

Ésta contiene varios elementos como el ácido graso esteárico que es inocuo a diferencia de otras grasas que aumentan el colesterol en la sangre. La teobromina es otra sustancia presente en los granos de cacao que, si bien es un estimulante del sistema nervioso como la cafeína o teína, es de menor intensidad en su efecto excitante.

Otros elementos presentes son las vitaminas A y B (B1), y minerales tales como hierro, potasio, calcio, fósforo además del ácido fólico. Los polifenoles que contienen ayudan con la prevención de trastornos cardiovasculares y estimulan las defensas del organismo.

Cabe resaltar, los polifenoles encontrados en el cacao previenen trastornos cardiovasculares y estimulan las defensas del organismo humano, evitando de esta manera la oxidación del colesterol.

El aporte de nutrición y energía que proporciona el cacao es altísimo, pues proporciona 293 calorías por cada 100 gramos.

En el siguiente cuadro se mostrará el valor nutricional del cacao: 
Tabla 5.1

Informe nutricional de chocolate orgánico premium con arándano rojo

\begin{tabular}{|c|c|c|c|}
\hline \multicolumn{4}{|c|}{ INFORME NUTRICIONAL } \\
\hline \multicolumn{2}{|l|}{ Tamaño por porción } & \multicolumn{2}{|l|}{$10 \mathrm{~g}$} \\
\hline \multicolumn{2}{|l|}{ Porciones por envase } & \multicolumn{2}{|l|}{5} \\
\hline \multicolumn{2}{|c|}{ Energía (calorías) por porción } & \multicolumn{2}{|l|}{$251 \mathrm{~kJ}(60 \mathrm{kcal})$} \\
\hline \multicolumn{2}{|c|}{ Energía de grasas (calorías de grasa) } & \multicolumn{2}{|l|}{$147 \mathrm{~kJ}(35 \mathrm{kcal})$} \\
\hline \multicolumn{4}{|c|}{$\%$ de valor diario* } \\
\hline Grasa total & $4 g$ & & $6 \%$ \\
\hline Grasa saturada & $2 g$ & & $10 \%$ \\
\hline Grasa mono insaturada & $1 \mathrm{~g}$ & & - \\
\hline Grasa poli insaturada & $0 \mathrm{~g}$ & & - \\
\hline Grasa trans & $0 \mathrm{~g}$ & & $0 \%$ \\
\hline Colesterol & $0 \mathrm{mg}$ & & $0 \%$ \\
\hline Sodio & $0 \mathrm{mg}$ & & $0 \%$ \\
\hline Carbohidratos totales & $5 g$ & & $2 \%$ \\
\hline Fibra dietética & $0 \mathrm{~g}$ & & $0 \%$ \\
\hline Azúcares & $5 g$ & & - \\
\hline Proteína & 19 & & $2 \%$ \\
\hline \multicolumn{4}{|c|}{ *Porcentaje de valores diarias basados en una dieta de 2000 calorías. } \\
\hline $\begin{array}{l}\text { INGREDIENTES: Pasta } \\
\text { deshidratado, lecitina d } \\
\text { cacahuates. }\end{array}$ & $\begin{array}{l}\text { azúca } \\
\text { ibre de }\end{array}$ & $\begin{array}{l}\text { acao, arandano } \\
\text { razas de leche, }\end{array}$ & \\
\hline
\end{tabular}

Nota: Chocolates Pacari 50gr.

Fuente: https://www.camari.org/index.php/catalogo/alimentos/confiteria/barra-de-chocolate-premiumorganico-con-arandano-rojo-pacari-detail\#tabla-nutricional (2019)

\subsubsection{Especificaciones técnicas, composición y diseño del producto}

El producto será una barra de chocolate orgánico al $65 \%$ con arándanos y frambuesas deshidratadas. Este producto pesará 50 gramos netos y la presentación será en un empaque ecofriendly hecho a base de papel ecológico y con una capa interna bilaminada. Poseerá los colores de la marca y el logotipo de esta. 
Figura 5.1

Ficha técnica del chocolate

FICHA TÉCNICA DE PRODUCTO

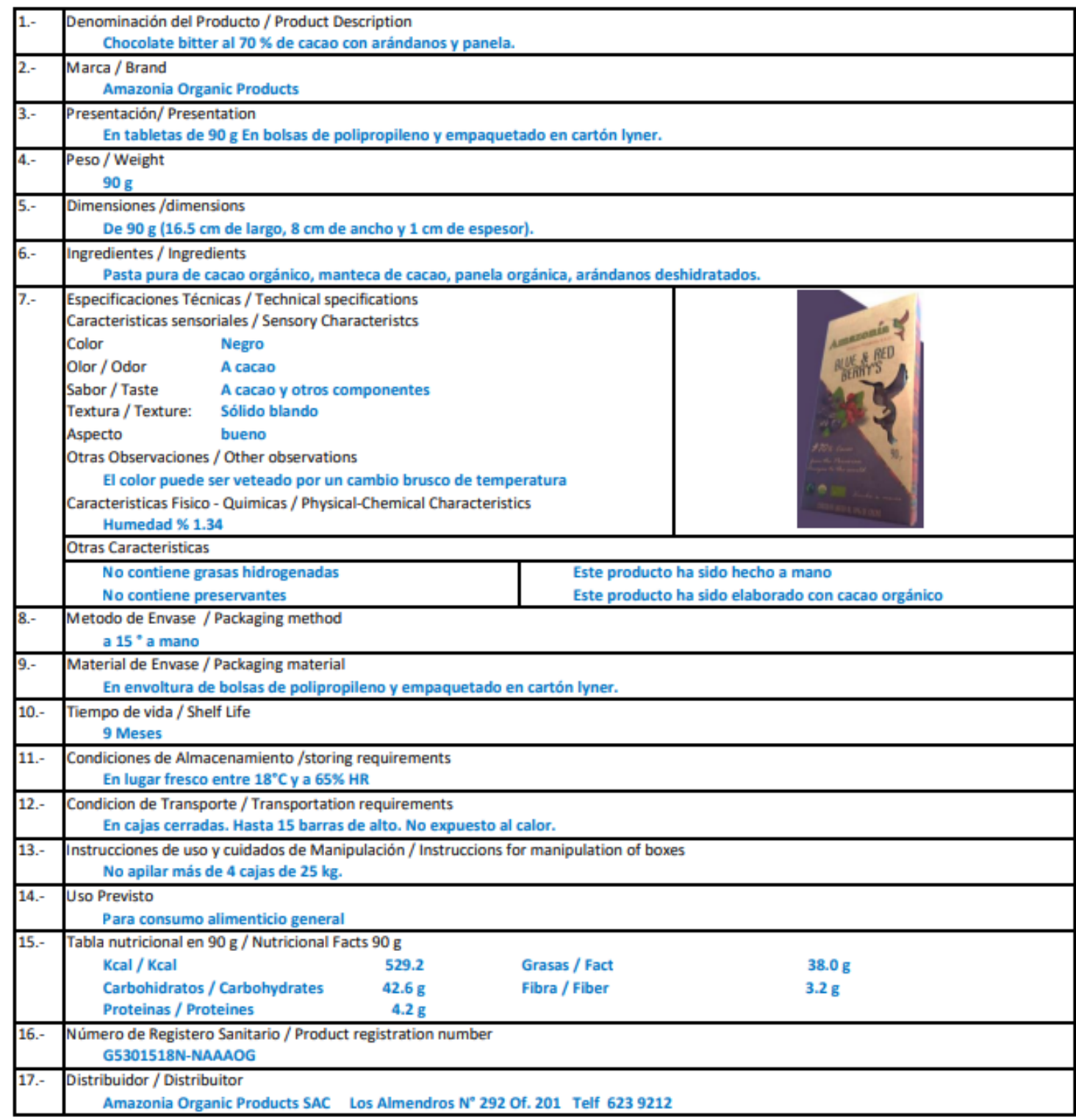

Fuente: Amazonía Organic Products SAC (2019)

\subsubsection{Marco regulatorio para el producto}

La diferencia entre una chocolatina y un verdadero chocolate, lo establece la Norma Técnica Peruana (NTP) de INDECOPI. Donde se denomina chocolate al alimento que tenga un mínimo de $35 \%$ de contenido cacao en su composición (18\% manteca de cacao y un $14 \%$ pasta de cacao). Para el chocolate de leche deberá tener un mínimo de 
25\% de cacao". En el caso del chocolate dark o negro, el contenido de cacao será más alto (65-90\%) no llevará leche y el porcentaje de azúcar será más bajo.

De esta manera, si un producto no alcanza el porcentaje indicado de cacao no puede denominarse chocolate, sino simplemente golosina.

En el Perú el Ministerio de Agricultura junto con SENASA (Servicio Nacional de Sanidad Agraria) tienen un conjunto de normas que declaran "La inocuidad en la cadena alimentaria del cacao y del chocolate", es decir que esta cadena alimentaria tiene la incapacidad de producir daño.

\subsection{Tecnologías existentes y procesos de producción}

\subsubsection{Naturaleza de la tecnología requerida}

\subsubsection{Descripción de las tecnologías existentes}

Para la producción chocolates, en todas sus variedades existe la posibilidad de fabricarlos con tecnología artesanal, semiautomatizada y automatizada.

La producción artesanal es reconocida de importancia trascendental por la UNESCO, puesto que su conocimiento es relevante para que este tipo de producción aun siga vigente. La producción artesanal transforma materia prima para dar forma a objetos que intervendrán en procesos de producción no industrial.

$\mathrm{Si}$ bien es cierto, en este caso, es reconocido que producir chocolates de manera artesanal con insumos de calidad y con altos estándares, se obtiene un producto fino y de calidad; la contraparte de esta producción es limitada en cuanto a la homologación de producto, a estandarizar los tiempos y a una mayor capacidad de producción.

De esta manera, factores como: mercado objetivo, cantidad de producción, calidad, inversión, etc. Serán decisivos a la hora de elegir el tipo de tecnología a utilizar.

\subsubsection{Selección de la tecnología}

Escogemos la tecnología semiautomatizada debido al volumen de producción y al tratarse de un producto Premium de alta calidad, con altos estándares de procesos productivos.

Gracias a esta tecnología se alcanza los objetivos trazados; tales como: homologación de proveedores, control de calidad, correcto uso de recursos productivos, entregas de pedidos a tiempo, ahorro de energía, eficiencia en control de costo, etc. 
Cabe destacar que algunas operaciones; como: llenado, transporte, moldeado, envasado, encajonado, se van a realizar manualmente por los operarios.

\subsubsection{Proceso de producción}

\subsubsection{Descripción del proceso}

El proceso de producción para la elaboración de chocolate premium orgánico con frutos del bosque en barra se inicia con el grano seco de cacao y se desarrolla como se detalla a continuación:

Se reciben de granos selectos de cacao, manteca de cacao, azúcar y frutos del bosque deshidratado, se almacenan para luego ser usados más tarde. Se toma la muestra del cacao para verificar el contenido de grasa del grano para su correcta formulación. Luego se procede con el pesado de los sacos de $50 \mathrm{~kg}$ a modo de verificación. El operario procederá al llenado de almendras (granos de cacao) mediante baldes hacia la tolva de carga de la tostadora, existiendo un punto de control llegando a los $130^{\circ} \mathrm{C} \mathrm{y} \mathrm{a}$ un $4 \%$ de humedad por un tiempo de $40 \mathrm{~min}$.

Una vez enfriado se procede al descascarillado en donde la maquina cumple su función realizando el quiebre, limpiando y separando las cascaras por diferencia de densidad de aire y tamizando el producto granular gracias a una malla vibroscriba. Es importante resaltar que el rendimiento de esta máquina permite un rendimiento del $79 \%$; es decir una alta recuperación de materia prima en comparación a otras máquinas.

Luego es llevado a la molienda para obtener la pasta de cacao, se hace uso del molino pre refinador por el tiempo de 1hora. Este equipo tiene una unidad de calentamiento y una unidad de enfriamiento para enfriar la máquina durante el ciclo de pre refinado.

A continuación, se tiene listo a la manteca de cacao (8\%) y el azúcar (28\%) previamente pesados para que en conjunto a la pasta de cacao ingresen al refinado de bolas donde se mezclan y adquieren al cabo de 1 hora la fineza de 18 micrones.

Una vez alcanzada la fineza esperada, se procede al conchado, proceso vital para alcanzar el sabor deseado. La máquina conchadora por medio de giros continuos, bate el chocolate contra las paredes de la tina para suprimir la humedad y la acidez residual. Este proceso tarda 4 horas.

En el temperado, el chocolate se enfría a $28{ }^{\circ} \mathrm{C}$ y se calienta a $31{ }^{\circ} \mathrm{C}$. Siendo estas temperaturas muy específicas para conseguir la consistencia requerida que brinde 
un acabado brillante, crujiente y más fino. Además, en este proceso se ingresan los frutos deshidratados $(20 \%)$ mezclándose para luego ser moldeados.

En el moldeado, ingresan los moldes, donde se llenen cada 3 tabletas con un contenido de $50 \mathrm{~g}$, los cuales son manipulados por 3 operarias. Luego una de ellas se encarga de movilizar los moldes y los lleva a enfriar en un refrigerador, para luego ser desmoldados y envasados. 


\subsubsection{Diagrama de proceso: DOP}

Figura 5.2

Diagrama de procesos DOP

\section{DIAGRAMA DE OPERACIONES DEL PROCESO DE PRODUCCIÓN DE CHOCOLATE ORGÁNICO EN BARRA}

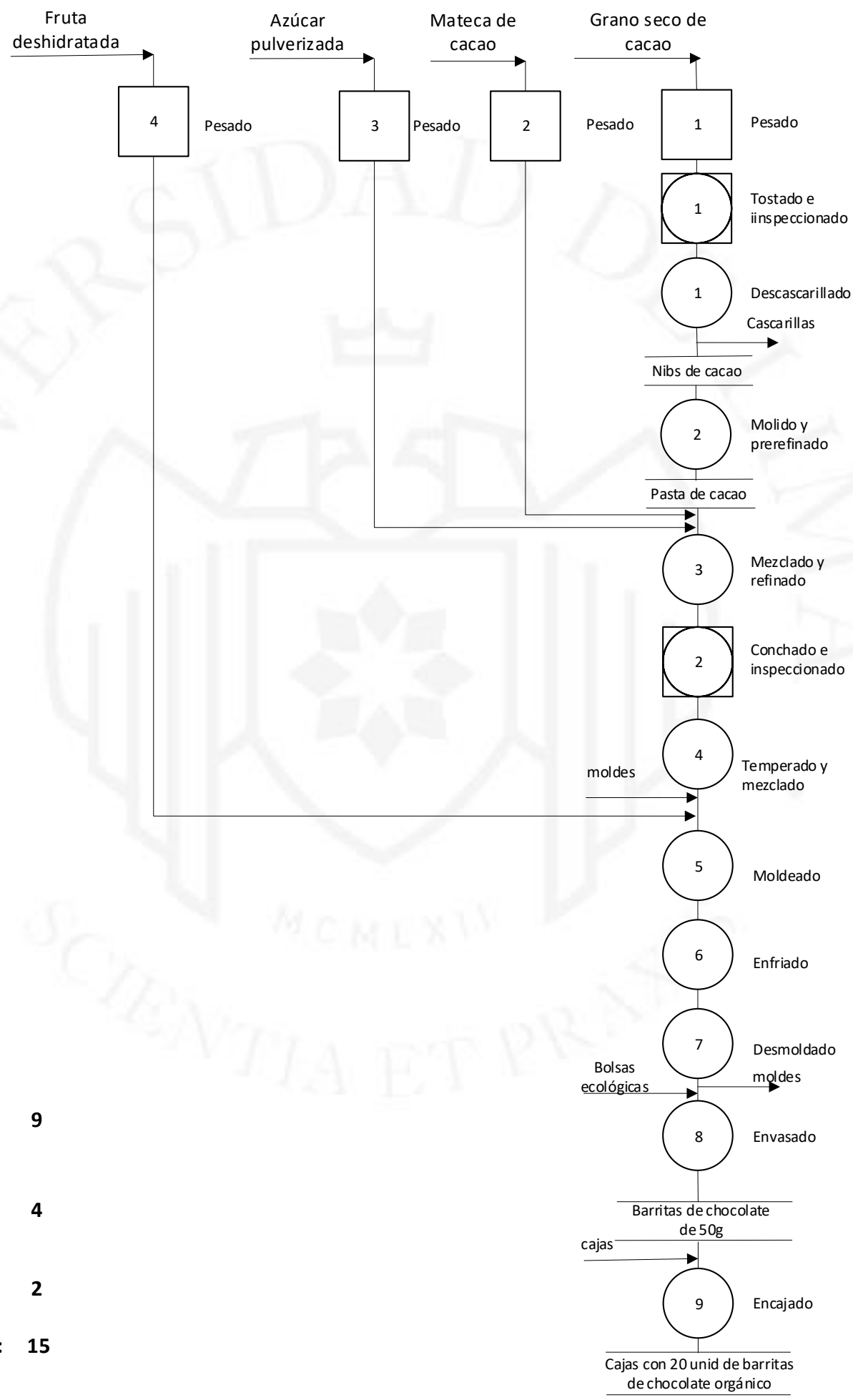

Elaboración propia 


\subsubsection{Balance de materia}

Figura 5.3

Balance de materia del año 2024

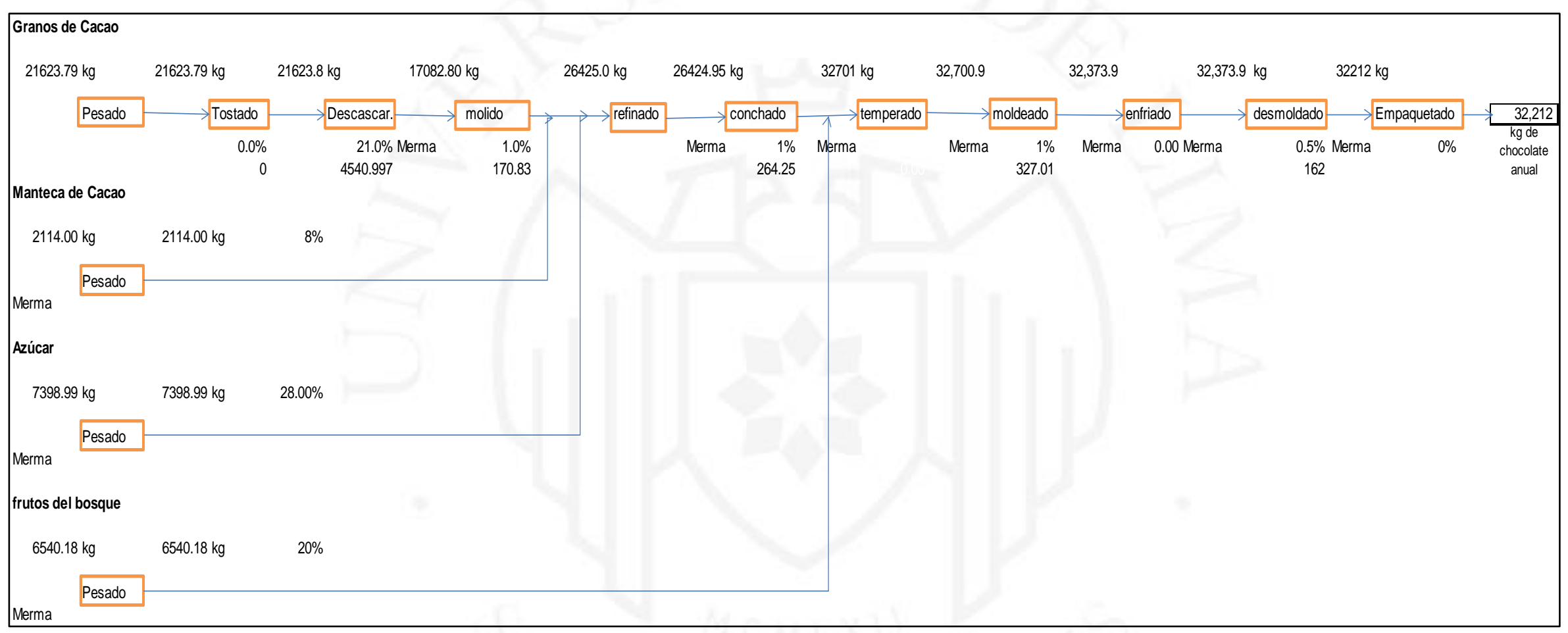

Elaboración propia 
Figura 5.4

Balance de energía tostado

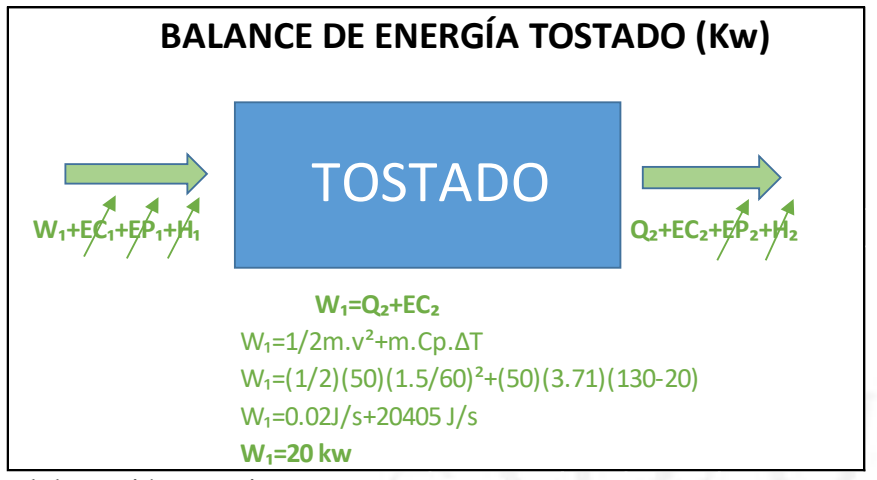

Elaboración propia

Figura 5.5

Balance de energía descascarillado

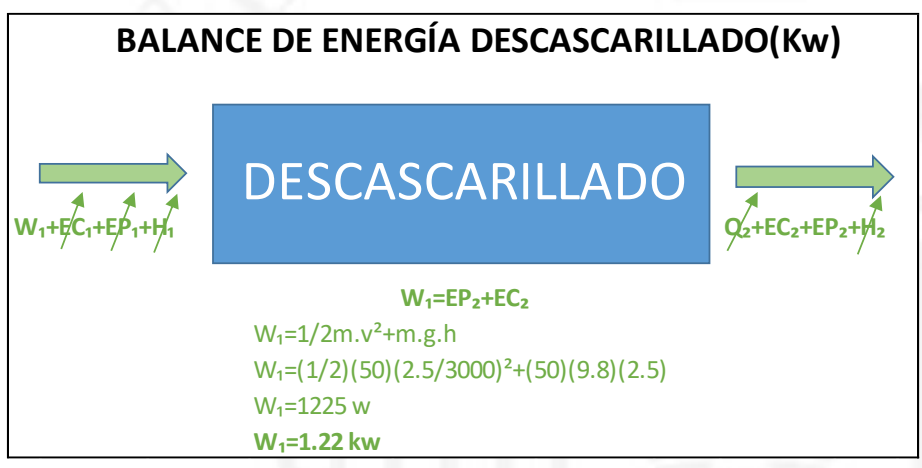

Elaboración propia

\subsection{Características de las instalaciones y equipos}

\subsubsection{Selección de la maquinaria y equipos}

Para el proceso de elaboración de chocolate en barra se realizan diferentes operaciones para la cual se necesitan diferentes maquinarias y equipos.

Tabla 5.2

Maquinarias y equipos requeridos

\begin{tabular}{l|c}
\hline Proceso & Máquinas y equipos \\
\hline Pesado & balanza de precisión \\
Tostado & Tostadora \\
Descascarillado & Descascarilladora \\
Molido y pre refinado & molino prerefinadora \\
Refinado & molino de bolas \\
Conchado & Conchadora \\
Temperado & Temperadora \\
Enfriado & Freezer industrial \\
\hline
\end{tabular}

Elaboración propia 


\subsubsection{Especificaciones de la maquinaria}

A continuación, se mostrarán las especificaciones técnicas de las maquinas seleccionadas para el proceso productivo:

\section{$\underline{\text { Tostadora infrarroja red60 }}$}

\section{Características principales:}

- Contiene marco compacto en acero inoxidable AISI 304 con aislamiento térmico (aislamiento doble en tina de tostado) Sección superior que se puede abrir para facilitar la limpieza y el mantenimiento.

- Tolva de carga del producto. En caso de carga manual será con baldes o contenedores: sensor de nivel del producto en la tolva de carga. En el caso de la línea automática la carga es a través de la cinta transportadora: células de carga para verificar el peso de lote del producto.

- Mezclar la parte inferior del producto de la sala de tostado en una hoja completa con una sección hecha en una hoja perforada, que se puede cambiar según los productos a ser tostados.

- Cóclea (espiral) colocada debajo de la lámina perforada para la recolección de cáscaras y restos de producción que podrían ocurrir durante el tostado. Se descargan en un contenedor ubicado dentro del tostador, a través de puertas que se pueden abrir. El nivel de llenado del recipiente es controlado por un sensor propio con alarma para el operador.

- Mezcla agradable del producto con la velocidad ajustable establecida en la receta.

- Calentamiento a través de lámparas infrarrojas de cerámica.

- Tubería de aire de entrada y chimenea de extracción de humedad con regulación de flujo de la receta (para una extracción más fuerte o ligera); descarga de humedad en el ambiente.

- Dispositivos para la carga del producto, la descarga del tostado y la descarga del enfriamiento con conducción neumática.

- Dispositivo de recolección de muestras durante el ciclo de tostado.

- Sensores de temperatura para un control integral de producción: Un termómetro para el control de la temperatura de las lámparas, uno para el control de la 
temperatura del producto, uno para el control de la temperatura de extracción de humedad.

- Enfriamiento del producto por aire, completo con sistema de filtrado con ciclón y filtro; para separar el polvo y la cáscara del aire de proceso.

- Fabricado en acero inoxidable AISI 304.

- Escalera de acceso.

Figura 5.6

Tostadora infrarroja red60

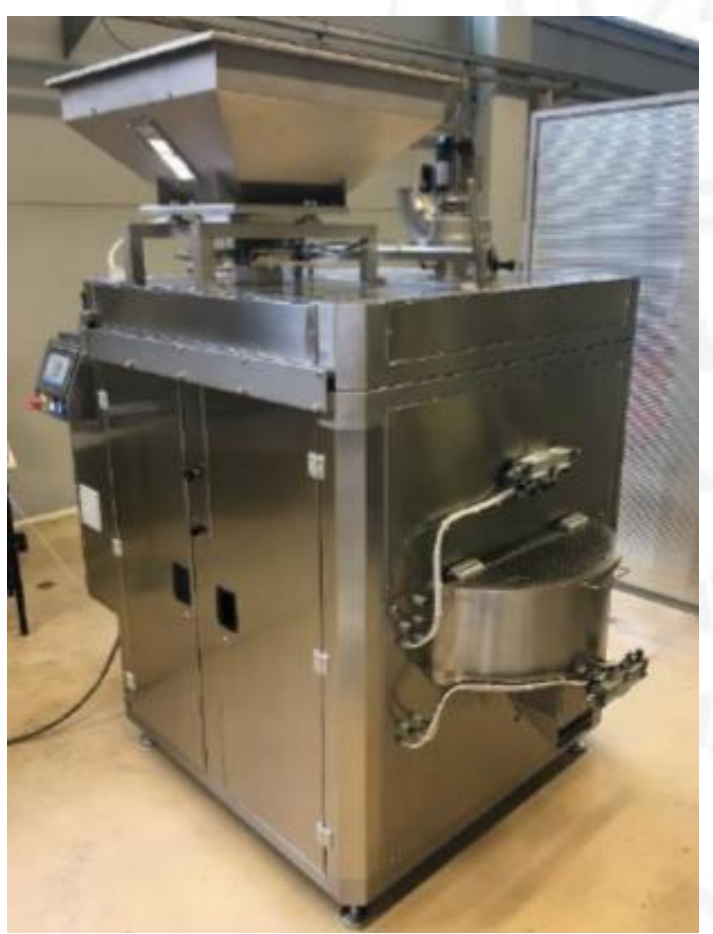

Fuente: Empresa Cultura Americana (2019)

\section{Descascarilladora RC50}

Diseñado para la molienda de granos de cacao tostados y su posterior limpieza de las cáscaras. Tiene Capacidad de producción: hasta 50-60 kg/h. La máquina de picar triturará los productos en pequeños pedazos para permitir la próxima limpieza y la separación de los granos de las cáscaras.

El producto de salida se separa según su dimensión de la criba vibrante; el polvo se descarga directamente en su propio contenedor, los granos (en dos tamaños diferentes) se limpian de las cáscaras a través de la aspiración (por diferencia de densidad del aire) antes de caer a sus contenedores. 
Las cáscaras son transportadas al aspirador ciclón y se recogerán en una carretilla y un saco. Este proceso elimina la cáscara que cubre la semilla del cacao. Los granos de cacao son primero descascarillados antes de transformarse en pasta o licor de cacao para ello tienen que ingresar los granos tostados y fríos. Para este proceso se utilizará la peladora de cacao PEL-4 que tiene las ventajas de pelar los granos de cacao sin dañarlos y es de fácil manejo y de mantenimiento.

\section{Características técnicas:}

- Máquina multietapa.

- Rodillos de cortados dentados y acanalados.

- Canaleta interior para el transporte del producto.

- Puertas frontales para la limpieza/manutención de los módulos.

- Regulación de tamaño de corte mediante una rueda de radio.

- Material: acero inoxidable AISI304.

Figura 5.7

Descarcarilladora RC50

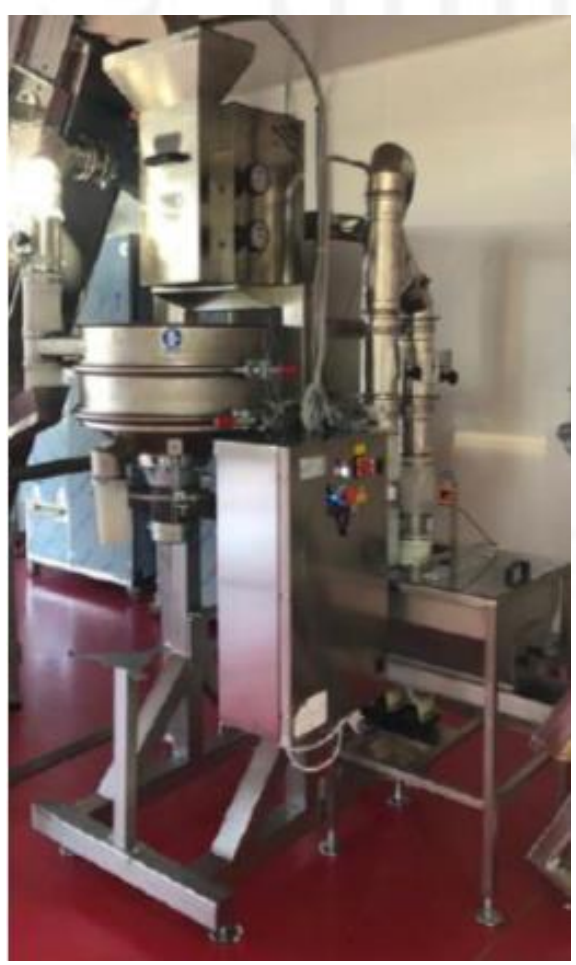

Fuente: Empresa Cultura Americana (2019) 


\section{Molino prerefinador mod mac5:}

El molino de molienda previo permite producir licor de cacao, pasta de avellanas y también es adecuado para el procesamiento de pistachos, cacahuetes, almendras y otros tipos de frutas fritas tostadas con un gran porcentaje de aceite. Los granos de cacao son triturados y producen el licor de cacao y las partículas restantes quedan suspendidas en lo que llega a ser manteca de cacao. El cacao tostado y limpio se muele mediante rodillos de acero (anteriormente eran de granito). La particularidad del molino de INOX-3 es que muele granos homogéneamente, impidiendo que se pegue a la máquina.

\section{Compuesta por:}

- Un bastidor de soporte en paneles de acero pintado.

- Placas de molienda.

- Regulación de la distancia de las placas.

- Tolva de carga con válvula, para la recepción de bultos del producto (Cap. 50 1) para la carga manual.

- Cabezales superiores e inferiores de acero inoxidable AISI 304 procesados en su totalidad, para permitir el paso del agua de refrigeración.

- Unidad de calentamiento con bomba y resistencia.

- Unidad de enfriamiento para enfriar la máquina durante el ciclo de prerefinado.

- 1 sonda colocada en la salida del producto (para el control del producto)

- 1 sonda en el agua (para calefacción)

- Panel eléctrico de acero inoxidable con PLC y pantalla táctil para el control de todos los parámetros de la máquina.

- La máquina también incluye una tolva de dosificación para la recepción del producto y su dosificación en el molino, completamente realizada en acero inoxidable AISI 304 para las partes en contacto con los alimentos.

- Canal de vibración para el suministro del producto compuesto.

- Producción aproximada: 40-60 kg / h considerando granos de cacao en grano con un porcentaje de aceite más del $45-50 \%$

- Dimensiones: 600x1000x1500 mm.

- Potencia instalada: $7 \mathrm{kw}$. 
Figura 5.8

Molino prerefinador mod mac5

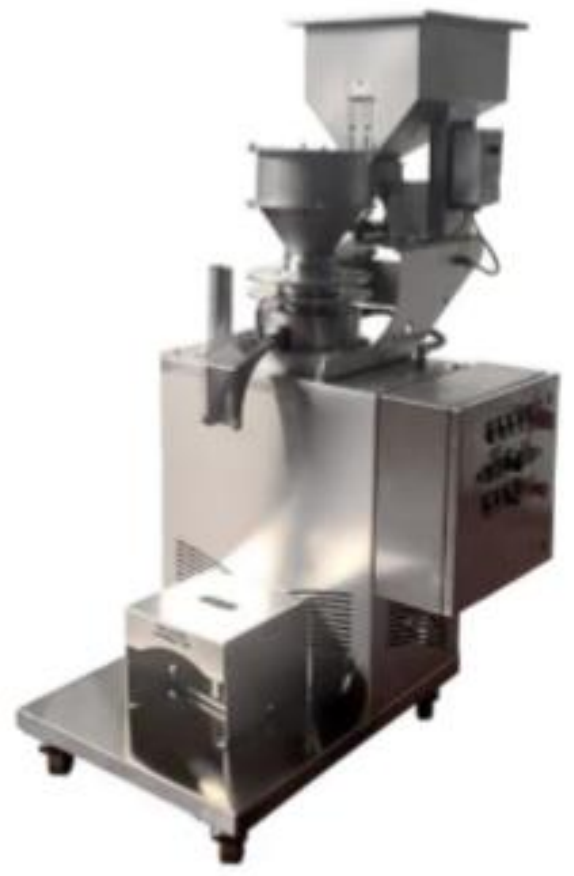

Fuente: Empresa Cultura Americana (2019)

\section{$\underline{\text { Refinador Sfera 20r: }}$}

Producción aproximada: 40-60 kg / h considerando granos de cacao en grano con un porcentaje de aceite más del $45-50 \%$. La fineza del producto que se puede obtener es de 18 hasta 26 micrones según el producto y el tiempo de refinación. El molino está compuesto por un contenedor interno y externo en acero inoxidable AISI 304 con agitador a clavijas en acero inoxidable antiabrasión. Incluye:

- Motor reductor agitador de 1,5 KW

- Bomba especial de paletas para la recirculación y la descarga del producto.

- Barril de calefacción tina con resistencia de $1 \mathrm{KW}$ y circulador.

- Enfriamiento con grupo frigorífico autónomo.

- Cuadro eléctrico en acero completamente realizado con componentes comerciales.

- Panel operador y PLC para la gestión de todas las funciones de la máquina.

- Potencia instalada: $3,75 \mathrm{~kW}$.

- Dimensiones: $850 \mathrm{~mm}$ x 650mm x 1600mm.

- Software para memorizar hasta 100 recetas y con HISTORIAL 
- Alarmas para encontrar la anomalía con fecha y hora.

- Flyp-flop sistema para la carga: la bomba en automático va adelante y atrás para evitar bloqueos en el filtro.

- La carga resultara así más rápida (aproximadamente 5 minutos según la receta)

- Alarma temperatura máxima de producto.

- Canal de carga productos desmontable a enclavamiento para la limpieza.

- Alarma temperatura máxima de agua.

Figura 5.9

Refinador Sfera 20r

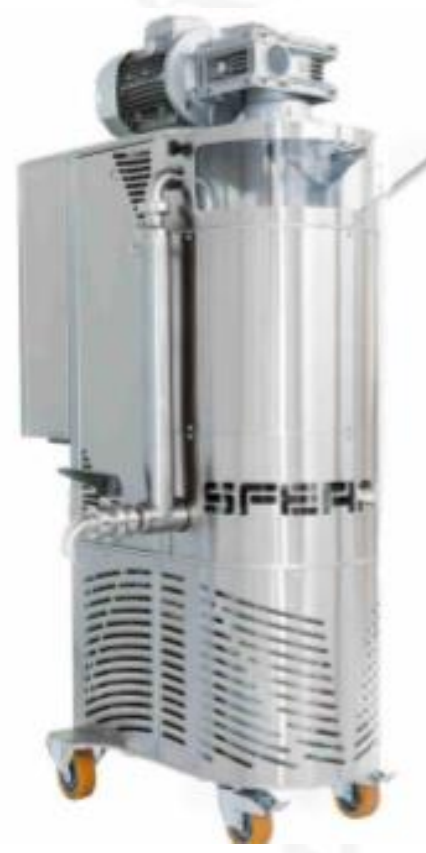

Fuente: Empresa Cultura Americana (2019)

\section{Conchadora CR 150}

El sabor de un trozo de chocolate estará determinado por la correcta sucesión de pasos para su elaboración. El conchado es el proceso final para obtener el sabor que se requiere y sin embargo no puede revertir los errores que se hayan cometido anteriormente como el sabor a humo o la presencia de moho causado por un deficiente secado como tampoco puede convertir un cacao de baja calidad en uno óptimo.

Esta máquina tiene la capacidad de conchar en seco a través de movimientos mecánico continuo donde baten el chocolate con agitadores especiales para extraer la humedad y la acidez residual. Y posee las siguientes características: 
- Posee una capacidad 150 kilogramos.

- Completamente construida en acero inoxidable AISI 304 con ruedas y frenos.

- Motor reductor para el mando del eje de la mezcla.

- Ventilador para la extracción de la humedad posicionado sobre de la tapa.

- Cuadro eléctrico de mando con pantalla táctil para gestionar (velocidad, temperatura y tiempo).

- Dimensiones: $\mathrm{mm} 600 \mathrm{~mm}$ x $1200 \mathrm{~mm}$ x $1250 \mathrm{~mm}$ de altura.

- Potencia instalada: $4 \mathrm{Kw}$.

Figura 5.10

Conchadora CR 150

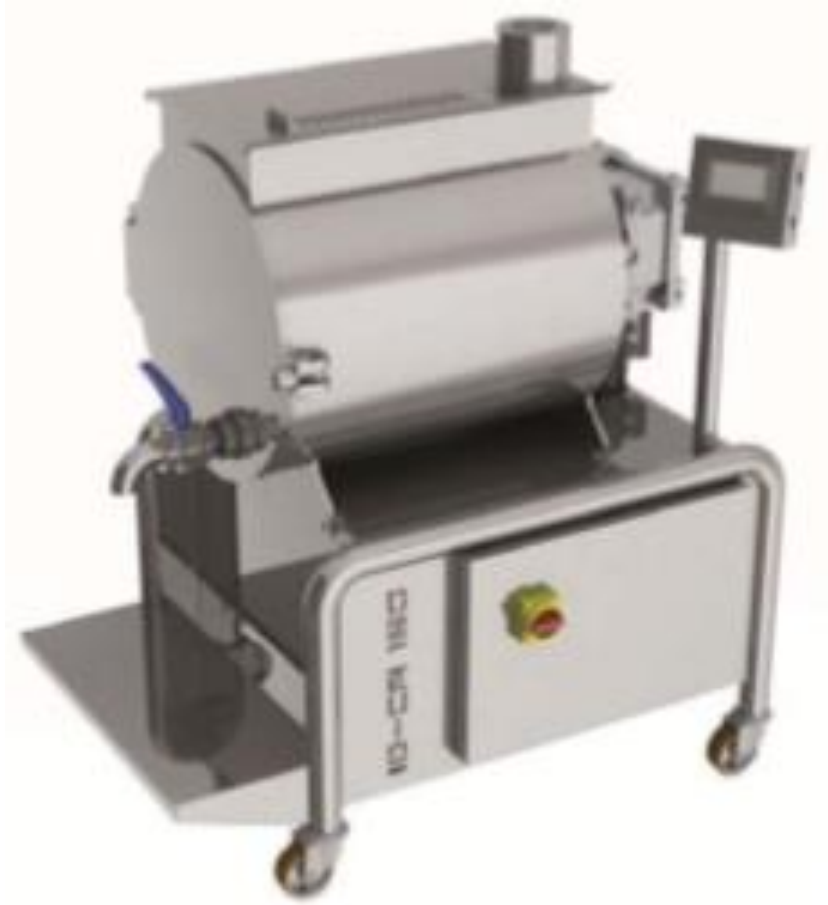

Fuente: Empresa Cultura Americana (2019)

\section{$\underline{\text { H-HM40V Temperadora con rueda y mesa vibratoria }}$}

Con la mejor relación entre calidad y precio, la máquina de moldaje H-HM40 templa el chocolate derretido mediante la adición de pedazos de chocolate, entregando un producto perfecto y listo para la producción. Esta máquina es ideal para trabajar con nueces, pasas y otros ingredientes granulados. A diferencia de las maquinarias con bombas que no pueden trabajar con ingredientes granulados.

El bajo costo de esta máquina la vuelve compañera ideal en la producción profesional. Tiene una capacidad $40 \mathrm{Kg}$ (Máquina de Moldaje) con mesa vibratoria incluido. 


\section{Características:}

- Capacidad del tanque: $40 \mathrm{Kg}$ de Chocolate.

- Cuerpo y acero inoxidable.

- Electricidad: modificado para América del Sur. Monofásico AC. Termostato digital.

- Dimensiones externas: 640mm x 640mm x 1400mm.

\section{Figura 5.11}

Temperadora con rueda y mesa vibratoria

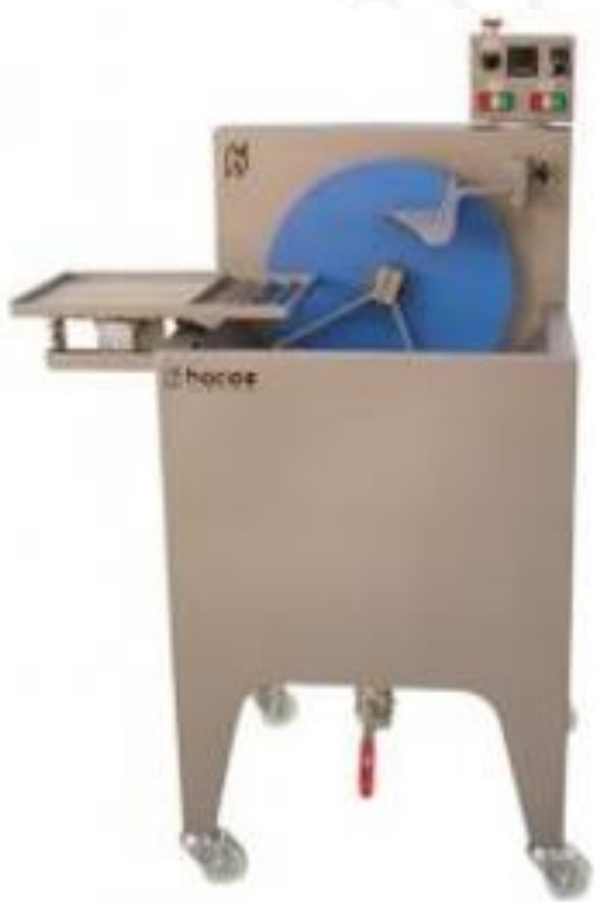

Fuente: Empresa Cultura Americana (2019)

\section{Línea Frío Freezer industrial VF4PS-1000}

\section{Características:}

- Trabajará a una temperatura de $-22^{\circ} \mathrm{C} \mathrm{a}-17^{\circ} \mathrm{C}$.

- Sistema de refrigeración con circulación de aire forzado.

- Estructura de 2 cuerpos con 4 puertas abatibles.

- Material de acero inoxidable en interior y exterior.

- Termostato digital.

- 4 ruedas móviles de base.

- Incluye 6 parrillas ajustables.

- Capacidad neta 800 lts. 
- Dimensiones: $1950 \mathrm{~mm}$ x $1200 \mathrm{mmx} 750 \mathrm{~mm}$

- Peso neto: $122 \mathrm{~kg}$.

- Potencia 741w. Consumo 8.5KW*h. Energía 220V/60Hz.

- Refrigerante R404a

Figura 5.12

Freezer Industrial VF4PS-1000

Línea Frío

FREEZER INDUSTRIAL

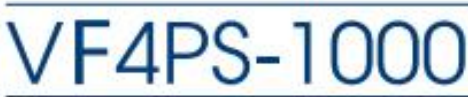

Ideales para la conservación de alimentos frescos

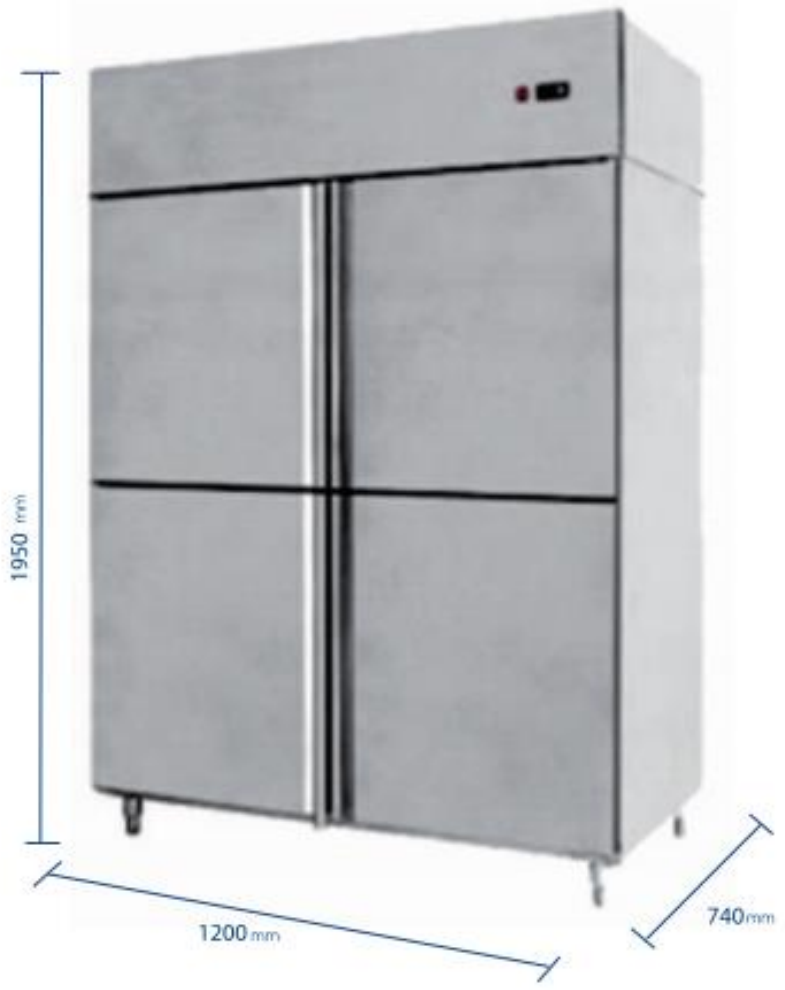

Fuente: Ventus corp. (2019)

\subsection{Capacidad instalada}

\subsubsection{Cálculo detallado del número de máquinas y operarios requeridos}

En el presente cuadro se puede observar el número de máquinas requeridas para el proceso de producción determinado por la fórmula: 


$$
\begin{gathered}
N^{\circ} \text { de Máquina }=\frac{\text { Producción }\left(\frac{\mathrm{kg}}{\mathrm{sem}}\right) \times \frac{1}{\text { rendimiento }}\left(\frac{\mathrm{kg}}{\mathrm{h}}\right)}{N^{\circ} \text { total de horas disponibles al año } * E * U} \\
N^{\circ} \text { total de horas disponibles al año }=9 \frac{\mathrm{hr}}{\text { turno }} \times 1 \frac{\text { turnos }}{\text { día }} \times 5 \frac{\text { días }}{\mathrm{sem}} \times 52 \frac{\mathrm{sem}}{\text { año }}
\end{gathered}
$$

Tabla 5.3

Cuadro cantidad de máquinas

\begin{tabular}{l|cccc}
\hline Operación & $\begin{array}{c}\text { Cap. } \\
\text { Producción }\end{array}$ & $\begin{array}{c}\text { Requerimiento } \\
\text { anual }(\mathrm{Kg})\end{array}$ & $\begin{array}{c}\mathrm{N}^{\circ} \text { de horas } \\
\text { disponibles } \\
\text { al año } \\
\text { (hrs/año) }\end{array}$ & $\begin{array}{c}\mathrm{N}^{\circ} \text { de } \\
\text { maquina } \\
(\mathrm{Kg})\end{array}$ \\
\hline Tostado & 50 & 21624 & 2338.2 & 0.24 \\
descascarillado & 39.5 & 21624 & 2338.2 & 0.31 \\
Molido & 49.5 & 17083 & 2338.2 & 0.19 \\
mezclado y & 20 & 26425 & 2338.2 & 0.74 \\
refinado & 37 & 26425 & 2338.2 & 0.40 \\
Conchado & 40 & 32701 & 2338.2 & 0.46 \\
Temperado & & &
\end{tabular}

Elaboración propia

\subsubsection{Cálculo de la capacidad instalada}

Para realizar este cálculo se consideró la cantidad de trabajo por día, los días a la semana, los meses y los factores de utilización y de eficiencia. Lo cual llevó a determinar la cantidad a producir en kilogramos de chocolate al año por cada proceso trabajando con la tecnología escogida con anterioridad.

- 9 horas por turno

- 1 turno al día

- Factor de utilización (FU): 0.92

- Factor de eficiencia (FE): 0.95 
Tabla 5.4

Cuadro capacidad instalada

\begin{tabular}{|c|c|c|c|c|c|c|c|c|c|c|c|c|c|c|}
\hline Operaciones & QE (Kg) & $\begin{array}{l}\text { Unidad de } \\
\text { medida }\end{array}$ & $\begin{array}{l}\text { Capacidad de } \\
\text { producción } \\
\text { máquinas }\end{array}$ & $\begin{array}{c}\text { Número de } \\
\text { máquinas o } \\
\mathbf{N}^{\circ} \\
\text { operarios }\end{array}$ & mes/año & $\begin{array}{c}\mathbf{s e m} / \mathbf{m} \\
\text { es }\end{array}$ & $\begin{array}{c}\text { días/s } \\
\text { em }\end{array}$ & $\begin{array}{l}\text { turnos/ } \\
\text { día }\end{array}$ & $\begin{array}{c}\text { horas/t } \\
\text { urno }\end{array}$ & $\begin{array}{c}\text { Factor } \\
\text { eficiencia }\end{array}$ & $\begin{array}{c}\text { Factor } \\
\text { utilización }\end{array}$ & $\begin{array}{l}\text { Capacidad de } \\
\text { producción según } \\
\text { balance de } \\
\text { materia para } \\
\text { cada operación }\end{array}$ & $\begin{array}{l}\text { Factor de } \\
\text { conversión }\end{array}$ & $\begin{array}{l}\text { Capacidad de } \\
\text { producción en kg } \\
\text { de PT para cada } \\
\text { operación }\end{array}$ \\
\hline Tostado & 21,624 & $\mathrm{~kg}$ & 50.00 & 1 & 12 & 4.33 & 5 & 1 & 9 & 0.95 & 0.92 & 102,179 & 0.671 & $68,592.61$ \\
\hline Descascarillado & 21,624 & $\mathrm{~kg}$ & 39.50 & 1 & 12 & 4.33 & 5 & 1 & 9 & 0.95 & 0.92 & 80,722 & 0.671 & $54,188.16$ \\
\hline Molido & 17,083 & $\mathrm{~kg}$ & 49.50 & 1 & 12 & 4.33 & 5 & 1 & 9 & 0.95 & 0.92 & 101,158 & 0.530 & $53,646.28$ \\
\hline $\begin{array}{l}\text { mezclado y } \\
\text { refinado }\end{array}$ & 26,425 & $\mathrm{~kg}$ & 20.00 & 1 & 12 & 4.33 & 5 & 1 & 9 & 0.95 & 0.92 & 40,872 & 0.820 & $33,528.92$ \\
\hline Conchado & 26,425 & $\mathrm{~kg}$ & 37.13 & 1 & 12 & 4.33 & 5 & 1 & 9 & 0.95 & 0.92 & 75,868 & 0.820 & $62,238.06$ \\
\hline Temperado & 32,701 & $\mathrm{~kg}$ & 40.00 & 1 & 12 & 4.33 & 5 & 1 & 9 & 0.95 & 0.92 & 81,743 & 1.015 & $82,984.08$ \\
\hline
\end{tabular}

Elaboración propia

Del presente cuadro se puede observar que el cuello de botella lo produce el equipo de refinado, por lo que en base a este se calculará la Capacidad de la planta, la cual sería de 33,528.92 Kg de chocolate orgánico / año, lo cual es equivalente a 33.5 Tm de chocolate orgánico premium / año. 


\subsection{Resguardo de la calidad y/o inocuidad del producto}

Con la finalidad de asegurar la calidad e inocuidad del producto se realizó un análisis de riesgo del producto que permita localizar los puntos críticos de control e implementar las buenas prácticas de manufactura y elaborar un programa HACCP que permita monitorear tales puntos críticos.

\subsubsection{Calidad de la materia prima, de los insumos, del proceso y del producto}

La calidad del producto final deberá asegurarse con la calidad de la materia prima y con los insumos que serán descritos a continuación:

\section{Calidad de la materia prima}

- Calidad del cacao

Respecto a los primeros eslabones de la cadena productiva, tenemos a los granos de cacao, traídos desde Satipo, de la comunidad ashaninka Kemito Ene que cuentan con certificación orgánica. La calidad del cacao es uno de los aspectos más relevantes en la cadena de producción, pues determinará la mayor o menor demanda del producto final. Las características físicas engloban tamaño, presentación de las almendras, así como sus características organolépticas y también las características químicas de las almendras fermentadas y secas.

\section{Tabla 5.5}

Composición nutricional de los granos de cacao orgánico

\begin{tabular}{lcc}
\hline Elemento & Unidad & Cantidad \\
Manteca de cacao & $\%$ & 54 \\
Proteína & $\%$ & 11.5 \\
Celulosa & $\%$ & 9 \\
Almidón & $\%$ & 7.5 \\
Taninos & $\%$ & 6 \\
Agua & $\%$ & 5 \\
otros elementos y sales & $\%$ & 2.6 \\
ácidos orgánicos y esencias & $\%$ & 2 \\
Teobromina & $\%$ & 1 \\
Azúcares & $\%$ & 1 \\
Cafeína & $\%$ & 0.2 \\
\hline
\end{tabular}

Fuente: Infoagro (2019)

\section{Calidad de insumos}

- Calidad de los arándanos y frambuesas 
Los arándanos y frambuesas deshidratados que utilizaremos para el proceso productivo serán adquiridos mediante un proveedor, el cual buscaremos que nos garantice la calidad de estos productos, para ello tomaremos en cuenta los siguientes factores de calidad:

- Características varietales semejantes a los arándanos y frambuesas frescos.

- Tener una humedad de $10 \%$.

- Tener buen sabor.

- Estar exentos de sabores y olores extraños.

- Estar exentos de mohos y otras materias perjudiciales extrañas.

Tabla 5.6

Tabla nutricional de la frambuesa

\begin{tabular}{lcc}
\hline \multicolumn{1}{c}{ COMPUESTO (Frambuesa 100 g de porción) } & Unidad & CANTIDAD \\
\hline Calorías & $\mathrm{Kcal}$ & 39 \\
Hidratos de carbono & $\mathrm{g}$ & 8 \\
Fibra & $\mathrm{g}$ & 7.4 \\
Potasio & $\mathrm{mg}$ & 220 \\
Magnesio & $\mathrm{mg}$ & 22 \\
Calcio & $\mathrm{mg}$ & 41 \\
Vitamina C & $\mathrm{mg}$ & 25 \\
Folatos & $\mathrm{mcg}$ & 45 \\
\hline
\end{tabular}

Fuente: Infoagro (2019)

Tabla 5.7

Tabla nutricional del arándano

\begin{tabular}{lcc}
\hline Compuesto (Arándano) & Unidad & Cantidad \\
\hline Calorías & $\mathrm{Kcal}$ & 41.68 \\
Carbohidratos & $\mathrm{G}$ & 6.05 \\
Grasas & $\mathrm{G}$ & 0.6 \\
Proteínas & $\mathrm{G}$ & 0.63 \\
Fibra & $\mathrm{G}$ & 4.9 \\
Colesterol & $\mathrm{Mg}$ & 0 \\
Sodio & $\mathrm{Mg}$ & 1 \\
Azúcares & $\mathrm{Gr}$ & 6.05 \\
Calcio & $\mathrm{Mg}$ & 10 \\
Hierro & $\mathrm{Gr}$ & 0.74 \\
Vitamina A & $\mathrm{Ug}$ & 5.7 \\
Cianocobalamina & $\mathrm{Ug}$ & 0 \\
Niacina & $\mathrm{Mg}$ & 0.09 \\
Ácido ascórbico & $\mathrm{Mg}$ & 22 \\
\hline Fuente: Infoagro (2019) & &
\end{tabular}




\section{Otros insumos:}

Estos deben cumplir ciertos requisitos de calidad:

Para el proceso de elaboración de chocolates se tomarán en cuenta los siguientes controles, identificando los puntos críticos de control por proceso, aplicando la metodología HACCP por medio del control de inocuidad del producto. 
Tabla 5.8

Análisis de puntos críticos

\begin{tabular}{|c|c|c|c|c|c|}
\hline $\begin{array}{l}\text { Etapas del } \\
\text { proceso }\end{array}$ & Peligro & $\begin{array}{l}\text { ¿Presenta } \\
\text { algún } \\
\text { peligro } \\
\text { significati } \\
\text { vo para la } \\
\text { seguridad } \\
\text { del } \\
\text { alimento? }\end{array}$ & Justificación de la decisión & Medios preventivos para aplicar & $\begin{array}{l}\text { ¿Representa } \\
\text { la etapa un } \\
\text { Punto } \\
\text { Crítico de } \\
\text { Control? }\end{array}$ \\
\hline Recepción & $\begin{array}{l}\text { Biológico: Toxicológico: } \\
\text { Aflatoxinas Ocratoxina } \\
\text { Cadmio. Otros: Arsénico y } \\
\text { plomo. } \\
\text { Físico: Presencia de sustancias } \\
\text { extrañas. }\end{array}$ & No & $\begin{array}{l}\text { Al grano de cacao se miden propiedades } \\
\text { físicas: humedad, tamaño de grano, materia } \\
\text { extraña, índice de fermentación, entre otros. Se } \\
\text { exigirá al proveedor la certificación de calidad que } \\
\text { cumplan con las especificaciones. }\end{array}$ & $\begin{array}{l}\text { Cumplir con la evaluación, selección y seguimiento } \\
\text { de proveedores calificados. Almacenar la materia } \\
\text { prima en silos diferentes para su buena conservación. }\end{array}$ & No \\
\hline $\begin{array}{l}\text { Almacenamien } \\
\text { to }\end{array}$ & $\begin{array}{l}\text { Físico: Infestación de plagas. } \\
\text { Heces de roedores. }\end{array}$ & $\mathrm{Si}$ & $\begin{array}{l}\text { Puede producirse crecimiento de mohos por malas } \\
\text { condiciones de almacenamiento, mal control de } \\
\text { temperatura y \% de humedad en almacén. }\end{array}$ & $\begin{array}{l}\text { Los insumos pasarán por un control de calidad, por } \\
\text { lo que de detectarse insumos en condiciones } \\
\text { inadecuadas serán devueltos al proveedor con una } \\
\text { penalidad. }\end{array}$ & No \\
\hline Pesado & $\begin{array}{l}\text { Biológico: Contaminación } \\
\text { microbiana. } \\
\text { Físico: Contaminación por el } \\
\text { contacto de residuos en la } \\
\text { balanza, por partículas } \\
\text { extrañas. }\end{array}$ & $\mathrm{Si}$ & $\begin{array}{l}\text { Si no se tiene la limpieza y el cuidado necesario } \\
\text { pueden resultar dañinos. Las materias primas e } \\
\text { insumos pueden contaminarse como consecuencia de } \\
\text { las malas prácticas de higiene. }\end{array}$ & $\begin{array}{l}\text { Uso de elementos de limpieza por parte del personal } \\
\text { y realizar una limpieza continua en el área de trabajo } \\
\text { (Balanza). Cumplir con el procedimiento de } \\
\text { limpieza, saneamiento, utensilios y accesorios de } \\
\text { producción. }\end{array}$ & No \\
\hline Tostado & $\begin{array}{l}\text { Biológico: Presencia de } \\
\text { Salmonella. }\end{array}$ & $\mathrm{Si}$ & $\begin{array}{l}\text { Si no se hace un correcto tostado la presencia de la } \\
\text { bacteria salmonelosis puede causar la infección de } \\
\text { salmonella. }\end{array}$ & $\begin{array}{l}\text { Realizar la inspección y los controles de temperatura } \\
\text { y humedad durante el proceso productivo. }\end{array}$ & $\mathrm{Si}$ \\
\hline Pelado & $\begin{array}{l}\text { Físico: Contaminación por } \\
\text { eliminación de cáscaras y } \\
\text { residuos sólidos a la salida del } \\
\text { proceso. }\end{array}$ & No & $\begin{array}{l}\text { Si no se realiza el descascarado adecuado del grano } \\
\text { seco estos podrían generar un cambio en el sabor de } \\
\text { la pasta de cacao. }\end{array}$ & $\begin{array}{l}\text { Cumplir con el proceso adecuado usando la malla } \\
\text { vibroscriba para tamizar de una manera óptima y } \\
\text { simultáneamente el uso del ciclón aspirador para } \\
\text { separar de manera eficiente las cascaras de la } \\
\text { almendra de cacao por densidad de aire. }\end{array}$ & No \\
\hline $\begin{array}{l}\text { Molido y } \\
\text { refinado }\end{array}$ & $\begin{array}{l}\text { Biológico: Contaminación } \\
\text { microbiana. }\end{array}$ & No & $\begin{array}{c}\text { Contaminación microbiana por mala limpieza de la } \\
\text { maquinaria. }\end{array}$ & $\begin{array}{c}\text { Realizar el plan de mantenimiento preventivo a la } \\
\text { máquina moledora }\end{array}$ & No \\
\hline
\end{tabular}




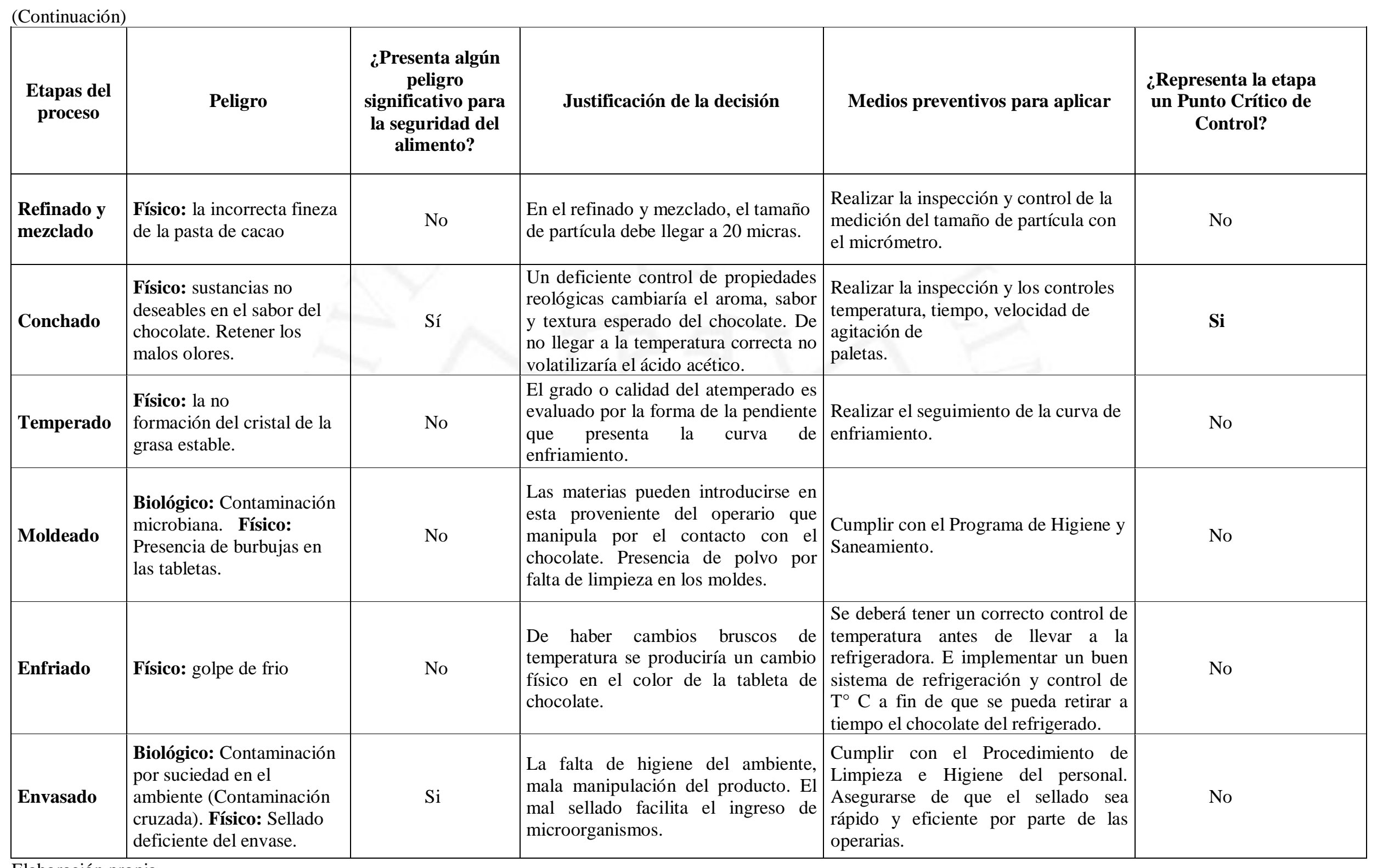

Elaboración propia 
Luego de identificar todos los puntos críticos de control se procedió a elaborar la matriz HACCP, como se aprecia a continuación:

Tabla 5.9

\section{Matriz HACCP}

\begin{tabular}{|c|c|c|c|c|c|c|c|c|c|}
\hline \multirow{2}{*}{$\begin{array}{l}\text { Puntos } \\
\text { críticos } \\
\text { de } \\
\text { Control }\end{array}$} & \multirow[b]{2}{*}{ Peligros significativos } & \multirow{2}{*}{$\begin{array}{c}\text { Límites } \\
\text { críticos para } \\
\text { cada medida } \\
\text { preventiva }\end{array}$} & \multicolumn{4}{|c|}{ Monitoreo } & \multirow[b]{2}{*}{$\begin{array}{l}\text { Acciones } \\
\text { correctoras }\end{array}$} & \multirow[b]{2}{*}{ Registros } & \multirow[b]{2}{*}{ Verificación } \\
\hline & & & Qué & Cómo & Frecuencia & Quién & & & \\
\hline Tostado & $\begin{array}{l}\text { Crecimiento bacteriano } \\
\text { por no alcanzar la } \\
\text { temperatura mínima } \\
\text { que desaparezca la } \\
\text { salmonella. } \\
\text { No culmina de } \\
\text { desarrollar los aromas } \\
\text { y } \\
\text { sabores propios del } \\
\text { cacao. }\end{array}$ & $\begin{array}{l}\text { Calibrar la } \\
\text { maquina } \\
\text { tostadora para } \\
\text { que alcance } \\
\mathrm{T}^{\circ}>70^{\circ} \mathrm{C} \text {. } \\
\mathrm{T}=<130^{\circ} \mathrm{C} \text { y } \\
\text { en un } \mathrm{t}=30 \\
\text { min-40min. }\end{array}$ & $\begin{array}{l}\text { Parámetros } \\
\text { de } \\
\text { temperatura, } \\
\text { tiempo y } \\
\text { control de } \\
\text { velocidad } \\
\text { de giro. }\end{array}$ & $\begin{array}{l}\text { Visualmente en } \\
\text { el panel de } \\
\text { control. Medir la } \\
\text { humedad del } \\
\text { grano al final del } \\
\text { proceso, una vez } \\
\text { frio. }\end{array}$ & $\begin{array}{l}\text { Al inicio y } \\
\text { al final del } \\
\text { molido }\end{array}$ & Operario 1. & $\begin{array}{l}\text { Tostar los granos } \\
\text { por un } \\
\text { determinado } \\
\text { tiempo hasta que } \\
\text { llegue a la } \\
\text { humedad } \\
\text { correcta y supere } \\
\text { la } \mathrm{T}^{\circ} \text { min. }\end{array}$ & $\begin{array}{l}\text { Registro de } \\
\text { control } \\
\text { curvas de } \\
\text { tostado. }\end{array}$ & $\begin{array}{l}\text { Verificar en cada } \\
\text { proceso }\end{array}$ \\
\hline Conchado & $\begin{array}{l}\text { Mantener sustancias no } \\
\text { deseables en el sabor y } \\
\text { olor del chocolate. } \\
\text { No contribuir a la } \\
\text { reducción del tamaño } \\
\text { de partícula } \\
\text { y los parámetros } \\
\text { reológicos. }\end{array}$ & $\begin{array}{l}\text { Calibrar la } \\
\text { maquina } \\
\text { conchadora }\end{array}$ & $\begin{array}{l}\text { Factores: } \\
\text { temperatura, } \\
\text { tiempo, } \\
\text { velocidad } \\
\text { de agitación } \\
\text { de } \\
\text { paletas. }\end{array}$ & $\begin{array}{l}\text { Verificar en el } \\
\text { panel de control. } \\
\text { Usar un } \\
\text { micrómetro para } \\
\text { medir el tamaño } \\
\text { de las partículas } \\
\text { del licor de } \\
\text { cacao. }\end{array}$ & $\begin{array}{l}\text { Al final de } \\
\text { la } \\
\text { operación. }\end{array}$ & Operario 2 & $\begin{array}{l}\text { Rechazar el licor } \\
\text { que no cumpla } \\
\text { con los } \\
\text { estándares } \\
\text { correctos. }\end{array}$ & $\begin{array}{l}\text { Calibración } \\
\text { de } \\
\text { instrumentos } \\
\text { y equipos. } \\
\text { Registros de } \\
\text { humedad y } \\
\text { temperatura. }\end{array}$ & $\begin{array}{l}\text { Verificar en cada } \\
\text { proceso. }\end{array}$ \\
\hline
\end{tabular}

Elaboración propia 


\subsection{Estudio de impacto ambiental}

Con la finalidad de medir el impacto y los efectos que puedan involucrar las actividades en toda la cadena de producción se procedió a elaborar la matriz de caracterización y la matriz Leopold, para evaluar el impacto cualitativamente que se genera al medio ambiente, permita identificar la magnitud de gravedad y controlar los posibles riesgos que estos puedan generar producto de las operaciones.

Antes de abordar la matriz de Leopold, primero se deben conocer los parámetros de valoración para la importancia y la magnitud del impacto. Se colocará signo (-) si el impacto es perjudicial y si es beneficioso (+).

Tabla 5.10

Parámetros de valoración de magnitud y valor

\begin{tabular}{|l|r|l|r|}
\hline \multicolumn{1}{|c|}{ Magnitud } & Valor & \multicolumn{1}{|c|}{ Importancia } & Valor \\
\hline Muy baja magnitud & 1 & Sin importancia & 1 \\
\hline Baja magnitud & 2 & Poco importante & 2 \\
\hline Mediana magnitud & 3 & Medianamente importante & 3 \\
\hline Alta magnitud & 4 & Importante & 4 \\
\hline Muy alta magnitud & 5 & Muy importante & 5 \\
\hline
\end{tabular}

Fuente: Leopold et al. (1971)

Elaboración propia

En cada intersección se debe realizar una evaluación de la magnitud y la importancia que tiene cada actividad en los diversos factores.

$$
\text { Intersección }=\frac{\text { Magnitud }(1-5)}{\text { Importancia }(1-5)}
$$

Los impactos potencialmente negativos se presentan en la etapa de construcción en los rubros de traslado de materiales de construcción, adecuación y construcción. En cuanto a la construcción y por el empleo de maquinaria para excavar, la cubierta del suelo se verá afectada y dependiendo de cuánto tiempo funcionará la planta, tras finalizar sus actividades está quedará inutilizable.

Pero si se sospesa también el impacto positivo, el proyecto es favorable pues logrará la conservación de la naturaleza y recolección de residuos porque la fabricación del chocolate será de forma natural. 
Por lo cual, el proyecto no afectará negativamente al medio ambiente, más bien protegerá las condiciones biológicas y factores culturales del ecosistema.

Tabla 5.11

Matriz de Leopold

\begin{tabular}{|c|c|c|c|c|c|c|c|c|c|c|c|c|c|}
\hline \multirow[b]{2}{*}{ Matriz de Leopold } & \multirow{2}{*}{$\begin{array}{c}\text { Acciones del } \\
\text { proyecto }\end{array}$} & \multicolumn{3}{|c|}{ Construcción } & \multicolumn{9}{|c|}{ Proceso del Chocolate } \\
\hline & & 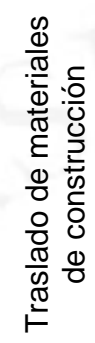 & 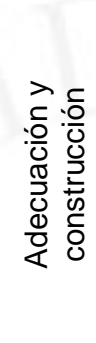 & 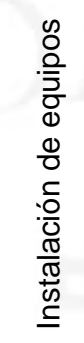 & $\begin{array}{l}\frac{0}{0} \\
\frac{\pi}{10} \\
\text { 0 }\end{array}$ & 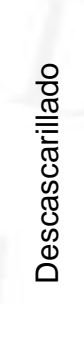 & 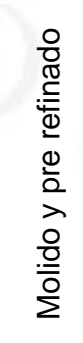 & 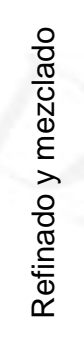 & $\begin{array}{l}\text { 음 } \\
\frac{0}{2} \\
\frac{c}{0} \\
\frac{0}{0}\end{array}$ & $\begin{array}{l}\frac{0}{0} \\
\frac{\pi}{\Phi} \\
\frac{0}{E} \\
\frac{1}{\oplus} \\
\vdash\end{array}$ & $\begin{array}{l}\frac{0}{0} \\
\frac{\mathbb{J}}{1} \\
\frac{0}{0} \\
\frac{0}{2}\end{array}$ & $\begin{array}{l}\frac{0}{0} \\
\frac{\pi}{0} \\
\frac{0}{0} \\
\frac{1}{0} \\
0 \\
0\end{array}$ & $\begin{array}{l}\frac{0}{0} \\
\frac{\pi}{\pi} \\
\frac{0}{0} \\
\frac{6}{0} \\
0 \\
\\
\frac{0}{0} \\
\frac{0}{0} \\
\frac{0}{0} \\
\frac{0}{E} \\
\frac{1}{4}\end{array}$ \\
\hline \multirow{3}{*}{$\begin{array}{c}\text { Características } \\
\text { físicas y } \\
\text { químicas }\end{array}$} & Agua & - & $-5 / 5$ & - & - & - & $-1 / 3$ & - & - & $-2 / 5$ & - & - & - \\
\hline & Aire & $-5 / 3$ & $-5 / 3$ & $-3 / 3$ & $-1 / 3$ & - & - & - & - & $-2 / 3$ & - & - & - \\
\hline & Suelos & $-5 / 5$ & $-5 / 5$ & $-5 / 5$ & $-3 / 5$ & $-3 / 5$ & $-3 / 5$ & $-3 / 5$ & $-3 / 5$ & $-2 / 5$ & $-1 / 5$ & $-2 / 5$ & $-5 / 5$ \\
\hline \multirow{2}{*}{$\begin{array}{c}\text { Condiciones } \\
\text { biológicas }\end{array}$} & Flora & $-3 / 3$ & $-3 / 3$ & & - & $-3 / 5$ & $-3 / 3$ & $-3 / 3$ & $-3 / 3$ & - & - & - & - \\
\hline & Fauna & $-3 / 3$ & $-3 / 3$ & - & - & - & - & - & - & - & - & - & - \\
\hline \multirow{2}{*}{$\begin{array}{l}\text { Características } \\
\text { socioeconómicas }\end{array}$} & $\begin{array}{l}\text { Salud } \\
\text { ocupacional }\end{array}$ & $-4 / 5$ & $-5 / 5$ & $-2 / 5$ & $-2 / 5$ & $-4 / 5$ & $-4 / 5$ & $-4 / 5$ & $-4 / 5$ & $-2 / 5$ & $-1 / 5$ & $-3 / 5$ & $-4 / 5$ \\
\hline & $\begin{array}{l}\text { Nivel de } \\
\text { empleo }\end{array}$ & $4 / 4$ & $5 / 4$ & $4 / 4$ & $3 / 4$ & $4 / 4$ & $4 / 4$ & $4 / 4$ & $4 / 4$ & $4 / 4$ & $1 / 4$ & $4 / 4$ & $4 / 4$ \\
\hline & & $-16 / 23$ & $-21 / 28$ & $-6 / 17$ & $-2 / 17$ & $-6 / 17$ & $-7 / 20$ & $-6 / 17$ & $-6 / 17$ & $-5 / 22$ & $-1 / 14$ & $-1 / 14$ & $-5 / 14$ \\
\hline
\end{tabular}

Fuente: Leopold et al. (1971)

Elaboración propia

Finalmente, se muestra la matriz de caracterización por cada una de las actividades que involucran el proceso productivo: 
Tabla 5.12

Matriz de caracterización por etapas

\begin{tabular}{|c|c|c|c|c|c|c|}
\hline ENTRADAS & PROCESO & SALIDAS & ASPECTO AMBIENTAL & IMPACTO AMBIENTAL & $\begin{array}{l}\text { MEDIO } \\
\text { AFECTADO }\end{array}$ & NORMAS AMBIENTALES \\
\hline \multirow{2}{*}{$\begin{array}{l}\text { Granos secos } \\
\text { de cacao }\end{array}$} & \multirow{2}{*}{$\begin{array}{l}\text { Recepción y } \\
\text { almacenami } \\
\text { ento de MP } \\
\text { e insumos }\end{array}$} & \multirow{2}{*}{$\begin{array}{l}\text { Granos } \\
\text { almacenados e } \\
\text { insumos en } \\
\text { silos. }\end{array}$} & \multirow{2}{*}{$\begin{array}{l}\text { * Emisión de gases por la } \\
\text { operación de vehículos. } \\
\text { *Tráfico y ruido de camiones. }\end{array}$} & \multirow{2}{*}{$\begin{array}{l}\text { *Contaminación del aire por } \\
\text { emisión de humos y gases de } \\
\text { combustión de motores. } \\
\text { Contaminación de suelos por } \\
\text { pérdidas de materia prima }\end{array}$} & \multirow{2}{*}{$\begin{array}{l}\text { *Aire } \\
* \text { Suelo }\end{array}$} & $\begin{array}{l}\text { * Ley General del Ambiente (Ley } \\
\text { 28611). }\end{array}$ \\
\hline & & & & & & $\begin{array}{l}\text { * Ley General de Residuos Sólidos } \\
\text { (Ley 27314). }\end{array}$ \\
\hline \multirow{3}{*}{ Granos secos } & \multirow{3}{*}{$\begin{array}{l}\text { descascarill } \\
\text { ado de } \\
\text { granos } \\
\text { secos }\end{array}$} & $\begin{array}{l}\text { Granos secos } \\
\text { pelados } \\
\text { (descascarado). }\end{array}$ & $\begin{array}{l}\text { *Residuos sólidos producto del } \\
\text { proceso de pelado (polvillo, otros } \\
\text { restos) }\end{array}$ & $\begin{array}{l}\text { *Contaminación de suelos por } \\
\text { los desechos de cáscaras. }\end{array}$ & *Suelo & $\begin{array}{l}\text { * Reglamento de } \\
\text { Nacionales de Calidad } \\
\text { para Ruido. }\end{array}$ \\
\hline & & $\begin{array}{ll}\text { Restos } & \text { de } \\
\text { cáscara } & \text { de } \\
\text { cacao. } & \\
\text { (Polvillo, } & \text { otros } \\
\text { restos.) } & \\
\end{array}$ & * Ruido y malos olores. & $\begin{array}{l}\text { *Estrés, contaminación } \\
\text { auditiva por ruido elevado. }\end{array}$ & $\begin{array}{l}\text { *Poblaciones } \\
\text { aledañas }\end{array}$ & \multirow[t]{2}{*}{ *Estándares de calidad para suelo. } \\
\hline & & & *Consumo de energía eléctrica & \begin{tabular}{|lll}
$\begin{array}{l}\text { *Escasez } \\
\text { energéticos }\end{array}$ & de & recursos \\
\end{tabular} & \begin{tabular}{|l}
$*$ Trabajadores \\
(seguridad y salud)
\end{tabular} & \\
\hline $\begin{array}{l}\text { Pasta } \\
\text { cacao }\end{array}$ & Refinado & $\begin{array}{l}\text { Pasta. Restos } \\
\text { de pasta } \\
\text { adheridas a la } \\
\text { refinadora. }\end{array}$ & $\begin{array}{l}\text { *Generación de residuos sólidos } \\
\text { (restos de pasta,). } \\
\text { *Consumo de energía eléctrica. } \\
\text { *Generación de efluentes por la } \\
\text { limpieza y mantenimiento de la } \\
\text { máquina. }\end{array}$ & $\begin{array}{l}\text { *Agotamiento del recurso } \\
\text { hídrico y energético. } \\
\text { *Contaminación del agua por } \\
\text { los efluentes generados de la } \\
\text { limpieza y mantenimiento de la } \\
\text { refinadora. }\end{array}$ & $\begin{array}{l}\text { *Recurso hídrico } \\
\text { *Energía } \\
\text { * Factor humano }\end{array}$ & $\begin{array}{l}\text { * Ley General del Ambiente. } \\
\text { *Ley General de Residuos Sólidos } \\
\text { (Ley 27314). } \\
\text { *Estándares Nacionales de Calidad } \\
\text { Ambiental de agua. }\end{array}$ \\
\hline $\begin{array}{l}\text { Tabletas de } \\
\text { chocolate }\end{array}$ & $\begin{array}{l}\text { Desmoldad } \\
\text { o }\end{array}$ & $\begin{array}{l}\text { Tabletas listas } \\
\text { para empacar. }\end{array}$ & $\begin{array}{l}\text { *Cansancio por adoptar malas } \\
\text { posturas, actividad repetitiva. }\end{array}$ & $\begin{array}{lccc}\text { *Molestias y estrés para el } & \text { el } \\
\text { personal que realiza } & \text { la } \\
\text { actividad. } & & & \\
& & & \end{array}$ & *Factor humano & $\begin{array}{l}\text { *Ley de Seguridad y Salud en el } \\
\text { Trabajo (29783), Reglamento de la } \\
\text { Ley de Seguridad y Salud en el } \\
\text { Trabajo. }\end{array}$ \\
\hline
\end{tabular}

(Continúa) 


\begin{tabular}{|c|c|c|c|c|c|c|}
\hline ENTRADAS & PROCESO & SALIDAS & ASPECTO AMBIENTAL & $\begin{array}{c}\text { IMPACTO } \\
\text { AMBIENTAL }\end{array}$ & $\begin{array}{c}\text { MEDIO } \\
\text { AFECTADO }\end{array}$ & NORMAS AMBIENTALES \\
\hline \multirow{2}{*}{$\begin{array}{l}\text { Bolsas, etiquetas, } \\
\text { tabletas de } \\
\text { chocolate }\end{array}$} & \multirow{2}{*}{ Envasado } & \multirow{2}{*}{$\begin{array}{l}\text { tabletas } \\
\text { empacadas }\end{array}$} & \multirow{2}{*}{$\begin{array}{l}\text { *Generación de residuos } \\
\text { sólidos (cajas, etiquetas, } \\
\text { bolsas) y productos no } \\
\text { conformes. }\end{array}$} & \multirow{2}{*}{$\begin{array}{l}\text { *Contaminación de } \\
\text { suelos por los } \\
\text { desperdicios sólidos. }\end{array}$} & * Suelo & *Ley General de Residuos Sólidos. \\
\hline & & & & & $\begin{array}{l}* \text { Factor } \\
\text { humano }\end{array}$ & * Estándares de calidad para suelo. \\
\hline \multirow{3}{*}{$\begin{array}{l}\text { Producto } \\
\text { empacado }\end{array}$} & \multirow{3}{*}{ Almacenamiento } & \multirow{3}{*}{$\begin{array}{l}\text { Producto } \\
\text { empacado y } \\
\text { almacenado }\end{array}$} & $\begin{array}{l}\text { *Generación de desperdicios } \\
\text { sólidos. }\end{array}$ & $\begin{array}{l}\text { *Contaminación de } \\
\text { suelos. }\end{array}$ & *Suelo & * Ley General de Residuos Sólidos. \\
\hline & & & \multirow{2}{*}{$\begin{array}{l}\text { *Tránsito continúo de } \\
\text { carritos, equipos móviles. } \\
\text { Traslado de productos } \\
\text { (Recepción, entrega y } \\
\text { despacho). }\end{array}$} & \multirow{2}{*}{$\begin{array}{l}\text { *Ruido y estrés } \\
\text { ocasionado r por } \\
\text { movimiento y traslado } \\
\text { de productos en } \\
\text { bandejas, carritos, etc. }\end{array}$} & \multirow{2}{*}{$\begin{array}{l}\text { *Factor } \\
\text { humano }\end{array}$} & * Procedimiento de manejo de residuos sólidos. \\
\hline & & & & & & * Políticas de Reciclaje. \\
\hline $\begin{array}{l}\text { Tabletas } \\
\text { empacadas, } \\
\text { camiones y } \\
\text { combustible }\end{array}$ & $\begin{array}{lr}\text { Transporte } & \mathrm{y} \\
\text { distribución } & \mathrm{de} \\
\text { galletas } & \end{array}$ & $\begin{array}{l}\text { Galletas } \\
\text { empacadas } \\
\text { para venta }\end{array}$ & 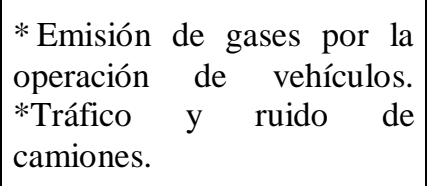 & $\begin{array}{l}\text { * Ruido y estrés por } \\
\text { tráfico. }\end{array}$ & $*$ Aire & $\begin{array}{l}\text { * Límites Máximos Permisibles de Emisiones } \\
\text { Contaminantes para Vehículos Automotores. }\end{array}$ \\
\hline
\end{tabular}

Elaboración propia 


\subsection{Seguridad y Salud ocupacional}

La empresa tiene un importante compromiso para salvaguardar la seguridad y salud de todos sus trabajadores, proveedores y clientes a través de la prevención de riesgos laborales, por lo que será necesario identificar todos los posibles riesgos que pueda originar daños. Una vez identificados, se tomarán las medidas necesarias de prevención mediante la práctica de mejoras, controles, etc. Para la implementación de salud y seguridad en los recintos de la planta será necesario acatar la ley $\mathrm{N}^{\circ} 29783$, en la cual la empresa debe garantizar a sus colaboradores las condiciones óptimas que protejan la vida, salud y bienestar propio, así mismo también de aquellos que prestan servicio a la empresa.

Para cumplir con todos los requisitos será necesario establecer, documentar, implementar y mejorar continuamente el sistema de gestión de seguridad y salud ocupacional.

Por otro lado, la empresa contará con señalizaciones en el área operativa y administrativa, además de ambientes seguros, bien iluminados, acondicionados y bien equipados (extintores), y se fomentará el uso obligatorio de implementos de seguridad, EPPS.

A continuación, procedemos a realizar una matriz que permita identificar los posibles peligros y riesgos por proceso: 
Tabla 5.13

Matriz IPERC

\begin{tabular}{|c|c|c|c|}
\hline Proceso & Peligro & Riesgo & Control \\
\hline $\begin{array}{l}\text { Recepción y } \\
\text { almacenamiento } \\
\text { de MP e } \\
\text { insumos }\end{array}$ & *Objetos pesados & $\begin{array}{l}\text { *Riesgo disergonómico. } \\
\text { Sobreesfuerzo por carga }\end{array}$ & $\begin{array}{l}\text { * Realizar la carga de los costales de } \\
\text { cacao con peso mayor a los } 50 \\
\text { kilogramos por lo menos con dos } \\
\text { trabajadores o mediante un } \\
\text { montacargas manual. Uso de EPP } \\
\text { calzado ocupacional. }\end{array}$ \\
\hline Tostado & $\begin{array}{l}\text { *Equipos en } \\
\text { movimiento } \\
\text { *Trabajo desnivel. }\end{array}$ & $\begin{array}{l}\text { *Atrapamiento } \\
\text { *Caída al momento del } \\
\text { llenado a la tolva } \\
\text { alimentadora }\end{array}$ & $\begin{array}{l}\text { *Colocar guardas de seguridad. Botón } \\
\text { de paro automático. } \\
\text { Uso de EPP: guantes, calzado } \\
\text { ocupacional, casco contra impacto. }\end{array}$ \\
\hline Descascarillado & $\begin{array}{l}\text { *Partículas } \\
\text { pequeñas } \\
\text { *Trabajo desnivel. }\end{array}$ & $\begin{array}{l}\text { *Exposición a respirar el } \\
\text { polvillo generado en el } \\
\text { proceso. } \\
\text { *Caída al momento del } \\
\text { llenado a la tolva } \\
\text { alimentadora }\end{array}$ & $\begin{array}{l}\text { *Mantener una buena ventilación del } \\
\text { área de trabajo. } \\
\text { Uso de EPP: mascarilla, calzado } \\
\text { ocupacional, casco contra impacto }\end{array}$ \\
\hline $\begin{array}{l}\text { Molido y } \\
\text { prerefinado }\end{array}$ & *Ruidos & *Exposición al ruido. & $\begin{array}{l}\text { *Proveer de EPPs al personal } \\
\text { (mascarillas y tapones auditivos). }\end{array}$ \\
\hline $\begin{array}{l}\text { Refinado y } \\
\text { conchado }\end{array}$ & $\begin{array}{l}\text { *Pasta de cacao } \\
\text { liquido }\end{array}$ & *Quemaduras. & *Uso de EPPs: guantes, mandil. \\
\hline Temperado & $\begin{array}{l}\text { *Pasta de cacao } \\
\text { liquido }\end{array}$ & *Quemaduras. & *Uso de EPPs: guantes, mandil. \\
\hline Moldeado & *Charola & *Riesgo disergonómico & *Pausas activas. \\
\hline Enfriado & $\begin{array}{l}* \text { Aire de } \\
\text { refrigerador. } \\
* \text { Superficie de } \\
\text { trabajo }\end{array}$ & $\begin{array}{l}\text { *Exposición al aire frío. } \\
\text { Caída al mismo nivel. }\end{array}$ & $\begin{array}{l}\text { *Uso de. EPPs: guantes, mascarilla, } \\
\text { mandil. }\end{array}$ \\
\hline Envasado & $\begin{array}{l}\text { *Postura } \\
\text { inadecuada }\end{array}$ & $\begin{array}{l}\text { *Riesgo disergonómico } \\
\text { por postura inadecuada }\end{array}$ & *Descansos periódicos. \\
\hline
\end{tabular}

Elaboración propia

Tabla 5.14

Criterio de evaluación de riesgos

\begin{tabular}{|c|l|c|c|c|c|c|c|}
\hline \multicolumn{2}{|c|}{ RIESGOS } & A & B & C & D & E & F \\
\cline { 3 - 8 } & $\begin{array}{c}\text { Frecuent } \\
\text { e }\end{array}$ & Probable & Ocasional & $\begin{array}{c}\text { Remot } \\
\text { o }\end{array}$ & Improbable & $\begin{array}{c}\text { Imposibl } \\
\text { e }\end{array}$ \\
\hline I & Catastrófico & 1 & $\begin{array}{c}\text { Riesgo alto } \\
2\end{array}$ & 4 & 7 & 11 & 15 \\
\hline II & Daño permanente & 3 & 5 & Riesgo medio 8 & 12 & 16 & 19 \\
\hline III & Daño temporal & 6 & 9 & 13 & 17 & Riesgo bajo 20 & 22 \\
\hline IV & Daño menor & 10 & 14 & 18 & 21 & 23 & 24 \\
\hline
\end{tabular}

Fuente: Portal calidad (2017) 
Tabla 5.15

Identificación de impactos por proceso

\begin{tabular}{|c|c|c|c|c|c|c|}
\hline Etapa & $\begin{array}{c}\text { Peligros } \\
\text { identificados }\end{array}$ & Causa & $\begin{array}{l}\text { Probab } \\
\text { ilidad }\end{array}$ & $\begin{array}{l}\text { Seve } \\
\text { ridad }\end{array}$ & $\begin{array}{l}\text { Puntua } \\
\text { ción }\end{array}$ & $\begin{array}{c}\text { ¿Se considera un peligro } \\
\text { significativo? }\end{array}$ \\
\hline $\begin{array}{l}\text { Recepción y } \\
\text { almacenamiento } \\
\text { de MP e insumos }\end{array}$ & $\begin{array}{l}\text { *Objetos } \\
\text { pesados }\end{array}$ & $\begin{array}{l}\text { *Riesgo } \\
\text { disergonómico. } \\
\text { Sobreesfuerzo } \\
\text { por carga }\end{array}$ & $\mathrm{C}$ & III & 13 & $\begin{array}{l}\text { El riesgo es bajo. No } \\
\text { representa un peligro } \\
\text { significativo }\end{array}$ \\
\hline \multirow{2}{*}{ Tostado } & $\begin{array}{l}\text { *Equipos en } \\
\text { movimiento }\end{array}$ & *Atrapamiento & B & II & 5 & $\begin{array}{l}\text { El riesgo es alto. } \\
\text { Representa un peligro } \\
\text { significativo, pero es } \\
\text { controlado. }\end{array}$ \\
\hline & $\begin{array}{l}* \text { Trabajo } \\
\text { desnivel. }\end{array}$ & $\begin{array}{l}\text { *Caída al } \\
\text { momento del } \\
\text { llenado a la tolva } \\
\text { alimentadora }\end{array}$ & $\mathrm{C}$ & III & 13 & $\begin{array}{l}\text { El riesgo es bajo. No } \\
\text { representa un peligro } \\
\text { significativo }\end{array}$ \\
\hline \multirow{2}{*}{ Descascarillado } & $\begin{array}{l}\text { *Partícula } \\
\text { pequeñas }\end{array}$ & $\begin{array}{l}\text { *Exposición a } \\
\text { respirar el } \\
\text { polvillo generado } \\
\text { en el proceso. }\end{array}$ & B & III & 9 & $\begin{array}{l}\text { El riesgo es medio. No } \\
\text { representa un peligro } \\
\text { significativo }\end{array}$ \\
\hline & $\begin{array}{l}\text { *Trabajo a } \\
\text { desnivel. }\end{array}$ & $\begin{array}{l}\text { *Caída al } \\
\text { momento del } \\
\text { llenado a la tolva } \\
\text { alimentadora }\end{array}$ & $\mathrm{C}$ & III & 13 & $\begin{array}{l}\text { El riesgo es bajo. No } \\
\text { representa un peligro } \\
\text { significativo }\end{array}$ \\
\hline $\begin{array}{l}\text { Molido y } \\
\text { prerefinado }\end{array}$ & *Ruidos & $\begin{array}{l}\text { *Exposición al } \\
\text { ruido. }\end{array}$ & B & III & 9 & $\begin{array}{l}\text { El riesgo es medio. No } \\
\text { representa un peligro } \\
\text { significativo }\end{array}$ \\
\hline $\begin{array}{l}\text { Refinado y } \\
\text { conchado }\end{array}$ & $\begin{array}{l}\text { *Pasta de } \\
\text { cacao liquido }\end{array}$ & *Quemaduras. & B & III & 9 & $\begin{array}{l}\text { El riesgo es medio. No } \\
\text { representa un peligro } \\
\text { significativo }\end{array}$ \\
\hline Temperado & $\begin{array}{l}\text { *Pasta de } \\
\text { cacao liquido }\end{array}$ & *Quemaduras. & B & III & 9 & $\begin{array}{l}\text { El riesgo es medio. No } \\
\text { representa un peligro } \\
\text { significativo }\end{array}$ \\
\hline Moldeado & *Charola & $\begin{array}{l}\text { *Riesgo } \\
\text { disergonómico }\end{array}$ & $\mathrm{C}$ & III & 13 & $\begin{array}{l}\text { El riesgo es bajo. No } \\
\text { representa un peligro } \\
\text { significativo }\end{array}$ \\
\hline \multirow{2}{*}{ Enfriado } & $\begin{array}{l}* \text { Aire de } \\
\text { refrigerador. }\end{array}$ & $\begin{array}{l}\text { *Exposición al } \\
\text { aire frio. }\end{array}$ & B & III & 9 & $\begin{array}{l}\text { El riesgo es medio. No } \\
\text { representa un peligro } \\
\text { significativo }\end{array}$ \\
\hline & $\begin{array}{l}* \text { Superficie } \\
\text { de trabajo }\end{array}$ & $\begin{array}{l}\text { *Caída al mismo } \\
\text { nivel. }\end{array}$ & $\mathrm{C}$ & III & 13 & $\begin{array}{l}\text { El riesgo es bajo. No } \\
\text { representa un peligro } \\
\text { significativo }\end{array}$ \\
\hline Envasado & $\begin{array}{l}\text { *Postura } \\
\text { inadecuada }\end{array}$ & $\begin{array}{l}\text { *Riesgo } \\
\text { disergonómico } \\
\text { por postura } \\
\text { inadecuada }\end{array}$ & $\mathrm{C}$ & III & 13 & $\begin{array}{l}\text { El riesgo es bajo. No } \\
\text { representa un peligro } \\
\text { significativo }\end{array}$ \\
\hline
\end{tabular}

Elaboración propia 


\subsection{Sistema de mantenimiento}

El mantenimiento es un eje fundamental en una empresa industrial puesto que garantiza el funcionamiento continuo de la maquinaria dentro de la planta industrial y está cuantificado en la productividad y calidad de la producción.

\section{Mantenimiento reactivo}

Es el conjunto de tareas destinadas a corregir los defectos que se van presentando en los distintos equipos y que son comunicados al departamento de mantenimiento por los usuarios de estos. Este modelo es el más básico, e incluye, además de las inspecciones visuales y la lubricación mencionadas anteriormente, la reparación de averías que surjan. Es aplicable, como veremos, a equipos con el más bajo nivel de criticidad, cuyas averías no suponen ningún problema, ni económico ni técnico. En el presupuesto se considera el $10 \%$ del mantenimiento programado.

\section{Mantenimiento autónomo}

Consiste principalmente en la prevención del deterioro de los equipos y sus componentes. Este tipo de mantenimiento será realizado por los operarios de esta manera se contribuirá considerablemente la eficacia del equipo. Esto se llevará a cabo con:

- Capacitación técnica.

- Limpieza diaria, como proceso de inspección.

- Lubricación periódica de los puntos claves de equipo.

- Inspección de los puntos clave del equipo en búsqueda de fugas, fuentes de contaminación, exceso o defecto de lubricación, etc.

- Pequeños ajustes.

- Reportar todas las fallas que no se puedan reparar en el momento de detección y programarlas.

\section{Mantenimiento preventivo}

Para que la empresa pueda operar de forma eficiente es fundamental que las máquinas se encuentren en buen estado y en operatividad constantemente, por ello a inicios de cada año se elaborará el Plan de Mantenimiento Preventivo para todas las máquinas, sin excepción, con el fin de lograr una mayor disposición de ellas y aumentar la calidad de los productos por la menor cantidad de productos defectuosos que puedan obtenerse en comparación de si hubiese fallas. 


\section{Estrategia de Mantenimiento:}

- Planificación de las revisiones.

- Programa de revisiones.

- Registro y documentación técnica.

- Control de repuestos.

A continuación, se presentará el programa de mantenimiento preventivo para cada equipo, se realizarán con la capacitación brindada por el proveedor, la empresa: Cultura Mecánica; ya que cabe resaltar que las máquinas con las que trabajaremos pertenecen a una gama considerablemente alta, cuentan con dispositivos que anticipan fallas en el proceso productivo. De esta manera se necesitará apoyarse en el conocimiento de la maquina en base a la experiencia y a los históricos obtenidos de las mismas.

\section{Tabla 5.16}

Tabla de mantenimientos programados

\begin{tabular}{|c|c|c|}
\hline Equipos & Mantenimiento recomendado & Frecuencia \\
\hline Balanza & Requiere calibración y tara & Diario \\
\hline Tostadora & Inspección y limpieza & Semanal \\
\hline Descascarilladora & Inspección, limpieza & Semanal \\
\hline Moledora & Inspección, limpieza & Semanal \\
\hline Refinadora & Inspección, limpieza & Semanal \\
\hline Conchadora & Inspección, limpieza & Semanal \\
\hline Temperadora & Inspección, limpieza & Diario \\
\hline
\end{tabular}

\section{Tabla 5.17}

Tabla de mantenimientos programados para complementos de las máquinas.

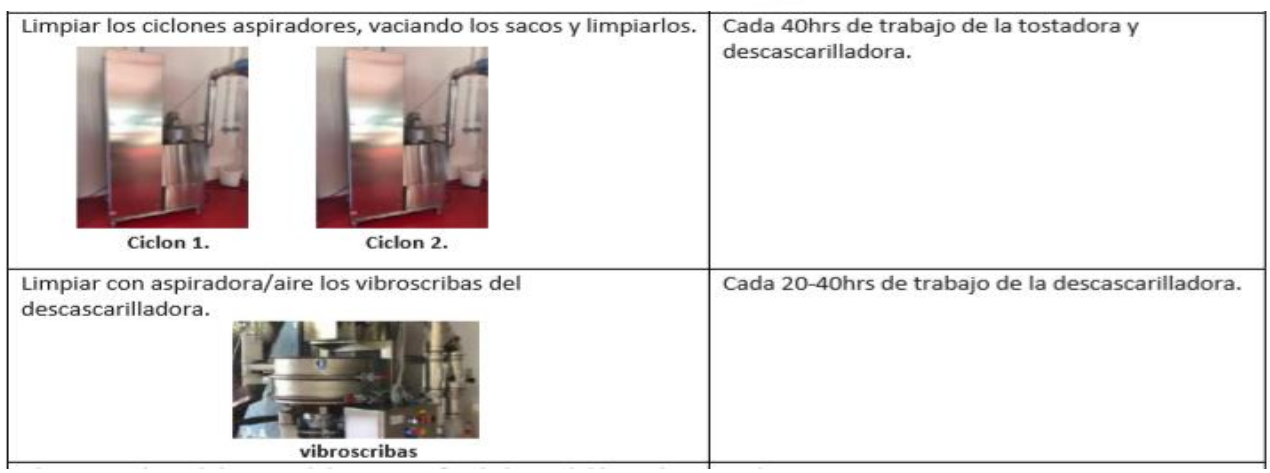

Fuente: Ideo Técnica Srl (2019) 


\subsection{Diseño de la cadena de suministro}

"Make to orden", es el proceso de fabricación que se tomará en cuenta para el presente proyecto, debido a que es un producto de consumo masivo. Este proceso inicia con la fabricación solo después de recibir el pedido del cliente. Después de recibir los pedidos del cliente comienza la operación de la cadena de suministro, la cual se lleva a cabo cuando se confirma la demanda, por eso se dice que se tira por la demanda.

Figura 5.13

Diseño de cadena de suministro

PROVEEDORES

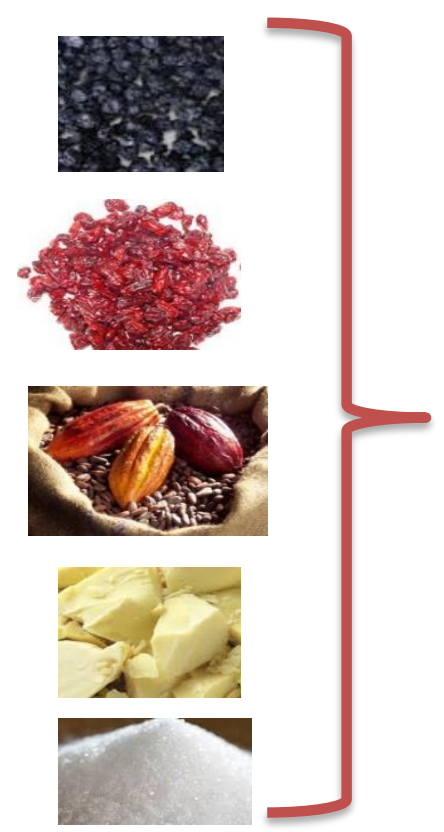

Elaboración propia

\section{FÁBRICA}

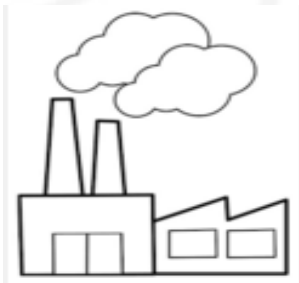

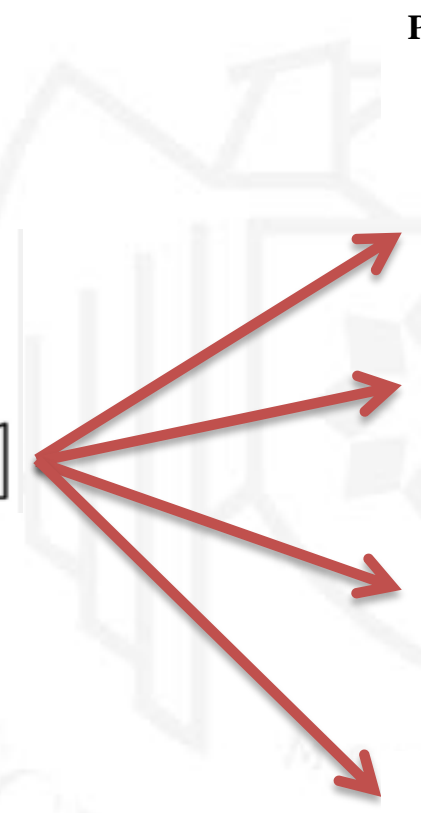

PUNTOS DE VENTA

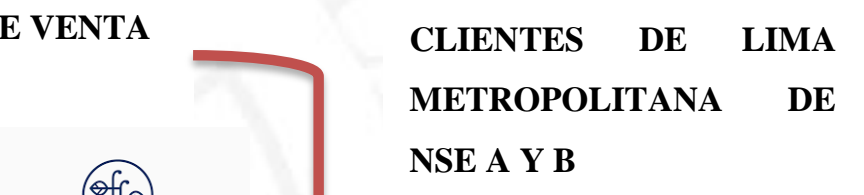

NSE A Y B

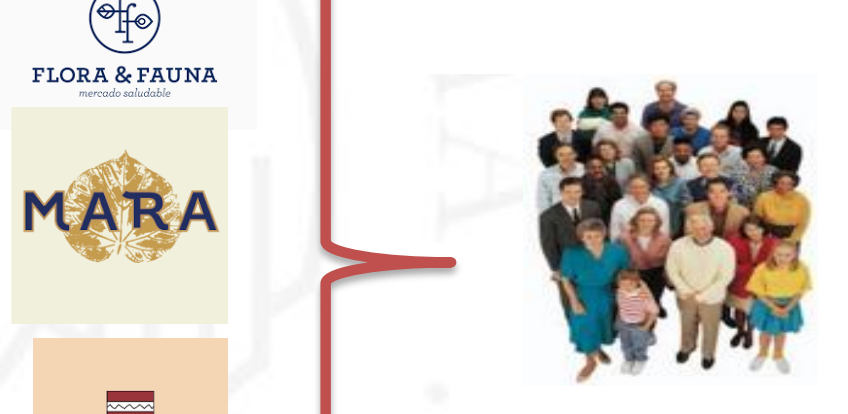




\subsection{Programa de producción}

Para el cálculo del programa de producción anual se consideró la demanda proyectada mensual multiplicado por el ratio de 0.17 meses, obtenido por política de inventarios, según el siguiente criterio:

Mantenimiento $=3$ días

Lead Time $=1$ día

Stock de Seguridad = 1 día.

Tabla 5.18

Plan de producción anual de chocolates

\begin{tabular}{lccccc}
\hline & $\mathbf{2 0 2 0}$ & $\mathbf{2 0 2 1}$ & $\mathbf{2 0 2 2}$ & $\mathbf{2 0 2 3}$ & $\mathbf{2 0 2 4}$ \\
\hline I. Inicial & 0 & 6534 & 7351 & 8215 & 9127 \\
Demanda & 425820 & 461200 & 518880 & 579900 & 644240 \\
I. Final & 6534 & 7351 & 8215 & 9127 & 9917 \\
\hline $\begin{array}{l}\text { Producción Final de } \\
\text { barras de chocolate. }\end{array}$ & 432354 & 462017 & 519744 & 580811 & 645030 \\
\hline Elaboración propia & & & & &
\end{tabular}

\subsection{Requerimiento de insumos, servicios y personal indirecto}

\subsubsection{Materia prima, insumos y otros materiales}

Según el balance de materia podemos obtener la siguiente relación entre materia prima y producto terminado, esto nos permite calcular los requerimientos por insumo.

El siguiente diagrama se conoce como diagrama de Gozinto y muestra las cantidades de suministros que se necesita para producir una barra de chocolate Premium.

Figura 5.14

Diagrama de Gozinto de una barra de chocolate premium con fruto deshidratado

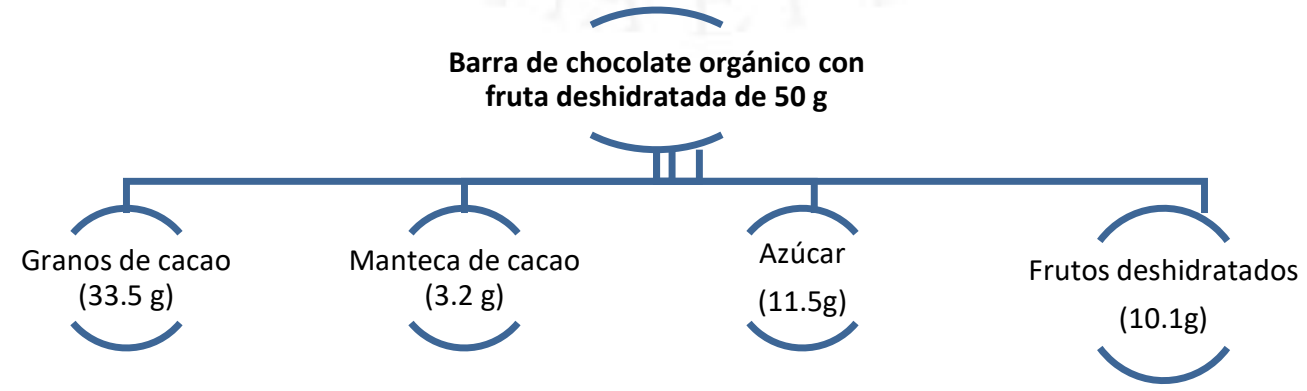

Elaboración propia 
Para obtener el Plan de materiales primero debemos definir las necesidades brutas (NB) de cada uno de los insumos con ayuda de la proporción del diagrama de gozinto y según el plan maestro de producto terminado, se determina la necesidad bruta para cada insumo.

$$
N . \text { neta }=\text { Saldo final }- \text { Saldo inicial }+N . \text { bruta }
$$

Para la obtención de Inventarios Finales se considera un stock de seguridad diferente para cada insumo con la siguiente formula. Se considera un $\mathrm{Z}=1.65$

$$
\begin{gathered}
S S=Z * \sigma t \\
\sigma t=\sqrt{\sigma^{2} * L T+\sigma l t^{2} * d^{2}}
\end{gathered}
$$

Datos:

SS: stock de seguridad

$\sigma t$ : Desviación estándar total

$\sigma$ : Desviación estándar de la demanda

LT: lead time

$\sigma l t:$ desviación estándar de Lead time

d: promedio de demanda

$$
\begin{gathered}
\text { Iprom }=\frac{Q}{2}+S S \\
Q=\sqrt{\frac{2 * D * S}{i * c}} \\
S S=Z * \sigma t \\
\sigma t=\sqrt{\sigma^{2} * L T+\sigma l t^{2} * d^{2}}
\end{gathered}
$$

Finalmente, se obtiene las cantidades requeridas de cada insumo se calculadas en los siguientes cuadros:

\section{Tabla 5.19}

Plan de materiales de cacao $(\mathrm{Kg})$

\begin{tabular}{|c|c|c|c|c|c|}
\hline Cacao & 2020 & 2021 & 2022 & 2023 & 2024 \\
\hline Necesidad Bruta & $14,511.88$ & $15,507.51$ & $17,416.11$ & $19,494.85$ & $21,650.31$ \\
\hline Q & 629 & 655 & 694 & 734 & 774 \\
\hline IF & 1,167 & 1,180 & 1,200 & 1,219 & 1,239 \\
\hline P.M & 15,679 & 15,520 & 17,436 & 19,515 & 21,670 \\
\hline
\end{tabular}

Elaboración propia 
Tabla 5.20

Inventario promedio cacao $(\mathrm{Kg})$

\begin{tabular}{|l|l|l|l|l|r|}
\hline Cacao & 2020 & 2021 & 2022 & 2023 & 2024 \\
\hline Inv. Prom & 1,167 & 1,180 & 1,200 & 1,219 & 1,239 \\
\hline
\end{tabular}

Elaboración propia

Tabla 5.21

Plan de materiales de manteca de cacao $(\mathrm{Kg})$

\begin{tabular}{|c|c|c|c|c|c|}
\hline Manteca & 2020 & 2021 & 2022 & 2023 & 2024 \\
\hline $\begin{array}{c}\text { Necesidad } \\
\text { Bruta }\end{array}$ & 1,419 & 1,516 & 1,703 & 1,906 & 2,117 \\
\hline Q & 112 & 116 & 123 & 130 & 137 \\
\hline IF & 145.6 & 147.9 & 151.4 & 154.9 & 158.5 \\
\hline P.M & $1,564.3$ & $1,518.3$ & $1,706.2$ & $1,909.4$ & $2,120.1$ \\
\hline
\end{tabular}

Elaboración propia

Tabla 5.22

Inventario promedio manteca $(\mathrm{Kg})$

\begin{tabular}{|l|l|l|l|l|l|}
\hline Manteca & 2020 & 2021 & 2022 & 2023 & 2024 \\
\hline Inv. Prom & 1,167 & 1,180 & 1,200 & 1,219 & 1,239 \\
\hline
\end{tabular}

Elaboración propia

Tabla 5.23

Plan de materiales de azúcar $(\mathrm{Kg})$

\begin{tabular}{|c|c|c|c|c|c|}
\hline Azúcar & 2020 & 2021 & 2022 & 2023 & 2024 \\
\hline Necesidad Bruta & 4,966 & 5,306 & 5,959 & 6,671 & 7,408 \\
\hline Q & 745 & 776 & 823 & 870 & 917 \\
\hline IF & 672 & 687 & 710 & 734 & 757 \\
\hline P.M & 5,637 & 5,321 & 5,983 & 6,694 & 7,432 \\
\hline
\end{tabular}

Elaboración propia

Tabla 5.24

Inventario promedio azúcar $(\mathrm{Kg})$

\begin{tabular}{|l|l|l|l|l|l|}
\hline Azúcar & 2020 & 2021 & 2022 & 2023 & 2024 \\
\hline Inv. Prom & 672 & 687 & 710 & 734 & 757 \\
\hline
\end{tabular}

Elaboración propia

Tabla 5.25

Plan de materiales de fruta deshidratada $(\mathrm{Kg})$

\begin{tabular}{|c|c|c|c|c|c|}
\hline $\begin{array}{c}\text { fruta } \\
\text { deshidratada }\end{array}$ & 2020 & 2021 & 2022 & 2023 & 2024 \\
\hline $\begin{array}{c}\text { Necesidad } \\
\text { Bruta }\end{array}$ & 4,389 & 4,690 & 5,268 & 5,896 & 6,548 \\
\hline Q & 135 & 140 & 149 & 157 & 166 \\
\hline IF & 322 & 324 & 329 & 333 & 337 \\
\hline P.M & 4,711 & 4,693 & 5,272 & 5,901 & 6,552 \\
\hline
\end{tabular}

Elaboración propia 
Tabla 5.26

Inventario fruta deshidratada $(\mathrm{Kg})$

\begin{tabular}{|l|l|l|l|l|l|}
\hline $\begin{array}{l}\text { fruta } \\
\text { deshidratada }\end{array}$ & 2020 & 2021 & 2022 & 2023 & 2024 \\
\hline Inv. Prom & 322 & 324 & 329 & 333 & 337 \\
\hline
\end{tabular}

Elaboración propia

Tabla V.27

Plan de materiales de insumos $(\mathrm{kg})$

\begin{tabular}{|l|l|l|l|l|l|}
\hline \multicolumn{1}{|c|}{ Plan de Materiales } & 2020 & 2021 & 2022 & 2023 & 2024 \\
\hline Cacao & 15,679 & 15,520 & 17,436 & 19,515 & 21,670 \\
\hline Manteca & 1,564 & 1,518 & 1,706 & 1,909 & 21,654 \\
\hline Azúcar & 5,637 & 5,321 & 5,983 & 6,694 & 7,432 \\
\hline fruta deshidratada & 4,711 & 4,693 & 5,272 & 5,901 & 6,552 \\
\hline
\end{tabular}

Elaboración propia

Es en este punto también se calcula el tamaño de almacén de materia prima y materiales mediante la fórmula de inventario promedio. Se elige el mayor valor de los inventarios promedios de los años de vida útil del proyecto. A continuación, las cantidades en $\mathrm{kg}$ requeridos para cada uno de los materiales.

Tabla V.28

Inventario promedio de cada material $(\mathrm{Kg})$

\begin{tabular}{|l|r|}
\cline { 2 - 2 } \multicolumn{1}{c|}{} & Inv. Promedio \\
\hline Cacao & 1,239 \\
\hline manteca & 158 \\
\hline Azúcar & 757 \\
\hline fruta deshidratada & 337 \\
\hline
\end{tabular}

Elaboración propia

\subsubsection{Servicios: energía eléctrica, agua, vapor, combustible, etc.}

\section{Energía eléctrica}

La energía eléctrica será brindada por luz del sur la cual es la empresa que corresponde a la zona de Pachacámac. Para el cálculo de requerimiento de energía se tomará en cuenta, tiempo de uso y potencia de los equipos industriales y los de oficina. 
Tabla 5.29

Consumo anual de energía eléctrica para máquinas de producción (S/.)

\begin{tabular}{|c|c|c|c|c|c|c|}
\hline Máquinas & $\begin{array}{l}\text { Potencia de la } \\
\text { máquina (KW) }\end{array}$ & 2020 & 2021 & 2022 & 2023 & 2024 \\
\hline \multicolumn{2}{|c|}{ horas/año } & 290 & 310 & 348 & 390 & 432 \\
\hline $\begin{array}{l}\text { Tostador }+ \\
\text { Ciclon }\left(^{*}\right)\end{array}$ & 22.2 & 6,455 & 6,898 & 7,747 & 8,671 & 9,618 \\
\hline \multicolumn{2}{|c|}{ horas/año } & 367 & 393 & 441 & 494 & 547 \\
\hline $\begin{array}{l}\text { Descascarillador } \\
+ \text { Ciclon }\left(^{\star}\right)\end{array}$ & 7.0 & 2,572 & 2,748 & 3,086 & 3,455 & 3,832 \\
\hline \multicolumn{2}{|c|}{ horas/año } & 232 & 247 & 278 & 311 & 345 \\
\hline \begin{tabular}{l|}
\multicolumn{1}{c|}{ Molino } \\
Prerefinador \\
MOD MAC5
\end{tabular} & 7.0 & 1,621 & 1,732 & 1,946 & 2,178 & 2,416 \\
\hline \multicolumn{2}{|c|}{ horas/año } & 887 & 948 & 1,064 & 1,191 & 1,321 \\
\hline $\begin{array}{c}\text { Refinador Sfera } \\
\text { 20R } \\
\end{array}$ & 6.3 & 5,542 & 5,922 & 6,651 & 7,445 & 8,258 \\
\hline \multicolumn{2}{|c|}{ horas/año } & 478 & 510 & 573 & 642 & 712 \\
\hline $\begin{array}{c}\text { Conchadora } \\
\text { CR150 }\end{array}$ & 5.0 & 2,388 & 2,552 & 2,866 & 3,209 & 3,559 \\
\hline \multicolumn{2}{|c|}{ horas/año } & 549 & 586 & 658 & 737 & 818 \\
\hline Temperador $\left(^{*}\right)$ & 6.7 & 3,698 & 3,952 & 4,438 & 4,968 & 5,510 \\
\hline \multicolumn{2}{|c|}{ horas/año } & 22,276 & 23,804 & 26,734 & 29,925 & 33,193 \\
\hline freezer & 0.741 & 4,591 & 4,906 & 5,510 & 6,168 & 6,841 \\
\hline \multicolumn{2}{|c|}{ Consumo de energía en KW-h/año } & 26,867 & 28,710 & 32,244 & 36,092 & 40,034 \\
\hline \multicolumn{2}{|c|}{$\begin{array}{l}\text { S/. Total }\left({ }^{*} 0.206 \mathrm{~S} / . / \mathrm{KW}-\mathrm{h}\right) \\
{ }^{*} \text { incluye compresor } 6 \text { bar }\end{array}$} & 5,537 & 5,917 & 6,645 & 7,439 & 8,251 \\
\hline
\end{tabular}

Fuente: Luz del Sur (2019)

Elaboración propia

Tabla 5.30

Consumo de energía eléctrica para uso administrativo y producción

\begin{tabular}{|c|c|c|c|c|c|c|c|c|}
\hline Equipos & horas/año & Kw /h & Cant. & S/. Kw & 2020 & 2022 & 2023 & 2024 \\
\hline $\begin{array}{l}\text { Aire } \\
\text { acondicionado } \\
\text { para Adm } \\
\end{array}$ & 800 & 0.3 & 1 & 0.206 & 49.46 & S/49.46 & $\mathrm{S} / 49.46$ & $\mathrm{~S} / 49.46$ \\
\hline $\begin{array}{l}\text { Aire } \\
\text { acondicionado } \\
\text { para Planta } \\
\end{array}$ & 800 & 1.5 & 1 & 0.206 & 247.32 & $\mathrm{~S} / 247.32$ & $\mathrm{~S} / 247.32$ & $\mathrm{~S} / 247.32$ \\
\hline Calefacción & 800 & 2 & 1 & 0.206 & 329.76 & $\mathrm{~S} / 329.76$ & $\mathrm{~S} / 329.76$ & $\mathrm{~S} / 329.76$ \\
\hline Fluorescentes & 2,338 & 0.032 & 17 & 0.206 & 262.13 & $\mathrm{~S} / 262.13$ & $\mathrm{~S} / 262.13$ & $\mathrm{~S} / 262.13$ \\
\hline $\begin{array}{l}\text { Focos (A. de } \\
\text { producción) }\end{array}$ & 2,338 & 0.024 & 11 & 0.206 & 127.21 & S/127.21 & $\mathrm{S} / 127.21$ & $\mathrm{~S} / 127.21$ \\
\hline $\begin{array}{l}\text { Focos (A. } \\
\text { administrativa) }\end{array}$ & 2,338 & 0.024 & 2 & 0.206 & 23.13 & $\mathrm{~S} / 23.13$ & $\mathrm{~S} / 23.13$ & $\mathrm{~S} / 23.13$ \\
\hline Microondas & 300 & 1 & 1 & 0.206 & 61.83 & $\mathrm{~S} / 61.83$ & S/61.83 & S/61.83 \\
\hline Laptop & 2,078 & 0.4 & 2 & 0.206 & 342.62 & $S / 342.62$ & $\mathrm{~S} / 342.62$ & $\mathrm{~S} / 342.62$ \\
\hline Proyector & 48 & 0.18 & 1 & 0.206 & 1.78 & $\mathrm{~S} / 1.78$ & $\mathrm{~S} / 1.78$ & $\mathrm{~S} / 1.78$ \\
\hline Computadoras & 2,078 & 0.5 & 11 & 0.206 & 2355.52 & $\mathrm{~S} / 2,355.52$ & $\mathrm{~S} / 2,355.52$ & $\mathrm{~S} / 2,355.52$ \\
\hline Red telefónica & 2,078 & 0.03 & 1 & 0.206 & 12.85 & $\mathrm{~S} / 12.85$ & $\mathrm{~S} / 12.85$ & $\mathrm{~S} / 12.85$ \\
\hline $\begin{array}{l}\text { Impresora } \\
\text { multifuncional }\end{array}$ & 900 & 0.5 & 1 & 0.206 & 92.75 & $\mathrm{~S} / 92.75$ & $\mathrm{~S} / 92.75$ & $\mathrm{~S} / 92.75$ \\
\hline $\begin{array}{l}\text { Total del } \\
\text { consumo s/. } \\
\text { Año }\end{array}$ & & & & & S/3,906.36 & S/3,906.36 & S/3,906.36 & S/3,906.36 \\
\hline
\end{tabular}

Fuente: Luz del Sur (2019)

Elaboración propia 


\section{Agua}

El agua se abastecerá por medio de Sedapal, el cual irá destinado a los servicios higiénicos, consumo humano y máquinas.

Tabla 5.31

Consumo de agua potable para uso administrativo y producción

\begin{tabular}{lccccccc}
\hline Área & $\begin{array}{c}\text { m3/mes- } \\
\text { persona }\end{array}$ & $\begin{array}{c}\mathbf{N}^{\circ} \\
\text { personas }\end{array}$ & $\mathbf{2 0 2 0}$ & $\mathbf{2 0 2 1}$ & $\mathbf{2 0 2 2}$ & $\mathbf{2 0 2 3}$ & $\mathbf{2 0 2 4}$ \\
\hline Producción & 3.48 & 6 & 1443.2 & 1443.2 & 1443.2 & 1443.2 & 1443.2 \\
Administración & 3.48 & 11 & 2645.9 & 2645.9 & 2645.9 & 2645.9 & 2645.9 \\
\hline Total & & $\mathbf{1 7}$ & $\mathbf{4 0 8 9 . 1}$ & $\mathbf{4 0 8 9 . 1}$ & $\mathbf{4 0 8 9 . 1}$ & $\mathbf{4 0 8 9 . 1}$ & $\mathbf{4 0 8 9 . 1}$ \\
\hline $\begin{array}{l}\text { Fuente: Sedapal (2019) } \\
\text { Elaboración propia }\end{array}$ & & & & & &
\end{tabular}

\subsubsection{Determinación del número de trabajadores indirectos}

Esta facción, la constituirá el personal administrativo que contribuirá con la gestión de la empresa. La siguiente tabla, presenta el número detallado de personal indirecto requerido para el funcionamiento de la empresa:

Tabla 5.32

Cargos de trabajadores indirectos

\begin{tabular}{lc}
\hline Cargos & $\begin{array}{c}\mathbf{N}^{\circ} \\
\text { Trabajadores }\end{array}$ \\
\hline Jefe de Planta & 1 \\
Asistente de calidad & 1 \\
\hline Elaboración propia &
\end{tabular}

\subsubsection{Servicios de terceros}

La empresa si contratará los servicios de algunos terceros para el desarrollo de sus actividades, como, por ejemplo, la vigilancia y el personal de limpieza. La empresa adquirirá servicios de limpieza para la planta y un servicio de vigilancia particular, el cual se encargará de cuidar la planta las 24 horas del día, además de llevar el control de ingresos y salidas de la planta, los cuales serán reportados al personal de la empresa. 
Tabla 5.33

Lista de trabajadores externos

\begin{tabular}{cc}
\hline Función & $\mathbf{N}^{\circ}$ trabajadores externos \\
\hline Limpieza & 2 \\
Seguridad & 2 \\
Community manager & 1 \\
Mantenimiento & 1 \\
Contador & 1 \\
Total & 7 \\
\hline
\end{tabular}

Elaboración propia

El servicio de mantenimiento se realizará con un técnico capacitado por el proveedor Cultura Mecánica. Especialistas en máquinas de producción cacao y chocolates Import - export - automatización - soporte técnico; quienes se encargarán de capacitar a los operarios encargados de la producción para cumplir la programación de mantenimiento. Para casos más puntuales, se contratará al soporte técnico de la empresa proveedora.

En cuanto al servicio de telefonía e internet, será importante para un adecuado manejo de las actividades administrativas, para ello se contará con un servicio de telefonía fija ilimitada de la empresa Telefónica del Perú. Además, se contratará con Internet de la misma empresa quien brinda un servicio diseñado especialmente para cada organización.

\subsection{Disposición de planta}

\subsubsection{Características físicas del proyecto}

\section{Factor edificio}

En principio se buscará el arrendamiento de una planta de producción que cumpla con los requerimientos básicos impuestos por el Reglamento Nacional de Edificaciones. Pachacamac al tener zona industrial, tiene cierta disponibilidad inmuebles en alquiler de este tipo. Para la adecuación e implementación se consideran los siguientes puntos:

- La planta estará diseñada y armada de un sólo piso. Las ventajas son las siguientes: fácil recepción de luz y ventilación natural, mayor flexibilidad de espacios libres, menores costos de manejo de materiales y fácil movimiento de equipo. La altura será de 3 metros desde el nivel el piso.

- Vías de acceso y salida: las vías y medios de circulación estarán situados y determinados de tal modo que los operarios y medios de acarreo puedan utilizarlos de forma fácil y segura. 
- Desagües y alcantarillado: se localizará en una zona alejada de las zonas críticas como la de producción con el fin de evitar contaminación.

- Las áreas de almacenamiento deberán contar con las condiciones adecuadas libre de contaminación. Además, se considerará un almacén de productos terminados requiriendo a la vez las condiciones adecuadas para mantener el producto antes de su distribución o almacenamiento temporal. Las paredes y pisos deberán ser de fácil limpieza y de superficie lisa, esto de acuerdo con las Buenas Prácticas de Almacenamiento - BPA.

- Pasadizos: se calculará en base al número potencial de usuarios considerando que el ancho mínimo será de $90 \mathrm{~cm}$. A la vez dependiendo de su ubicación en producción o áreas administrativas, se diseñarán recto o con esquinas.

- Baños: Se considerará dos baños ubicados en la zona de producción como en las áreas administrativas.

\section{Factor servicio}

Se considera servicio a otras actividades que dan apoyo a actividades de procesos, de máquinas, de personal e incluso a personas externas de planta. Los cuales requieren de espacios físicos.

Según recomienda la National Standard Plumbing Code que las plantas industriales tengan 01 inodoro por cada 10 personas. Para la zona productiva se considera 1 baño para mujeres y varones; para la zona administrativa se consideran 1 baño, de igual manera.

Además de ello, se considerará un área de vestuarios donde los operarios se podrán vestir correctamente antes de ingresar al área de producción. También se considerará un comedor con un horno microondas exclusivo para los trabajadores de la empresa para atender los servicios de alimentación.

La planta tendrá instalación de aire acondicionado para la zona productiva y administrativa de manera que permita la comodidad de los empleados y la conservación a temperaturas adecuadas para para mantener los insumos, productos intermedios $\mathrm{y}$ productos terminados en buen estado.

Como medidas de protección contra incendios: se colocarán señales de escape en caso de incendios y de ubicación de los extintores. Asimismo, capacitación del personal en el uso de estos. Respecto a los materiales; se controlará la calidad de este a través de pruebas en el laboratorio de calidad. Finalmente, se trabajará con una empresa dedicada a la limpieza de las diferentes áreas del edificio. 


\subsubsection{Determinación de las zonas físicas requeridas}

- Almacén de materia prima. En esta zona se realizará la recepción de la materia prima como son los granos de cacao, manteca de cacao, el azúcar, los frutos deshidratados por parte de los proveedores. Para el cálculo de números de parihuelas a necesitar se obtuvo mediante cálculos previos en el plan de materiales punto 5.10. Según la cantidad de inventarios promedio se encuentra que se necesita $17 \mathrm{~m}^{2}$ en total para esta zona.

- En caso de los granos de cacao se considerarán 5 niveles y 2 sacos de $50 \mathrm{~kg}$ por nivel; por lo tanto, se requieren 3 palets.

- En el caso de los sacos de azúcar se considerarán 5 niveles y 2 sacos por nivel de $50 \mathrm{~kg}$ por nivel; en consecuencia, se requiere 2 palet.

- Para la manteca se considerarán 5 niveles y 8 cajas de $10 \mathrm{~kg}$ por nivel; en consecuencia, se requiere 1 palet.

- Para las frutas deshidratadas se considerarán 5 niveles y 8 cajas de $10 \mathrm{~kg}$ por nivel; en consecuencia, se requiere 1 palet. En total se calculó 7 parihuelas. Además de ello, se considerará una holgura entre parihuelas de $0.1 \mathrm{~m}$ y un diseño volumétrico.

- Zona de producción, se encontrarán las distintas máquinas dedicadas al proceso productivo, las mismas que contarán con medidas de seguridad para su correcta operación y control de temperatura. De esta manera, se preservará la calidad e integridad del producto y de los operarios. En la cual se encontrarán los equipos de producción de chocolate.

- Almacén de productos terminados Se acopiarán las cajas de productos terminados y también servirá para hacer los despachos. Sus dimensiones se calcularán tomando en cuenta un inventario de 5 días. Contará con aire acondicionado para conservar en correctas condiciones a las barras de chocolate.

- Según el plan maestro de producción se calculó un total de 5 parihuelas para el almacenamiento de producto terminado. Con un total de $12 \mathrm{~m}^{2}$.

- La zona administrativa: es donde se ubicará el personal administrativo quienes contarán con escritorios y computadoras para cada uno de los 18 puestos descritos en el organigrama. 
- Se consideran 2 servicios higiénicos en toda la planta. Lo cuales; 1 de ellos destinados para los trabajadores de la zona productiva por la cercanía y el otro, en la zona administrativa.

- Vestuario y baño: $10 \mathrm{~m}^{2}$

- Sala de reunión: $15 \mathrm{~m}^{2}$

- Comedor: $15 \mathrm{~m}^{2}$

- Vigilancia: $5 \mathrm{~m}^{2}$

- Recepción: 7 m²

\subsubsection{Cálculo de áreas para cada zona}

Para el cálculo de la zona de producción se realizó un análisis Guerchet.

Tabla 5.34

Cálculo de Guerchet

\begin{tabular}{|c|c|c|c|c|c|c|c|c|c|c|c|c|c|}
\hline Elementos & Máquinas & $\mathbf{L}$ & $\mathbf{A}$ & h & $\mathbf{N}$ & $\mathbf{N}$ & Ss & Sg & Se & St & $\begin{array}{l}\text { Ss } \times n \\
\times \mathbf{h}\end{array}$ & Ss $\times \mathrm{n}$ & $\begin{array}{c}\text { Anál } \\
\text { isis } \\
\text { del } \\
30 \%\end{array}$ \\
\hline \multirow{9}{*}{ Estáticos } & Balanza & 1.50 & 1.00 & 1.50 & 1.00 & 1.00 & 1.50 & 1.50 & 1.45 & 4.45 & 2.25 & 1.50 & \\
\hline & Tostadora & 2.00 & 1.49 & 2.57 & 1.00 & 1.00 & 2.98 & 2.98 & 2.88 & 8.84 & 7.66 & 2.98 & \\
\hline & Descascarilladora & 2.50 & 1.56 & 2.70 & 2.00 & 1.00 & 3.90 & 3.90 & 3.77 & 11.57 & 10.53 & 3.90 & \\
\hline & Molino & 1.00 & 6.00 & 1.50 & 1.00 & 1.00 & 6.00 & 6.00 & 5.80 & 17.80 & 9.00 & 6.00 & \\
\hline & Refinador & 0.84 & 0.72 & 1.61 & 2.00 & 1.00 & 0.60 & 0.60 & 0.58 & 1.78 & 0.97 & 0.60 & \\
\hline & Conchadora & 1.20 & 0.60 & 1.25 & 2.00 & 1.00 & 0.72 & 0.72 & 0.70 & 2.14 & 0.90 & 0.72 & \\
\hline & Temperadora & 0.76 & 0.58 & 1.53 & 1.00 & 1.00 & 0.44 & 0.44 & 0.43 & 1.31 & 0.67 & 0.44 & \\
\hline & $\begin{array}{l}\text { Punto de espera } \\
\text { tostadora }\end{array}$ & 0.92 & 0.60 & 0.86 & & 1.00 & 0.55 & 0.55 & 0.53 & 1.64 & & & $19 \%$ \\
\hline & $\begin{array}{l}\text { Punto de espera } \\
\text { descascarilladora }\end{array}$ & 0.92 & 0.60 & 0.86 & & 2.00 & 0.55 & & 0.27 & 0.82 & 0.95 & 1.10 & $37 \%$ \\
\hline \multirow{3}{*}{ Móviles } & Operarios & & & 1.65 & & 6.00 & 0.50 & & & & 4.95 & 3.00 & \\
\hline & Carretillas & 1.4 & 1.2 & 1.45 & & 1.00 & 1.68 & & & & 2.44 & 1.68 & \\
\hline & Carritos & 0.65 & 0.45 & 3.71 & & 3.00 & 0.29 & & & & 3.25 & 0.88 & \\
\hline
\end{tabular}

Elaboración propia

Tabla 5.35

Calculo de valor de " $k=0.48$ "

\begin{tabular}{lrcc}
\hline Hee & 31.98 & 16.14 & 1.98 \\
Hem & 10.64 & 5.56 & 1.91 \\
\hline & & & \\
\cline { 1 - 1 } Largo & 10.03 & & \\
\multicolumn{2}{l}{ Ancho } & 5.02 \\
Elaboración propia & &
\end{tabular}

Área total: $50.33 \mathrm{~m}$ 


\subsubsection{Dispositivos de seguridad industrial y señalización}

La empresa tiene como política interna de trabajo el uso elementos de protección, dispositivos industriales con el fin de evitar o reducir daños mayores, tales como se muestran a continuación:

- Señalizaciones a la entrada y salida del área de producción y en área administrativa (que sean de fácil acceso y visibles en paredes)

- Uso de extintores (Clasificados por tipo de material combustible)

- Cintas amarillas que limiten al personal sobrepasar ciertas zonas de trabajo

- Señalizaciones en caso de sismos o desastres naturales (Símbolos verdes)

- Señalizaciones que indiquen el uso obligatorio de EPPs, herramientas, etc.

- Señalizaciones de zonas restringidas y de fácil acceso solo a personal autorizado, de prohibición o de peligro.

- Señalizaciones en la máquina que forman parte de las maquinas desempeñan una función de advertencia y prevención de riesgos residuales que no podrían haberse evitado en el diseño y la construcción de la máquina.

Figura 5.15

Señalizaciones en las máquinas

\begin{tabular}{|l|l|}
\hline SIMBOL & DESCRIPCION \\
\hline 4 & PELIGRO DE VOLTAJE \\
\hline OO & PELIGRO COMPONENTES EN FUNCIONAMIENTO \\
\hline
\end{tabular}

Fuente: Ideo Técnica Srl (2019)

Figura 5.16

Señalizaciones de salvamento o de auxilio
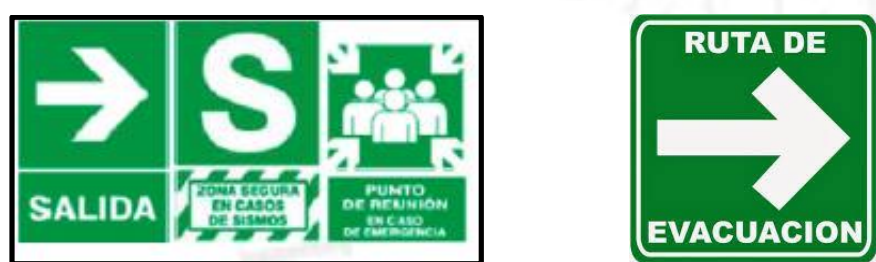

Fuente: Google (2019) 
Figura 5.17

Señales de prohibiciones, peligros
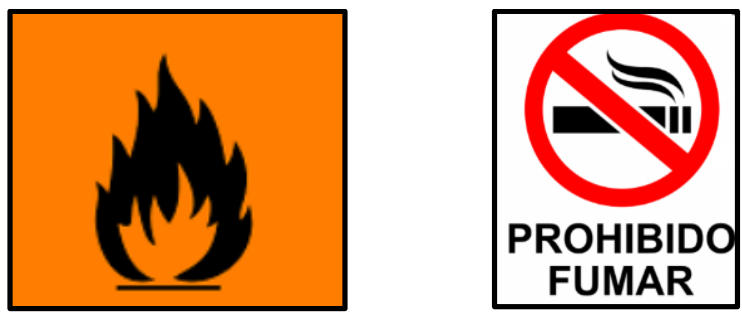

Fuente: Google (2019)

Figura 5.18

Señalización de uso obligatorio de EPP

USO OBLIGATORIO DE EQUIPO

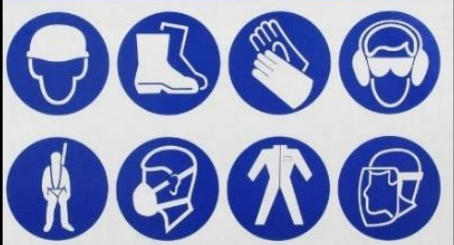

Fuente: Google (2019)

\subsubsection{Disposición de detalle de la zona productiva}

Para una mejor comprensión de la zona productiva se realizó un análisis relacional que consiste en desarrollar la tabla relacional y el diagrama relacional de espacios.

\section{Tabla relacional}

Lista de objetivos:

1. Flujo de proceso

2. Servicio a producción

3. Higiene de alimentos

4. Comodidad personal

Tabla 5.36

Códigos de proximidades para el diagrama relacional

\begin{tabular}{llll}
\hline Código & Proximidad & Color & N. $^{\circ}$ Líneas \\
\hline A & Absolutamente necesario & Rojo & 4 rectas \\
E & Especialmente importante & Amarillo & 3 rectas \\
I & Importante & Verde & 2 rectas \\
O & Normal & Azul & 1 recta \\
U & Sin importancia & - & - \\
X & No deseable & Plomo & 1 zig-zag \\
XX & Altamente deseable & Plomo & 2 zig-zag \\
\hline
\end{tabular}

Elaboración propia 
Considerando los códigos de proximidades como las señales que distinguen a cada área definida en la planta se a continuación la relación de la ubicación de las áreas con los motivos mencionados previamente.

Figura 5.19

Diagrama relacional de actividades

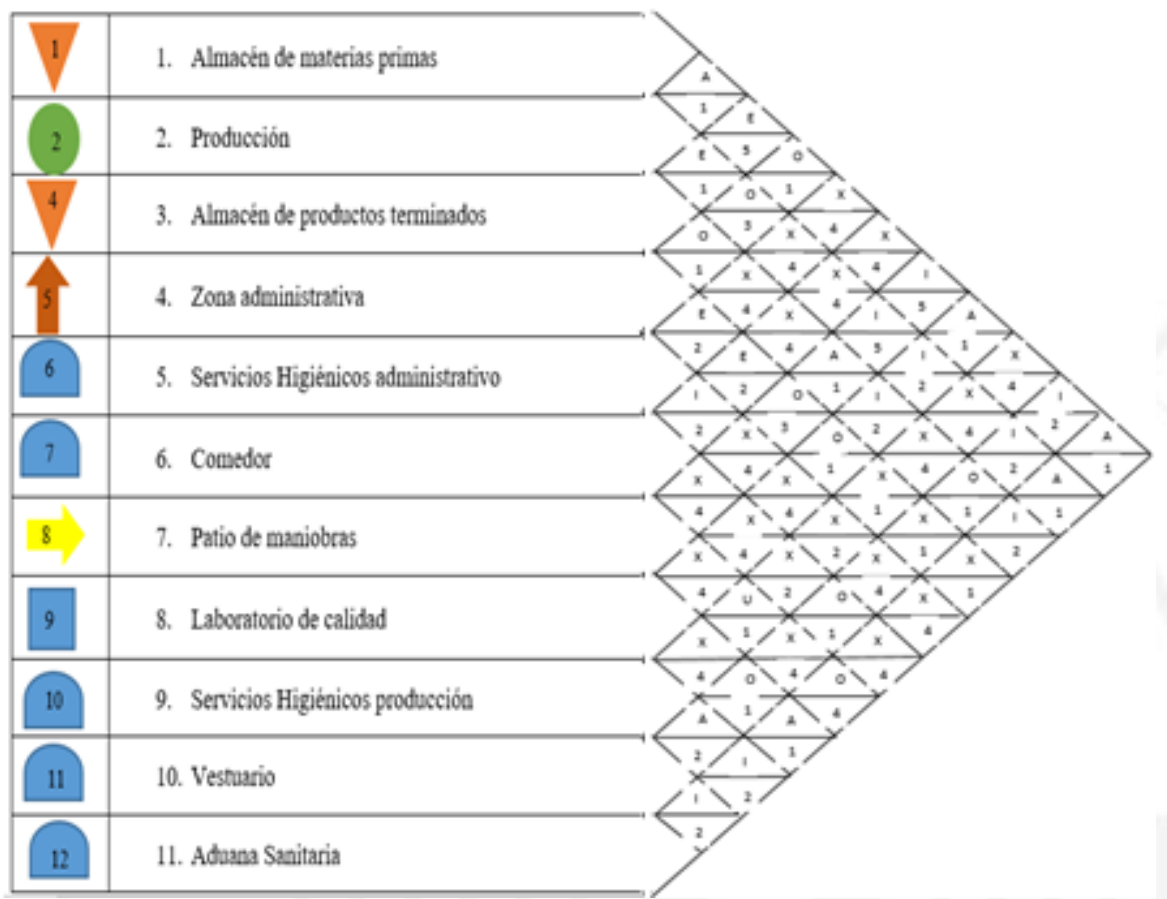

Elaboración propia

Figura 5.20

Diagrama Relacional
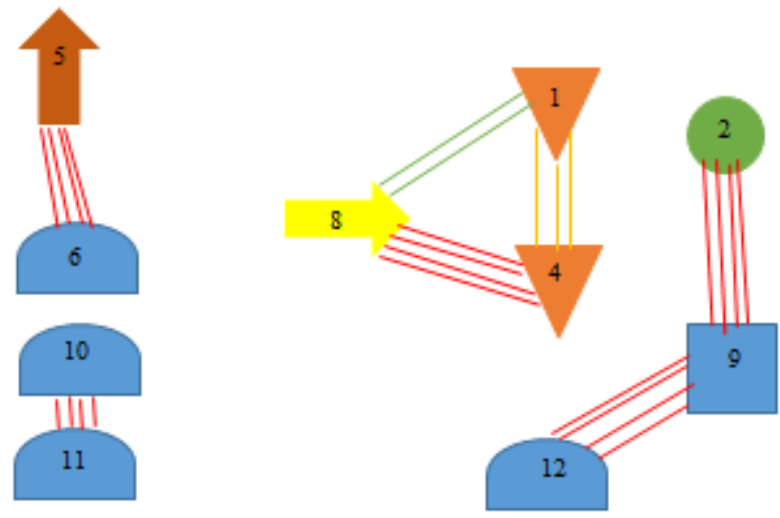

Elaboración propia 


\subsubsection{Disposición general}

En el siguiente plano se muestra la disposición general de la planta procesadora de chocolate orgánico premium.

Figura 5.21

Plano de Planta

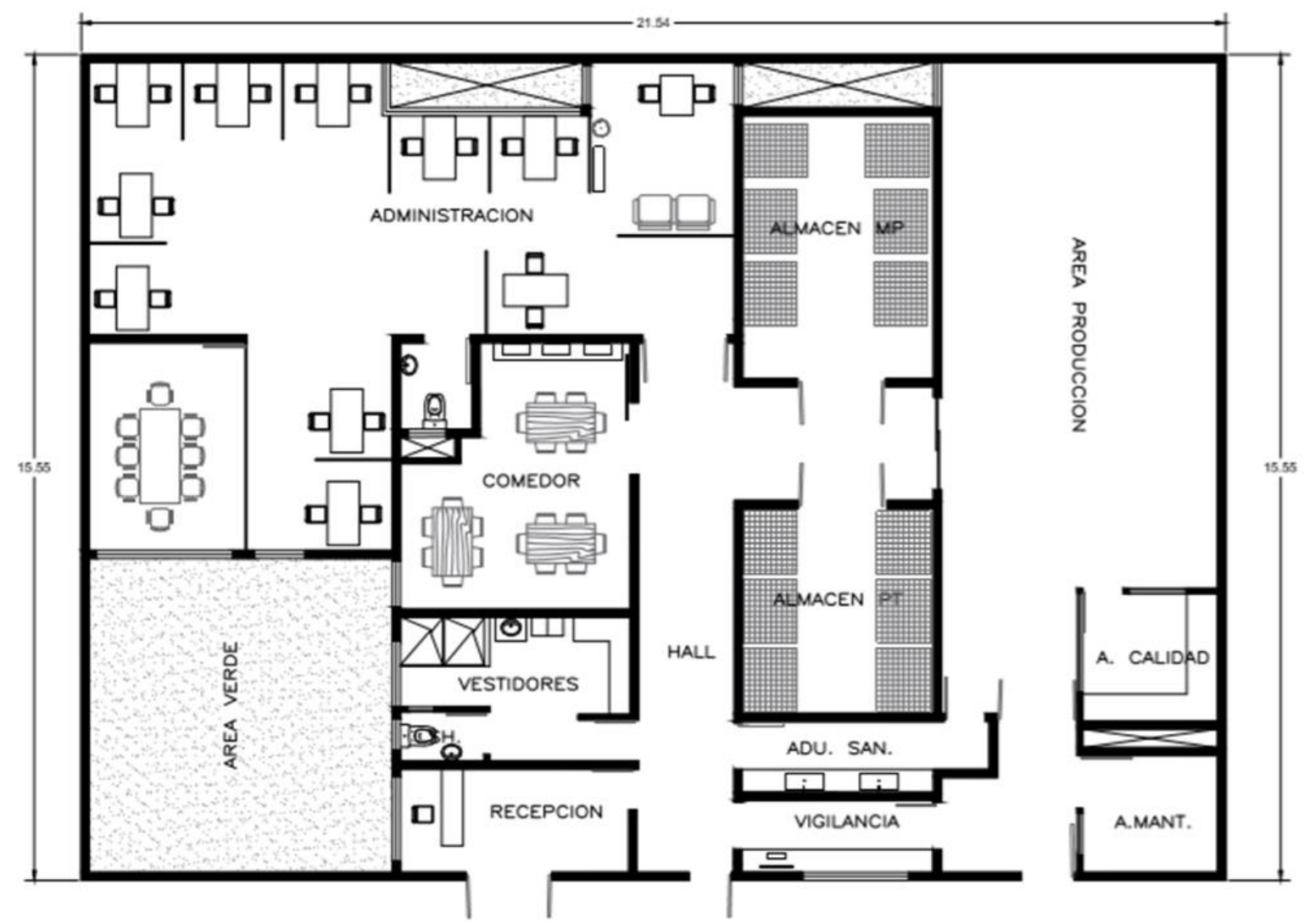

Elaboración propia 


\subsection{Cronograma de implementación del proyecto}

Figura 5.22

Cronograma de implementación del proyecto

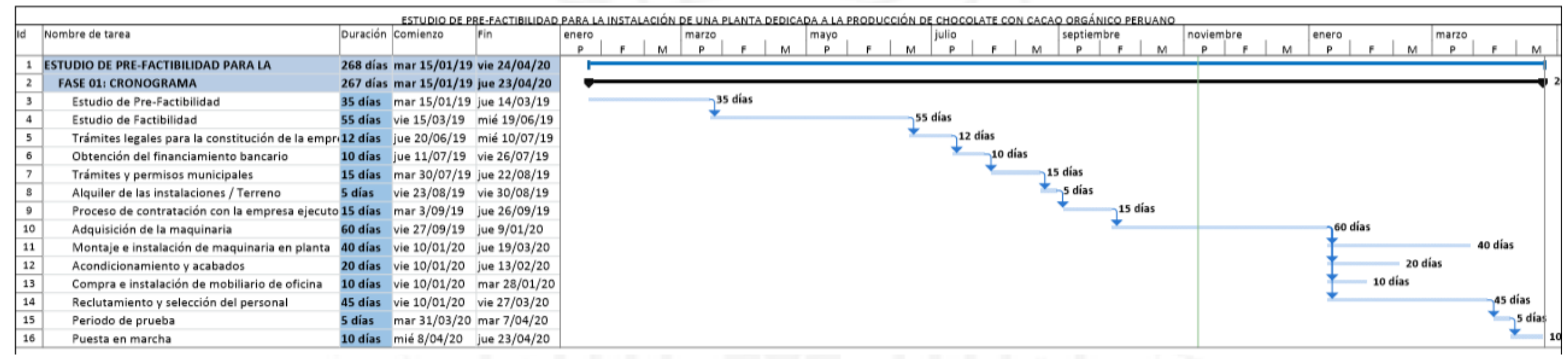

Elaboración propia 


\section{CAPÍTULO VI: ORGANIZACIÓN ADMINISTRATIVA}

La organización es una parte medular para cualquier gestión empresarial encaminada al éxito. Una organización acertada permitirá que las tareas sean hechas correctamente, reduciendo así costos, agilizando procesos y evitando esfuerzos innecesarios.

En el presente capítulo se brindará la información necesaria para la formación de la organización de la empresa. Se definirá a los actores principales y sus roles a desempeñar. La importancia de definir de forma clara y acertada las funciones permite un desempeño más eficiente.

\subsection{Formación de la organización empresarial}

Para el inicio de operaciones en planta es necesario manejar ciertos pasos que deben estar regularizados para evitar inconvenientes con el Estado u otro organismo regulador. Es muy importante el marco legal y adquisiciones como el montaje de la planta y la puesta en marcha, todo ello incluye los puntos siguientes:

- Constitución de la empresa: Al momento de constituir una empresa es necesario especificar qué tipo de sociedad queremos formar. Es de vital importancia especificar con qué tipo de sociedad trabajará. La adecuada para el proyecto es la Sociedad Anónima Cerrada (S.A.C.) puesto que puede funcionar sin directorio.

- Elaboración de la minuta de constitución: Es un documento legal en el cual se especifica detalles importantes de la empresa.

- Escritura Pública: Se realiza con la aprobación de un notario público.

- Inscripción en los registros públicos: Inscripción de la empresa en las oficinas de la SUNARP.

- Obtención del RUC: El Registro Único del Contribuyente (RUC) es solicitado ante la SUNAT (Superintendencia Nacional de Administración Tributaria) de manera gratuita.

- Licencia municipal de funcionamiento: La otorga el municipio correspondiente y el pago de la tasa dependerá del rubro del negocio y área que ocupe. 
- Alquiler de la planta: Corresponde a la realización del alquiler con el arrendador.

- Implementación de instalaciones: Abarca todo el periodo de adecuación de la planta de producción y oficinas.

- Compra de maquinaria: Serán comprados en el mercado local.

- Licencias y marca: Se realiza el diseño de marca en y se lanza el registro a INDECOPI.

- Reclutamiento, capacitación y contratación del personal: Desde el día uno comienza las entrevistas y se selecciona personal para planta y administración.

- Compras de insumos y materia prima: Se abastece el depósito de materia prima con lo necesario para comenzar la fabricación de los chocolates.

Además de todos estos puntos mencionados es necesario que el personal conozca nuestra misión y visión como empresa, ya que esto será su motivación para alcanzar nuestros objetivos como fuerza humana.

\section{Misión de la empresa}

Ser una empresa dedicada a la producción y comercialización de chocolate orgánico con sabores novedosos, compuesta por personas innovadoras y con valores; enfocados en fijar estándares de calidad, excelencia de nuestros productos y comprometidos con el medio ambiente y la sociedad.

\section{Visión de la empresa}

Ser una empresa con reconocimiento a nivel nacional y mundial por innovar y llevar al mercado productos de alto valor agregado, satisfaciendo las necesidades y superando las expectativas de nuestros clientes.

Seguidamente, se muestran todos los puestos de trabajo que se consideran tanto para el área de producción como para administración: 


\section{Tabla 6.1}

Detalle de personal administrativo y producción

\begin{tabular}{lc}
\hline Puesto & $\begin{array}{c}\text { Cantidad de } \\
\text { personal }\end{array}$ \\
\hline Gerente general & 1 \\
Jefe de planta & 1 \\
Asistente de calidad & 1 \\
Asistente de logística & 1 \\
Operario de producción & 6 \\
Ejecutivo de ventas & 3 \\
Analista de marketing y publicidad & 1 \\
Gerente de comercial y marketing & 1 \\
Gerente financiero & 1 \\
Encargada de RR.HH. & 1 \\
\hline
\end{tabular}

Elaboración propia.

\subsection{Requerimientos de personal directivo, administrativo y de servicios;} funciones generales de los principales puestos.

Esta organización debe ser dinámica y funcionar de manera armoniosa de tal manera que todo el personal de la empresa pueda cumplir sus funciones con la máxima eficiencia posible, para lograr la consecución de este objetivo. En los siguientes párrafos se detallarán los puestos y sus funciones dentro de la organización:

\section{Gerente general:}

La máxima autoridad en la gestión de toda la empresa. También, será el encargado de manejar la empresa de forma integral y verificar el desempeño de todos los trabajadores con el objetivo de mantener una alta rentabilidad. Responsable directo ante los socios de la disposición de fondos económicos, así como de la viabilidad y sostenibilidad financiera. Las competencias que debe poseer son: Liderazgo, pensamiento estratégico, iniciativa, autocontrol, trabajo bajo presión, empatía, asertividad, manejo de conflictos y comunicación persuasiva. Gestionará las políticas administrativas y supervisará el adecuado cumplimiento del Plan Estratégico de la empresa.

\section{Jefe de planta}

Será el encargado de brindar un seguimiento constante al área productiva, almacén, logística, Control de Calidad (mano de obra, materiales y MP, equipos, maquinaria, etc.) en función a los programas de producción, así como asegurar el cumplimiento de 
producción. Reporta directamente a Gerencia General sobre el desempeño de la gestión de la producción.

\section{Asistente logístico}

Se encargará de prever los requerimientos de insumos, materiales, materias primas y otros para abastecer a almacén y a producción, gestionar toda la logística del contacto con el proveedor, seguimiento y manejo de inventarios, lanzamientos para la producción.

\section{Gerente financiero}

Encargado de gestionar la liquidez de la empresa, poniendo en marcha un sistema de control de costos. Es quien analiza posibilidades de inversión impulsando proyectos de mercados alternativos, elaborará planes de inversión para cada caso. Es el encargado de obtener financiamiento externo argumentando el por qué la empresa lo merece y sí está capacitada para cubrir las exigencias que esto conlleva. Administra informes financieros, carteras de inversión, la contabilidad y todo tipo de análisis financiero de la empresa. De esta manera trabajará con un asistente contable externo.

\section{Jefe de comercial y marketing}

Se encargará de realizar la planificación de ventas y buscará cerrar relaciones comerciales con el canal moderno, teniendo a su cargo las órdenes de compra, así como el seguimiento correspondiente a la entrega de la mercadería. Tendrá a su cargo a 3 ejecutivos de venta con quienes coordinará el cumplimiento de las metas de venta y la colocación adecuada del producto. También será el encargado de la elaboración del Plan de Marketing de la empresa, trabajará de la mano con el analista de marketing y publicidad. Con quien diseñara estrategias de promoción y publicidad para los canales de venta.

\section{Analista de marketing y publicidad}

Desarrollará estrategias de marketing que permitan colocar adecuadamente los productos en el mercado y tiendas del canal moderno. Será el encargado de la construcción de la marca y diseñara mejores prácticas de brand awareness; es decir la conciencia de marca que hará que los consumidores registren a la marca como 
chocolate premium. Gestionará la logística de publicidad en los medios de comunicación o redes sociales, difundir novedades sobre trabajos exitosos durante cada mes, etc. Tendrá el apoyo de un community manager externo.

\section{Encargada de RR.HH.}

Será el responsable de manejar los procesos de reclutamiento y selección de personal, contratación, inducción, pago de remuneraciones y BBSS. También elaborará el plan de capacitación anual, perfiles de puestos, actualizar el Manual Operativo de Funciones, procedimientos y manuales de cada proceso, organizar eventos o actividades, etc. Velar por el bienestar laboral y desarrollo profesional mostrando un buen clima laboral, impulsando y motivando a los equipos de trabajo a cumplir con sus objetivos.

\section{Asistente de calidad e investigación}

Se encargará de controlar, verificar los procesos de laboratorio, organizar programas de certificación; así como el aseguramiento de los materiales y productos finales cumplan con todas las especificaciones de las normas. También desarrollaran nuevas fórmulas para la elaboración del producto. Adicional a ello, realizará investigaciones de productos funcionales y nuevas mezclas de sabores para dar propuestas innovadoras y realizar análisis de mercado y de costos; pues pertenecerá al equipo de I+D e Innovación.

\section{Operario de producción}

Será el responsable de operar las máquinas y herramientas para lograr la transformación del producto, cumplir con los programas de producción en las fechas definidas.

\section{Ejecutivo de ventas}

Será el encargado de promocionar la venta de productos vía telefónica, realizar visitas presenciales al cliente, ordenar la mercadería en tiendas especializadas, minimarkets y supermercados; como también, ampliar nuevas oportunidades de venta mediante visitas a clientes nuevos. 


\subsection{Esquema de la estructura organizacional}

En el diagrama de la estructura organizacional, se muestran los diferentes departamentos de la organización, así como los cargos que dependen de estos:

\section{Figura 6.1}

Organigrama general de la empresa

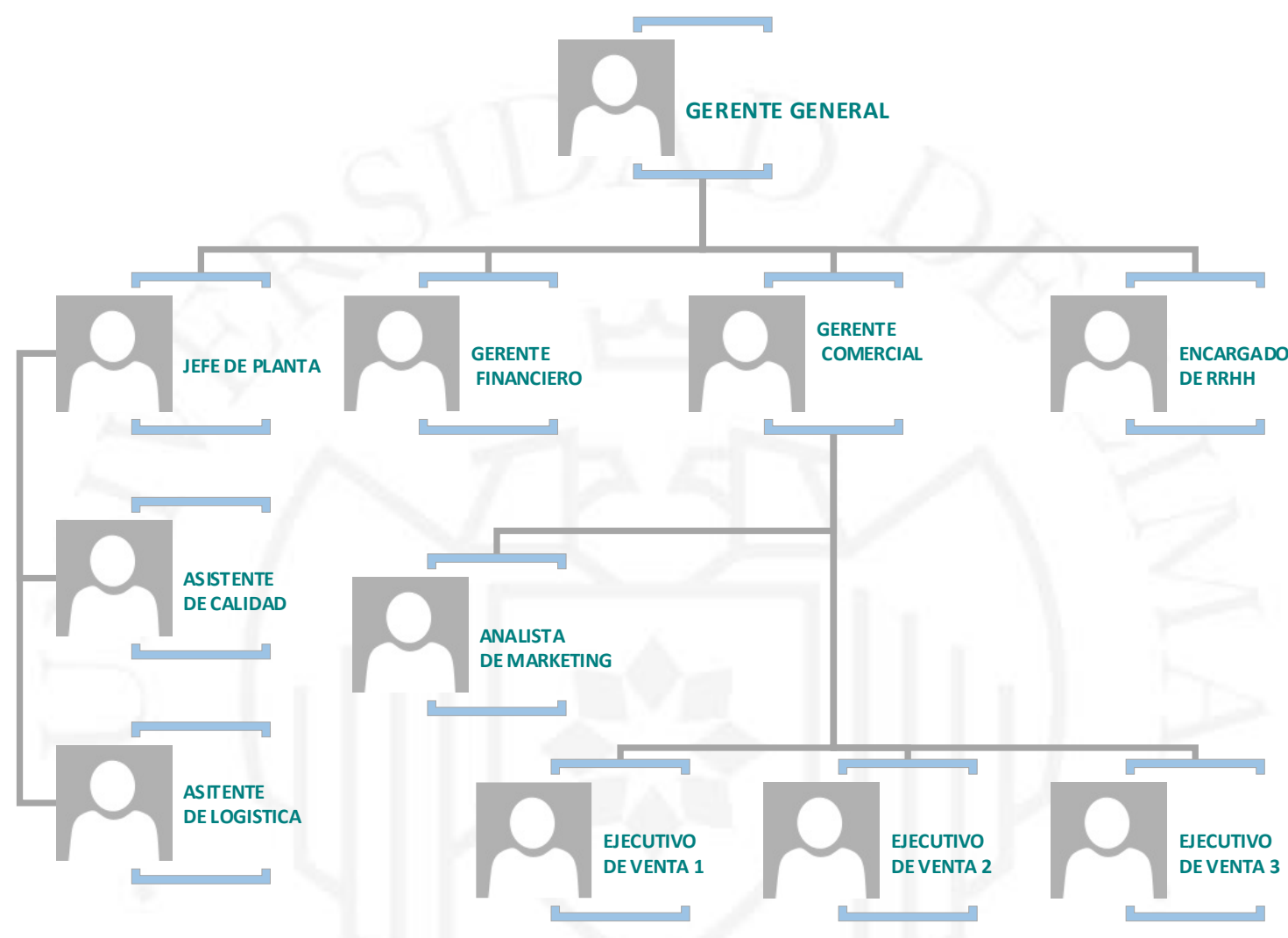

Elaboración propia 


\section{CAPÍTULO VII: PRESUPUESTOS Y EVALUACIÓN DEL PROYECTO}

En esta sección se presentará y analizará la situación económica y financiera en la cual se desarrollará el proyecto; de tal manera que se presentará los diferentes costos y gastos, presupuestos operativos y financieros; con ello se procederá a evaluar la situación económica y financiera. Es importante reconocer la rentabilidad de las empresas dedicadas al rubro para que una vez que se desglose la información, se encuentre los indicadores que permitan hacer un comparativo de como el proyecto se situará frente a ellos y cuan atractiva es la presente idea de negocio para otros inversionistas.

\subsection{Inversiones}

Se determinarán los costos iniciales según los activos tangibles, intangibles y al capital de trabajo. De esta manera se obtendrá el cálculo de la inversión.

\subsubsection{Estimación de las inversiones de largo plazo (tangibles e intangibles)}

\section{Activos tangibles}

- Maquinaria y equipos

Comprende la inversión de toda la maquinaria y equipos contemplados en el proceso de fabricación, así como de los muebles y enseres que se requerirán. En el siguiente cuadro, se presenta la inversión presupuestada para las maquinarias. 
Tabla 7.1

Costos de maquinaria y equipo

\begin{tabular}{llccc}
\hline $\mathbf{N}^{\circ}$ & Maquinaria & Cantidad & \multicolumn{2}{c}{ Inversión Total } \\
\hline 1 & Tostador & 1 & S/ & $183,331.00$ \\
2 & Descascarillador & 1 & S/ & $129,545.00$ \\
3 & Molino pre refinador & 1 & S/ & $81,844.00$ \\
4 & Refinador & 1 & S/ & $70,016.00$ \\
5 & Conchadora & 1 & S/ & $77,893.00$ \\
6 & Temperador & 1 & \$ & $27,305.00$ \\
7 & Freezer & 1 & S/ & $40,000.00$ \\
\hline & & & S/ & $\mathbf{6 0 9 , 9 3 4 . 0 0}$ \\
\hline
\end{tabular}

Fuente: Elaboración propia

- Terreno y edificio

Para el presente proyecto se encontró conveniente alquilar un terreno, tomando en cuenta los parámetros considerados para la instalación de la fábrica. Por otro lado, se considerará el costo de alquiler de 4.26 dólares por $\mathrm{m} 2$ en el distrito de Pachacamac Zona Sur (Colliers International, 2018).

Tabla 7.2

Alquiler del terreno anual

\begin{tabular}{lc}
\hline Área del terreno $(\mathrm{m} 2):$ & 350 \\
Precio $(\$ / \mathrm{m} 2)$ & 4.9539 \\
Gasto de alquiler del terreno & $\mathrm{S} / 58,488.95$ \\
$(\mathrm{~S} /)$. & \\
\hline Elaboración propia &
\end{tabular}

- Mobiliario y enseres

La importancia de tener un ambiente laboral que cumpla con los estándares necesarios en cuanto a seguridad, comodidad y donde los trabajadores encuentren lo necesario para realizar sus tareas de manera eficiente, nos lleva a considerar los siguientes gastos: 
Tabla 7.3

Inversión de muebles y enseres

\begin{tabular}{|c|c|c|c|}
\hline Activos tangibles & Monto & Cantidad & Total \\
\hline \multicolumn{4}{|l|}{ Infraestructura } \\
\hline Instalaciones eléctricas & S/.4,500.00 & 1 & $\mathrm{~S} / .4,500.00$ \\
\hline Compresor & S/. 300.00 & 1 & $\mathrm{~S} / .300 .00$ \\
\hline Montaje de aire acondicionado + aire comprimido & S/. 3,000.00 & 1 & $\mathrm{~S} / .3,000.00$ \\
\hline Transformador & S/. 250.00 & 1 & $\mathrm{~S} / .250 .00$ \\
\hline \multicolumn{4}{|l|}{ Acondicionamiento } \\
\hline Extintores & S/. 200.00 & 5 & $\mathrm{~S} / .1,000.00$ \\
\hline Aire acondicionado para administración & S/. 2,500.00 & 1 & $\mathrm{~S} / .2,500.00$ \\
\hline Aire acondicionado para planta & S/. 3,000.00 & 1 & $\mathrm{~S} / .3,000.00$ \\
\hline Calefacción & S/. 400.00 & 3 & $\mathrm{~S} / .1,200.00$ \\
\hline Fluorescente & S/. 30.00 & 17 & $\mathrm{~S} / .510 .00$ \\
\hline Focos (área de producción) & S/. 7.00 & 11 & $\mathrm{~S} / .77 .00$ \\
\hline Focos (área administrativa) & S/. 7.00 & 2 & $\mathrm{~S} / .14 .00$ \\
\hline \multicolumn{4}{|l|}{ Instalaciones higiénicas } \\
\hline Retretes & S/. 150.00 & 4 & S/.600.00 \\
\hline Lavaderos & S/. 100.00 & 6 & S/.600.00 \\
\hline Lockers 06 casilleros & S/. 500.00 & 2 & $\mathrm{~S} / .1,000.00$ \\
\hline Tachos para baños & S/. 30.00 & 4 & $\mathrm{~S} / .120 .00$ \\
\hline \multicolumn{4}{|l|}{ Comedor } \\
\hline Mesas de comedor & S/. 200.00 & 3 & $\mathrm{~S} / .600 .00$ \\
\hline Mesas para microondas & S/. 100.00 & 1 & S/.100.00 \\
\hline Microondas & $\mathrm{S} / .250 .00$ & 1 & $\mathrm{~S} / .250 .00$ \\
\hline \multicolumn{4}{|l|}{ Área de Operaciones } \\
\hline Sillas de comedor & S/. 50.00 & 18 & S/.900.00 \\
\hline \multicolumn{4}{|l|}{ Almacenes } \\
\hline Bandejas / baldes de acero inoxidable & S/. 50.00 & 8 & $\mathrm{~S} / .400 .00$ \\
\hline Estantes para PT & S/. 120.00 & 2 & S/.240.00 \\
\hline Carritos (para materia prima + producto terminado) & S/. 200.00 & 3 & S/.600.00 \\
\hline \multicolumn{4}{|l|}{ Producción } \\
\hline Mesas de trabajo de acero inoxidable & $\mathrm{S} / .500 .00$ & 2 & $\mathrm{~S} / .1,000.00$ \\
\hline Moldes, charolas, envases & S/. 5000.00 & 1 & S/. 5000.00 \\
\hline Balanza de precisión & S/. 500.00 & 1 & $\mathrm{~S} / .500 .00$ \\
\hline $\begin{array}{l}\text { Utensilios para laboratorio } \\
\text { (termómetro+higómetro+cronómetros, etc.) }\end{array}$ & S/. 2,000.00 & 1 & $\mathrm{~S} / .2,000.00$ \\
\hline Tachos basura & S/. 25.00 & 3 & $\mathrm{~S} / .75 .00$ \\
\hline Estantes de acero inoxidable & S/. 250.00 & 2 & $\mathrm{~S} / .500 .00$ \\
\hline \multicolumn{4}{|l|}{ Área Administrativa } \\
\hline $\begin{array}{l}\text { Artículos de limpieza (desinfectantes+cubetas, } \\
\text { escobas, etc.) }\end{array}$ & S/. 1,000.00 & 1 & $\mathrm{~S} / .1,000.00$ \\
\hline \multicolumn{4}{|c|}{$\begin{array}{ll} & \text { Oficinas administrativas } \\
\end{array}$} \\
\hline Escritorios de oficina & $\mathrm{S} / .250 .00$ & 11 & $\mathrm{~S} / .2,750.00$ \\
\hline Sillas de escritorio & S/. 150.00 & 11 & $\mathrm{~S} / .1,650.00$ \\
\hline Sillas para sala de reuniones & S/.100.00 & 8 & $\mathrm{~S} / .800 .00$ \\
\hline Sofá para visitas & S/. $1,200.00$ & 1 & $\mathrm{~S} / .1,200.00$ \\
\hline Mesa de centro & S/. 150.00 & 1 & S/.150.00 \\
\hline Laptop & S/. $2,500.00$ & 2 & $\mathrm{~S} / .5,000.00$ \\
\hline Computadoras & S/. $1,500.00$ & 11 & S/.16,500.00 \\
\hline Tachos de basura & S/. 25.00 & 11 & S/.275.00 \\
\hline Estantes & S/. 150.00 & 4 & S/.600.00 \\
\hline Red telefónica & $\mathrm{S} / .600 .00$ & 1 & $\mathrm{~S} / .600 .00$ \\
\hline Impresora multifuncional & S/. 2,000.00 & 1 & $\mathrm{~S} / .2,000.00$ \\
\hline Impresora básica & S/. 400.00 & 1 & $\mathrm{~S} / .400 .00$ \\
\hline Útiles de oficina & S/.600.00 & 1 & S/.600.00 \\
\hline Total & & & $\mathrm{S} / .64,361.00$ \\
\hline
\end{tabular}

Elaboración propia 


\section{Activos intangibles}

A continuación, se describen los activos intangibles o también conocidos como capital intelectual. Las inversiones incurridas en estos activos permiten los estudios previos, la puesta marcha, capacitaciones, patentes y licencias, etc.

- Estudios previos

Son aquellos estudios previos a la puesta en marcha; tales como: estudios de factibilidad, estudio de mercados, estructura, resultados, estudio informativo, etc. Se estima un gasto de 30000 soles.

- Gastos de puesta en marcha

Son gastos necesarios para la iniciación de las actividades en la empresa. Serán gastos de adecuación y como tales resultarán amortizables en un período máximo de cinco ejercicios. Se estima un gasto de S/. 50,000.00.

- Patentes y licencias

Permisos municipales, derechos de marca, autorizaciones notariales.

- Contingencias

Para todo caso aislado que ocurra durante la instalación. Se presupuesta un $10 \%$ de la sumatoria de todos los activos intangibles. Siendo un monto de S/. 14,500.

- Sistemas de información

Son los gastos incurridos en la obtención de los programas a usar para las operaciones necesarias en cada proceso.

- Capacitaciones

Se consideran las capacitaciones programadas para el área administrativa. Se estima un gasto de 20,000 soles.

De esta manera, a continuación, se presenta los siguientes gastos. 
Tabla 7.4

Inversión de Activos Fijos Intangibles

\begin{tabular}{lc}
\hline Activo Fijo intangible & Importe (Soles) \\
\hline Estudios previos & $30,000.00$ \\
Gastos de puesta en marcha & $50,000.00$ \\
Patentes y licencias & $15,000.00$ \\
Sistemas de información & $30,000.00$ \\
Capacitaciones & $20,000.00$ \\
Contingencias (10\%) & $14,500.00$ \\
\hline Total & $\mathbf{1 5 9 , 5 0 0 . 0 0}$ \\
\hline
\end{tabular}

Elaboración propia

\subsubsection{Estimación de las inversiones de corto plazo (Capital de trabajo)}

El capital de trabajo es el recurso económico empleado que se utilizará para poner en marcha el proyecto una vez que inicie la fase de fabricación. En otras palabras, el capital de trabajo permite solventar los gastos que se vayan a generar antes del ingreso de dinero por las ventas. Dicho monto comprende:

- Sueldos, salarios, gastos por servicios.

- Suministro de materia prima, insumos, productos en proceso y terminados.

- Pago de anticipo a proveedores.

Tabla 7.5

Cálculo del gasto operativo anual

\begin{tabular}{lc}
\hline Costo de ventas & $1,679,017.01$ \\
Gastos admi+vts+log & $1,376,775.22$ \\
Gao & $3,055,792.23$ \\
Kw & $753,483.02$ \\
\hline
\end{tabular}

Elaboración propia

Una vez calculado el GAO, se procederá a calcular el capital de trabajo en base al flujo de caja, teniendo en cuenta la siguiente fórmula.

$$
\text { Capital de trabajo }(K W)=\frac{G A O}{365} \quad X \text { Ciclo de caja (días) }
$$

Capital de trabajo $=3,055,792.23 / 365 \times 90=\mathrm{S} / .753,483.02$ 


\subsection{Costos de producción}

\subsubsection{Costos de las materias primas}

En la siguiente tabla, figuran los costos que incurren en la compra de todos los insumos que intervienen en el proceso productivo.

Tabla 7.6

Presupuesto de materia prima (S/. año)

\begin{tabular}{|c|c|c|c|c|c|}
\hline & 2020 & 2021 & 2022 & 2023 & 2024 \\
\hline $\begin{array}{l}\text { Requerimiento de } \\
\text { cacao }\end{array}$ & 15,679 & 15,520 & 17,436 & 19,515 & 21,670 \\
\hline $\begin{array}{c}\text { Costo total de } \\
\text { cacao }\end{array}$ & S/. 220,385.56 & S/. 215,759.32 & S/. 242,401.76 & S/. 271,295.90 & S/. $\quad 301,256.52$ \\
\hline $\begin{array}{l}\text { Requerimiento de } \\
\text { manteca }\end{array}$ & 1,564 & 1,518 & 1,706 & 1,909 & 2,120 \\
\hline $\begin{array}{c}\text { Costo total de } \\
\text { manteca }\end{array}$ & S/.125,146.64 & S/.121,466.30 & $\mathrm{S} / .136,493.80$ & $\mathrm{~S} / .152,751.33$ & S/.169,608.92 \\
\hline $\begin{array}{l}\text { Requerimiento de } \\
\text { azúcar }\end{array}$ & 5,637 & 5,321 & 5,983 & 6,694 & 7,432 \\
\hline $\begin{array}{l}\text { Costo total de } \\
\text { azúcar }\end{array}$ & $\mathrm{S} / . \quad 25,367.38$ & S/. 23,946.11 & S/. $\quad 26,922.52$ & S/. $30,123.18$ & $33,441.96$ \\
\hline $\begin{array}{l}\text { Requerimiento de } \\
\text { fruta deshidratada }\end{array}$ & 4,711 & 4,693 & 5,272 & 5,901 & 6,552 \\
\hline $\begin{array}{c}\text { Costo total de } \\
\text { fruta } \\
\text { deshidratada }\end{array}$ & S/. 423,967.46 & S/. 422,372.95 & S/. 474,462.46 & S/. 531,046.85 & S/. $\quad \mathbf{5 8 9 , 7 1 9 . 8 0}$ \\
\hline $\begin{array}{l}\text { Requerimiento } \\
\text { empaque ecológico }\end{array}$ & 432,354 & 462,017 & 519,744 & 580,812 & 645,030 \\
\hline $\begin{array}{c}\text { Costo total de } \\
\text { empaque } \\
\text { ecológico }\end{array}$ & S/. $194,559.30$ & S/. 207,907.65 & $\mathrm{S} / . \mathbf{2 3 3 , 8 8 4 . 8 0}$ & $\mathrm{S} / . \mathbf{2 6 1 , 3 6 5 . 4 0}$ & S/. $\quad 290,263.50$ \\
\hline $\begin{array}{l}\text { Requerimiento } \\
\text { cajas }\end{array}$ & 21,618 & 23,101 & 25,987 & 29,041 & 32,252 \\
\hline $\begin{array}{l}\text { Costo total de caja } \\
\times 20 \text { unid }\end{array}$ & 216.18 & S/. $\quad 231.01$ & 259.87 & 290.41 & 322.52 \\
\hline $\begin{array}{c}\text { Costo de } \\
\text { Materiales } \\
\text { Directos }\end{array}$ & 989,643 & 991,683 & $1,114,425$ & $1,246,873$ & $1,384,613$ \\
\hline
\end{tabular}

Elaboración propia

\subsubsection{Costo de la mano de obra directa}

Para el siguiente cálculo, se consideraron 14 sueldos al año, los cuales incluyen pagos que corresponden por ley a aquellos trabajadores que pertenecen a planilla, los cuales son la gratificación (Julio y diciembre), CTS (mayo y noviembre) y aportes que realizará el empleador como parte de sus obligaciones como son ESSALUD y SENATI, con porcentajes del $9 \%$ y $0.75 \%$ respectivamente. Asimismo, se procedió a calcular los 
sueldos más el pago de beneficios anuales y finalmente se multiplicó por el número de trabajadores de producción a contratar.

Tabla 7.7

Presupuesto de mano de obra (S/. año)

\begin{tabular}{|l|c|c|c|c|c|c|c|c|c|}
\cline { 3 - 9 } \multicolumn{2}{|c|}{} & $\begin{array}{c}\text { Descuento } \\
\text { s al } \\
\text { trabajador }\end{array}$ & \multicolumn{5}{|c|}{ Aportes del empleador } & \multicolumn{3}{|c|}{} \\
\hline Cargos & $\begin{array}{c}\text { Sueldo } \\
\text { Bruto } \\
\text { (S/.) }\end{array}$ & $\begin{array}{c}\text { AFP } \\
(13 \%)\end{array}$ & $\begin{array}{c}\text { Essal } \\
\text { ud } \\
(9 \%)\end{array}$ & $\begin{array}{c}\text { SENATI } \\
(0.75 \%)\end{array}$ & $\begin{array}{c}\text { Gratific } \\
\text { ación }\end{array}$ & CTS & $\begin{array}{c}\text { Sueldo } \\
\text { Neto }\end{array}$ & $\begin{array}{c}\mathrm{N}^{\circ} \\
\text { Trabaj } \\
\text { adores }\end{array}$ & $\begin{array}{c}\text { T. Sueldo } \\
\text { Neto(S/.) }\end{array}$ \\
\hline $\begin{array}{l}\text { Operario de } \\
\text { Producción }\end{array}$ & 1500 & 195 & 135 & 11 & 3000 & 1500 & 21915 & 5 & 109575 \\
\hline $\begin{array}{l}\text { Operario de } \\
\text { Producción- } \\
\text { TECNICO }\end{array}$ & 2000 & 260 & 180 & 15 & 4000 & 2000 & 29220 & 1 & 29220 \\
\hline Total & & & & & & & & & 138795 \\
\hline
\end{tabular}

Elaboración propia

\subsubsection{Costo indirecto de fabricación (materiales indirectos, mano de obra} indirecta y costos generales de planta)

Para el presente cálculo se tuvo en cuenta los siguientes costos: herramientas de trabajo, implementos de seguridad (EPPs), servicios de terceros (mantenimiento, limpieza, vigilancia, community manager), mano de obra indirecta, depreciación de planta, etc.

Tabla 7.8

Costos indirectos de fabricación

\begin{tabular}{lccccc}
\cline { 2 - 6 } & $\mathbf{2 0 2 0}$ & $\mathbf{2 0 2 1}$ & $\mathbf{2 0 2 2}$ & $\mathbf{2 0 2 3}$ & $\mathbf{2 0 2 4}$ \\
\hline Consumo eléctrico & $6,173.97$ & $6,553.87$ & $7,282.13$ & $8,075.32$ & $8,887.66$ \\
Consumo agua potable & $1,440.72$ & $1,440.72$ & $1,440.72$ & $1,440.72$ & $1,440.72$ \\
Materiales indirectos & $7,506.00$ & $7,506.00$ & $7,506.00$ & $7,506.00$ & $7,506.00$ \\
Depreciación fabril & $61,410.40$ & $61,410.40$ & $61,410.40$ & $61,410.40$ & $61,410.40$ \\
Mano de obra indirecta & $175,320.00$ & $175,320.00$ & $175,320.00$ & $175,320.00$ & $175,320.00$ \\
Seguro de maquinaria & $18,298.02$ & $18,298.02$ & $18,298.02$ & $18,298.02$ & $18,298.02$ \\
Servicios de terceros & $163,200.00$ & $163,200.00$ & $163,200.00$ & $163,200.00$ & $163,200.00$ \\
Gasto por mantenimiento & $70,000.00$ & $70,000.00$ & $70,000.00$ & $70,000.00$ & $70,000.00$ \\
Gasto por gestiones & $50,000.00$ & $50,000.00$ & $50,000.00$ & $50,000.00$ & $50,000.00$ \\
ambientales & & & & & \\
Gasto por alquiler de local & $23,395.58$ & $23,395.58$ & $23,395.58$ & $23,395.58$ & $23,395.58$ \\
\hline Total CIF (S/.) & $576,744.68$ & $577,124.59$ & $577,852.85$ & $578,646.04$ & $579,458.38$
\end{tabular}

Elaboración propia 
- Energía eléctrica y agua potable

Como insumos adicionales que se requerirán para el proceso productivo tenemos a la energía eléctrica y el agua potable, los cuales se disgregan en los siguientes cuadros:

Tabla 7.9

Costo de energía eléctrica de máquinas de producción (S/.año)

\begin{tabular}{|l|c|c|c|c|c|}
\hline REQ. ENERGÍA & $\mathbf{2 0 2 0}$ & $\mathbf{2 0 2 1}$ & $\mathbf{2 0 2 2}$ & $\mathbf{2 0 2 3}$ & $\mathbf{2 0 2 4}$ \\
\hline $\begin{array}{l}\text { Tostador + Ciclon } \\
(*)\end{array}$ & $1,330.35$ & $1,421.62$ & $1,596.59$ & $1,787.16$ & $1,982.32$ \\
\hline $\begin{array}{l}\text { Descascarillador + } \\
\text { Ciclon (*) }\end{array}$ & 530.03 & 566.40 & 636.11 & 712.03 & 789.79 \\
\hline $\begin{array}{l}\text { Molino Prerefinador } \\
\text { MOD MAC5 }\end{array}$ & 334.13 & 357.06 & 401.00 & 448.87 & 497.89 \\
\hline Refinador Sfera 20R & $1,142.18$ & $1,220.54$ & $1,370.76$ & $1,534.37$ & $1,701.93$ \\
\hline Conchadora CR150 & 492.25 & 526.02 & 590.77 & 661.28 & 733.49 \\
\hline Temperador $(*)$ & 762.13 & 814.42 & 914.65 & $1,023.82$ & $1,135.63$ \\
\hline Freezer & 946.22 & 1011.14 & 1135.59 & 1271.13 & 1409.94 \\
\hline $\begin{array}{l}\text { CONSUMO } \\
\text { TOTAL (S/.) } \\
\text { *incluye compresor } \\
\text { 6 bar }\end{array}$ & $\mathbf{5 , 5 3 7 . 3 0}$ & $\mathbf{5 , 9 1 7 . 2 1}$ & $\mathbf{6 , 6 4 5 . 4 7}$ & $\mathbf{7 , 4 3 8 . 6 5}$ & $\mathbf{8 , 2 5 1 . 0 0}$ \\
\hline
\end{tabular}

Elaboración propia

Tabla 7.10

Costo de energía eléctrica de otros equipos para producción (S/. año)

\begin{tabular}{|l|c|c|c|c|c|c|c|c|c|}
\hline Req. Energía & horas/año & Kw /h & Cantidad & S/. Kw & $\mathbf{2 0 2 0}$ & $\mathbf{2 0 2 1}$ & $\mathbf{2 0 2 2}$ & $\mathbf{2 0 2 3}$ & $\mathbf{2 0 2 4}$ \\
\hline $\begin{array}{l}\text { Aire } \\
\text { acondicionado } \\
\text { para Planta }\end{array}$ & 800 & 1.5 & 1 & 0.206 & 247 & 247 & 247 & 247 & 247 \\
\hline Fluorescentes & 2,338 & 0.032 & 17 & 0.206 & 262 & 262 & 262 & 262 & 262 \\
\hline $\begin{array}{l}\text { Focos (A. de } \\
\text { producción) }\end{array}$ & 2,338 & 0.024 & 11 & 0.206 & 127 & 127 & 127 & 127 & 127 \\
\hline $\begin{array}{l}\text { Costo de energía. } \\
\text { (S/.) }\end{array}$ & & & & & 637 & 637 & 637 & 637 & 637 \\
\hline
\end{tabular}

Elaboración propia

Tabla 7.11

Costo de agua potable (S/. año)

\begin{tabular}{lccccccc}
\hline Área & $\begin{array}{c}\text { m3/mes- } \\
\text { persona }\end{array}$ & $\begin{array}{c}\mathbf{N}^{\circ} \\
\text { personas }\end{array}$ & $\mathbf{2 0 2 0}$ & $\mathbf{2 0 2 1}$ & $\mathbf{2 0 2 2}$ & $\mathbf{2 0 2 3}$ & $\mathbf{2 0 2 4}$ \\
\hline Producción & 3.48 & 6 & 1441 & 1441 & 1441 & 1441 & 1441 \\
\hline
\end{tabular}

Elaboración propia 
- Materiales indirectos

Para que las actividades dentro de producción se den en condiciones seguras, será necesario comprar herramientas, implementos de seguridad y materiales que se requerirán para el mantenimiento de las máquinas.

Tabla 7.12

Costo de herramientas por año

\begin{tabular}{lcc}
\hline Materiales indirectos & Mensual & Anual (S/.) \\
\hline Franelas & 10 & 120 \\
Aceites + Lubricantes & 50 & 600 \\
Útiles de limpieza y aseo & 300 & 3600 \\
\hline Total de M. Indirectos (S/.) & $\mathbf{3 6 0}$ & $\mathbf{4 3 2 0}$ \\
\hline
\end{tabular}

Elaboración propia

Tabla 7.13

Costo de implementos de seguridad por año

\begin{tabular}{lccc}
\hline EPPS & $\begin{array}{c}\text { Costo } \\
\text { unit. }\end{array}$ & Cantidad & Anual (S/.) \\
\hline Mascarillas & 22 & 20 & 440 \\
Tapones para oído & 35 & 10 & 350 \\
Mandiles blancos & 35 & 18 & 630 \\
Gorros cofia blanca & 14 & 4 & 56 \\
Lentes de seguridad & 25 & 15 & 375 \\
Guantes térmicos & 45 & 3 & 135 \\
Guantes blancos de PVC & 200 & 2 & 400 \\
Cascos & 60 & 8 & 480 \\
Botas blancas de PVC punta de acero & 40 & 8 & 320 \\
\hline Total de costo de EPPS (S/.) & $\mathbf{4 7 6}$ & & $\mathbf{3 1 8 6}$ \\
\hline
\end{tabular}

Elaboración propia

- Depreciación fabril

La depreciación fabril está conformada por las depreciaciones de los equipos y los muebles y enseres del área de producción. 
Tabla 7.14

Depreciación de maquinarias de producción

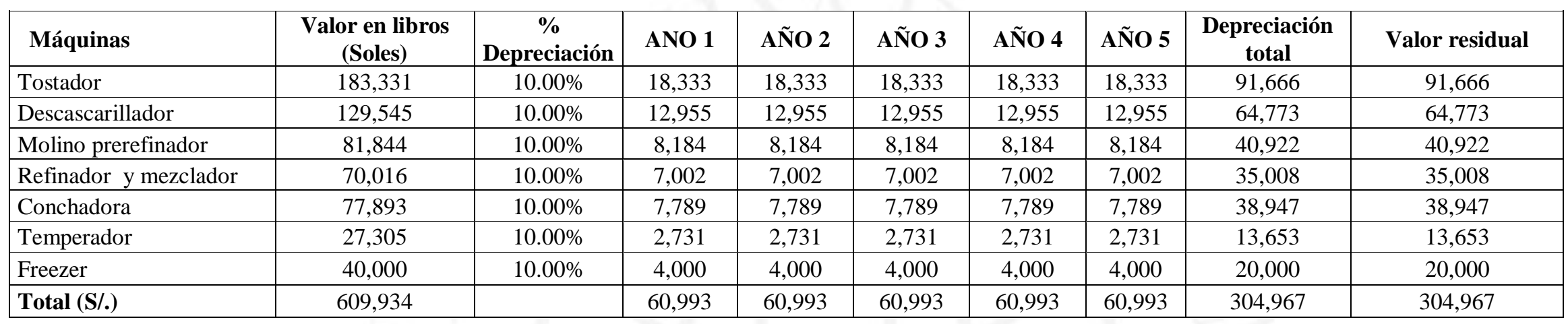

Elaboración propia

Tabla 7.15

Depreciación de equipos y muebles de producción

\begin{tabular}{|c|c|c|c|c|c|c|c|c|c|}
\hline Conceptos de dep. Fabril & Monto & $\%$ depr. & Año 01 & Año 02 & Año 03 & Año 04 & Año 05 & Dep. Total & $\begin{array}{c}\text { Valor } \\
\text { residual }\end{array}$ \\
\hline \multicolumn{10}{|l|}{ Acondicionamiento } \\
\hline Instalaciones eléctricas & 2,340 & $3 \%$ & 70 & 70 & 70 & 70 & 70 & 351 & 1,989 \\
\hline $\begin{array}{l}\text { Montaje de aire acondicionado + aire } \\
\text { comprimido }\end{array}$ & 1,560 & $3 \%$ & 47 & 47 & 47 & 47 & 47 & 234 & 1,326 \\
\hline Aire acondicionado para planta & 3,000 & $10 \%$ & 300 & 300 & 300 & 300 & 300 & 1,500 & 1500 \\
\hline Maquinarias y equipos & 609,934 & $10 \%$ & 60,993 & 60,993 & 60,993 & 60,993 & 60,993 & 304,967 & 304,967 \\
\hline \multicolumn{3}{|l|}{ Total depreciación fabril } & $61,410.40$ & $61,410.40$ & $61,410.40$ & $61,410.40$ & $61,410.40$ & $307,052.00$ & $309,782.00$ \\
\hline
\end{tabular}

Elaboración propia 
- Mano de obra indirecta

Se consideraron como mano de obra indirecta a todo aquel personal que realiza alguna labor indirectamente en la producción, como los que se detalla a continuación:

Tabla 7.16

Cálculo de mano de obra indirecta (S/. año)

\begin{tabular}{|c|c|c|c|c|c|c|c|c|c|}
\hline & & $\begin{array}{c}\text { Descuento } \\
\text { s al }\end{array}$ & & Aportes d & el emplead & & & & \\
\hline Cargos & $\begin{array}{c}\text { Sueldo } \\
\text { Bruto }\end{array}$ & $\begin{array}{c}\text { AFP } \\
(13 \%)\end{array}$ & $\begin{array}{c}\text { Essalud } \\
(9 \%)\end{array}$ & $\begin{array}{c}\text { SENATI } \\
(0.75 \%)\end{array}$ & $\begin{array}{c}\text { Gratifica- } \\
\text { ción }\end{array}$ & CTS & $\begin{array}{c}\text { Sueldo } \\
\text { Neto }\end{array}$ & $\begin{array}{c}\mathrm{N}^{\circ} \\
\text { Trabaja- } \\
\text { dores }\end{array}$ & $\begin{array}{c}\text { T. Sueldo } \\
\text { Neto }\end{array}$ \\
\hline $\begin{array}{l}\text { Jefe de } \\
\text { Planta }\end{array}$ & 8,000 & 1,040 & 720 & 60 & 16,000 & 8,000 & 116,880 & 1 & 116,880 \\
\hline $\begin{array}{l}\text { Asisten } \\
\text { te de } \\
\text { calidad }\end{array}$ & 4,000 & 520 & 360 & 30 & 8,000 & 4,000 & 58,440 & 1 & 58,440 \\
\hline $\begin{array}{l}\text { Total } \\
\text { MOI }\end{array}$ & 12,000 & 1,560 & 1,080 & 90 & 24,000 & 12,000 & 175,320 & 2 & 175,320 \\
\hline
\end{tabular}

Elaboración propia

- Servicios de terceros

Como se mencionó inicialmente se tercerizará los servicios del personal de limpieza, vigilancia, community manager y del personal de mantenimiento.

Tabla 7.17

Costos de servicios de terceros (S/. año)

\begin{tabular}{lc}
\hline Gastos de Terceros & Tarifa \\
\hline Community manager & 2000 \\
Vigilancia (2) & 2800 \\
Limpieza (2) & 2000 \\
Mantenimiento & 1800 \\
Contador & 5000 \\
Total mensual & 13600 \\
\hline Total anual $(\mathbf{S} /)$. & $\mathbf{1 6 3 2 0 0}$ \\
\hline
\end{tabular}

Elaboración propia 


\subsection{Presupuesto operativo}

\subsubsection{Presupuesto de ingreso por ventas}

Para realizar el presupuesto operativo se consideraron dos factores: La cantidad de barras de chocolate a vender y el precio de venta unitario por barra de chocolate.

Tabla 7.18

Presupuesto de ingreso por ventas (S/.)

\begin{tabular}{lccccc}
\hline Años & 2020 & 2021 & 2022 & 2023 & 2024 \\
\hline Demanda (barras) & 425,820 & 461,200 & 518,880 & 579,900 & 644,240 \\
valor venta por barra & 8.90 & 8.90 & 8.90 & 8.90 & 8.90 \\
Ventas (S/.) & $3,789,076$ & $4,103,898$ & $4,617,153$ & $5,160,127$ & $5,732,644$ \\
\hline
\end{tabular}

Elaboración propia

\subsubsection{Presupuesto operativo de costos}

En el siguiente presupuesto se debe calcular en primer lugar el costo de producción, en función a la materia prima, mano de obra directa y los costos indirectos de fabricación. Posteriormente, se procedió a calcular el costo de ventas, tomando en cuenta los inventarios inicial y final.

Tabla 7.19

Presupuesto operativo

\begin{tabular}{lccccc}
\hline & AÑN 01 & AÑO 02 & AÑO 03 & AÑO 05 & AÑO 06 \\
\hline Materiales directos & $989,642.51$ & $991,683.34$ & $1,114,425.21$ & $1,246,873.06$ & $1,384,613.22$ \\
Mano de obra directa & 138,795 & 138,795 & 138,795 & 138,795 & 138,795 \\
Costos indirectos de & 576,745 & 577,125 & 577,853 & 578,646 & 579,458 \\
fabricación & & & & & \\
\hline Costo de producción(S/.) & $1,705,182.20$ & $1,707,602.92$ & $1,831,073.06$ & $1,964,314.10$ & $2,102,866.60$ \\
\hline Elaboración propia & & & & &
\end{tabular}

Tabla 7.20

Cálculo de costo de ventas

\begin{tabular}{|c|c|c|c|c|c|}
\hline & AÑNO 01 & AÑN 02 & AÑNO 03 & AÑO 04 & AÑO 05 \\
\hline Costo de producción & $1,705,182$ & $1,707,603$ & $1,831,073$ & $1,964,314$ & $2,102,867$ \\
\hline $\begin{array}{l}\text { Inventario Inicial } \\
\text { Valorizado }\end{array}$ & - & 24,192 & 25,941 & 27,827 & 29,791 \\
\hline $\begin{array}{l}\text { Inventario Final } \\
\text { Valorizado }\end{array}$ & 26,165 & 27,217 & 28,990 & 30,916 & 32,370 \\
\hline Costo de ventas (S/.) & $1,679,017$ & $1,704,578$ & $1,828,024$ & $1,961,225$ & $2,100,288$ \\
\hline
\end{tabular}

Elaboración propia 


\subsubsection{Presupuesto operativo de gastos}

Se consideraron todas las remuneraciones al personal del área administrativa, al gasto de alquiler de la planta (en proporción al área administrativa), amortización de intangibles, depreciación no fabril.

Tabla 7.21

Presupuesto de gastos administrativos, ventas y marketing

\begin{tabular}{|c|c|c|c|c|c|}
\hline Gastos & AÑNO 01 & AÑ̃ 02 & AÑ̃ 03 & AÑO 04 & AÑO 05 \\
\hline Sueldos administrativos y ventas & 749,036 & 749,744 & 750,898 & 752,118 & 753,405 \\
\hline Gasto de alquiler de local & 35,093 & 35,093 & 35,093 & 35,093 & 35,093 \\
\hline Consumo de agua potable & 2,641 & 2,641 & 2,641 & 2,641 & 2,641 \\
\hline Consumo de electricidad & 3,484 & 3,484 & 3,484 & 3,484 & 3,484 \\
\hline Depreciación no fabril & 6,233 & 6,233 & 6,233 & 6,230 & 358 \\
\hline Amortización de intangibles & 31,900 & 31,900 & 31,900 & 31,900 & 31,900 \\
\hline Gastos administrativos & 828,388 & 829,096 & 830,249 & 831,467 & 826,881 \\
\hline Gastos de logística & 48,387 & 48,918 & 49,783 & 50,699 & 51,664 \\
\hline Gastos de publicidad y mkt & 500,000 & 550,000 & 605,000 & 665,500 & 732,050 \\
\hline Total de gastos adm+vts+log & $1,376,775$ & $1,428,014$ & $1,485,032$ & $1,547,665$ & $1,610,595$ \\
\hline
\end{tabular}

Elaboración propia

A continuación, se procederá a detallar cada uno de los ítems correspondientes al presupuesto de gastos administrativos, ventas y marketing.

Tabla 7.22

Presupuesto de sueldos administrativos (S/. año)

\begin{tabular}{|l|c|c|c|c|c|c|c|c|}
\hline \multicolumn{2}{|c|}{ Gastos Adm. y Ventas } & $\begin{array}{c}\text { Descuentos } \\
\text { al trabajador }\end{array}$ & \multicolumn{2}{c|}{ Aportes del empleador } & \multicolumn{2}{c|}{} \\
\hline Cargos & $\begin{array}{c}\text { Sueldo } \\
\text { Bruto }\end{array}$ & AFP (13\%) & $\begin{array}{c}\text { Essalud } \\
(9 \%)\end{array}$ & $\begin{array}{c}\text { Gratifi- } \\
\text { cación }\end{array}$ & CTS & $\begin{array}{c}\text { Sueldo } \\
\text { Neto }\end{array}$ & $\begin{array}{c}N^{\circ} \\
\text { Trabaja- } \\
\text { dores }\end{array}$ & $\begin{array}{c}\text { T. } \\
\text { Sueldo } \\
\text { Neto }\end{array}$ \\
\hline Gerente General & 12,000 & 1,560 & 1,080 & 24,000 & 12,000 & 174,240 & 1 & 174,240 \\
\hline Gerente financiero & 10,000 & 1,300 & 900 & 20,000 & 10,000 & 145,200 & 1 & 145,200 \\
\hline $\begin{array}{l}\text { Jefe de Marketing } \\
\text { y Ventas }\end{array}$ & 8,000 & 1,040 & 720 & 16,000 & 8,000 & 116,160 & 1 & 116,160 \\
\hline $\begin{array}{l}\text { Encargada de } \\
\text { RR.HH. }\end{array}$ & 7,000 & 910 & 630 & 14,000 & 7,000 & 101,640 & 1 & 101,640 \\
\hline Ejecutivo de venta & 2,000 & 260 & 180 & 4,000 & 2,000 & 29,040 & 3 & 87,120 \\
\hline $\begin{array}{l}\text { Asistente } \\
\text { Logìstico }\end{array}$ & 4,000 & 520 & 360 & 8,000 & 4,000 & 58,080 & 1 & 58,080 \\
\hline $\begin{array}{l}\text { Analista de } \\
\text { marketing y } \\
\text { publicidad }\end{array}$ & 4,000 & 520 & 360 & 8,000 & 4,000 & 58,080 & 1 & 58,080 \\
\hline $\begin{array}{l}\text { Total Gastos } \\
\text { Adm. Y Ventas }\end{array}$ & 47,000 & 6,110 & 4,230 & 94,000 & 47,000 & 682,440 & 9 & 740,520 \\
\hline
\end{tabular}

Elaboración propia 
Tabla 7.23

Costo de agua potable para administración (soles/año)

\begin{tabular}{lrrrrrrr}
\hline Área & $\begin{array}{l}\mathbf{m}^{3} / \mathbf{m e s}- \\
\text { persona }\end{array}$ & $\begin{array}{l}\text { N } \\
\text { personas }\end{array}$ & $\mathbf{2 0 2 0}$ & $\mathbf{2 0 2 1}$ & $\mathbf{2 0 2 2}$ & $\mathbf{2 0 2 3}$ & $\mathbf{2 0 2 4}$ \\
\hline Administración & 3.48 & 11 & 2641 & 2641 & 2641 & 2641 & 2641 \\
\hline
\end{tabular}

Elaboración propia

Tabla 7.24

Costo de energía eléctrica para administración (soles/año)

\begin{tabular}{|l|c|c|c|c|c|c|c|c|c|}
\hline ENERGÍA & horas/año & Kw /h & Cantidad & $\begin{array}{c}\text { S/. } \\
\text { Kw }\end{array}$ & $\mathbf{2 0 2 0}$ & $\mathbf{2 0 2 1}$ & $\mathbf{2 0 2 2}$ & $\mathbf{2 0 2 3}$ & $\mathbf{2 0 2 4}$ \\
\hline $\begin{array}{l}\text { Aire acondicionado } \\
\text { para Adm }\end{array}$ & 800 & 0.3 & 1 & 0.2061 & 49 & 49 & 49 & 49 & 49 \\
\hline Calefacción & 800 & 2 & 1 & 0.2061 & 330 & 330 & 330 & 330 & 330 \\
\hline $\begin{array}{l}\text { Focos (A. } \\
\text { administrativa) }\end{array}$ & 2,338 & 0.024 & 2 & 0.2061 & 23 & 23 & 23 & 23 & 23 \\
\hline Microondas & 300 & 1 & 1 & 0.2061 & 62 & 62 & 62 & 62 & 62 \\
\hline Laptop & 2,078 & 0.4 & 2 & 0.2061 & 343 & 343 & 343 & 343 & 343 \\
\hline Proyector & 48 & 0.18 & 1 & 0.2061 & 2 & 2 & 2 & 2 & 2 \\
\hline Computadoras & 2,078 & 0.5 & 11 & 0.2061 & 2356 & 2356 & 2356 & 2356 & 2356 \\
\hline Red telefónica & 2,078 & 0.03 & 1 & 0.2061 & 13 & 13 & 13 & 13 & 13 \\
\hline $\begin{array}{l}\text { Impresora } \\
\text { multifuncional }\end{array}$ & 900 & 0.5 & 1 & 0.2061 & 93 & 93 & 93 & 93 & 93 \\
\hline Gastos administrativos (S/.) & & & & 3270 & 3270 & 3270 & 3270 & 3270 \\
\hline
\end{tabular}

Elaboración propia

Por otro lado, también se tomó en cuenta la depreciación de los equipos y muebles de escritorio que se requerirán para el personal administrativo.

Tabla 7.25

Depreciación no fabril

\begin{tabular}{|c|c|c|c|c|c|c|c|c|c|}
\hline $\begin{array}{l}\text { Conceptos de dep. no } \\
\text { fabril }\end{array}$ & Monto & $\begin{array}{c}\% \\
\text { depr. }\end{array}$ & $\begin{array}{c}\text { Año } \\
01\end{array}$ & $\begin{array}{c}\text { Año } \\
02\end{array}$ & $\begin{array}{c}\text { Año } \\
\mathbf{0 3}\end{array}$ & $\begin{array}{c}\text { Año } \\
04\end{array}$ & $\begin{array}{c}\text { Año } \\
05\end{array}$ & $\begin{array}{l}\text { Dep. } \\
\text { Total }\end{array}$ & $\begin{array}{l}\text { Valor } \\
\text { residual }\end{array}$ \\
\hline \multicolumn{10}{|l|}{ Acondicionamiento } \\
\hline Instalaciones eléctricas & 2160 & $3 \%$ & 65 & 65 & 65 & 65 & 65 & 324 & 1,836 \\
\hline $\begin{array}{l}\text { Montaje de aire } \\
\text { acondicionado + aire } \\
\text { comprimido }\end{array}$ & 1440 & $3 \%$ & 43 & 43 & 43 & 43 & 43 & 216 & 1,224 \\
\hline $\begin{array}{l}\text { Aire acondicionado para } \\
\text { administración }\end{array}$ & 2500 & $10 \%$ & 250 & 250 & 250 & 250 & 250 & 1,250 & 1250 \\
\hline \multicolumn{10}{|l|}{ Muebles de oficina } \\
\hline Laptop & 5000 & $25 \%$ & 1,250 & 1,250 & 1,250 & 1,249 & 0 & 4,999 & $\mathrm{~S} / .1 .00$ \\
\hline Computadora & 16500 & $25 \%$ & 4,125 & 4,125 & 4,125 & 4,124 & 0 & 16,499 & $\mathrm{~S} / .1 .00$ \\
\hline Impresora multifuncional & 2000 & $25 \%$ & 500 & 500 & 500 & 499 & 0 & 1,999 & $\mathrm{~S} / .1 .00$ \\
\hline \multicolumn{3}{|c|}{ Total depreciación no fabril } & 6,233 & 6,233 & 6,233 & 6,230 & 358 & 25,287 & 4,313 \\
\hline
\end{tabular}

Elaboración propia 


\subsection{Presupuestos financieros}

\subsubsection{Presupuesto de servicio de deuda}

Se determina que el $50 \%$ del proyecto será financiado por la entidad bancaria GNB. Para ello, se considerará cuotas crecientes y una TEA del 12.5\% (SBS, 2019).

Tabla 7.26

Servicio de deuda

\begin{tabular}{lrrccc}
\hline Años & \multicolumn{1}{c}{ Deuda } & \multicolumn{1}{c}{ Interés } & Amortización & Cuota & Saldo Final \\
\hline 1 & 834,339 & 104,292 & 55623 & $159,914.98$ & 778,716 \\
2 & 778,716 & 97,340 & 111245 & $208,584.75$ & 667,471 \\
3 & 667,471 & 83,434 & 166868 & $250,301.70$ & 500,603 \\
4 & 500,603 & 62,575 & 222490 & $285,065.83$ & 278,113 \\
5 & 278,113 & 34,764 & 278113 & $312,877.13$ & - \\
\hline \multicolumn{2}{l}{ Elaboración propia } & & & &
\end{tabular}

\subsubsection{Presupuesto de estado resultados}

En la siguiente tabla se muestra el estado de resultado proyectado hasta el año 2024 . Asimismo, se decidió que debido a que se obtienen ingresos por cada año se destinará un porcentaje del $8 \%$ como participaciones en forma proporcional para todo el personal.

Tabla 7.27

Estado de resultados (Soles/año)

\begin{tabular}{lccccc}
\hline Rubro & Año 1 & Año 2 & Año 3 & Año 4 & Año 5 \\
\hline Ingreso por ventas & $3,789,076$ & $4,103,898$ & $4,617,153$ & $5,160,127$ & $5,732,644$ \\
(-) costo de ventas & $1,679,017$ & $1,704,578$ & $1,828,024$ & $1,961,225$ & $2,100,288$ \\
(=) utilidad bruta & $2,110,059$ & $2,399,320$ & $2,789,128$ & $3,198,902$ & $3,632,356$ \\
(-) gastos administrativos & 828,388 & 829,096 & 830,249 & 831,467 & 826,881 \\
(-) gastos de ventas y marketing & 500,000 & 550,000 & 605,000 & 665,500 & 732,050 \\
(-) gastos de logística & 48,387 & 48,918 & 49,783 & 50,699 & 51,664 \\
(=) utilidad antes de intereses, imp y & 733,284 & 971,307 & $1,304,096$ & $1,651,237$ & $2,021,761$ \\
partic & & & & & \\
(-) gastos financieros & $-104,292$ & $-97,340$ & $-83,434$ & $-62,575$ & $-34,764$ \\
Utilidad antes de impuestos y & 628,992 & 873,967 & $1,220,662$ & $1,588,662$ & $1,986,997$ \\
participaciones & & & & & \\
Impuesto a la renta (29.5\%) & 185,553 & 257,820 & 360,095 & 468,655 & 586,164 \\
Participaciones (8\%) & 50,319 & 69,917 & 97,653 & 127,093 & 158,960 \\
Utilidad antes de reserva legal & 393,120 & 546,230 & 762,914 & 992,914 & $1,241,873$ \\
Reserva legal (10\%) & 39,312 & 54,623 & 76,291 & 99,291 & 124,187 \\
Utilidad libre disponible & 353,808 & 491,607 & 686,623 & 893,622 & $1,117,686$ \\
\hline
\end{tabular}

Elaboración propia 


\subsubsection{Presupuesto de estado de situación financiera (apertura)}

Tabla 7.28

Estado de situación financiera de apertura (2020)

\begin{tabular}{|c|c|c|c|}
\hline Activos corrientes & & Deuda & $834,339.01$ \\
\hline Caja & $753,483.02$ & Patrimonio & \\
\hline $\begin{array}{l}\text { Gastos pagados } \mathrm{x} \\
\text { adelantado }\end{array}$ & & Capital Social & $834,339.01$ \\
\hline \multicolumn{4}{|l|}{ Activos no corrientes } \\
\hline Activos Fijos & $915,195.00$ & & \\
\hline Total Fijos & $1,668,678.02$ & $\begin{array}{c}\text { Pasivo + } \\
\text { Patrimonio }\end{array}$ & $1,668,678.02$ \\
\hline
\end{tabular}

Elaboración propia

\subsection{Flujo de fondos netos}

\subsubsection{Flujo de fondos económicos}

Tabla 7.29

Flujo de fondos económicos (Soles/año)

\begin{tabular}{|c|c|c|c|c|c|c|}
\hline Años & 0 & 1 & 2 & 3 & 4 & 5 \\
\hline Inversión total & $-1,668,678$ & & & & & \\
\hline Utilidad antes de reserva legal & & 393,120 & 546,230 & 762,914 & 992,914 & $1,241,873$ \\
\hline (+) Amortización de intangibles & & 31,900 & 31,900 & 31,900 & 31,900 & 31,900 \\
\hline (+) Depreciación fabril & & 61,410 & 61,410 & 61,410 & 61,410 & 61,410 \\
\hline (+) Depreciación no fabril & & 6,233 & 6,233 & 6,233 & 6,230 & 358 \\
\hline (+) Gastos financieros (1-t) & & 73,526 & 68,624 & 58,821 & 44,116 & 24,509 \\
\hline \multirow[t]{2}{*}{ (+) Valor residual (v. libros) } & & & & & & 423,010 \\
\hline & & & & & & 753,483 \\
\hline \multicolumn{7}{|l|}{ Recuperación de capital de trabajo } \\
\hline Flujo neto de fondo económico & $-1,668,678$ & 566,189 & 714,397 & 921,278 & $1,136,570$ & $2,536,543$ \\
\hline
\end{tabular}




\subsubsection{Flujo de fondos financieros}

Tabla 7.30

Flujo de fondos financieros (Soles/año)

\begin{tabular}{|c|c|c|c|c|c|c|}
\hline Año & 0 & 1 & 2 & 3 & 4 & 5 \\
\hline Inversión & $-1,668,678$ & & & & & \\
\hline Prestamo & 834,339 & & & & & \\
\hline $\begin{array}{l}\text { Utilidad antes de reserva } \\
\text { legal }\end{array}$ & & 393,120 & 546,230 & 762,914 & 992,914 & $1,241,873$ \\
\hline $\begin{array}{l}\text { (+) Amortización de } \\
\text { intangibles }\end{array}$ & & 31,900 & 31,900 & 31,900 & 31,900 & 31,900 \\
\hline (+) Depreciación fabril & & 61,410 & 61,410 & 61,410 & 61,410 & 61,410 \\
\hline (+) Depreciación no fabril & & 6,233 & 6,233 & 6,233 & 6,230 & 358 \\
\hline $\begin{array}{l}\text { (-) Amortización del } \\
\text { préstamo }\end{array}$ & & $-55,623$ & $-111,245$ & $-166,868$ & $-222,490$ & $-278,113$ \\
\hline $\begin{array}{l}\text { Recuperación de valor en } \\
\text { libros }\end{array}$ & & & & & & 423,010 \\
\hline Capital de trabajo & & & & & & 753,483 \\
\hline $\begin{array}{l}\text { Flujo neto de fondo } \\
\text { financiero }\end{array}$ & $-834,339$ & 437,041 & 534,528 & 695,589 & 869,964 & $2,233,922$ \\
\hline
\end{tabular}

Elaboración propia

\subsection{Evaluación económica y financiera}

Para el cálculo del costo de oportunidad se empleará el modelo de valoración del precio de los activos financieros, más conocido como CAPM, cuyo objetivo es medir el riesgo y rentabilidad requerida del proyecto, empleando la siguiente fórmula:

$$
\text { Costo de oportunidad }=\mathrm{Rf}+\beta *(\mathrm{Rm}-\mathrm{Rf})
$$

Para el cálculo del beta apalancado, se hizo uso de la siguiente fórmula:

$$
\text { Beta apalancado }=0.6 *(1+(\text { Deuda } / \text { Patrimonio }) *(1-\text { Tasa de impuesto })
$$

Rm: Rentabilidad promedio del mercado

Rf: Tasa libre de riesgo

$\beta$ : Beta apalancado

Rm - Rf: Prima de riesgo 
Tabla 7.31

Cálculo del costo de oportunidad

\begin{tabular}{lr}
\hline Rf & $5.72 \%$ \\
Beta & 1.42 \\
Rm & $13.46 \%$ \\
COK & $16.7 \%$ \\
\hline
\end{tabular}

Fuente: Damoarang Bloomberg (2019)

Elaboración propia

Tabla 7.32

Cálculo del WACC o CPPC

\begin{tabular}{lcccc}
\hline Rubro & Importe & \% Participación & Costo del dinero & Tasa de descuento \\
\hline Accionistas & $819,868.31$ & $50 \%$ & $16.71 \%$ & $8.35456 \%$ \\
Prestamo & $819,868.31$ & $50 \%$ & $12.50 \%$ & $4.41 \%$ \\
& & & CPPC & $12.76 \%$ \\
\hline
\end{tabular}

Elaboración propia

\subsubsection{Evaluación económica: VAN, TIR, B/C, PR}

En base al Flujo económico desarrollado en el punto anterior, se encontró que el proyecto es económicamente viable por las siguientes razones: el VAN económico es mayor a cero, el TIR económico es superior al COK (obtenido por el método CAPM), la relación beneficio/costo es de 2,02 y el periodo de recupero de 1,5 años; es decir: la inversión será recuperada en año y medio.

Tabla 7.33

Evaluación económica

\begin{tabular}{lc}
\hline COK & $16.71 \%$ \\
VAN & $1,704,498$ \\
TIR & $45.49 \%$ \\
B/C & 2.02 \\
PR & 1.54 \\
\hline
\end{tabular}

Elaboración propia

\subsubsection{Evaluación financiera: VAN, TIR, B/C, PR}

En base al Flujo financiero desarrollado anteriormente, se determinó que el proyecto es financieramente viable, principalmente por los resultados obtenidos en la evaluación financiera, obteniéndose lo siguiente: el VAN financiero es mayor a cero, el TIR financiero es superior al COK, la relación beneficio/costo es de 3,24 y el periodo de recupero de 1,37 años. 
Tabla 7.34

Evaluación financiera

\begin{tabular}{lc}
\hline COK & $16.71 \%$ \\
VAN & $1,870,700$ \\
TIR & $70.82 \%$ \\
B/C & 3.24 \\
PR & 1.37 \\
\hline
\end{tabular}

Elaboración propia

7.6.3 Análisis de ratios (liquidez, solvencia, rentabilidad) e indicadores económicos y financieros del proyecto

Dicho análisis es trascendente; ya que permite obtener conclusiones sobre la situación financiera real que atraviesa la empresa, lo que permite a la Gerencia General tomar decisiones con rapidez, certeza y confianza.

\section{Análisis de liquidez:}

$1^{\circ}$ Razón corriente

Activo $=8,6$ veces

Pasivo corriente

- El indicador razón corriente es bueno e indica que la empresa sí se encuentra en la capacidad para solventar sus deudas a corto plazo.

$2^{\circ}$ Razón ácida

Activo corriente - inventarios $=8,2$ veces

Pasivo corriente

- Este indicador se interpreta como bueno, pues indica que la empresa se encuentra en condiciones favorables para cumplir con sus pagos.

$3^{\circ}$ Capital de trabajo

Activo - Pasivo $=1417496$ soles

- Este ratio indica que la empresa cuenta con los recursos económicos necesarios para que pueda operar.

\section{Análisis de solvencia}

$1^{\circ}$ Razón deuda patrimonio

Pasivo = 1 veces

Patrimonio 
Esta ratio indica la relación que existe entre la deuda total con los aportes realizados de los propietarios. Es decir, que por cada sol aportado se tiene 1 soles de deuda.

$2^{\circ}$ Razón de deuda

$\frac{\text { Pasivo }}{\text { Activo }}=50 \%=0.51$

Este ratio muestra la proporción de financiamiento externo (acreedores) ha recibido la empresa para la inversión.

\section{Análisis de rentabilidad}

$1^{\mathrm{o}}$ Rentabilidad neta sobre ventas

$\frac{\text { Utilidad Neta }}{\text { Ventas }}=10,38 \%$

Este indicador refleja la imagen de la empresa, es decir, lo que realmente está ganando o perdiendo.

$2^{\circ}$ Rentabilidad bruta sobre ventas

$\frac{\text { Utilidad Bruta }}{\text { Ventas }}=55,69 \%$

Este indicador fija el margen bruto recibido por las ventas.

$3^{\circ}$ Rentabilidad neta del patrimonio (ROE)

$\underline{\text { Utilidad Neta }}=33,1 \%$

Patrimonio

Este ratio evalúa la capacidad que tiene la empresa para generar beneficios a partir de la inversión realizada por los accionistas.

$4^{\circ}$ Rentabilidad neta sobre activos (ROA)

$$
\text { Utilidad Neta } \quad=16,2 \%
$$

Activo Total

Este indicador mide si la empresa está utilizando de forma eficiente sus activos, y relacionada con la rotación de los activos. 


\subsubsection{Análisis de sensibilidad del proyecto}

Para el análisis de sensibilidad del presente proyecto se pueden tomar en cuenta diversas variables, entre las más sensibles destacan las siguientes: precio de venta, demanda del mercado, participación de mercado, valor residual de la inversión, entre otros. Sin embargo; de entre todas las mencionadas, se determinó que el precio de venta del producto representa a la variable más sensible.

En base a la variación del precio de venta del producto, se tomaron en cuenta tres escenarios (optimista, conservador y pesimista), los cuales se detallan a continuación:

Tabla 7.35

Análisis de sensibilidad de precios

\begin{tabular}{|l|l|l|l|}
\hline Escenarios & Probabilidad de ocurrencia & Impacto & Valor de Venta (S/.) \\
\hline Pesimista & $30 \%$ & Precio - 10\% & 8.01 \\
\hline Conservador & $45 \%$ & Precio real & 8.90 \\
\hline Optimista & $25 \%$ & Precio $+10 \%$ & 9.79 \\
\hline
\end{tabular}

Elaboración propia

A continuación, se mostrará y analizará la interpretación de los Flujos de Fondos Financieros para cada uno de los escenarios.

\section{Escenario conservador}

Es el mismo que se obtuvo en el capítulo previo, en el punto 7.5.2

Tabla 7.36

Resultados del escenario conservador

\begin{tabular}{lc}
\hline Indicador & Resultado \\
\hline VAN F & $1,870,699.93$ \\
TIR F & $70.82 \%$ \\
B/C F & 3.24 \\
P. Recupero & 1.37 \\
\hline Elaboración propia &
\end{tabular}

\section{Escenario pesimista}

Para el análisis de este escenario fue necesario volver a calcular el estado de resultados y el Flujo de Fondo Financiero, tomando en cuenta la reducción del 10\% en el precio de venta del producto. 
Tabla 7.37

Resultados del escenario pesimista

\begin{tabular}{lc}
\hline Indicador & Resultado \\
\hline VAN F & $975,101.55$ \\
TIR F & $44.81 \%$ \\
B/C F & 2.17 \\
P. Recupero & 1.63 \\
\hline
\end{tabular}

Elaboración propia

\section{Escenario optimista}

Asimismo, se procedió a calcular nuevamente el estado de resultados y el Fondo de Flujo Financiero, pero esta vez contemplando el crecimiento del $10 \%$ en el precio de venta del producto.

Tabla 7.38

Resultados del escenario optimista

\begin{tabular}{lc}
\hline Indicador & Resultado \\
\hline VAN F & $2,766,298.31$ \\
TIR F & $97.10 \%$ \\
B/C F & 4.32 \\
P. Recupero & 1.19 \\
\hline
\end{tabular}

Elaboración propia

Tabla 7.39

Estado de resultados para el escenario pesimista

\begin{tabular}{|l|c|c|c|c|c|}
\hline Rubro & Año 1 & Año 2 & Año 3 & Año 4 & Año 5 \\
\hline Ingreso por ventas & $3,410,169$ & $3,693,508$ & $4,155,437$ & $4,644,114$ & $5,159,380$ \\
\hline (-) Costo de ventas & $1,679,017$ & $1,704,578$ & $1,828,024$ & $1,961,225$ & $2,100,288$ \\
\hline (=) Utilidad bruta & $1,731,152$ & $1,988,931$ & $2,327,413$ & $2,682,890$ & $3,059,092$ \\
\hline (-) Gastos administrativos & 828,388 & 829,096 & 830,249 & 831,467 & 826,881 \\
\hline $\begin{array}{l}\text { (-) Gastos de ventas y } \\
\text { marketing }\end{array}$ & 500,000 & 550,000 & 605,000 & 665,500 & 732,050 \\
\hline (-) Gastos de logística & 48,387 & 48,918 & 49,783 & 50,699 & 51,664 \\
\hline $\begin{array}{l}\text { (=) Utilidad antes de intereses, } \\
\text { imp y partic }\end{array}$ & 354,376 & 560,917 & 842,381 & $1,135,225$ & $1,448,497$ \\
\hline $\begin{array}{l}\text { (-) Gastos financieros } \\
\text { Utilidad antes de impuestos y } \\
\text { participaciones }\end{array}$ & $-93,863$ & $-87,606$ & $-75,091$ & $-56,318$ & $-31,288$ \\
\hline Impuesto a la renta (29.5\%) & 76,851 & 473,311 & 767,290 & $1,078,907$ & $1,417,209$ \\
\hline Participaciones (8\%) & 20,841 & 37,865 & 61,383 & 86,313 & 113,377 \\
\hline $\begin{array}{l}\text { Utilidad antes de reserva legal } \\
\text { Reserva legal (10\%) }\end{array}$ & 162,821 & 295,820 & 479,556 & 674,317 & 885,756 \\
\hline Utilidad libre disponible & 16,282 & 29,582 & 47,956 & 67,432 & 88,576 \\
\hline
\end{tabular}

Elaboración propia 
Tabla 7.40

Flujo de fondo financiero - pesimista (S/.)

\begin{tabular}{|l|c|c|c|c|c|c|}
\hline Año & 0 & 1 & 2 & 3 & 4 & 5 \\
\hline Inversión & $-1,668,678$ & & & & & \\
\hline Prestamo & 834,339 & & & & & \\
\hline Utilidad antes de reserva legal & & 162,821 & 295,820 & 479,556 & 674,317 & 885,756 \\
\hline$(+)$ amortización de intangibles & & 31,900 & 31,900 & 31,900 & 31,900 & 31,900 \\
\hline$(+)$ depreciación fabril & & 61,410 & 61,410 & 61,410 & 61,410 & 61,410 \\
\hline$(+)$ depreciación no fabril & & 6,233 & 6,233 & 6,233 & 6,230 & 358 \\
\hline$(-)$ amortización del préstamo & & $-55,623$ & $-111,245$ & $-166,868$ & $-222,490$ & $-278,113$ \\
\hline Recuperación de valor en libros & & & & & & 423,010 \\
\hline Capital de trabajo & & & & & & 753,483 \\
\hline Flujo neto de fondo financiero & $-834,339$ & 206,742 & 284,118 & 412,232 & 551,367 & $1,877,804$ \\
\hline
\end{tabular}

Elaboración propia

Tabla 7.41

Estado de resultados para el escenario optimista

\begin{tabular}{|l|r|r|r|r|r|}
\hline Rubro & \multicolumn{1}{|c|}{ Año 1 } & \multicolumn{1}{c|}{ Año 2 } & \multicolumn{1}{c|}{ Año 3 } & \multicolumn{1}{c|}{ Año 4 } & \multicolumn{1}{c|}{ Año 5 } \\
\hline Ingreso por ventas & $4,167,984$ & $4,514,288$ & $5,078,868$ & $5,676,140$ & $6,305,908$ \\
\hline (-) costo de ventas & $1,679,017$ & $1,704,578$ & $1,828,024$ & $1,961,225$ & $2,100,288$ \\
\hline (=) utilidad bruta & $2,488,967$ & $2,809,710$ & $3,250,844$ & $3,714,915$ & $4,205,621$ \\
\hline (-) gastos administrativos & 828,388 & 829,096 & 830,249 & 831,467 & 826,881 \\
\hline (-) gastos de ventas y marketing & 500,000 & 550,000 & 605,000 & 665,500 & 732,050 \\
\hline (-) gastos de logística & 48,387 & 48,918 & 49,783 & 50,699 & 51,664 \\
\hline $\begin{array}{l}\text { (=) utilidad antes de intereses, imp y } \\
\text { partic }\end{array}$ & $1,112,192$ & $1,381,697$ & $1,765,811$ & $2,167,250$ & $2,595,026$ \\
\hline (-) gastos financieros & $-114,722$ & $-107,074$ & $-91,777$ & $-68,833$ & $-38,241$ \\
\hline $\begin{array}{l}\text { Utilidad antes de impuestos y } \\
\text { participaciones }\end{array}$ & 997,470 & $1,274,623$ & $1,674,034$ & $2,098,417$ & $2,556,785$ \\
\hline Impuesto a la renta (29.5\%) & 294,254 & 376,014 & 493,840 & 619,033 & 754,252 \\
\hline Participaciones (8\%) & 79,798 & 101,970 & 133,923 & 167,873 & 204,543 \\
\hline Utilidad antes de reserva legal & 623,419 & 796,639 & $1,046,271$ & $1,311,511$ & $1,597,991$ \\
\hline Reserva legal (10\%) & 62,342 & 79,664 & 104,627 & 131,151 & 159,799 \\
\hline Utilidad libre disponible & 561,077 & 716,976 & 941,644 & $1,180,360$ & $1,438,192$ \\
\hline
\end{tabular}

Elaboración propia 
Tabla 7.42

Flujo de fondo financiero - optimista

\begin{tabular}{|l|c|c|c|c|c|c|}
\hline Año & 0 & 1 & 2 & 3 & 4 & 5 \\
\hline Inversión & $-1,668,678$ & & & & & \\
\hline Préstamo & 834,339 & & & & & \\
\hline $\begin{array}{l}\text { Utilidad antes de reserva } \\
\text { legal }\end{array}$ & & 623,419 & 796,639 & $1,046,271$ & $1,311,511$ & $1,597,991$ \\
\hline $\begin{array}{l}(+) \text { amortización de intangibles } \\
(+) \text { depreciación fabril }\end{array}$ & & 31,900 & 31,900 & 31,900 & 31,900 & 31,900 \\
\hline $\begin{array}{l}(+) \text { depreciación no fabril } \\
(-) \text { amortización del préstamo }\end{array}$ & & 61,410 & 61,410 & 61,410 & 61,410 & 61,410 \\
\hline $\begin{array}{l}\text { Recuperación de valor en } \\
\text { libros }\end{array}$ & & $-5,233$ & 6,233 & 6,233 & 6,230 & 358 \\
\hline $\begin{array}{l}\text { Capital de trabajo } \\
\text { Flujo neto de fondo } \\
\text { financiero }\end{array}$ & $-834,339$ & 667,340 & 784,938 & 978,947 & $1,188,561$ & $2,590,039$ \\
\hline
\end{tabular}

Elaboración propia

Por último, con las probabilidades de ocurrencia con cada uno de los VAN F, se obtuvo el VAN esperado y el rango de fluctuación.

Tabla 7.43

Cálculo por escenarios

\begin{tabular}{lccccc}
\hline Escenarios & $\begin{array}{c}\text { Prob. De } \\
\text { ocurrencia }\end{array}$ & VAN F & VAN Esperado & R B/C F & $\begin{array}{c}\text { R B/C } \\
\text { Esperado }\end{array}$ \\
Pesimista & $44 \%$ & $975,101.55$ & $429,044.68$ & 2.17 & 0.95 \\
Conservador & $32 \%$ & $1,870,699.93$ & $598,623.98$ & 3.24 & 1.04 \\
Optimista & $24 \%$ & $2,766,298.31$ & $663,911.59$ & 4.32 & 1.04 \\
\hline
\end{tabular}

Elaboración propia

Tabla 7.44

Valores esperados

\begin{tabular}{lc}
\hline Indicador & Resultado \\
& \\
VAN Esperado & $1,691,580.26$ \\
R B/C Esperado & 3.03 \\
\hline
\end{tabular}

Elaboración propia 


\section{CAPÍTULO VIII: EVALUACIÓN SOCIAL DEL PROYECTO}

En este último capítulo se identificará los beneficios que el presente proyecto fomentará a la sociedad. De tal manera se determinará la rentabilidad social del proyecto y su contribución al bienestar del país.

\section{Beneficios para la sociedad}

- Generación de empleo

- Productividad de la mano de obra

- Rendimiento del capital

- Generación de Divisas

\subsection{Indicadores sociales}

Tabla 8.1

Indicadores sociales

\begin{tabular}{|l|c|c|c|c|c|}
\hline AÑOS & 1 & 2 & 3 & 4 & 5 \\
\hline RUBROS & & & & 61,410 & 61,410 \\
\hline $\begin{array}{l}\text { Depreciación } \\
\text { fabril }\end{array}$ & 61,410 & 61,410 & 61,410 & 6,230 & 358 \\
\hline $\begin{array}{l}\text { Depreciación } \\
\text { no fabril }\end{array}$ & 6,233 & 6,233 & 6,233 & & 31,900 \\
\hline Amortización & 31,900 & 31,900 & 31,900 & $1,054,635$ & $1,054,635$ \\
\hline Sueldos & $1,054,635$ & $1,054,635$ & $1,054,635$ & 62,575 & 34,764 \\
\hline Intereses & 104,292 & 97,340 & 83,434 & 15,641 & 16,454 \\
\hline Servicios & 13,740 & 14,120 & 14,848 & 468,655 & 586,164 \\
\hline Impuestos & 185,553 & 257,820 & 360,095 & 893,622 & $1,117,686$ \\
\hline Utilidad Neta & 353,808 & 491,607 & 686,623 & $2,594,670$ & $2,903,371$ \\
\hline TOTAL & $1,811,571$ & $2,015,065$ & $2,299,178$ & & \\
\hline
\end{tabular}

Elaboración propia

Como indicadores sociales tenemos a indicadores de empleabilidad, rendimiento de capital y de divisas.

\subsection{Interpretación de indicadores sociales}

Posteriormente se muestran los siguientes indicadores con su respectiva interpretación:

\section{Indicadores de empleabilidad}

- $\quad$ Valor agregado $=\mathrm{S} / .7,992,484.33$ 
WACC $=12.76 \%$ calculado en la tabla 7.32. También conocido Costo Promedio Ponderado de Capital (CPPC).

Se pudo determinar que el valor agregado que la empresa genera a los diferentes agentes de la sociedad es de S/. S/.7,992,484.33

- $\quad$ Densidad de capital $=S / .98,158$

Es la relación entre la inversión del capital y el empleo generado.

Tabla 8.2

Densidad de capital

\begin{tabular}{lc}
\hline $\begin{array}{l}\text { Inv. Total / Total } \\
\text { trabajadores }\end{array}$ & $\mathrm{S} / .98,158$ \\
\hline $\begin{array}{l}\text { Cantidad de } \\
\text { trabajadores }\end{array}$ & 17 \\
Inversión total & $\mathrm{S} / .1,668,678.02$ \\
\hline
\end{tabular}

Elaboración propia

- Productividad de mano de obra $=\mathrm{S} / . \quad \mathrm{S} / .275,328$

Permite el análisis de la capacidad de la mano de obra empleada para realizar la producción esperada.

Tabla 8.3

Productividad de mano de obra

\begin{tabular}{lc}
\hline V. prod anual/ Puestos generados & $\mathrm{S} / .275,328$ \\
\hline Valor de producción anual & $\mathrm{S} / .4,680,580$ \\
Puestos generados & 17 \\
\hline Elaboración propia &
\end{tabular}

\section{Indicadores de rendimiento de capital}

- Intensidad de capital

Relaciona la inversión total con el valor agregado del proyecto. 
Tabla 8.4

Intensidad de capital

Inv. Total/Valor agregado 0.21

Inversión total

S/. $1,668,678.02$

Valor agregado

S/. $7,992,484.33$

Elaboración propia

Se determina que el proyecto tiene un valor agregado de $21 \%$ sobre los insumos respecto a la inversión total.

\section{- Relación producto-capital}

Nos muestra la relación entre el valor agregado generado en el proyecto, versus el monto total de la inversión.

$$
\text { Relación producto capital }=\frac{\text { valor agregado }}{\text { inversión total }}=4.8
$$

El proyecto tiene un valor agregado 4 veces respecto a la inversión total. 


\section{CONCLUSIONES}

- En base a lo desarrollado a lo largo del presente proyecto se identificó como competencia directa a marcas reconocidas como Cacaosuyo, Shattel, Maraná; entre otros, quienes de no seguir las tendencias de innovación y desarrollo de producto permiten la posibilidad a la aparición de nuevas marcas que cubran las expectativas de clientes modernos. Pues en el Perú, el mercado de chocolates y productos orgánicos se encuentra en reciente crecimiento

- Según el estudio de mercado de consumo de chocolates orgánicos en el Perú desarrollado en el capítulo II. Se encuentra que la producción de chocolates orgánicos Premium, en función a la demanda proyectada, es viable; debido a la aceptación del producto basado en las encuestas realizadas a consumidores de nivel socioeconómico A y B del sector 7 quienes se encuentran entre los 18 y 55 años.

- A lo largo del capítulo III se evaluó en el marco de macrolocalización a departamentos como: Cusco, Junín, San Martín y Lima; siendo este último elegido por factores como cercanía al mercado y por proximidad de materia prima. En el marco de microlocalización se evaluó y se seleccionó al distrito de Pachacamac por factores de disponibilidad de terreno y costo de alquiler de terreno.

- $\quad$ El presente estudio se considera tecnológicamente viable; debido a que el tamaño de planta representa el nivel óptimo de producción, según los análisis realizados en el capítulo IV. Se determina que el tamaño máximo de planta tiene como límite superior al tamaño de recursos productivos de cacao orgánico, siendo Perú el segundo exportador de cacao orgánico y como límite inferior a el punto de equilibrio. De tal modo que el tamaño de tecnología considerado para el presente estudio no es un limitante permitiendo la viabilidad del proyecto.

- La importancia de definir el tipo de tecnología óptima en función al proceso productivo desarrollado a lo largo del capítulo $\mathrm{V}$, permitió los cálculos correctos de la capacidad instalada, la creación de sistemas de mantenimiento, el diseño del programa de producción; así como, el adecuado diseño de disposición de 
planta. De esta manera se determinó y desarrollo los conceptos claves de la ingeniería del proyecto.

- Cabe resaltar que el presente proyecto se considera medio ambientalmente viable; ya que no produce impactos considerablemente altos que puedan afectar nocivamente a nuestro ecosistema.

- $\quad$ Se considera como agente de vital importancia al recurso de mano de obra; pues son ellos quienes trabajando en sinergia aportan gran valor para lograr resultados de excelencia. Por ello la importancia de seleccionar un correcto equipo de trabajo, como se realizó a lo largo del capítulo VI.

- El valor de venta de una barra de Amora Chocolate en el canal detallista se encuentra en 8,9 soles la unidad y el costo de venta por cada barra corresponde a 3,7 soles; esto solo para tomar una referencia en valores unitarios. El proyecto se considera viable; ya que el VAN económico es mayor a cero, el TIR económico es superior al COK la relación beneficio/costo es de 2,02 y el periodo de recupero de 1,5 años; es decir: la inversión será recuperada en 1 año y medio.

- $\quad$ Se determina que el proyecto es financieramente viable, principalmente por los resultados obtenidos en la evaluación financiera, obteniéndose lo siguiente: el VAN financiero de 1,870,700 soles, el TIR financiero de $70 \%$ siendo superior al COK, la relación beneficio/costo es de 3,24 y el periodo de recupero de 1 año y 4 meses. De esta manera, se tiene la capacidad de soportar gastos acorto, mediano y largo plazo.

- Según los indicadores realizados en el capítulo VIII se pudo determinar que el valor agregado que la empresa genera a los diferentes agentes de la sociedad es de S/. 7,992,484. 


\section{RECOMENDACIONES}

A continuación, detallaremos las recomendaciones:

- $\quad$ Si bien es cierto el estudio realizado concluye ser viable. Se recomienda un análisis más exhaustivo en cuanto al mercado objetivo; realizar focus group para determinar la aceptación del producto a comercializar, la aceptación de la marca, del tipo empaque y de esta manera comprender de forma verídica la real aceptación de Amora Chocolate.

- Se recomienda evaluar constantemente el mercado; pues es de saber que nos encontramos en un mundo donde lo único constante es el cambio. Quiere decir que debemos estar siempre a la vanguardia y con más razón hacia mercado al cual se encuentra dirigido nuestro producto. Asimismo, se recomienda que la empresa esté atenta a cambios y pueda adaptarse fácilmente para responder de manera acertada sin afectar su estabilidad en el mercado.

- Se recomienda siempre buscar realizar mejoras en los tiempos de fabricación y mermas. Lo cual ayudará a aumentar la productividad de la empresa incidiendo en las utilidades de esta.

- Se recomienda realizar capacitaciones en cuanto a formulaciones y desarrollo de producto; ya que, al existir una constante competencia, debemos de ser consecuentes con nuestra propuesta de valor incidiendo siempre en la calidad, sabores innovadores y diversidad de productos. 


\section{REFERENCIAS}

Agro Negocios Peru. (Mayo, 2017). Perú, segundo país productor de cacao orgánico en el mundo. Recuperado de https://agronegociosperu.org/2017/05/18/perusegundo-pais-productor-de-cacao-organico-en-el-mundo/

Arbulú-Zumaeta, P., y García-Román, C. C. (2016). Estudio de pre-factibilidad para la implementación de una planta de producción de bebidas energizantes a base de caña de azúcar (Tesis de Licenciatura). Recuperado de http://repositorio.ulima.edu.pe/bitstream/handle/ulima/3490/Arbulu_Zumaeta_Pi ero.pdf?sequence $=1 \&$ is Allowed $=\mathrm{y}$

Asencios, L y Delgado C. (2014). Estudio de pre factibilidad para la implementación de una planta para la elaboración de bombones rellenos de ganache de frutas peruanas para Lima Metropolitana (Tesis de Titulo). Universidad de Lima.

Chávez, S. 1. V. (2016). Apoyar al sector artesanal mediante un estudio de factibilidad para la implementación de una microempresa dedicada a la producción y comercialización de chocolates rellenos de ganache de plátano, ubicada en el distrito metropolitano de quito año 2016 (Tesis de Bachiller). Recuperado de http://www.dspace.cordillera.edu.ec/handle/123456789/2423

Coronado, M., Vega y León, S., Gutiérrez, R., Vázquez, M., y Radilla, C. (2015). Antioxidantes: perspectiva actual para la salud humana. Revista chilena de nutrición, 42(2), 206-212.

Descascarillar. (s.f). En Real Academia Española diccionario online. Recuperado de https://dle.rae.es/descascarillar

El mundo. (11 de octubre de 2009). El secreto de la felicidad. Recuperado de https://www.elmundo.es/yodona/blogs/secreto-felicidad/2012/10/11/lafeniletalamina-el-chocolate-la.html

El Salous, A., Cadena, N., Mosquera, C., y Martínez, T. (2018). Elaboración de Chocolate con Espirulina (Spirulina Máxima) Endulzado con Stevia y Frutas Deshidratadas. KnE Engineering, 3(1), 28-37. 
Espinoza, R. P. (2016). Estudio de prefactibilidad para la instalación de una planta procesadora de aguaymanto deshidratado en la provincia de Celendín (Tesis de Título). Recuperado de http://repositorio.unp.edu.pe/bitstream/handle/UNP/656/IND-ESP-MEL16.pdf?sequence $=1$

Estrada Huamán, M. Y. (2017). Aplicación del Mantenimiento Productivo Total (TPM) para mejorar la productividad en el área de mantenimiento en la Empresa Corporación Logística \& Transporte SAC, Lima, 2016. Recuperado de http://181.224.246.201/bitstream/handle/UCV/1479/Estrada_HMY.pdf?sequenc $\underline{\mathrm{e}=1 \& \text { isAllowed }=\mathrm{y}}$

Heredia, N.A.M. (2009). Desarrollo de un programa de un mantenimiento preventivo total (TPM) en el refinador de licor de cacao en la Empresa Infelersa S.A. (Tesis de Licenciatura). Recuperado de http://www.dspace.espol.edu.ec/xmlui/bitstream/handle/123456789/31730/D65709.pdf?sequence $=-1 \&$ isAllowed $=y$

Innecco, D. (14 de septiembre de 2017). Fruta deshidratada. eSalud. Recuperado de https://www.esalud.com/fruta-deshidratada/

Innovación. (s.f). En Real Academia Española diccionario online. Recuperado de https://dle.rae.es/innovaci\%C3\%B3n

Innovaciones en empaque: Los empaques son cada vez más importantes para los productos ya que forman una parte significativa del valor de la marca, la innovación e imagen y se adecuan a las necesidades de los consumidores, adaptándose al estilo de vida cada vez más cambiante. (2014, Febrero). Industria Alimenticia, 25(2), 16+. Recuperado de https://link-galecom.ezproxy.ulima.edu.pe/apps/doc/A366346983/IFME?u=ulima\&sid=IFME\& $\underline{\text { xid=6ec97811 }}$

Jiménez Antonioli, J. M., Manottupa Loayza, R., Mezarina Beltrán, R., Pérez Requena, W., y Quinto Vila, S. M. (2018). Plan de marketing estratégico y de lanzamiento para la implementación de una empresa de venta de chocolates elaborados a base de cacao orgánico (Tesis de Maestría). 
Manera, M. (marzo, 2013). Chocolate: ¿qué tipos hay y cuáles son sus características? Consumer. Recuperado de https://www.consumer.es/alimentacion/chocolateque-tipos-hay-y-cuales-son-sus-caracteristicas.html

Manrique, W. (28 de octubre de 2019). El avance del canal moderno en el Perú. El peruano. Recuperado de https://www.elperuano.pe/noticia-el-avance-del-canalmoderno-el-peru-85901.aspx

Martínez, M. y Arroyo-Rizo-Patrón, M. (2015). Exportación de aguaymanto orgánico deshidratado cubierto con chocolate bitter a Estados Unidos (Tesis para titulo). Universidad de Lima.

Mendoza, L. (15 de marzo de 2018). El 93\% de la producción peruana de cacao se concentra en 7 regiones. Agraria. Recuperado de https://agraria.pe/noticias/el93-de-la-produccion-peruana-de-cacao-se-concentra-en-7-re-16171

Ministerio de Agricultura y Riego. (10 de octubre de 2019). Minagri: En el Perú más de 100 mil familias se dedican al cultivo de cacao en 16 regiones (nota de prensa). Recuperado de https://www.gob.pe/institucion/minagri/noticias/52030minagri-en-el-peru-mas-de-100-mil-familias-se-dedican-al-cultivo-de-cacao-en16-regiones

Ministerio del Ambiente. (4 de julio de 2014). Sepa dónde conseguir productos orgánicos en Lima y para todos los gustos. Recuperado de http://www.minam.gob.pe/notas-de-prensa/sepa-donde-conseguir-productosorganicos-en-lima-y-para-todos-los-gustos/

Mundo chocolate. (s.f). El chocolate: nos hace sentir enamorados. Recuperado de https://mundochocolates.com/salud/2017/el_chocolate_nos_hace_sentir_enamor $\underline{\operatorname{ados} / \mathrm{index} \cdot \mathrm{html}}$

Notexmex. (23 de febrero de 2019). Nutrióloga resalta propiedades estimulantes del chocolate. Recuperado de https://search-proquestcom.ezproxy.ulima.edu.pe/docview/2185047817?pq-origsite=summon

Nuevos sabores para chocolate. (2009, Julio). Industria Alimenticia, 20(7), 10. Recuperado de https://link-gale- 
com.ezproxy.ulima.edu.pe/apps/doc/A206689283/IFME?u=ulima\&sid=IFME\& $\underline{\mathrm{xid}=2962 \mathrm{c} 836}$

Palomino, R. y Rojas, D. (2017). Estudio de pre-factibilidad para la instalación de una planta dedicada a la producción de chocolate con cacao orgánico peruano. (Tesis de titulo). Universidad de Lima.

Perú Retail. (28 de enero de2019). Perú: Industria de alimentos habría crecido 17\% durante el 2018. Recuperado de https://www.peru-retail.com/peru-industriaalimentos-2018/

Procesamiento real de chocolate: el sistema de molino de bola que vino a mejorar los procesos. (2012, Enero). Industria Alimenticia, 23(1), 52+. Recuperado de https://link-gale-

com.ezproxy.ulima.edu.pe/apps/doc/A292513880/IFME?u=ulima\&sid=IFME\& $\underline{\mathrm{xid}=9 \mathrm{bd} 15051}$

Rojas-Bustamante, D. A., y Palomino-Salazar, R. A. (2017). Estudio de pre-factibilidad para la instalación de una planta dedicada a la producción de chocolate con cacao orgánico peruano (Tesis de Licenciatura). Recuperado de http://repositorio.ulima.edu.pe/bitstream/handle/ulima/5955/Palomino_Salazar_ $\underline{\text { Rodrigo_Alejandro.pdf?sequence }=1 \& \text { isAllowed }=\mathrm{y}}$

Saldaña, P. (mayo, 2019). La producción de cacao peruano aumentaría en 2019. Mercados \& Regiones. Recuperado de https://www.mercadosyregiones.com/2019/05/29/la-produccion-de-cacaoperuano-aumentaria-en-2019/

Secretaría del Trabajo y Previsión Social, Gobierno Federal México. (2009). Producción de chocolate: Prácticas Seguras en el Sector Agroindustrial. Recuperado de http://www.stps.gob.mx/bp/secciones/dgsst/publicaciones/prac_seg/prac_chap/P S\%20Produccion\%20de\%20Chocolate.pdf

SM, G. T., \& RW, H. (2019). Optimización de la formulación de chocolate oscuro a partir de la mezcla de granos de cacao y contenido de cacao aplicando método de superficie de respuesta. Enfoque UTE, 10(3), 42-54. 
Sociedad Nacional de Industrias. (Enero, 2019). Industria de cacao, chocolate y productos de confitería (reporte sectorial $\mathrm{N}^{\circ} 01-2019$ ). Recuperado de https://www.sni.org.pe/enero-2019-reporte-sectorial-cacao-chocolate-productos$\underline{\text { confiteria/ }}$

Valenzuela, A. (2007). El chocolate, un placer saludable. Revista chilena de nutrición, 34(3), 180-190. Recuperado de http://dx.doi.org/10.4067/S071775182007000300001.

Vázquez-Ovando, A., Ovando-Medina, I., Adriano-Anaya, L., Betancur-Ancona, D., y Salvador-Figueroa, M. (2016). Alcaloides y polifenoles del cacao, mecanismos que regulan su biosíntesis y sus implicaciones en el sabor y aroma. Archivos latinoamericanos de nutrición, 66(3), 239-254. 


\section{BIBLIOGRAFIA}

Arroyo, P. A., y Vásquez, R. (2017). Ingeniería económica. Lima: Fondo Editorial Universidad de Lima.

Beckett, S. T. (2008). The Science of Chocolate. Cambridge: The Royal Society of Chemistry.

Díaz, B., y Noriega, M. T. (2017). Manual para el diseño de instalaciones manufactureras y de servicios. Lima: Fondo Editorial Universidad de Lima.

Porter, M. E. (2017). Ser competitivo. Barcelona: Ediciones Deusto. 
ANEXOS 


\section{Anexo 1: Encuesta de chocolate orgánico}

\section{CHOCOLATE ORG ÁNICO}

Buen día. Nos encontramos en una investigación de mercado sobre la industria del chocolate orgánico fino. ¿Tendría la amabilidad de respondernos la siguiente encuesta? Gracias por su tiempo.

${ }^{*}$ Obligatorio

DIRECCIÓN DE CORREO ELECTRÓNICO *

Tu dirección de correo electrónico

1.- SELECCIONE EL RANGO DE EDAD AL QUE PERTENECE: "

- menor que 18 años

- entre 18 y 24 años

○ entre 25 y 39 años

- entre 40 y 55 años

- mayor que 56 años

2.- SELECCIONAR LA ZONA EN LA QUE RESIDE: *

Elegir

3.- ¿CUÁL ES EL GRADO DE ESTUDIO ALCANZADO? *

Elegir

4.- ¿CONSUME O COMPRA PRODUCTOS ORGÁNICOS? (PRODUCTOS LIBRES DE PESTICIDA, FERTILIZANTES SINTÉTICOS, MODIFICACIÓN GENÉTICA, ETC.) *

○ Sí

O No

- Tal vez. No sabía que era.

EL ALIMENTO DE LOS DIOSES: (UN VERDADERO CHOCOLATE TIENE COMO MÍNIMO 35 \% DE CACAO, DE LO CONTR ARIO ES UN GOLOSINA)

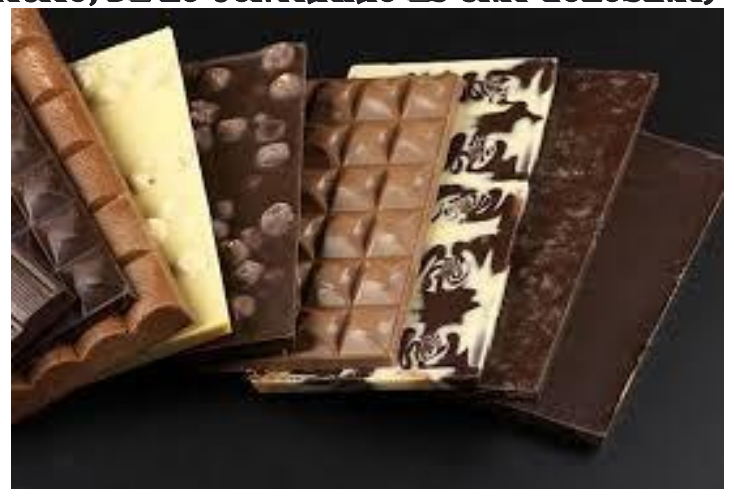

5.- ¿CONSUME O COMPRA CHOCOLATE? *

- Sí

○ No 
○ Chocolate blanco

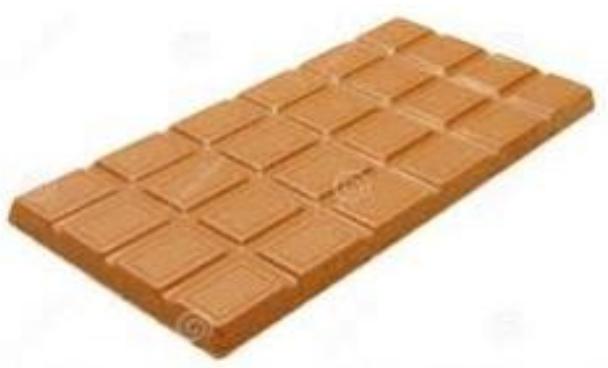

- Chocolate con leche

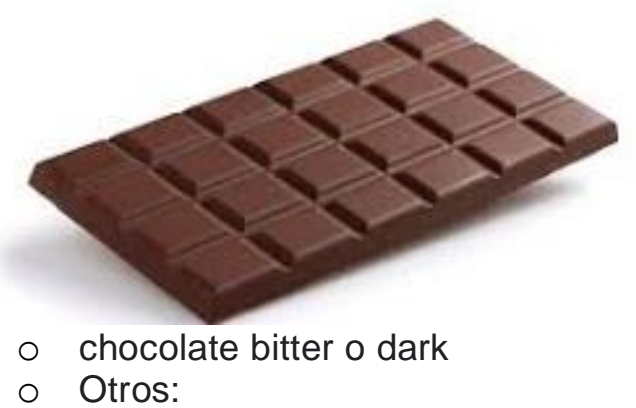

O Otros:

6.- ¿CON QUÉ FRECUENCIA COMPRA O CONSUME CHOCOLATES? *

- Mas de una vez a la semana

- Una vez a la semana

- Una vez al mes

- Cada tres meses

- Cada seis meses

- Una vez al año

\section{7.- ¿DÓNDE COMPRA NORMALMENTE CHOCOLATES?}

- Bodegas o kioskos

- Supermercados o tiendas departamentales

- Tiendas saludables (Ecomarkets, biomarkets, etc)

- Chocolatiers

- Por internet

o Otros: 
8.- ¿COMPRARÍA CHOCOLATE ORGÁNICO BITTER AL 65\% EN BARRA CON TROCITOS DE FRUTOS DEL BOSQUE (FRAMBUESAS Y ARÁNDANOS)? *

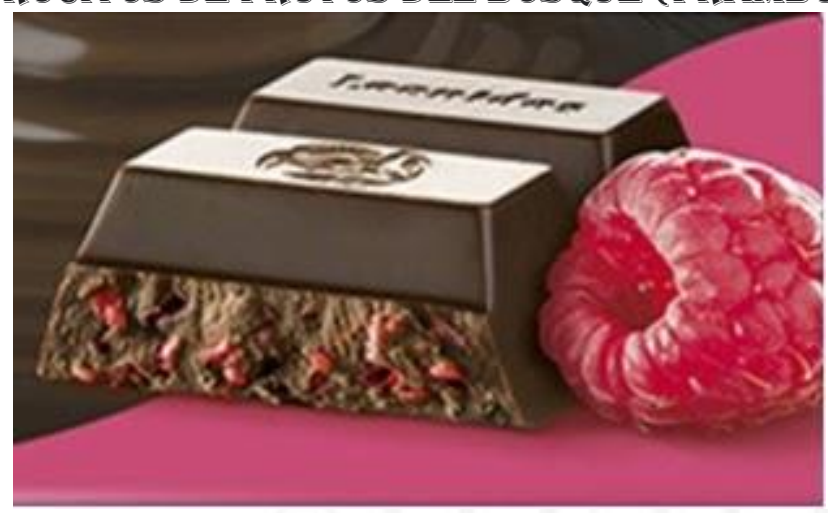

○ Sí

○ No

9.- ¿CUÁNTO ESTARÍA USTED DISPUESTO A PAGAR POR UNA CAJA DE 50 G. DE CHOCOLATE ORGÁNICO BITTER CON TROCITOS DE FRUTOS DEL BOSQUE DESHIDRATADO? *

- Entre 10 a 15 soles

- Entre 16 a 20 soles

- Entre 21 a 25 soles

○ De 25 soles +

10.- DEL 1 AL 10. SIENDO 10 EL NIVEL MÁS ALTO DE SEGURIDAD DE COMPRA ¿CUÁL SERÍA EL GRADO REAL DE DISPOSICIÓN A COMPRAR UN CHOCOLATE ORGÁNICO BITTER AL 55\% EN BARRA CON TROCITOS DE FRUTOS DEL BOSQUE? *

$\begin{array}{ll}\circ & 1 \\ \circ & 2 \\ \circ & 3 \\ \circ & 4 \\ \circ & 5 \\ \circ & 6 \\ \circ & 7 \\ \circ & 8 \\ \circ & 9 \\ \circ & 10\end{array}$

